\title{
Chlamydia trachomatis : identifying women with tubal factor subfertility
}

Citation for published version (APA):

den Hartog, J. E. (2010). Chlamydia trachomatis : identifying women with tubal factor subfertility. [Doctoral Thesis, Maastricht University]. Datawyse / Universitaire Pers Maastricht.

https://doi.org/10.26481/dis.20100616jh

Document status and date:

Published: 01/01/2010

DOI:

10.26481/dis.20100616jh

Document Version:

Publisher's PDF, also known as Version of record

\section{Please check the document version of this publication:}

- A submitted manuscript is the version of the article upon submission and before peer-review. There can be important differences between the submitted version and the official published version of record.

People interested in the research are advised to contact the author for the final version of the publication, or visit the DOI to the publisher's website.

- The final author version and the galley proof are versions of the publication after peer review.

- The final published version features the final layout of the paper including the volume, issue and page numbers.

Link to publication

\footnotetext{
General rights rights.

- You may freely distribute the URL identifying the publication in the public portal. please follow below link for the End User Agreement:

www.umlib.nl/taverne-license

Take down policy

If you believe that this document breaches copyright please contact us at:

repository@maastrichtuniversity.nl

providing details and we will investigate your claim.
}

Copyright and moral rights for the publications made accessible in the public portal are retained by the authors and/or other copyright owners and it is a condition of accessing publications that users recognise and abide by the legal requirements associated with these

- Users may download and print one copy of any publication from the public portal for the purpose of private study or research.

- You may not further distribute the material or use it for any profit-making activity or commercial gain

If the publication is distributed under the terms of Article $25 \mathrm{fa}$ of the Dutch Copyright Act, indicated by the "Taverne" license above, 
Chlamydia trachomatis Identifying women with tubal factor subfertility 
(C) Copyright J.E. den Hartog, Maastricht 2010

Graphic design and printing by Datawyse / Universitaire Pers Maastricht ISBN 9789052789569

The studies described in this thesis were financially supported in part by an unrestricted research grant from Organon Nederland N.V. (now Schering-Plough Nederland B.V.). 


\title{
Chlamydia trachomatis Identifying women with tubal factor subfertility
}

\author{
PROEFSCHRIFT
}

ter verkrijging van de graad van doctor aan de Universiteit Maastricht, op gezag van de Rector Magnificus, Prof. mr. G.P.M.F. Mols, volgens het besluit van het College van Decanen,

in het openbaar te verdedigen

op woensdag 16 juni 2010 om 14:00 uur

door

Janneke Eva den Hartog

geboren op 4 oktober 1976 te Dordrecht

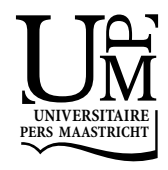




\section{Promotores}

Prof. dr. J.L.H. Evers

Prof. dr. J.A. Land (Universitair Medisch Centrum Groningen)

Prof. dr. C.A. Bruggeman

\section{Copromotor}

Dr. S.A. Morré (VU Medisch Centrum, Amsterdam)

\section{Beoordelingscommissie}

Prof. dr. M.H.V. de Baets (voorzitter)

Prof. dr. A. Brand

Dr. C.D. Dirksen

Prof. dr. F.M. Helmerhorst (Leids Universitair Medisch Centrum)

Prof. dr. P.H.M. Savelkoul (VU Medisch Centrum, Amsterdam) 


\section{Contents}

$\begin{array}{ll}\text { Abbreviations } & 6\end{array}$

$\begin{array}{lll}\text { Chapter } 1 \text { General introduction } & 9\end{array}$

Chapter 2 Serological markers of persistent Chlamydia trachomatis infections 41 in women with tubal factor subfertility

Chapter 3 The role of chlamydia genus-specific and species-specific IgG antibody testing in predicting tubal disease in subfertile women

Chapter 4 Screening strategies for tubal factor subfertility 65

Chapter 5 TLR4 in Chlamydia trachomatis infections: knockout mice, STD $\quad 85$ patients and women with tubal factor subfertility

Chapter 6 The CD14 functional gene polymorphism $-260 \mathrm{C}>\mathrm{T}$ is not involved 101 in either the susceptibility to Chlamydia trachomatis infection or the development of tubal pathology

Chapter 7 Do host genetic traits in the bacterial sensing system play a role in the development of Chlamydia trachomatis-associated tubal pathology in subfertile women?

Chapter 8 Detection methods for Chlamydia trachomatis in endometrium of subfertile women: a pilot study using immunohistochemical staining and PCR

Chapter 9 General discussion 149

$\begin{array}{ll}\text { Summary } & 161\end{array}$

$\begin{array}{ll}\text { Samenvatting } & 165\end{array}$

$\begin{array}{ll}\text { Dankwoord } & 169\end{array}$

$\begin{array}{ll}\text { Curriculum vitae } & 173\end{array}$ 
ABBREVIATIONS

$\begin{array}{ll}\text { APC } & \text { antigen-presenting cell } \\ \text { bp } & \text { base pair } \\ \text { BSA } & \text { bovine serum albumin } \\ \text { C. } & \text { Chlamydia } \\ \text { CARD } & \text { caspase recruitment domain } \\ \text { CAT } & \text { Chlamydia IgG antibody testing } \\ \text { CCR } & \text { chemokine (C-C motif) receptor } \\ \text { CD } & \text { cluster of differentiation } \\ \text { cHSP } & \text { chlamydia heat shock protein } \\ \text { CI } & \text { confidence interval } \\ \text { Cpn } & \text { C. pneumoniae } \\ \text { CPS } & \text { C. psittaci } \\ \text { Ctr } & \text { C. trachomatis } \\ \text { DAB } & \text { diaminobenzidine } \\ \text { DTP } & \text { distal tubal pathology } \\ \text { EB } & \text { elementary body } \\ \text { ELISA } & \text { enzyme-linked immunosorbent assay } \\ \text { HC } & \text { healthy controls } \\ \text { HEp } & \text { human epithelial } \\ \text { hHSP } & \text { human heat shock protein } \\ \text { hs-CRP } & \text { high-sensitivity C-reactive protein } \\ \text { HSG } & \text { hysterosalpingography } \\ \text { IFN } & \text { interferon } \\ \text { IFU } & \text { inclusion-forming units } \\ \text { Ig } & \text { immunoglobulin } \\ \text { IL } & \text { interleukin } \\ \text { int. conc. } & \text { interval conception } \\ \text { KO } & \text { knockout } \\ \text { LCR } & \text { ligase chain reaction } \\ \text { LGV } & \text { lymphogranuloma venereum } \\ \text { LPB } & \text { LPS-binding protein } \\ \text { LPS } & \text { lipopolysaccharide } \\ \text { LS } & \text { laparoscopy } \\ \end{array}$




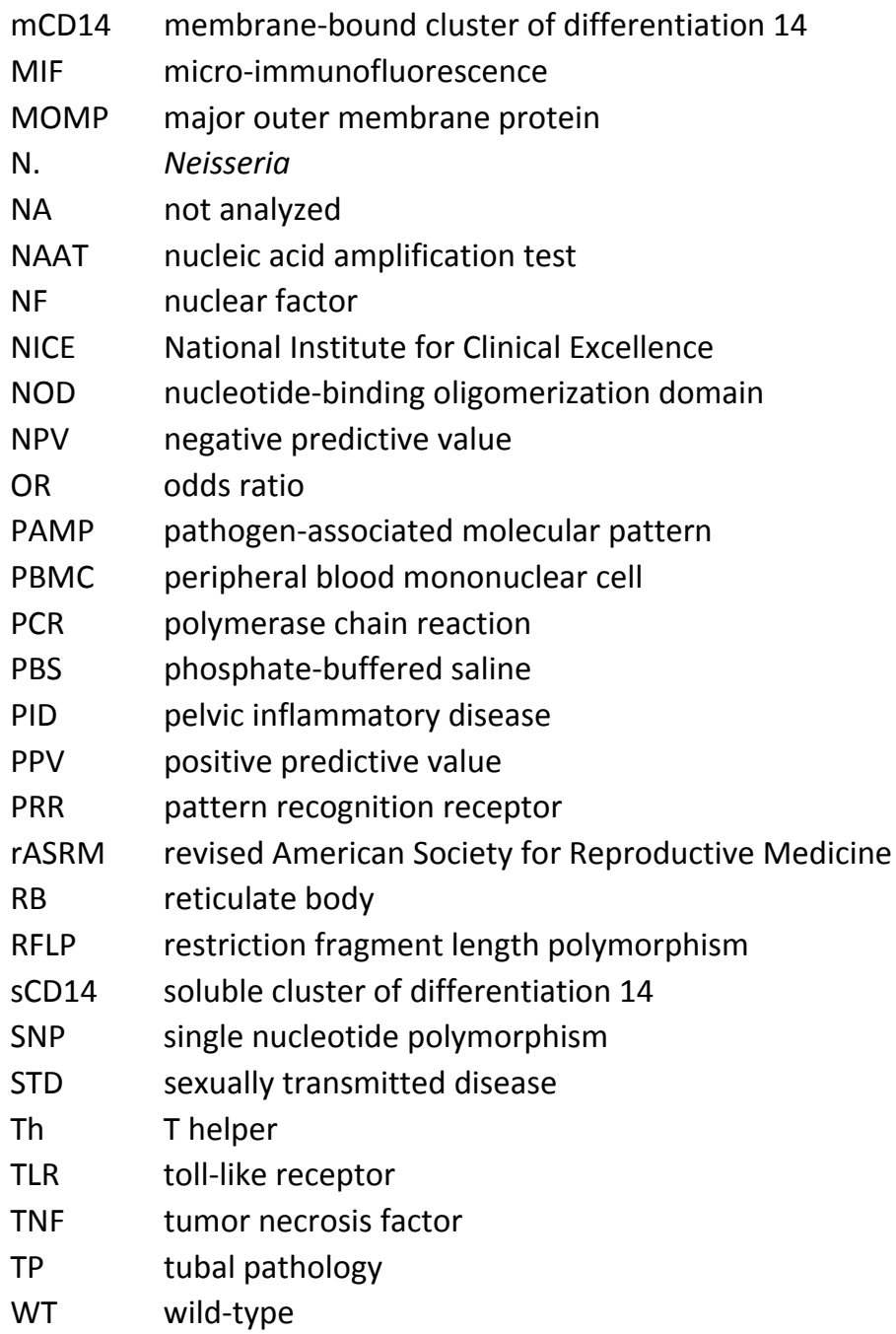





\section{Chapter 1 \\ General introduction}

\section{Adapted from:}

Chlamydia trachomatis-associated tubal factor subfertility: immunogenetic aspects and serological screening JE den Hartog, SA Morré, JA Land

Human Reproduction Update 2006, 12 (6): 719-730 


\section{INTRODUCTION}

\section{History and taxonomy}

After analysis of medical papyri, ancient depictions and mummy autopsy data, it was suggested that the ocular disease currently known as trachoma had been endemically present, as nehat disease, in Egypt since ancient times (Nunn, 1996). It took until 1957 to isolate the micro-organism Chlamydia (C.) trachomatis for the first time (Wang, 1999). The causal relationship between $C$. trachomatis and both trachoma and genital tract infection was established in 1958 (Collier et al., 1958). Resemblances in microscopic characteristics between trachoma and psittacosis (later identified as caused by C. psittaci) were already noticed in the early 1930s by an ophthalmologist (Thygeson, 1934). Gene sequence studies resulted in the discovery of C. pneumoniae at the end of the 1980s (Grayston, 1989). New molecular diagnostic methods ultimately led to a new taxonomy of the order of Chlamydiales, splitting the family of Chlamydiaceae into two genera: Chlamydia (with amongst others the species C. trachomatis) and Chlamydophila (Table I) (Everett et al., 1999, Bush and Everett, 2001).

\section{Characteristics of Chlamydiaceae}

Chlamydiaceae are obligate intracellular pathogens, which are unable to replicate outside a host cell. Chlamydiaceae have a unique biphasic developmental cycle (Figure I). The extracellular forms, elementary bodies (EBs), are infectious and metabolically inactive. After being endocytosed by host cells, they group into intracytoplasmic vacuoles (referred to as inclusions) within 12 to 24 hours. Subsequently, EBs transform into non-infectious but metabolically active and replicating reticulate bodies (RBs). Two or more days after host cell infection, RBs convert back into EBs, followed by their release through cell rupture or fusion of the inclusion with the host cell membrane.

C. trachomatis is subdivided in three human biovars. The trachoma biovar consists of serovars $\mathrm{A}$ to $\mathrm{C}$, which are mainly associated with trachoma, but with genital tract infections and reactive arthritis as well. The oculogenital biovar consists of serovars $\mathrm{D}$ to $\mathrm{K}$, which are associated with genital tract infections, neonatal and adult conjunctivitis, respiratory tract infections and reactive arthritis. The lymphogranuloma venereum (LGV) biovar consists of serovars L1 to L3, causing infections of the inguinal lymph nodes. 
Chapter 1

Table I. Taxonomy of the order of Chlamydiales (adapted from Bush and Everett, 2001).

\begin{tabular}{|c|c|c|c|c|c|}
\hline Order & Family & Genus & Species & Typical host & Disease \\
\hline \multirow[t]{13}{*}{ Chlamydiales } & Chlamydiaceae & Chlamydophila & C. abortus & $\begin{array}{l}\text { Mammals } \\
\text { (sheep, cattle, } \\
\text { goats) }\end{array}$ & Abortion \\
\hline & & & C. psittaci & Birds & $\begin{array}{l}\text { Ocular infection } \\
\text { Respiratory tract } \\
\text { infection } \\
\text { Gastro-intestinal } \\
\text { infection }\end{array}$ \\
\hline & & & C. felis & Cats & $\begin{array}{l}\text { Ocular infection } \\
\text { Respiratory tract } \\
\text { infection }\end{array}$ \\
\hline & & & C. caviae & Guinea pigs & Ocular infection \\
\hline & & & C. pecorum & $\begin{array}{l}\text { Mammals } \\
\text { (sheep, cattle, } \\
\text { goats, koalas, } \\
\text { swine) }\end{array}$ & $\begin{array}{l}\text { Ocular infection } \\
\text { Respiratory tract } \\
\text { infection } \\
\text { Urogenital tract } \\
\text { infection } \\
\text { Abortion }\end{array}$ \\
\hline & & & C. pneumoniae & Humans & $\begin{array}{l}\text { Respiratory tract } \\
\text { infection } \\
\text { Atherosclerosis } \\
\text { Alzheimer's dis- } \\
\text { ease }\end{array}$ \\
\hline & & Chlamydia & C. trachomatis & Humans & $\begin{array}{l}\text { Ocular infection } \\
\text { Genital tract } \\
\text { infection } \\
\text { Lymphogranu- } \\
\text { loma venereum } \\
\text { Reactive arthritis }\end{array}$ \\
\hline & & & C. suis & Pigs & Intestinal infection \\
\hline & & & C. muridarum & Mice, hamsters & $\begin{array}{l}\text { Genital tract } \\
\text { infection }\end{array}$ \\
\hline & Parachlamydiaceae & & P. acanthamoebae & Amoebae & $\begin{array}{l}\text { Respiratory tract } \\
\text { infection }\end{array}$ \\
\hline & & & N. hartmannellae & Amoebae & Ocular infection \\
\hline & Waddliaceae & & W.chondrophila & Cows & Abortion \\
\hline & Simkaniaceae & & S. nevegensis & Humans & $\begin{array}{l}\text { Respiratory tract } \\
\text { infection }\end{array}$ \\
\hline
\end{tabular}




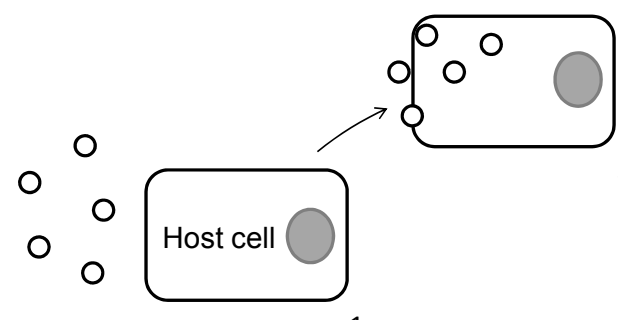

1

2
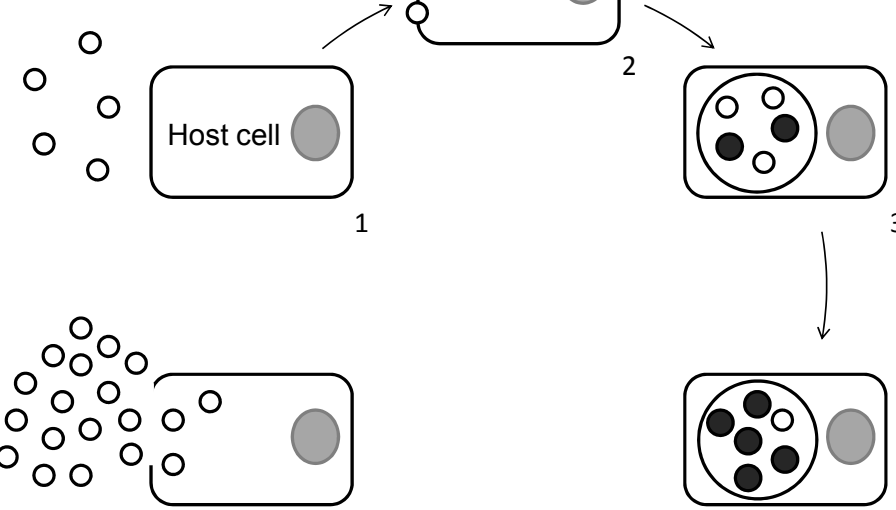

O Elementary body

Reticulate body

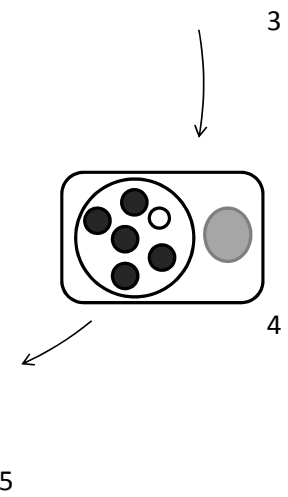

Figure I. Developmental cycle of $C$. trachomatis.

Elementary bodies (EBs) approach the host cell (1) and enter the host cell by endocytosis (2). EBs group into an inclusion and transform into reticulate bodies (RBs) (3). RBs replicate (4) and convert back into EBs (5), which are released from the host cell (6).

\section{Clinical introduction}

C. trachomatis is a sexually transmitted pathogen primarily targeting columnar epithelial cells of the cervix. In the Netherlands, an estimated 35000 cases of $C$. trachomatis cervicitis occur annually (Health Council of The Netherlands, 2004). Symptoms of $C$. trachomatis cervicitis are vaginal discharge, irregular or post-coital bleeding and dysuria. However, up to $70-80 \%$ of the $C$. trachomatis infections in women are asymptomatic, and therefore remain unrecognized and untreated (Rahm et al., 1988). A normal immune response (rather than antibiotic treatment) is therefore essential to clear the pathogen and to protect women from ascendance of the infection to the upper genital tract and/or transmission to a sexual partner. Studies on the natural course of untreated $C$. trachomatis lower genital tract infections in women show spontaneous clearance rates of $\sim 20-30 \%$ in the first weeks to months, $\sim 50 \%$ in one year, $~ 80 \%$ in two years and $~ 94 \%$ in four years (review by Golden et al., 2000, Joyner et al., 2002, Morré et al., 2002, Molano et al., 2005, Geisler et al., 2008). Although these studies suggest that the majority of infected women seems to have an adequate local immune response, a subset of infected 
women will have a long-lasting $C$. trachomatis infection and therefore an increased risk of ascendance and late sequelae. The above-mentioned studies on spontaneous clearance of $C$. trachomatis lower genital tract infections may even underestimate the percentage of women at risk of complications, since clearance from the lower genital tract does not necessarily mean that the infection has not already ascended to the upper genital tract. Given a worldwide prevalence of 50 million new $C$. trachomatis infections in women each year, a clinically significant group of infected women will be at risk of late sequelae (World Health Organization, 2001).

If a cervical $C$. trachomatis infection is not cleared adequately, the infection may ascend to the endometrium, tubes, pelvis and peri-hepatic region (due to spread of the micro-organism via the paracolic gutters to the liver capsule) and lead to pelvic inflammatory disease (PID). The estimated prevalence of $C$. trachomatis PID in the Netherlands is 5 000-10 000 cases each year (Health Council of The Netherlands, 2004). PID can cause low-grade fever, vaginal discharge and abdominal complaints, but often gives rise to virtually no or only non-specific symptoms.

In $30-40 \%$ of women with cervicitis, histological evidence of endometritis has been found (Paavonen et al., 1985a, Wiesenfeld et al., 2002). The micro-organism itself has been isolated from the endometrium in one-third of women with a $C$. trachomatis cervicitis and/or urethritis (Jones et al., 1986). In 70\% of women with suspected PID, histological evidence of endometritis has been demonstrated (Paavonen et al., 1985b). Salpingitis has been demonstrated in $10 \%$ of women with endometritis (Cates and Wasserheit, 1991). In patients with tubal factor subfertility or ectopic pregnancy, the mean detection rate of $C$. trachomatis in tubal tissue is 11\% (range 0-70\%) (Osser and Persson, 1992, Lan et al., 1995, Haeusler et al., 1997, Gérard et al., 1998, Hinton et al., 2000, Barlow et al., 2001, Noguchi et al., 2002, Debattista et al., 2004, Bjartling et al., 2007). In the Netherlands, C. trachomatis has been estimated to be responsible for tubal factor subfertility in $1000-2000$ women each year and for 200-400 cases of ectopic pregnancies, which is half of the total yearly number of ectopic pregnancies (Health Council of The Netherlands, 2004). Tubal pathology accounts for $20-25 \%$ of the cases of subfertility in developed countries (Collins et al., 1995, Collins and Van Steirteghem, 2004) and for up to 80\% of the cases of subfertility in developing countries (Collet et al., 1988).

The pathogenesis of $C$. trachomatis-associated tubal pathology is not yet fully understood. Two mechanisms are assumed to be responsible for the development of tubal damage. The first and probably most important mechanism is by a persistent infection causing a chronic low-grade immune response, which attacks and destroys the host cells (i.e. epithelial cells of the distal part of the fallopian tubes) (LaVerda et al., 1999). Secondly, C. trachomatis itself can damage the host tubal epithelial cells when its replication cycle has been completed and elementary bodies are released by cytolysis of the host cell. The latter mechanism does not appear to play a major role in persistent infections, since persistence is characterized by reduced replica- 
tion of the dormant pathogen (AbdelRahman and Belland, 2005, Mpiga and Ravaoarinoro, 2006). These aberrant persisting chlamydia particles have been identified in the genital tract, while previously these aberrant forms were only visualized in cell culture under special conditions (Bragina et al., 2001). More studies are needed to elucidate the precise immunopathogenesis of $C$. trachomatis infections.

\section{SCREENING FOR C. TRACHOMATIS-ASSOCIATED TUBAL FACTOR SUBFERTILITY}

\section{History}

Since the majority of $C$. trachomatis infections remains asymptomatic, a patient's history will usually not be helpful in assessing the risk of a previous $C$. trachomatis infection and tubal factor subfertility (Rahm et al., 1988, Logan et al., 2003, Coppus et al., 2007). Conversely, a history of (suspected) previous genital tract infection is not necessarily associated with tubal pathology or subfertility (Hubacher et al., 2004, Andersen et al., 2005). In a cohort of 321 subfertile women undergoing laparoscopy with tubal testing, no correlation has been found between a history of symptoms associated with a possible previous upper genital tract infection (prolonged abdominal pain, dyspareunia or pain during pelvic examination, which was reported by $48 \%$ of participants) or a history of symptoms associated with a possible previous lower genital tract infection (vaginal discharge, which was reported by $72 \%$ of participants) and the presence of tubal pathology at laparoscopy (Hubacher et al., 2004). A large follow-up study, which has evaluated the risk of subfertility following a positive $C$. trachomatis test on samples obtained from the cervix and/or urethra, has shown that birth rates and time to birth were comparable between women testing positive and negative respectively, although it should be noted that nearly all positive cases in this study received antibiotic treatment (Andersen et al., 2005). The risk of subfertility following untreated $C$. trachomatis lower genital tract infections is therefore assumed to be higher. If a patient's history mentions a PID, the risk of tubal pathology is increased (Weström, 1980, Weström et al., 1992, review by Luttjeboer et al., 2009), although it should be noted that in 30\% of women presenting with abdominal pain and clinical signs of PID, immediate laparoscopic findings do not support this diagnosis (Bevan et al., 1995). A clear correlation has been demonstrated between both the number of episodes and severity of laparoscopically verified PID and the risk of tubal disease (Weström, 1980, Weström et al., 1992). In a large follow-up study in women with laparoscopically verified PID diagnosed between 1960 and 1984, the risk of tubal factor subfertility was about $10 \%$ after one episode of PID, 20\% after two episodes and $40 \%$ after three episodes (Table II). C. trachomatis accounted for nearly $40 \%$ of all PIDs in this study, although 
routine $C$. trachomatis testing was introduced in the authors' clinic only in 1977 and was therefore not applied in all PID cases (Weström et al., 1992). The incidence of tubal factor subfertility increased significantly with the severity of PID at laparoscopy, and was $0.6 \%$ after one mild episode, $6 \%$ after one moderately severe episode and $21 \%$ after one severe episode of PID (Weström et al., 1992) (Table II).

Table II. The number of episodes and severity of laparoscopically verified pelvic inflammatory disease (PID) in relation to the risk of tubal factor subfertility (TFS) (adapted from Weström et al., 1992).

\begin{tabular}{lllc}
\hline No. of episodes of PID & Severity of PID & $\mathrm{n}(\%)$ & Risk of TFS (\%) \\
\hline One & Mild & $312(25)$ & 0.6 \\
& Moderate & $450(36)$ & 6.2 \\
& Severe & $229(18)$ & 21.4 \\
& All grades & $991(80)$ & 8.0 \\
Two & & $185(15)$ & 19.5 \\
Three or more & $65(5)$ & 40.0 \\
& & & \\
TOTAL & & $1241(100)$ & 11.4 \\
\hline
\end{tabular}

Several test methods are available to assess the risk of $C$. trachomatis-associated tubal pathology in subfertile women. The reference standard for diagnosing tubal pathology in subfertile women is laparoscopy with tubal dye testing, by which tubal patency and the presence of peri-adnexal adhesions can be assessed. However, laparoscopy has several disadvantages. First, it is an invasive and expensive procedure (in the Netherlands about 1000 euros) (Fiddelers et al., 2004), requiring general anaesthesia. Operating facilities may not be easily available in every clinic. Furthermore, it holds a $1.5 \%$ risk of surgical complications (e.g. bleeding, infection) (Chapron et al., 1998). Owing to these disadvantages, laparoscopy with tubal dye testing is unsuitable as a screening procedure in subfertile women on a large scale. It would be preferable to estimate the risk of tubal pathology before laparocopy, in order to select only high-risk patients for this procedure. Two frequently used screening methods for assessing the risk of tubal pathology are hysterosalpingography (HSG) and serological testing.

\section{Hysterosalpingography}

Today, HSG is a widely used screening method for evaluating tubal patency in subfertile women. Compared to laparoscopy with tubal testing, HSG is less expensive (in the Netherlands about 150 euros) (Fiddelers et al., 2004). Furthermore, an advantage of HSG is that tubal flushing using oil-soluble contrast medium has a positive effect on pregnancy rates (Luttjeboer et al., 2007). However, HSG is less accurate in diagnosing tubal pathology as compared to laparoscopy with tubal testing. 
HSG has a sensitivity of $58 \%$ and a specificity of $77 \%$ for diagnosing tuboperitoneal abnormalities (defined as at least unilateral tubal obstruction and/or hydrosalpinx and/or peri-adnexal adhesions) as compared to laparoscopy (Dabekausen et al., 1994). A meta-analysis has been performed to determine the accuracy of HSG in diagnosing tubal patency and adhesions separately (Swart et al., 1995). As compared to laparoscopy with tubal testing, HSG has a sensitivity of $65 \%$ and a specificity of $85 \%$ for diagnosing tubal patency, whereas HSG is unreliable for diagnosing peri-adnexal adhesions (Swart et al., 1995). The low sensitivity of HSG (tubal pathology at laparoscopy despite normal HSG findings) may be due to peri-adnexal adhesions not visualized by the procedure or to incorrect interpretation of the HSG results. The specificity of HSG is higher, i.e. HSG is accurate in confirming tubal patency, but still approximately $25 \%$ of women with patent tubes at laparoscopy has abnormal HSG findings (Mol et al., 1999). These false-positive HSG findings may be due to tubal spasms, dissimilar tubal filling pressure, too high viscosity of the contrast medium used or technical failure (Dabekausen et al., 1994). Other disadvantages of HSG are that it is considered a painful test by patients and that it holds a risk of infection, which is up to $10 \%$ in patients with tubal pathology (Forsey et al., 1990).

Because HSG has a limited predictive value for tubal disease and carries a risk of febrile morbidity, it has been questioned whether HSG is the best screening test in high-risk patients. Owing to the disadvantages of both laparoscopy and HSG, clinicians have tried to find an inexpensive and non-invasive test, which could accurately discern patients with a high versus low risk of tubal factor subfertility. Ideally, based on the results of such a screening test one would subject high-risk patients to diagnostic testing (i.e. laparoscopy), and delay additional invasive and expensive testing in low-risk patients. For this purpose, serological screening tests for tubal factor subfertility have been developed.

\section{IgG to C. trachomatis (chlamydia IgG antibody testing)}

Since the association between $C$. trachomatis immunoglobulin (Ig) $\mathrm{G}$ antibodies in serum and tubal pathology has been noted (Punnonen et al., 1979), serum chlamydia IgG antibody testing (CAT) has been introduced as a screening test for tubal pathology in the fertility work-up. Following $C$. trachomatis infections, which mainly affect adolescents, a decade or more may pass until women present with subfertility. Serum IgG antibodies are known to remain detectable for many years (Gijsen et al., 2002), even after antibiotic treatment (Puolakkainen et al., 1986, Chaim et al., 1992, Piura et al., 1993, Henry-Suchet et al., 1994). Therefore, in subfertile women CAT is considered a useful tool since it reflects a previous $C$. trachomatis infection. The costs of CAT are low (in the Netherlands about ten euros) (Fiddelers et al., 2004) and the patient's discomfort is negligible. 
The negative predictive value (NPV) of CAT in subfertile women is $85-90 \%$ (Mouton et al., 2002, Veenemans and Van der Linden, 2002, Akande et al., 2003, Land et al., 2003, Logan et al., 2003), although NPVs around 75\% have been reported (EggertKruse et al., 1997, Tiitinen et al., 2006). Because of the high NPV, the presence of tubal pathology in patients with a negative CAT is unlikely.

The positive predictive value (PPV) of CAT in subfertile women is lower than the NPV and ranges between 30\% and 65\% (Eggert-Kruse et al., 1997, Mouton et al., 2002, Veenemans and Van der Linden, 2002, Akande et al., 2003, Land et al., 2003, Logan et al., 2003). The results reported on the diagnostic accuracy of CAT are heterogeneous due to differences in CAT tests, cut-off levels for a positive test, reference standard and definition of tubal pathology used (Land et al., 1998, Land et al., 2003) (Table III). However, the main limitation of CAT is the number of false-positive results, i.e. positive CAT in absence of tubal pathology, as reflected by the low PPV. A major concern of this high false-positive rate is that laparoscopies will be performed in women without tubal pathology. Unintended cross-reactivity with highly prevalent $C$. pneumoniae IgG antibodies has been suggested to account for falsepositive test results in some CAT tests (Gijsen et al., 2001, Land et al., 2003). An even more important cause of false-positive CAT results is that a positive CAT is a marker of a previous $C$. trachomatis infection, but does not reflect the course of the infection and neither the eventual extent of the resulting tubal damage. CAT is incapable in discriminating between clearance and persistence of a $C$. trachomatis infection, while persistence is a major risk factor for tubal pathology. In order to screen for persistent $C$. trachomatis infections, the value of serological evidence of persistent $C$. trachomatis genital tract infections has been evaluated over the last few years in order to identify subfertile women at highest risk of tubal disease. In the following section, different serological markers of persistence will be described and discussed.

\section{SEROLOGICAL MARKERS OF PERSISTENCE}

\section{IgG to chlamydia heat shock protein 60}

Heat shock proteins (HSPs) are a family of proteins which are present in both $C$. trachomatis and humans. Their expression is up-regulated in response to stress, in order to protect the organism against stress-related damage. Chlamydia heat shock protein 60 (cHSP60) is a chlamydia genus-specific protein, serving as a strong antigenic target for the immune system (Morrison et al., 1989, Kaufmann et al., 1990). Antibodies to cHSP60 have been suggested as markers of chronic inflammation (Kaufmann et al., 1990) and may therefore be good predictors for the risk of tubal pathology. Studies have shown a strong association between anti-cHSP60 antibod- 
ies and tubal factor subfertility. Anti-cHSP60 antibodies are significantly more prevalent in subfertile women with tubal disease (44-79\%) as compared to those without tubal disease or fertile controls (8-23\%) (Freidank et al., 1995, Claman et al., 1997, Ault et al., 1998, Persson et al., 1999, Tiitinen et al., 2006). Among subfertile women with antibodies to $C$. trachomatis, anti-cHSP60 antibodies are significantly more prevalent in women with tubal pathology (76-81\%) as compared to those without tubal pathology (0-22\%) (Toye et al., 1993, Arno et al., 1995). Heterogeneity between the results of the different studies may be due to methodologic differences, such as the type of cHSP60 IgG tests, cut-off levels, reference standard and definition of tubal pathology used. In particular, cross-reaction with the highly prevalent and highly similar $C$. pneumoniae HSP60 IgG may account for false-positive results. As predictors of tubal factor subfertility, cHSP60 IgG antibodies perform well, though not always superior to CAT (Persson et al., 1999, Tiitinen et al., 2006). It remains to be established whether cHSP60 IgG testing should be implemented in the fertility work-up as a screening method for $C$. trachomatis-associated tubal pathology.

Table III. Predictive value of different tests and cut-off levels for tubal pathology (TP) in subfertile women (adapted from Land et al., 2003).

\begin{tabular}{|c|c|c|c|c|c|c|c|c|c|}
\hline $\begin{array}{l}\text { Chlamydia anti- } \\
\text { body test }\end{array}$ & Cut-off & $\begin{array}{l}\text { No. of patients } \\
\text { with positive } \\
\text { test }\end{array}$ & $\begin{array}{l}\text { No. of patients } \\
\text { with positive } \\
\text { test and TP }\end{array}$ & $\begin{array}{l}\text { Sens } \\
(\%)\end{array}$ & $\begin{array}{l}\text { Spec } \\
(\%)\end{array}$ & $\begin{array}{l}\text { PPV } \\
\text { (\%) }\end{array}$ & $\begin{array}{l}\text { NPV } \\
(\%)\end{array}$ & OR & $95 \% \mathrm{Cl}$ \\
\hline \multirow[t]{5}{*}{ MIF Biomerieux } & 8 & 231 & 45 & 88 & 30 & 19 & 93 & 3.1 & $1.2-9.9$ \\
\hline & 16 & 149 & 39 & 76 & 58 & 26 & 93 & 4.6 & $2.1-10.3$ \\
\hline & 32 & 132 & 37 & 73 & 64 & 28 & 92 & $4.7^{\mathrm{a}}$ & $2.3-10.2$ \\
\hline & 64 & 104 & 36 & 71 & 74 & 35 & 93 & 6.9 & $3.3-14.9$ \\
\hline & 128 & 60 & 29 & 57 & 88 & 48 & 91 & 9.9 & $4.7-21.1$ \\
\hline \multirow{5}{*}{$\begin{array}{l}\text { MIF AniLabsys- } \\
\text { tems }\end{array}$} & 8 & 91 & 32 & 61 & 77 & 34 & 91 & 5.3 & $2.6-10.8$ \\
\hline & 16 & 75 & 32 & 61 & 83 & 41 & 92 & 7.8 & $3.7-16.2$ \\
\hline & 32 & 52 & 30 & 59 & 92 & 58 & 92 & $15.7^{b}$ & $7.1-35.1$ \\
\hline & 64 & 37 & 24 & 47 & 95 & 65 & 90 & 17.2 & 7.1-42.4 \\
\hline & 128 & 19 & 13 & 25 & 98 & 68 & 87 & 14.7 & $4.6-52.4$ \\
\hline \multirow{3}{*}{$\begin{array}{l}\text { ELISA AniLabsys- } \\
\text { tems }\end{array}$} & Equivocal & 84 & 23 & 45 & 77 & 27 & 88 & 2.7 & $1.3-5.4$ \\
\hline & Positive & 53 & 19 & 37 & 87 & 36 & 88 & $4.0^{c}$ & $1.9-8.4$ \\
\hline & $\begin{array}{l}\text { Highly } \\
\text { positive }\end{array}$ & 26 & 12 & 24 & 95 & 46 & 87 & 5.5 & $2.0-14.4$ \\
\hline \multirow[t]{2}{*}{ pELISA Medac } & Equivocal & 74 & 28 & 55 & 83 & 38 & 90 & 5.8 & $2.8-11.8$ \\
\hline & Positive & 62 & 28 & 55 & 87 & 45 & 91 & $8.2^{d}$ & $3.9-17.3$ \\
\hline \multirow[t]{2}{*}{ ELISA Savyon } & Equivocal & 99 & 26 & 51 & 72 & 26 & 88 & 2.7 & $1.4-5.4$ \\
\hline & Positive & 87 & 25 & 49 & 77 & 29 & 89 & $3.1^{\mathrm{e}}$ & $1.6-6.3$ \\
\hline
\end{tabular}

${ }^{b}$ versus $^{\mathrm{a}, \mathrm{c}, \mathrm{d}, \mathrm{e}}$ and ${ }^{\mathrm{d}}$ versus ${ }^{\mathrm{c}, \mathrm{e}} P<0.05$.

Abbreviations: $\mathrm{Cl}$ = confidence interval; ELISA = enzyme-linked immunosorbent assay; $\mathrm{MIF}=$ microimmunofluorescence; NPV = negative predictive value; $\mathrm{OR}=$ odds ratio; $\mathrm{PPV}=$ positive predictive value; sens $=$ sensitivity; spec $=$ specificity . 


\section{IgA to C. trachomatis and cHSP60}

The presence of IgA antibodies has been proposed to reflect persistent infection more accurately as compared to IgG antibodies (Romano Carratelli et al., 2006). Previous studies have demonstrated an association between $C$. pneumoniae IgA antibodies and its chronic sequelae, e.g. respiratory and cardiovascular morbidity (Saikku, 1999, Falck et al., 2002, Wong et al., 2002, Yavuz et al., 2006). However, validated studies on the correlation between $C$. pneumoniae $\operatorname{IgA}$ antibodies and disease status are lacking and IgA antibody testing is therefore not recommended as a serological marker of persistent $C$. pneumoniae infection (Dowell et al., 2001).

Contradictory findings have been reported on the value of $C$. trachomatis IgA antibodies in screening for tubal factor subfertility. Mouton and co-workers (2002) have found that IgA antibodies are more useful than IgG antibodies in diagnosing tubal pathology, whereas Paukku and co-workers (1998) have reported that IgG antibodies are better predictors for tubal pathology than IgA antibodies. These apparently contradictory findings may be due to methodological differences. Although the presence of serum IgA antibodies has been associated with chronic inflammation, the diagnostic accuracy is not superior to CAT or CHSP60 IgG testing. Therefore, $C$. trachomatis IgA antibody testing should not replace CAT in the fertility work-up.

The value of measuring cHSP60 IgA antibodies in subfertile women has been examined. CHSP60 IgA antibodies have been shown to be significantly more prevalent in subfertile women (regardless of the cause of subfertility) as compared to fertile controls (Karinen et al., 2004). Dieterle and Wollenhaupt (1996) have found that cHSP60 IgA antibodies are significantly more prevalent in subfertile women with tubal pathology as compared to subfertile controls with patent tubes. So far, it is unclear whether cHSP60 IgA antibody testing is superior to CAT and whether it should deserve a role in screening for tubal factor subfertility.

\section{IgG to C. trachomatis lipopolysaccharide}

Lipopolysaccharides (LPS) are genus-specific components of the chlamydial envelope, which are acting as antigenic triggers for the immune system (Raulston et al., 1995). Previous studies have suggested that anti-LPS antibodies are indicators of ongoing chlamydia infections (Tuuminen et al., 2000, Schumacher et al., 2005, Kaklikkaya et al., 2006). The prevalence of anti-LPS IgG antibodies has been found to be higher in patients with tubal factor subfertility as compared to fertile controls (Paukku et al., 1998, Persson et al., 1999). However, CAT and antibodies to cHSP60 have appeared to be better predictors of tubal factor subfertility (Persson et al., 1999), indicating that LPS antibody testing has no additional value in the fertility work-up. 


\section{High-sensitivity C-reactive protein}

The acute phase protein C-reactive protein (CRP) is a general serological marker of inflammation. CRP levels are $>10 \mathrm{mg} / \mathrm{L}$ in acute infections and $<1 \mathrm{mg} / \mathrm{L}$ in absence of an infection. CRP levels between $1 \mathrm{mg} / \mathrm{L}$ and $10 \mathrm{mg} / \mathrm{L}$ (so-called elevated levels within the normal range) are assumed to reflect a low-grade inflammation (Pearson et al., 2003) and can be detected using a high-sensitivity (hs) CRP test. The role of elevated hs-CRP levels as markers of an ongoing low-grade inflammation has been evaluated in studies on the relationship between persistent $C$. pneumoniae infections and cardiovascular diseases. These studies have shown that the association between $C$. pneumoniae and cardiovascular diseases is even stronger in presence of slightly elevated hs-CRP levels (Roivainen et al., 2000, Gattone et al., 2001, Johnston et al., 2001, Romano Carratelli et al., 2006, Tiirola et al., 2006, Yavuz et al., 2006). So far, the value of hs-CRP in predicting the risk of fertility disorders following $C$. trachomatis genital tract infection has not been studied.

\section{INTER-PATIENT VARIABILITY IN COURSE AND OUTCOME}

A large inter-patient variability exists in the course and outcome of a $C$. trachomatis infection. Some women clear the infection adequately without developing tissue damage, whereas others develop a persistent infection, which increases the risk of tubal damage and may result in tubal factor subfertility. There is no generally accepted definition of persistence. From a clinical point of view, persistence involves exposure of the host to the pathogen during a longer period, increasing the risk of ascendance to the upper genital tract, endosalpingeal tissue damage and tubal factor subfertility. However, no consensus exists on the length of this period. From a scientific point of view, persistence is assumed to be characterized by a chronic lowgrade immune response and/or the presence of aberrant $C$. trachomatis particles (AbdelRahman and Belland, 2005, Mpiga and Ravaoarinoro, 2006). In this thesis, we use both the clinical and scientific description of persistence. The course and outcome of infectious diseases are generally determined by virulence factors of the pathogen, environmental factors and host immune factors, and these factors will be discussed below.

\section{Virulence factors of the pathogen}

Several studies have evaluated whether different serovars are associated with differences in the clinical course of $C$. trachomatis infections, i.e. symptomatic versus asymptomatic infection, lower versus upper genital tract infection and clearance 
versus persistence (Ito et al., 1990, Persson and Osser, 1993, Dean et al., 2000, Morré et al., 2000, Geisler et al., 2003, Molano et al., 2005).

Serovars $D, E$ and $F$ account for the majority of $C$. trachomatis infections (Persson and Osser, 1993, Morré et al., 2000, Geisler et al., 2003, Molano et al., 2005). Two studies reported a significant relationship between serovars and symptoms: serovar $\mathrm{F}$ (Geisler et al., 2003) and the less-common serovar K (Morré et al., 2000) were associated with a symptomatic course, whereas serovar la was found in asymptomatic women only (Morré et al., 2000). However, both studies could not confirm each other's findings (Morré et al., 2000, Geisler et al., 2003), and Persson and Osser (1993) could not establish any relationship between serovars and symptoms.

In asymptomatic untreated patients, spontaneous clearance from the cervix occurred more often in women infected with the common serovars $F$ and $G$, whereas persistent $C$. trachomatis infections were observed more frequently among serovars $D$ and $E$ and the less-common serovars $B, H, I$, J and $K$ (Molano et al., 2005). Remarkably, despite antibiotic treatment, serovars $\mathrm{H}, \mathrm{I}$ and $\mathrm{J}$ were able to persist for two or three years in the lower genital tract of women (Dean et al., 2000). In a mouse model, the duration of lower genital tract infection was longest with serovars $D$ and $E$, and ascendance to the upper genital tract occurred more often in mice infected with serovar $\mathrm{D}$ as compared to mice infected with serovar $\mathrm{H}$ (Ito et al., 1990).

Studies on the association between different $C$. trachomatis serovars and clinical course and outcome of the disease are not only relevant in the field of subfertility, but also in the field of oncology. It has been shown that $C$. trachomatis cervical infections are associated with cervical squamous cell carcinoma, but not cervical adenocarcinoma, by increasing the risk of persistence of the high-risk types of the oncogenic human papillomavirus (Samoff et al., 2005, Quint et al., 2009). Serovar studies have revealed that exposure to certain single $C$. trachomatis serovars $(G, I$ and $D$ ) or to multiple $C$. trachomatis serovars is associated with the development of cervical squamous cell carcinoma (Anttila et al., 2001).

In brief, studies on the association between virulence of the most common serovars and the course of $C$. trachomatis infections did not yield consistent and clinically applicable results. A hypothesis which is currently under investigation is that genetic variations in the plasticity zone (i.e. a virulence region in the bacterial genome) may account for intra-serovar or intra-strain differences in the course and outcome of $C$. trachomatis infections (Read et al., 2000, Read et al., 2003, Carlson et al., 2004, Nelson et al., 2006). Furthermore, a cryptic $7.5-\mathrm{kb}$ plasmid has been shown to initiate and sustain $C$. trachomatis infection in the female mouse genital tract by regulating gene expression, and is therefore also proposed as a virulence factor (Carlson et al., 2008). 


\section{Environmental factors}

As mentioned earlier, the risk of tubal pathology is dependent on the number of episodes and the severity of PID (Weström, 1980, Weström et al., 1992) (Table II). Furthermore, it has been suggested that the presence of multiple micro-organisms in the genital tract increases the risk of PID (Paisarntantiwong et al., 1995), although little data are available. In large community-based and school-based screening programmes in the United Kingdom and in the United States of America, 4-12\% of all $C$. trachomatis-infected women had a co-infection with other micro-organisms, such as Neisseria (N.) gonorrhoeae (Harindra et al., 2002, Kent et al., 2002, Miller et al., 2004, Nsuami et al., 2004). Studies in women attending clinics for sexually transmitted diseases (STDS) have shown a 13-28\% rate of co-infections in C. trachomatisinfected women (Harindra et al., 2002, Creighton et al., 2003). N. gonorrhoeae infections are more often symptomatic than $C$. trachomatis infections. However, Nsuami and co-workers (2004) have reported that only $14 \%$ of women with both $C$. trachomatis and $N$. gonorrhoeae infections reported symptoms. This indicates that in the majority of women genital tract infections with these two micro-organisms will remain unnoticed and untreated, thereby increasing the risk of late sequelae.

\section{Host immune factors}

Because environmental factors and virulence factors do not seem to play a prominent role in the difference of the clinical course and outcome of $C$. trachomatis female genital tract infections, host immune factors are considered of more importance. Since especially pattern recognition receptors (PRRs) of the innate immune system are suggested to be involved in clearance of the infection, genetic variations in PRRs may contribute to an aberrant immune response and persistence, thereby increasing the risk of tubal pathology. In order to understand the contribution of host immune factors as determinants of the course and outcome of $C$. trachomatis infections, the normal immune response and its variations will be discussed.

\section{THE NORMAL IMMUNE RESPONSE TO INFECTIONS}

\section{Innate immune system}

The innate immune system is a general and non-specific system, which is the first line of defence against pathogens that are unknown to the host. Key elements of the innate immune system are macrophages, neutrophils, dendritic cells and natural killer cells. Several studies have suggested that besides the above-mentioned immune cells, epithelial cells play an important role in the early immune response to 
infections (Rasmussen et al., 1997, Quayle, 2002, Stephens, 2003, Mackern-Oberti et al., 2006).

Both epithelial cells and circulating cells of the innate immune system possess cellsurface-bound or intracellular PRRs. The two most important families of PRRs are the toll-like receptor (TLR) family and the nucleotide-binding oligomerization domain (NOD) proteins. PRRs recognize and bind pathogen-associated molecular patterns (PAMPs), which are components on and in foreign organisms. Binding of a PRR to its PAMP initiates several intracellular reactions, including a signal transduction cascade with nuclear factor (NF)-KB as the end product. NF-KB is able to bind to specific DNA sequences in the nucleus, thereby enhancing the production of (amongst others) pro-inflammatory cytokines. Some PRRs, such as cluster of differentiation (CD) 14, (partly) exist in a soluble extracellular form and act as a coreceptor. Initiation of the immune response then occurs by binding of an extracellular PAMP-PRR complex to a transmembrane PRR. Because different PRRs recognize different PAMPs, the PRR system provides a complex and flexible initiation of the innate immune response. Figure II shows the initiation of the innate immune response by PAMP-PRR complexes.

When a pathogen enters the body, epithelial cells are the first line of defence. The epithelial PRRs bind to the pathogen, and the epithelial cells start to secrete chemokines (which attract circulating cells of the innate immune system to the site of infection) and other pro-inflammatory cytokines. When the circulating cells of the innate immune system arrive at the site of infection, their PRRs bind to the pathogen. Subsequently, macrophages, neutrophils and dendritic cells ingest the pathogen by phagocytosis and destroy it within the cell. Natural killer cells directly destroy the pathogen by cytolysis. Macrophages and dendritic cells are able to express pathogen-components (antigens) bound to major histocompatibility complexproteins (also known as human leucocyte antigens) on their surface and to serve as antigen-presenting cells (APCs), which can activate the acquired immune system. Circulating cells of the innate immune system also produce pro-inflammatory cytokines. 


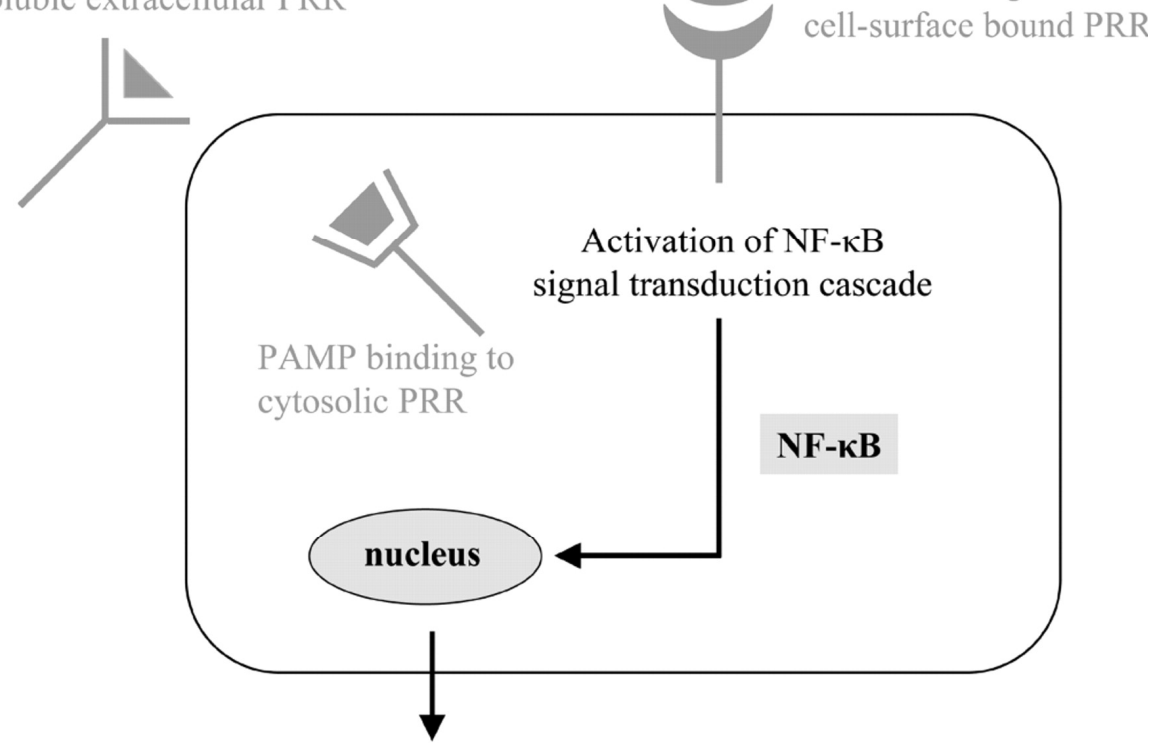

pro-inflammatory response

(e.g. cytokines, acute phase proteins)

Figure II. The initiation of the innate immune response.

The initiation of the innate immune response starts by binding of pathogen-associated molecular patterns (PAMPs) to their pattern recognition receptors (PRRs) on or in circulating cells of the innate immune system (e.g. macrophages, neutrophils, dendritic cells, natural killer cells) or local epithelial cells or to soluble extracellular PRRs. This leads to activation of the nuclear factor (NF)-KB signal transduction cascade. Its end product NF-KB binds to specific DNA sequences in the nucleus, thereby enhancing the production of pro-inflammatory cytokines and acute phase proteins.

\section{Acquired immune system}

The acquired (or adaptive) immune system is a specific system, which develops after the first contact with a pathogen. It builds up a memory against the pathogen, which is responsible for a quick immune response following re-infection. The acquired immune system consists of a humoral arm (with B lymphocytes, mainly targeting extracellular pathogens) and a cell-mediated arm (with T lymphocytes, mainly targeting intracellular pathogens), which closely interact.

In the humoral arm, B lymphocytes are activated by APCs (cells of the innate immune system or T lymphocytes). Activated B lymphocytes develop into plasma cells and produce antibodies which neutralize the antigen or directly destroy the pathogen. An antibody-antigen complex can also activate the complement system. Furthermore, B lymphocytes can serve as APCs for T lymphocytes. 
In the cell-mediated arm, T lymphocytes are activated by APCs (cells of the innate immune system or B lymphocytes). Most T lymphocytes are T helper (Th) cells. Th cells produce pro-inflammatory cytokines. The Th1 subclass produces interleukin (IL)-12 and interferon $\gamma$, which support the cell-mediated system. The Th2 subclass produces IL-4, IL-5, IL-6 and IL-10, which support the humoral system. The relative contributions of the two respective subclasses of Th cells determine whether the cell-mediated or the humoral arm is predominant. Cytotoxic T cells (or killer cells) directly attack and destroy a pathogen and produce pro-inflammatory cytokines. Suppressor $\mathrm{T}$ cells provide a negative feedback mechanism to protect the host against an excessive immune response (i.e. hyperinflammation).

\section{Complement system}

The complement system consists of a group of over twenty proteins. Most of them are circulating in an inactive form (precursors). Once the complement system is activated, a cascade of reactions leads to active end products, which enhance the immune response or destroy the pathogen. Activation of the complement system can be induced by an antibody-antigen complex (classical pathway) or by membrane components of the pathogen (alternate pathway).

\section{RECOGNITION OF C. TRACHOMATIS}

\section{Clearance of a C. trachomatis infection}

In most women a normal immune response to a $C$. trachomatis infection will occur, resulting in adequate clearance (reviewed by Golden et al., 2000, Joyner et al., 2002, Morré et al., 2002, Molano et al., 2005, Geisler et al., 2008). The host is exposed to the pathogen during a short period of time, leading to no or minimal tissue damage. A key element of a normal immune response to a $C$. trachomatis infection is an adequate recognition of the pathogen by PRRs on and in epithelial cells in the genital tract and the initiation of the immune response. The role of PRRs of the TLR and NOD families in C. trachomatis recognition and an early initiation of the immune response will be discussed (summarized in Table IV).

\section{TLRs}

TLRs are cell-surface-bound or intracellular PRRs. So far, eleven different TLRs have been identified. The PAMPs of all TLRs, except TLR10, are known (Akira and Takeda, 2004). Binding of a TLR to its PAMP initiates the immune response by triggering the NF-KB signal transduction cascade. It is plausible that TLRs play a role in the host 
defence mechanism against $C$. trachomatis genital tract infections, because some TLRs are able to recognize $C$. trachomatis PAMPs, and are expressed in epithelial cells in the human genital tract.

Table IV. Presence of TLRs and NODs in the genital tract and their common genetic variations.

\begin{tabular}{|c|c|c|c|c|c|c|}
\hline \multirow[t]{3}{*}{ PRR } & \multirow[t]{3}{*}{ PAMP } & \multicolumn{4}{|c|}{ Presence in genital tract } & \multirow[t]{3}{*}{ Common genetic variation } \\
\hline & & \multicolumn{2}{|c|}{ Human studies } & \multicolumn{2}{|c|}{ Animal studies } & \\
\hline & & In vivo & In vitro & In vivo & In vitro & \\
\hline TLR2 & Peptidoglycan & + & + & + & + & $\begin{array}{l}\text { GT repeat in intron } 2 \\
\text { Arg753GIn } \\
-16933 \mathrm{~T}>\mathrm{A}\end{array}$ \\
\hline TLR4 & LPS and HSP & + & + & + & $+/-$ & $\begin{array}{l}\text { +896 A>G (Asp299Gly) } \\
\text { +1196 Thr399lle }\end{array}$ \\
\hline TLR9 & Bacterial DNA & NA & + & NA & NA & $\begin{array}{l}-1237 \mathrm{~T}>\mathrm{C} \\
+2848 \mathrm{G}>\mathrm{A}\end{array}$ \\
\hline NOD1 & Peptidoglycan & NA & NA & NA & + & Del T/Ins GG +32656 \\
\hline NOD2 & Peptidoglycan & NA & NA & NA & + & $\begin{array}{l}2023 \text { C > ( }(\text { SNP8, R675W) } \\
2641 \text { G>C (SNP12, G1881R) } \\
\text { 2936insC (SNP13, Leu1007fsinsC, 980fs981X) }\end{array}$ \\
\hline
\end{tabular}

$+=$ Present in genital tract. +/- = Present in genital tract in some, but not all, studies.

Abbreviations: HSP = heat shock protein; LPS = lipopolysaccharide; NA = not analyzed; NOD = nucleotide oligomerization domain; $\mathrm{PAMP}=$ pathogen-associated molecular pattern; $\mathrm{PRR}=$ pattern recognition receptor; TLR = toll-like receptor.

TLR2 is the PRR for the C. trachomatis component peptidoglycan (Schwandner et al., 1999, Yoshimura et al., 1999), and TLR4 is the PRR for the C. trachomatis components LPS and HSP (Poltorak et al., 1998, Ohashi et al., 2000). TLR2 and TLR4 are expressed in the human female genital tract (Pioli et al., 2004, Fazeli et al., 2005) and in epithelial cell lines derived from the human genital tract (Schaefer et al., 2004, O'Connell et al., 2006). TLR2 is also expressed in a cloned murine tubal epithelial cell line (Derbigny et al., 2005). Differential expression along the human genital tract has been observed for TLR2, mainly expressed in the tubes and cervix, and for TLR4, mainly expressed in the tubes and endometrium and weakly expressed or even absent in the ectocervix (Pioli et al., 2004, Fazeli et al., 2005). These differences in expression may be related to the different functions of the different parts of the genital tract: protection against sexually transmitted pathogens without disturbing the functional vaginal commensal flora and toleration of semen and embryonic implantation. Up-regulation of TLR2 and TLR4 expression following chlamydial infection has been noted in several studies (Mackern-Oberti et al., 2006, O'Connell et al., 2006).

TLR9 recognizes bacterial DNA (Hemmi et al., 2000). So far, the expression of TLR9 has not been studied in the human female genital tract, although TLR9 expression has been found in the human uterine epithelial cell line ECC-1 (Schaefer et al., 
2004). Its precise role in C. trachomatis female genital tract infections remains to be established.

TLR1, TLR3, TLR5 and TLR6 are also present in the human female genital tract (Pioli et al., 2004, Fazeli et al., 2005), but they do not recognize C. trachomatis PAMPs. This suggests that these TLRs may play a role in the host defence against non- $C$. trachomatis and/or polymicrobial genital tract infections.

Animal studies are able to provide information on the role of PRRs in C. trachomatis infections that cannot be obtained by human studies, although results of animal studies may not be freely translated to the human in vivo situation and the strain of C. trachomatis used (e.g. C. muridarum versus serovars $\mathrm{D}-\mathrm{K}$ versus the more invasive LGV serovar) may influence the outcome in any of the models used. Knockout (KO) mouse technology offers the opportunity to remove entire genes of interest from the genome and to compare the course and outcome of infectious diseases between KO mice and wild-type (WT) mice, which possess the gene of interest. Darville and co-workers (2003) have designed a KO mouse model to study the role of TLR2 and TLR4 in the course and outcome of a $C$. muridarum infection, which is the mouse variant of $C$. trachomatis. WT mice with normal TLR2 and TLR4 genes served as controls. The in vitro cytokine production of macrophages was down-regulated, but not totally inhibited, in macrophages derived from TLR2 KO mice, whereas it was up-regulated in macrophages derived from TLR4 KO mice. The in vivo resolution of a $C$. muridarum infection was equally efficient in KO and WT mice, indicating that the remaining and/or compensatory immune mechanisms seem to lead to sufficient clearance in KO mice. Remarkably, TLR2 KO mice developed less tubal pathology in comparison with WT mice, despite a down-regulated cytokine production. These findings suggest that TLR2 genetic variations may provide a balanced immune response leading to efficient clearance, rather than hypo- or hyperinflammation, and serve as protection against tissue damage (Darville et al., 2003).

\section{NODs}

NOD proteins are intracellular PRRs. The family of NOD proteins contains at least 25 proteins, including NOD1 and NOD2 (Inohara and Nuňez, 2003). NOD1 and NOD2 are also referred to as caspase recruitment domain (CARD) 4 and CARD15, respectively. NODs are able to recognize intracytoplasmatic bacterial PAMPs, such as LPS and peptidoglycan (Inohara et al., 2001, Girardin et al., 2003). Binding of a NOD to its PAMP activates the NF-KB signal transduction cascade, which initiates the immune response.

Because $C$. trachomatis is an intracellular pathogen containing LPS and peptidoglycan, a role of intracellular NODs in the recognition of $C$. trachomatis has been suggested. This is supported by findings of several studies (Derbigny et al., 2005, Opitz et al., 2005, Welter-Stahl et al., 2006, Buchholz and Stephens, 2008). Welter-Stahl 
and co-workers (2006) have found that $C$. trachomatis produces at least the rudimentary proteoglycan motif recognized by NOD1. Furthermore, it has been proven that NOD1 and NOD2 are expressed in a cloned murine fallopian tube epithelial cell line (Derbigny et al., 2005). C. pneumoniae has been shown to induce a NODmediated pro-inflammatory immune response in endothelial cells in vitro (Opitz et al., 2005). The most recent study has concluded that, in epithelial cells in vitro, the inflammatory response following $C$. trachomatis infection is NOD1-dependent (Buchholz and Stephens, 2008).

\section{PERSISTENCE OF A C. TRACHOMATIS INFECTION}

In some women, a C. trachomatis infection will not be cleared adequately and may result in a persistent infection. The host is exposed to the pathogen during a longer period of time, increasing the risk of ascendance to the upper genital tract, endosalpingeal tissue damage and tubal factor subfertility. The course of a $C$. trachomatis infection (i.e. whether the infection will be cleared or persist) may be determined by host immune factors.

\section{Introduction to immunogenetics}

Although differences in the infectivity among $C$. trachomatis strains have been reported and reinfection has been shown to influence the clinical course, at this time neither virulence factors of the pathogen nor environmental factors do seem to play a major role in the difference of the clinical course of $C$. trachomatis infections, suggesting that host immune factors are to be considered more important determinants of the inter-patient variability in the course and outcome.

Immunogenetic studies evaluate the role of genetic variations in immunologically important host genes in the course and outcome of infectious diseases. Among these genetic variations are single nucleotide polymorphisms (SNPS), in which one nucleotide has been substituted, inserted or deleted, and variations in the number of repetitive DNA sequences (variable number of tandem repeats). Carrying a genetic variation may have direct or indirect biological consequences. Potential direct biological consequences of carrying a genetic variation are translation of an aberrant protein, or up- or down-regulation of the translation of a normal protein. If a genetic variation is not functional, i.e. does not change the function of the gene studied, it may have indirect biological consequences when it is inherited together with another, sometimes still unidentified, functional gene nearby (linkage).

During the past years, immunogenetic studies have provided more insight in the inter-patient variability in the course and outcome of infectious diseases. Several studies have found an association between carriage of genetic variations and infec- 
tious diseases, such as hepatitis, inflammatory bowel diseases, meningococcal infections and Ureoplasma urealyticum lower genital tract infections (Jeremias et al., 1999, Smirnova et al., 2003, Franchimont et al., 2004, Peeters et al., 2004, Frodsham, 2005). Regarding $C$. trachomatis ocular infections, a $40 \%$ genetic predisposition was noted in a Gambian twin study, supporting the relevance of genetics in $C$. trachomatis infections (Bailey et al., 1998, Bailey et al., 2009).

As discussed previously, a normal immune response to a $C$. trachomatis infection is based on an adequate recognition of the pathogen by, amongst others, TLRs and NODs on epithelial cells in the genital tract. In the next paragraphs, the role of genetic variations in genes encoding TLRs and NODs as potential risk factors for persistent $C$. trachomatis infections will be discussed (see also Table IV).

\section{Variations in TLR genes}

It is likely that TLR2, TLR4 and TLR9 play a role in the recognition of $C$. trachomatis in the genital tract, because they are expressed in the human female genital tract and because they are able to recognize $C$. trachomatis PAMPs. It is assumed that genetic variations in TLR genes may result in aberrant receptor density on or in cells or in dysfunctional receptors, leading to an inadequate recognition of $C$. trachomatis and an increased risk of persistence. However, not many human studies have tested this hypothesis.

Regarding TLR4, it is known that only homozygous carriage of the $T L R 4+896 \mathrm{~A}>\mathrm{G}$ (also referred to as Asp299Gly) and Thr399Ile SNPs affects the LPS receptor function, whereas heterozygous carriage has no effect on the LPS receptor function (Erridge et al., 2003). Homozygous carriage of the TLR4 +896 A $>G$ SNP is rare. In a study comparing 30 CAT-positive subfertile women with tubal pathology with 41 CAT-positive subfertile women without tubal pathology, only one woman carried the homozygous TLR4 +896 A $>$ G SNP, and no significant association between this SNP and C. trachomatis-associated tubal pathology could be found (Morré et al., 2003). So far, the latter two studies are the only human studies on the role of TLR genetic variations and susceptibility to $C$. trachomatis genital tract infections. The number of human studies may be limited due to difficulties in collecting adequate sample sizes, because patients who have undergone a $C$. trachomatis infection ánd have had evaluation of the tubal function ánd carry a single or multiple genetic variations are exceedingly rare. Multi-center trials might resolve this drawback. Although functional SNPs in the TLR2 gene have been described in relation to infection and inflammation (Lorenz et al., 2000, Sutherland et al., 2005, Yim et al., 2006), no studies have yet been performed for $C$. trachomatis infections.

Further studies are needed to investigate the precise role of TLRs in $C$. trachomatis genital tract infections, in particular to determine whether TLR genetic variations 
act in a damaging way, as generally assumed, or in a protective way, as suggested by Darville and co-workers in their KO mouse model (2003).

\section{Variations in NOD genes}

The precise role of NOD proteins in the intracellular recognition of $C$. trachomatis in the genital tract has not been established, although several studies suggest that NODs are involved in the immune response to $C$. trachomatis genital tract infections (Inohara et al., 2001, Girardin et al., 2003, Derbigny et al., 2005, Opitz et al., 2005, Welter-Stahl et al., 2006, Buchholz and Stephens, 2008). If this association could be confirmed, NOD genetic variations may be risk factors of inadequate recognition and persistence in $C$. trachomatis infections.

Several genetic variations in the NOD2 genes have been associated with the susceptibility to inflammatory bowel disease (Hugot et al., 2001, Ogura et al., 2001, Hampe et al., 2002, Murillo et al., 2002, McGovern et al., 2005). Carrying a NOD2 genetic variation seems to result in hyporesponsiveness to enteric bacteria, increasing the risk of chronic bowel inflammation. Hugot and co-workers (2001) have also identified a so-called gene-dosage effect: the higher the number of genetic variations in a patient, the higher the risk of Crohn's disease. As compared to patients without NOD2 variations, the relative risk of Crohn's disease was 3 in heterozygous carriers of a single variation, 38 in homozygous carriers of a single variation and 44 in heterozygous carriers of two variations (Hugot et al., 2001). In a recent study, this gene-dosage effect has also been demonstrated for NOD2 variations and variations in other disease-associated genes in Crohn's disease (Weersma et al., 2009).

As NOD2, NOD1 is also a ubiquitous cytosolic receptor for peptidoglycan from Gram-negative bacteria, and recent studies have suggested that $C$. trachomatis and C. muridarum do, in fact, produce at least the rudimentary proteoglycan motif recognized by NOD1. Welter-Stahl and co-workers (2006) have demonstrated that NOD1 deficiency has no effect on the duration of chlamydia infection, the intensity of cytokine secretion, or the extent of pathology in KO mice, compared with WT controls. Thus, chlamydia may not produce sufficient peptidoglycan to stimulate NOD1-dependent pathways efficiently, or other receptors of the innate immune system may compensate for the absence of NOD1 during chlamydia infection in vivo, as has been shown by Netea and co-workers (2005). But, on the contrary, a recent in vitro study has found reduced IL-8 levels in NOD1 knockdown HeLa cells following $C$. trachomatis infection, suggesting that the inflammatory response to $C$. trachomatis infection is NOD1 dependent (Buchholz and Stephens, 2008).

The studies mentioned encourage to investigate whether NODs play a role as PRRs for $C$. trachomatis, and if so, whether genetic variations increase the risk of an aberrant immune response and persistence of $C$. trachomatis infections. 


\section{Conclusive remarks on immunogenetics}

Carriage of a single variation in a single host gene does not necessarily lead to an increased risk of developing late sequelae of infectious diseases, especially in case of a polygenic multivariate infection like $C$. trachomatis. The immune system is a complex and flexible system, and compensatory routes will, to a certain extent, provide alternative pathways to trigger the immune response. For instance, disfunctionality of the NOD1 pathway can be partially overcome by functional TLRs (Netea et al., 2005), and not only PRRs but also the complement system is involved in pathogen recognition. Furthermore, heterozygous carriage of some genetic variations may not have a large effect on the function of the gene (Erridge et al., 2003) because the other allele can compensate. It is also hypothesized that the risk of late sequelae increases with the number of genetic variations, as found for variations in NODs and other disease-associated genes in Crohn's disease (Hugot et al., 2001, Weersma et al., 2009) and for TLR variations in meningococcal infections (Smirnova et al., 2003).

In general, the main goal of immunogenetic studies is to provide more insight in the immunopathogenesis of infectious diseases and to identify genetic markers related to the susceptibility to and severity of infection. The end goal is to identify patients at highest risk of complications and to assess whether immunogenetic analyses can be applied in screening for tubal pathology. Regarding $C$. trachomatis female genital tract infections, the precise role of PRRs and their genetic variations remains to be elucidated.

\section{AIMS OF THE THESIS}

The thesis focusses on persistent $C$. trachomatis infections and the ensuing tubal factor subfertility. The first aim of the thesis is to improve the predictive value of CAT in assessing the risk of $C$. trachomatis-associated tubal factor subfertility. It is hypothesized that serological markers of persistent $C$. trachomatis infections can be used to identify subfertile women at highest risk of tubal pathology. In addition, different screening strategies for tubal factor subfertility which can be applied in the fertility work-up are appraised. Secondly, the role of host immunogenetic factors contributing to the course of $C$. trachomatis infections is explored. Furthermore, different detection methods for persistent $C$. trachomatis in endometrial tissue of subfertile women are studied. 


\section{OUTLINE OF THE THESIS}

The first part of the thesis describes different screening methods for the risk assessment of $C$. trachomatis-associated tubal factor subfertility. The risk of developing tubal pathology following $C$. trachomatis infection depends on the course of the infection. Most women will effectively clear a C. trachomatis infection and have a low risk of developing complications. However, women with a persistent $C$. trachomatis infection are assumed to be at highest risk for tubal factor subfertility. In Chapter 2, it will be evaluated whether serological markers of persistence ( $C$. trachomatis IgA antibodies, cHSP60 IgG antibodies and hs-CRP) can identify women at highest risk of tubal factor subfertility. In Chapter 3, anti-LPS IgG antibodies will be tested as potential markers of persistence. Furthermore, the contribution of $C$. pneumoniae and $C$. psittaci infections, following a primary $C$. trachomatis infection, to the development of tubal pathology will be studied. In Chapter 4, three screening strategies to estimate the risk of tubal pathology in subfertile women will be explored. The screening strategies comprise $C$. trachomatis IgG antibody testing, hsCRP and HSG. One of the screening strategies is based on our findings described in Chapter 2.

The second part of this thesis focusses on immunogenetic aspects of $C$. trachomatisassociated tubal factor subfertility. Amongst others, SNPs (i.e. genetic variations) in immunologically important host genes are determinants of the inter-patient variability of $C$. trachomatis infections. In Chapter 5, the TLR4 +896 A>G SNP will be studied in relation to the susceptibility to $C$. trachomatis infections (in a cohort of women who visited an outpatient STD clinic) and outcome of $C$. trachomatis infections (in a cohort of subfertile women). Additionally, a knock-out mouse model will be used to test the role of TLR4 in the susceptibility and outcome of primary C. trachomatis infections and re-infections. In Chapter 6, the role of the CD14-260 C>T SNP in the susceptibility to and severity of $C$. trachomatis infections will be evaluated in the STD cohort and subfertility cohort. In Chapter 7, the hypothesis that carrying multiple SNPs in pattern recognition receptor genes, rather than a single SNP, may result in the highest risk of tubal pathology following $C$. trachomatis infection will be tested.

The third part of this thesis addresses the question whether endometrial sampling can be used as a diagnostic method for identifying persistent $C$. trachomatis upper genital tract infection in subfertile women. In Chapter 8, a pilot study using immunohistochemical staining methods and polymerase chain reaction will be performed to detect $C$. trachomatis in the endometrium of subfertile women. The results will be correlated to the presence of $C$. trachomatis IgG antibodies in serum and the presence of tubal pathology at laparoscopy.

In Chapter 9, the results will be summarized. Recommendations for clinical application and future research will be presented. 


\section{REFERENCES}

AbdelRahman YM, Belland RJ (2005) The chlamydial developmental cycle. FEMS Microbiol Rev 29, 949959.

Akande VA, Hunt LP, Cahill DJ, Caul EO, Ford WCL, Jenkins JM (2003) Tubal damage in infertile women: prediction using chlamydia serology. Hum Reprod 18, 1841-1847.

Akira S, Takeda K (2004) Toll-like receptor signalling. Nat Rev Immunol 4, 499-511.

Andersen B, Østergaard L, Puho E, Skriver MV, Schønheuder HC (2005) Ectopic pregnancies and reproductive capacities after Chlamydia trachomatis positive and negative test results: a historical followup study. Sex Transm Dis 32, 377-381.

Anttila T, Saikku P, Koskela P, Bloigu A, Dillner J, Ikaheimo I, Jellum E, Lehtinen M, Lenner P, Hakulinen T et al. (2001) Serotypes of Chlamydia trachomatis and risk for development of cervical squamous cell carcinoma. JAMA 285, 47-51.

Arno JN, Yuan Y, Cleary RE, Morrison RP (1995) Serologic responses of infertile women to the 60-kd chlamydial heat shock protein (hsp60). Fertil Steril 64, 730-735.

Ault KA, Statland BD, Smith King MM, Dozier DIL, Joachims ML, Gunter J (1998) Antibodies to the chlamydial 60 kilodalton heat shock protein in women with tubal factor infertility. Infect Dis Obstet Gynecol 6, 163-167.

Bailey RL, Holland MJ, Whittle HC, Mabey DCW (1995) Subjects recovering from human ocular chlamydial infection have enhanced lymphoproliferative responses to chlamydial antigens compared to those of persistently diseased controls. Infect Immun 63, 389-392.

Bailey RL, Fowler A, Peeling R, Mabey D, Whittle H, Jepson A (1998) Lymphoproliferative responses to C. trachomatis EBS in a Gambian twin population; Estimating the role of host genetic factors. Proceedings of the Ninth International Symposium on Human Chlamydial Infections, Napa, California, USA, June 21-26, 1998, pp 474-477.

Bailey RL, Natividad-Sancho A, Fowler A, Peeling RWW, Mabey DCW, Whittle HC, Jepson AP (2009) Host genetic contribution to the cellular immune response to Chlamydia trachomatis: heritability estimate from a Gambian twin study. Drugs Today 45 (Suppl B), 45-50.

Barlow REL, Cooke ID, Odukoya O, Heatley MK, Jenkins J, Narayansingh G, Ramsewak SS, Eley A (2001) The prevalence of Chlamydia trachomatis in fresh tissue specimens from patients with ectopic pregnancy or tubal factor infertility as determined by PCR and in-situ hybridisation. J Med Microbiol 50, 902-908.

Bevan CD, Johal BJ, Mumtaz G, Ridgway GL, Siddle NC (1995) Clinical, laparoscopic and microbiological findings in acute salpingitis: report on a United Kingdom cohort. Br J Obstet Gynecol 102, 407-414.

Bjartling C, Osser S, Persson K (2007) Deoxyribonucleic acid of Chlamydia trachomatis in fresh tissue from the Fallopian tubes of patients with ectopic pregnancy. Eur J Obstet Gynecol Reprod Biol 134, 95100.

Bragina EY, Gomberg MA, Dmitriev GA (2001) Electron microscopic evidence of persistent chlamydial infection following treatment. J Eur Acad Dermatol Venereol 15, 405-409.

Buchholz KR, Stephens RS (2008) The cytosolic pattern recognition receptor NOD1 induces inflammatory interleukin-8 during Chlamydia trachomatis infection. Infect Immun 76, 3150-3155.

Carlson JH, Hughes S, Hogan D, Cieplak G, Sturdevant DE, McClarty G, Caldwell HD, Belland RJ (2004) Polymorphisms in the Chlamydia trachomatis cytotoxin locus associated with ocular and genital isolates. Infect Immun 72, 7063-7072.

Carlson JH, Whitmire WM, Crane DD, Wicke L, Virtaneva K, Sturdevant DE, Kupko JJ $3^{\text {rd }}$, Porcella SF, Martinez-Orengo N, Heinzen RA et al. (2008) The Chlamydia trachomatis plasmid is a transciptional regulator of chromosomal genes and a virulence factor. Infect Immun 76, 2273-2283.

Cates W, Wasserheit JN (1991) Genital chlamydial infections: epidemiology and reproductive sequelae. Am J Obstet Gynecol 164, 1771-1781. 
Chaim W, Edelstein Z, Sarov B, Sarov I (1992) The long-term follow-up of asymptomatic women with Chlamydia trachomatis. Arch Gynecol Obstet 251, 159-164.

Chapron C, Querleu D, Bruhart MA, Madelenat P, Fernandez H, Pierre F, Dubuisson JB (1998) Surgical complications of diagnostic and operative gynaecological laparoscopy: a series of 29966 cases. Hum Reprod 13, 867-872.

Claman P, Honey L, Peeling RW, Jessamine P, Toye B (1997) The presence of serum antibody to the chlamydial heat shock protein (CHSP60) as a diagnostic test for tubal factor infertility. Fertil Steril 67, 501-504.

Collet M, Reniers J, Frost E, Gass R, Yvert F, Leclerc A, Roth-Meyer C, Ivanoff B, Meheus A (1988) Infertility in Central Africa: infection is the cause. Int J Gynecol Obstet 26, 423-428.

Collier LH, Duke-Elder S, Jones BR (1958) Experimental trachoma produced by cultured virus. Br J Ophthalmol 42, 705-720.

Collins JA, Burrows EA, Willan AR (1995) The prognosis for live birth among untreated infertile couples. Fertil Steril 64, 22-28.

Collins JA, Van Steirteghem A (2004) Overall prognosis with current treatment of infertility. Hum Reprod Update 10, 309-316.

Coppus SFPJ, Opmeer BC, Logan S, Van der Veen F, Bhattacharya S, Mol BWJ (2007) The predictive value of medical history taking and Chlamydia IgG ELISA antibody testing (CAT) in the selection of subfertile women for diagnostic laparoscopy: a clinical prediction model approach. Hum Reprod 22, 13531358.

Creighton S, Tenant-Flowers M, Taylor CB, Miller R, Low N (2003) Co-infection with gonorrhoea and chlamydia: how much is there and what does it mean? Int J STD AIDS 14, 109-113.

Dabekausen YA, Evers JLH, Land JA, Stals FS (1994) Chlamydia trachomatis antibody testing is more accurate than hysterosalpingography in predicting tubal factor infertility. Fertil Steril 61, 833-837.

Darville T, O'Neill JM, Andrews CW, Nagarajan UM, Stahl L, Ojcius DM (2003) Toll-like receptor-2, but not toll-like receptor-4, is essential for development of oviduct pathology in chlamydial genital tract infection. J Immunol 171, 6187-6197.

Dean D, Suchland RJ, Stamm WE (2000) Evidence for long-term cervical persistence of Chlamydia trachomatis by omp1 genotyping. J Infect Dis 182, 909-916.

Debattista J, Gazzard CM, Wood RN, Allan JA, Allan JM, Scarman A, Mortlock M, Timms P, Knox CL (2004) Interaction of microbiology and pathology in women undergoing investigations for infertility. Infect Dis Obstet Gynecol 12, 135-145.

Derbigny WA, Kerr MS, Johnson RM (2005) Pattern recognition molecules activated by Chlamydia muridarum infection of cloned murine oviduct epithelial cell lines. J Immunol 175, 6065-6075.

Dieterle S, Wollenhaupt J (1996) Humoral immune response to the chlamydial heat shock proteins hsp60 and hsp70 in Chlamydia-associated chronic salpingitis with tubal occlusion. Hum Reprod 11, 13521356.

Dowell SF, Peeling RW, Boman J, Carlone GM, Fields BS, Guarner J, Hammerschlag MR, Jackson LA, Kuo CC, Maass M et al. (2001) Standardizing Chlamydia pneumoniae assays: Recommendations from the Centers for Disease Control and Prevention (USA) and the Laboratory Centre for Disease Control (Canada). Clin Infect Dis 33, 492-503.

Eggert-Kruse W, Rohr G, Demirakca T, Rusu R, Näher H, Petzoldt D, Runnebaum B (1997) Chlamydial serology in 1303 asymptomatic subfertile couples. Hum Reprod 12, 1464-1475.

Erridge C, Stewart J, Poxton IR (2003) Monocytes heterozygous for the Asp299Gly and Thr399Ile mutations in the toll-like receptor 4 gene show no deficit in lipopolysaccharide signalling. J Exp Med 197, 1787-1791.

Everett KDE, Bush RM, Andersen AA (1999) Emended description of the order Chlamydiales, proposal of Parachlamydiaceae fam. nov. and Simkaniaceae fam. nov., each containing one monotypic genus, revised taxonomy of the family Chlamydiaceae, including a new genus and five new species, and standards for the identification of organisms. Int J Syst Bacteriol 49, 415-440. 
Falck G, Gnarpe J, Hansson LO, Svärdsudd K, Gnarpe H (2002) Comparison of individuals with and without specific IgA antibodies to Chlamydia pneumoniae. Respiratory morbidity and the metabolic syndrome. Chest 122, 1587-1593.

Fazeli A, Bruce C, Anumba DO (2005) Characterization of Toll-like receptors in the female reproductive tract in humans. Hum Reprod 20, 1372-1378.

Fiddelers AAA, Land JA, Voss G, Kessels AGH, Severens JL (2005) Cost-effectiveness of Chlamydia antibody tests in subfertile women. Hum Reprod 20, 425-432.

Forsey J, Caul E, Paul ID, Hull MGR (1990) Chlamydia trachomatis, tubal disease and the incidence of symptomatic and asymptomatic infection following hysterosalpingography. Hum Reprod 5, 444-447.

Franchimont D, Vermeire S, El Housni H, Pierik M, Van Steen K, Gustot T, Quertinmont E, Abramowicz M, Van Gossum A, Devière J et al. (2004) Deficient host-bacteria interactions in inflammatory bowel disease? The toll-like receptor (TLR)-4 Asp299gly polymorphism is associated with Crohn's disease and ulcerative colitis. Gut 53, 987-992.

Freidank HM, Clad A, Herr AS, Wiedmann-Al-Ahmad M, Jung B (1995) Immune response to Chlamydia trachomatis heat-shock protein in infertile female patients and influence of Chlamydia pneumoniae antibodies. Eur J Clin Microbiol Infect Dis 14, 1063-1069.

Frodsham AJ (2005) Host genetics and the outcome of hepatitis B viral infection. Transpl Immunol 14, 183-186.

Gattone M, lacoviello L, Colombo M, Di Castelnuovo A, Soffiantino F, Gramoni A, Picco D, Benedetta M, Giannuzzi P (2001) Chlamydia pneumoniae and cytomegalovirus seropositivity, inflammatory markers, and the risk of myocardial infarction at a young age. Am Heart J 142, 633-640.

Geisler WM, Suchland RJ, Whittington WLH, Stamm WE (2003) The relationship of serovar to clinical manifestations of urogenital Chlamydia trachomatis infection. Sex Transm Dis 30, 160-165.

Geisler WM, Wang C, Morrison SG, Black CM, Bandea CI, Hook EW $3^{\text {rd }}(2008)$ The natural history of untreated Chlamydia trachomatis infection in the interval between screening and returning for treatment. Sex Transm Dis 35, 119-123.

Gérard HC, Branigan PJ, Balsara GR, Heath C, Minassian SS, Hudson AP (1998) Viability of Chlamydia trachomatis in fallopian tubes of patients with ectopic pregnancy. Fertil Steril 70, 945-948.

Gijsen AP, Land JA, Goossens VJ, Leffers P, Bruggeman CA (2001) Chlamydia pneumoniae and screening for tubal factor subfertility. Hum Reprod 16, 487-491.

Gijsen AP, Land JA, Goossens, VJ, Slobbe MEP, Bruggeman CA (2002) Chlamydia antibody testing in screening for tubal factor subfertility: the significance of IgG antibody decline over time. Hum Reprod 17, 669-703.

Girardin SE, Boneca IG, Viala J, Chamaillard M, Labigne A, Thomas G, Philpott DJ, Sansonetti PJ (2003) Nod2 is a general sensor of peptidoglycan through muramyl dipeptide (MDP) detection. J Biol Chem $278,8869-8872$.

Golden MR, Schillinger JA, Markowitz L, St Louis ME (2000) Duration of untreated genital infections with Chlamydia trachomatis: a review of the literature. Sex Transm Dis 27, 329-337.

Grayston JT (1989) Chlamydia pneumoniae, strain TWAR. Chest 95, 664-669.

Hampe J, Frenzel H, Mirza MM, Croucher PJP, Cuthbert A, Mascheretti S, Huse K, Platzer M, Bridger S, Meyer B et al. (2002) Evidence for a NOD2-independent susceptibility locus for inflammatory bowel disease on chromosome 16p. Proc Natl Acad Sci U S A 99, 321-326.

Haeusler G, Tempfer C, Lehner R, Sam C, Kainz C (1997) Fallopian tissue sampling with a cytobrush during hysteroscopy: a new approach for detecting tubal infection. Fertil Steril 67, 580-582.

Harindra V, Tobin JM, Underhill G (2002) Opportunistic chlamydia screening; should positive patients be screened for co-infections? Int J STD AIDS 13, 822-825.

Hawkins RA, Rank RG, Kelly KA (2002) A Chlamydia trachomatis-specific Th2 clone does not provide protection against a genital infection and displays reduced trafficking to the infected genital mucosa. Infect Immun 70, 5132-5139.

Health Council of The Netherlands (2004) Screening for Chlamydia. The Hague: Health Council of The Netherlands. Publication no. 2004/07. 
Hemmi H, Takeuchi O, Kawai T, Kaisho T, Sato S, Sanjo H, Matsumoto M, Hoshino K, Wagner H, Takeda K et al. (2000) A toll-like receptor recognizes bacterial DNA. Nature 408, 740-745.

Henry-Suchet J, Askienazy-Elbhar M, Thibon M, Revol C, Akue BA (1994) The post-therapeutic course of serum antibody titres in women with acute salpingitis and tubal infertility. Fertil Steril 62, 296-304.

Hinton EL, Bobo LD, Wu TC, Kurman RJ, Viscidi RP (2000) Detection of Chlamydia trachomatis DNA in archival paraffinized specimens from chronic salpingitis cases using the polymerase chain reaction. Fertil Steril 74, 152-157.

Holland MJ, Bailey RL, Conway DJ, Culley F, Miranpuri G, Byrne GI, Whittle HC, Mabey DCW (1996) T helper type-1 (Th1)/Th2 profiles of peripheral blood mononuclear cells (PBMC); response to antigens of Chlamydia trachomatis in subjects with severe trachomatous scarring. Clin Exp Immunol 105, 429435.

Hubacher D, Grimes D, Lara-Ricalde R, De la Jara J, Garcia-Luna A (2004) The limited clinical usefulness of taking a history in the evaluation of women with tubal factor infertility. Fertil Steril 81, 6-10.

Hugot JP, Chamaillard M, Zouali H, Lesage S, Cézard JP, Belaiche J, Almer S, Tysk C, O'Morrain CA, Gassull $\mathrm{M}$ et al. (2001) Association of NOD2 leucine-rich repeat variants with susceptibility to Crohn's disease. Nature 411, 599-603.

Inohara N, Ogura Y, Chen FF, Muto A, Nuňez G (2001) Human Nod1 confers responsiveness to bacterial lipopolysaccharides. J Biol Chem 276, 2551-2554.

Inohara N, Nuňez G (2003) NODs: intracellular proteins involved in inflammation and apoptosis. Nat Rev Immunol 3, 371-382.

Ito JI, Lyons JM, Airo-Brown LP (1990) Variation in virulence among oculogenital serovars of Chlamydia trachomatis in experimental genital tract infection. Infect Immun 58, 2021-2023.

Jeremias J, Giraldo P, Durrant S, Ribeiro-Filho A, Witkin SS (1999) Relationship between Ureoplasma urealyticum vaginal colonization and polymorphism in the interleukin-1 receptor antagonist gene. J Infect Dis 180, 912-914.

Johnston SC, Messina LM, Browner WS, Lawton MT, Morris C, Dean D (2001) C-reactive protein levels and viable Chlamydia pneumoniae in carotid artery atherosclerosis. Stroke 32, 2748-2752.

Jones RB, Mammel JB, Shepard MK, Fisher RR (1986) Recovery of Chlamydia trachomatis from the endometrium of women at risk for chlamydial infection. Am J Obstet Gynecol 155, 35-39.

Joyner JL, Douglas JM, Foster M, Judson FN (2002) Persistence of Chlamydia trachomatis infection detected by polymerase chain reaction in untreated patients. Sex Transm Dis 29, 196-200.

Kaklikkaya I, Kaklikkaya N, Buruk K, Pulathan Z, Koramaz I, Aydin F, Tosun I, Kilic AO, Özcan F (2006) Investigation of Chlamydia pneumoniae DNA, chlamydial lipopolysaccharide antigens, and Helicobacter pylori DNA in atherosclerotic plaques of patients with aortoiliac occlusive disease. Cardiovasc Pathol 15, 105-109.

Karinen L, Pouta A, Hartikainen A-L, Bloigu A, Paldanius M, Leinonen M, Saikku P, Järvelin M-R (2004) Antibodies to Chlamydia trachomatis heat shock proteins Hsp60 and Hsp10 and subfertility in general population at age 31. Am J Reprod Immunol 52, 291-297.

Kaufmann SHE (1990) Heat shock proteins and the immune response. Immunol Today 11, 129-136.

Kent CK, Branzuela A, Fischer L, Bascom T, Klausner JD (2002) Chlamydia and gonorrhoea screening in San Francisco high schools. Sex Transm Dis 29, 373-375.

Lan J, Van den Brule AJC, Hemrika DJ, Risse EKJ, Walboomers JMM, Schipper MEI, Meijer CJLM (1995) Chlamydia trachomatis and ectopic pregnancy: retrospective analysis of salpingectomy specimens, endometrial biopsies, and cervical smears. J Clin Pathol 48, 815-819.

Land JA, Evers JLH, Goossens VJ (1998) How to use Chlamydia antibody testing in subfertility patients. Hum Reprod 13, 1094-1098.

Land JA, Gijsen AP, Kessels AGH, Slobbe MEP, Bruggeman CA (2003) Performance of five serological chlamydia antibody tests in subfertile women. Hum Reprod 18, 2621-2627.

LaVerda D, Kalayoglu MV, Byrne GI (1999) Chlamydial heat shock proteins and disease pathology: new paradigms for old problems? Infect Dis Obstet Gynecol 7, 64-71. 
Logan S, Gazvani R, McKenzie H, Templeton A, Bhattacharya S (2003) Can history, ultrasound, or ELISA chlamydial antibodies, alone or in combination, predict tubal factor infertility in subfertile women? Hum Reprod 18, 2350-2356.

Lorenz E, Mira JP, Cornish KL, Arbour NC, Schwartz DA (2000) A novel polymorphism in the toll-like receptor 2 gene and its potential association with staphylococcal infection. Infect Immun 68, 6398-6401.

Luttjeboer F, Harada T, Hughes E, Johnson N, Lilford R, Mol BWJ (2007) Tubal flushing for subfertility. Cochrane Database Syst Rev Issue 3: CD003718.

Luttjeboer FY, Verhoeve HR, Van Dessel HJ, Van der Veen F, Mol BWJ, Coppus SFPJ (2009) The value of medical history taking as risk indicator for tuboperitoneal pathology: a systematic review. BJOG 116, 612-625.

Mackern-Oberti JP, Maccioni M, Cuffini C, Gatti G, Rivero VE (2006) Susceptibility of prostate epithelial cells to Chlamydia muridarum infection and their role in innate immunity by recruitment of intracellular toll-like receptors 4 and 2 and MyD88 to the inclusion. Infect Immun 74, 6973-6981.

McGovern DPB, Hysi P, Ahmad T, Van Heel DA, Moffat MF, Carey A, Cookson WOL, Jewell DP (2005) Association between a complex insertion/deletion polymorphism in NOD1 (CARD4) and susceptibility to inflammatory bowel disease. Hum Mol Genet 14, 1245-1250.

Miller WC, Ford CA, Morris M, Handcock MS, Schmitz JL, Hobbs MM, Cohen MS, Harris KM, Udry JR (2004) Prevalence of chlamydial and gonococcal infections among young adults in the United States. JAMA 291, 2229-2236.

Mol BWJ, Collins JA, Burrows EA, Van der Veen F, Bossuyt PMM (1999) Comparison of hysterosalpingography and laparoscopy in predicting fertility outcome. Hum Reprod 14, 1237-1242.

Molano M, Meijer CJLM, Weiderpass E, Arslan A, Posso H, Franceschi S, Ronderos M, Muňoz N, Van den Brule AJC (2005) The natural course of Chlamydia trachomatis infection in asymptomatic Colombian women: a 5-year follow-up study. J Infect Dis 191, 907-916.

Morré SA, Rozendaal L, Van Valkengoed IGM, Boeke AJP, Van Voorst Vader PC, Schirm J, De Blok S, Van den Hoek JAR, Van Doornum GJJ, Meijer CJLM et al. (2000) Urogenital Chlamydia trachomatis serovars in men and women with a symptomatic or asymptomatic infection: an association with clinical manifestations? J Clin Microbiol 38, 2292-2296.

Morré SA, Van den Brule AJC, Rozendaal L, Boeke AJP, Voorhorst FJ, De Blok S, Meijer CJLM (2002) The natural course of asymptomatic Chlamydia trachomatis infections: $45 \%$ clearance and no development of clinical PID after one-year follow-up. Int J STD AIDS 13 (Suppl 2), 12-18.

Morré SA, Murillo LS, Bruggeman CA, Peña AS (2003) The role that the functional Asp299Gly polymorphism in the toll-like receptor-4 gene plays in the susceptibility to Chlamydia trachomatis-associated tubal infertility. J Infect Dis 187, 341-342.

Morrison RP, Lyng K, Caldwell HD (1989) Chlamydial disease pathogenesis. Ocular hypersensitivity elicited by a genus-specific 57-kD protein. J Exp Med 169, 663-675.

Mouton JW, Peeters MF, Van Rijssort-Vos JH, Verkooyen RP (2002) Tubal factor pathology caused by Chlamydia trachomatis: the role of serology. Int J STD AIDS 13 (Suppl 2), 26-29.

Mpiga P, Ravaoarinoro M (2006) Chlamydia trachomatis persistence: an update. Microbiol Res 161, 9-19.

Murillo L, Crusius JBA, Van Bodegraven AA, Alizadeh BZ, Peña AS (2002) CARD15 gene and the classification of Crohn's disease. Immunogenetics 54, 59-61.

Nelson DE, Crane DD, Taylor LD, Dorward DW, Goheen MM, Caldwell HD (2006) Inhibition of Chlamydiae by primary alcohols correlates with the strain-specific complement of plasticity zone phospholipase D genes. Infect Immun 74, 73-80.

Netea MG, Ferwerda G, De Jong DJ, Werts C, Boneca IG, Jéhanno M, Van der Meer JWM, MenginLecreulx D, Sansonetti PJ, Philpott DJ et al. (2005) The frameshift mutation in Nod2 results in unresponsiveness not only to Nod2- but also Nod1-activating peptidoglycan agonists. J Biol Chem 280, 35859-35867.

Noguchi Y, Yabushita H, Noguchi M, Fujita M, Asai M, Del Carpio CA (2002) Detection of Chlamydia trachomatis infection with DNA extracted from formalin-fixed paraffin-embedded tissues. Diagn Microbiol Infect Dis 43, 1-6. 
Nsuami M, Cammarata CL, Brooks BN, Taylor SN, Martin DH (2004) Chlamydia and gonorrhea cooccurrence in a high-school population. Sex Transm Dis 31, 424-427.

Nunn JF (1996) Ancient Egyptian medicine. British Museum Press, London, United Kingdom. ISBN 0-71410981-9, pp. 197-202.

O'Connell CM, Ionova IA, Quayle AJ, Visintin A, Ingalls RR (2006) Localization of TLR2 and MyD88 to Chlamydia trachomatis inclusions. Evidence for signalling by intracellular TLR2 during infection with an obligate intracellular pathogen. J Biol Chem 281, 1652-1659.

Ogura Y, Bonen DK, Inohara N, Nicolaes DL, Chen FF, Ramos R, Britton H, Moran T, Karaliuskas R, Duerr RH et al. (2001) A frameshift mutation in NOD2 associated with susceptibility to Crohn's disease. Nature 411, 603-606.

Ohashi K, Burkart V, Flohé S, Kolb H (2000) Cutting edge: Heat shock protein 60 is a putative endogenous ligand of the toll-like receptor-4 complex. J Immunol 164, 558-561.

Opitz B, Förster S, Hocke AC, Maass M, Schmeck B, Hippenstiel S, Suttorp N, Krüll M (2005) Nod1mediated endothelial cell activation by Chlamydophila pneumoniae. Circ Res 96, 319-326.

Osser S, Persson K (1992) Chlamydial antibodies and deoxyribonucleic acid in patients with ectopic pregnancy. Fertil Steril 57, 578-582.

Paavonen J, Kiviat N, Brunham RC, Stevens CE, Kuo CC, Stamm WE, Miettinen A, Soules M, Eschenbach DA, Holmes KK (1985a) Prevalence and manifestations of endometritis among women with cervicitis. Am J Obstet Gynecol 152, 280-286.

Paavonen J, Aine R, Teisala K, Heinonen PK, Punnonen R, Lehtinen M, Miettinen A, Grönroos P (1985b) Chlamydial endometritis. J Clin Pathol 38, 726-732.

Paisarntantiwong R, Brockmann S, Clarke L, Landesman S, Feldman J, Minkoff H (1995) The relationship of vaginal trichomoniasis and pelvic inflammatory disease among women colonized with Chlamydia trachomatis. Sex Transm Dis 22, 344-347.

Paukku M, Närvänen A, Puolakkainen M, Dreesbach K, Tiitinen A, Hao W, Anttila TI, Paavonen J (1998) Detection of Chlamydia trachomatis antibodies by 2 novel tests: rELISA and peptide EIA. Int J STD AIDS 9, 604-607.

Pearson TA, Mensah GA, Alexander RW, Anderson JL, Cannon RO, Criqui M, Fadl YY, Fortmann SP, Hong $Y$, Myers GL et al. (2003) Markers of inflammation and cardiovascular disease. Application to clinical and public health practice. A statement for healthcare professionals from the Centers for Disease Control and Prevention and the American Heart Association. Circulation 107, 499-511.

Peeters H, Vander Cruyssen B, Laukens D, Coucke P, Marichal D, Van Den Berghe M, Cuvelier C, Remaut E, Mielants H, De Keyser F et al. (2004) Radiological sacroiliitis, a hallmark of spondylitis, is linked with CARD15 gene polymorphisms in patients with Crohn's disease. Ann Rheum Dis 63, 1131-1134.

Persson K, Osser S (1993) Lack of evidence of a relationship between genital symptoms, cervicitis and salpingitis and different serovars of Chlamydia trachomatis. Eur J Clin Microbiol Infect Dis 12, 195 199.

Persson K, Osser S, Birkelund S, Christiansen G, Brade H (1999) Antibodies to Chlamydia trachomatis heat shock proteins in women with tubal factor infertility are associated with prior infection by $C$. trachomatis but not by C. pneumoniae. Hum Reprod 14, 1969-1973.

Pioli PA, Amiel E, Schaefer TM, Connolly JE, Wira CR, Guyre PM (2004) Differential expression of Toll-like receptors 2 and 4 in tissues of the human female reproductive tract. Infect Immun 72, 5799-5806.

Piura B, Sarov B, Sarov I (1993) Persistence of antichlamydial antibodies after treatment of acute salpingitis with doxycycline. Eur J Obstet Gynecol Reprod Biol 48, 117-121.

Poltorak A, He X, Smirnova I, Liu MY, Van Huffel C, Du X, Birdwell D, Alejos E, Silva M, Galanos C et al. (1998) Defective LPS signaling in $\mathrm{C} 3 \mathrm{H} / \mathrm{HeJ}$ and $\mathrm{C} 57 \mathrm{BL} / 10 \mathrm{ScCr}$ mice: mutations in T/r4 gene. Science 282, 2085-2088.

Punnonen R, Terho P, Nikkanen V, Meurman O (1979) Chlamydial serology in infertile women by immunofluorescence. Fertil Steril 31, 656-659.

Puolakkainen M, Vesterinen E, Purola E, Saikku P, Paavonen J (1986) Persistence of chlamydial antibodies after pelvic inflammatory disease. J Clin Microbiol 23, 924-928. 
Quayle AJ (2002) The innate and early immune response to pathogen challenge in the female genital tract and the pivotal role of epithelial cells. J Reprod Immunol 57, 61-79.

Quint KD, De Koning MNC, Geraets DT, Quint WGV, Pirog E (2009) Comprehensive analysis of Human Papillomavirus and Chlamydia trachomatis in in-situ and invasive cervical adenocarcinoma. Gynecol Oncol 114, 390-394.

Rahm VA, Gnarpe H, Odlind V (1988) Chlamydia trachomatis among sexually active teenage girls. Lack of correlation between chlamydial infection, history of the patient and clinical signs of infection. $\mathrm{Br} \mathrm{J}$ Obstet Gynaecol 95, 916-919.

Rasmussen SJ, Eckmann L, Quayle AJ, Shen L, Zhang YX, Anderson DJ, Fierer J, Stephens RS, Kagnoff MF (1997) Secretion of proinflammatory cytokines by epithelial cells in response to Chlamydia infection suggests a central role for epithelial cells in chlamydial pathogenesis. J Clin Invest 99, 77-87.

Raulston JE (1995) Chlamydial envelope components and pathogen-host cell interactions. Mol Microbiol 15, 6-7-616.

Read TD, Brunham RC, Shen C, Gill SR, Heidelberg JF, White O, Hickey EK, Peterson J, Utterback T, Berry K et al. (2000) Genome sequences of Chlamydia trachomatis MoPn and Chlamydia pneumoniae AR39. Nucleic Acids Res 28, 1397-1406.

Read TD, Myers GSA, Brunham RC, Nelson WC, Paulsen IT, Heidelberg J, Holtzapple E, Khouri H, Federova NB, Carty HA et al. (2003) Genome sequence of Chlamydophila caviae (Chlamydia psittaci GPIC): examining the role of niche-specific genes in the evolution of the Chlamydiaceae. Nucleic Acids Res 31 , 2134-2147.

Roivainen M, Viik-Kajander M, Palosuo T, Toivanen P, Leinonen M, Saikku P, Tenkanen L, Manninen V, Hovi T, Mänttäri M (2000) Infections, inflammation, and the risk of coronary heart disease. Circulation 101, 252-257.

Romano Carratelli C, Nuzzo I, Cozzolino D, Bentivoglio C, Paolillo R, Rizzo A (2006) Relationship between Chlamydia pneumoniae infection, inflammatory markers, and coronary heart diseases. Int Immunopharmacol 6, 848-853.

Saikku P (1999) Epidemiology of Chlamydia pneumoniae in atherosclerosis. Am Heart J 138, S500-503.

Samoff E, Koumans EH, Markowitz LE, Sternberg M, Sawyer MK, Swan D, Papp JR, Black CM, Unger ER (2005) Association of Chlamydia trachomatis with persistence of high-risk types of human papillomavirus in a cohort of female adolescents. Am J Epidemiol 162, 668-675.

Schaefer TM, Desouza K, Fahey JV, Beagley KW, Wira CR (2004) Toll-like receptor (TLR) expression and TLR-mediated cytokine/chemokine production by human uterine epithelial cells. Immunology 112, 428-436.

Schumacher A, Seljeflot I, Lerkerød AB, Sommervoll L, Oterstad JE, Arnesen H (2005) Chlamydia LPS and MOMP seropositivity are associated with different cytokine profiles in patients with coronary heart disease. Eur J Clin Invest 35, 431-437.

Schwandner R, Dziarski R, Wesche H, Rothe M, Kirschning CJ (1999) Peptidoglycan- and lipoteichoic acidinduced cell activation is mediated by toll-like receptor 2. J Biol Chem 274, 17406-17409.

Smirnova I, Mann N, Dols A, Derkx HH, Hibberd ML, Levin M, Beutler B (2003) Assay of locus-specific genetic load implicates rare Toll-like receptor 4 mutations in meningococcal susceptibility. Proc Natl Acad Sci U S A 100, 6075-6080.

Stephens RS (2003) The cellular paradigm of chlamydial pathogenesis. Trends Microbiol 11, 44-51.

Sutherland AM, Walley KR, Russell JA (2005) Polymorphisms in CD14, mannose-binding lectin, and Tolllike receptor 2 are associated with increased prevalence of infection in critically ill adults. Crit Care Med 33, 638-644.

Swart P, Mol BWJ, Van der Veen F, Van Beurden M, Redekop WK, Bossuyt PMM (1995) The accuracy of hysterosalpingography in the diagnosis of tubal pathology: a meta-analysis. Fertil Steril 64, 486-491.

Thygeson P (1934) The etiology of inclusion blennorrhea. Am J Ophthalmol 17, 1019-1035.

Tiirola T, Sinisalo J, Nieminen MS, Silvennoinen-Kassinen S, Paldanius M, Saikku P, Jauhiainen M, Leinonen $M$ (2006) Chlamydial lipopolysaccharide is present in serum during acute coronary syndrome and correlates with CRP levels. Atherosclerosis 194, 403-407. 
Tiitinen A, Surcel HM, Halttunen M, Birkelund S, Bloigu A, Christiansen G, Koskela P, Morrison SG, Morrison RP, Paavonen J (2006) Chlamydia trachomatis and chlamydial heat shock protein 60-specific antibody and cell-mediated responses predict tubal factor infertility. Hum Reprod 21, 1533-1538.

Toye B, Laferrière C, Claman P, Jessamine P, Peeling R (1993) Association between antibody to the chlamydial heat-shock protein and tubal infertility. J Infect Dis 168, 1236-1240.

Tuuminen T, Palomäki P, Paavonen J (2000) The use of serologic tests for the diagnosis of chlamydial infections. J Microbiol Meth 42, 265-279.

Veenemans LMW, Van der Linden PJQ (2002) The value of Chlamydia trachomatis antibody testing in predicting tubal factor infertility. Hum Reprod 17, 695-698.

Wang Y (1999) Etiology of trachoma: a great success in isolating and cultivating Chlamydia trachomatis. Chin Med J 112, 938-941.

Weersma RK, Stokkers PCF, Van Bodegraven AA, Van Hogezand RA, Verspaget HW, De Jong DJ, Van der Woude CJ, Oldenburg B, Linskens RK, Festen EAM et al. (2009) Molecular prediction of disease risk and severity in a large Dutch Crohn's disease cohort. Gut 58, 388-395.

Welter-Stahl L, Ojcius DM, Viala J, Girardin S, Liu W, Delarbre C, Philpott D, Kelly KA, Darville T (2006) Stimulation of the cytosolic receptor for peptidoglycan, Nod1, by infection with Chlamydia trachomatis or Chlamydia muridarum. Cell Microbiol 8, 1047-1057.

Weström L (1980) Incidence, prevalence, and trends of acute pelvic inflammatory disease and its consequences in industrialized countries. Am J Obstet Gynecol 138, 880-892.

Weström L, Joesoef R, Reynolds G, Hagdu A, Thompson SE (1992) Pelvic inflammatory disease and fertility. A cohort study of 1,844 women with laparoscopically verified disease and 657 control women with normal laparoscopic results. Sex Transm Dis 19, 185-192.

Wiesenfeld HC, Hillier SL, Krohn MA, Amortegui AJ, Heine RP, Landers DV, Sweet RL (2002) Lower genital tract infection and endometritis: insight into subclinical pelvic inflammatory disease. Obstet Gynecol 100, 456-463.

Wong BYL, Gnarpe J, Teo KK, Ohman EM, Prosser C, Gibler WB, Langer A, Chang WC, Armstrong PW (2002) Does chronic Chlamydia pneumoniae infection increase the risk of myocardial injury? Insights from patients with non-ST-elevation acute coronary syndromes. Am Heart J 144, 987-994.

World Health Organization (2001) Global prevalence and incidence of selected curable sexually transmitted infections. http://www.who.int/docstore/hiv/GRSTI.

Yavuz MT, Yavuz O, Yazici M, Guler S, Ozhan H, Albayrak S, Coskun A (2006) Interaction between Chlamydia pneumoniae seropositivity, inflammation and risk factors for atherosclerosis in patients with severe coronary stenosis. Scand I Clin Lab Invest 66, 523-534.

Yim JJ, Lee HW, Lee HS, Kim YW, Han SK, Shim YS, Holland SM (2006) The association between microsatellite polymorphisms in intron II of the human Toll-like receptor 2 gene and tuberculosis among Koreans. Genes Immun 7, 150-155.

Yoshimura A, Lien E, Ingalls RR, Tuomanen E, Dziarski R, Golenbock D (1999) Cutting edge: Recognition of Gram-positive bacterial cell wall components by the innate immune system occurs via toll-like receptor 2. J Immunol 163, 1-5. 


\section{Chapter 2}

Serological markers of persistent Chlamydia trachomatis infections in women with tubal factor subfertility

JE den Hartog, JA Land, FRM Stassen, AGH Kessels, CA Bruggeman

Human Reproduction 2005, 20 (4): 986-990 


\section{ABSTRACT}

\section{Background}

Persistent Chlamydia (C.) trachomatis infections are assumed to increase the risk of tubal pathology. We studied whether serological markers, assumed to be associated with persistent $C$. trachomatis infections, could identify subfertile women at risk of tubal pathology.

\section{Methods}

Sera of 313 subfertile women, who all underwent a laparoscopy with tubal testing to assess the grade of tubal pathology, were tested for the presence of immunoglobulin (Ig) $\mathrm{G}$ and IgA antibodies to C. trachomatis, IgG antibodies to chlamydia heat shock protein 60 (cHSP60) and high-sensitivity C-reactive protein (hs-CRP).

\section{Results}

C. trachomatis IgA, cHSP60 IgG and hs-CRP, all serological markers of persistent infections, were significantly more prevalent in women with tubal pathology as compared to those without tubal pathology. The predictive value of the currently used screening test for tubal pathology (IgG to $C$. trachomatis) could be significantly improved by adding the hs-CRP test.

\section{Conclusions}

In subfertile women with tubal pathology, serological markers of persistent $C$. trachomatis infections are significantly more common as compared to women without tubal pathology. C. trachomatis IgG-positive subfertile women with slightly elevated ( $<10 \mathrm{mg} / \mathrm{L}$ ) hs-CRP levels are at highest risk of persistent $C$. trachomatis infections and tubal pathology. 


\section{INTRODUCTION}

Chlamydia $(C$.$) trachomatis infections are a major cause of tubal factor subfertility.$ However, the precise pathogenesis of $C$. trachomatis infections remains to be elucidated. Not all women who have undergone a $C$. trachomatis infection will develop tubal pathology. Host factors, virulence factors of the micro-organism and environmental factors determine the course and morbidity of $C$. trachomatis infections. Depending on these factors and their interaction, $C$. trachomatis infections will either be cleared or persist. A clearance rate of $44.7 \%$ has been reported in asymptomatic and untreated women after one year follow-up (Morré et al., 2002). In women who clear a $C$. trachomatis infection adequately, the risk of tubal damage may be low, since the host has been exposed to the micro-organism during a short period. Persistent exposure to the micro-organism may result in a chronic inflammatory response and may increase the risk of tubal damage, as has been suggested previously (Grayston et al., 1985, Patton et al., 1994a).

Previous studies, in which evidence of persistent $C$. trachomatis infections has been found in the upper genital tract of women with tubal damage, support this hypothesis. Gérard et al. (1998) have found viable C. trachomatis micro-organisms in seven out of ten tubes of patients with ectopic pregnancies. Furthermore, $C$. trachomatis has been detected in $56-79 \%$ of the tubes of women with tubal factor subfertility, who underwent reconstructive tubal surgery (Campbell et al., 1993, Patton et al., 1994b). Previously, we have demonstrated that genus-specific immunoglobulin (Ig) $\mathrm{G}$ antibodies to chlamydia lipopolysaccharide, which are supposed to be markers of persistent infections, are significantly more often detectable in sera of subfertile women with distal tubal pathology (62.7\%) as compared to those without distal tubal pathology (33.9\%) (Den Hartog et al., 2004).

Since the association between $C$. trachomatis-specific IgG antibodies and tubal pathology has been noted (Punnonen et al., 1979), measuring C. trachomatis IgG antibodies in serum is used as a screening method for tubal pathology. Although species-specific $C$. trachomatis IgG antibodies are markers of previous infections, their presence does not reflect the course of the infection. Therefore, measuring $\operatorname{lgG}$ antibodies to $C$. trachomatis is not useful in discriminating between clearance or persistence of the infection.

We hypothesize that persistent $C$. trachomatis infections play an important role in the development of tubal pathology, and have studied known serological markers of persistent infections in subfertile women with and without tubal pathology. Elevated levels of IgA antibodies and C-reactive protein (CRP), in the absence of an acute infection, have been suggested to be markers of chronic inflammation and infection, and have been evaluated previously in studies on the relationship between chronic $C$. pneumoniae infections and respiratory and cardiovascular disease (Roivainen et al., 2000, Gattone et al., 2001, Johnston et al., 2001, Falck et al., 2002, 
Wong et al., 2002). IgG antibodies to chlamydia heat shock protein 60 (cHSP60) have also been associated with chronic inflammation (Morrison et al., 1989), and have been studied previously in subfertile women with tubal pathology (Toye et al., 1993, Arno et al., 1995, Freidank et al., 1995, Claman et al., 1997).

Sera of subfertile women were tested for the presence of $\lg G$ and $\operatorname{IgA}$ antibodies to C. trachomatis, IgG antibodies to CHSP60 and CRP. All women underwent a laparoscopy with tubal testing. We correlated the serological test results with the presence of tubal pathology at laparoscopy, and evaluated the role of single tests and test combinations in predicting the risk of persistent $C$. trachomatis infections and tubal pathology.

\section{MATERIALS AND METHODS}

The study was performed in subfertile women who entered our clinic between December 1990 and November 2000. As part of their fertility work-up, in all female patients blood was drawn at their initial visit for a chlamydia IgG antibody test (CAT). All spare sera were cryopreserved and thawed for this study. Patients with a negative CAT and an otherwise normal fertility work-up underwent a hysterosalpingography (HSG) to evaluate the tubal status. If the HSG showed abnormalities, or if they did not conceive within 6 months after the HSG, a laparoscopy with tubal testing was performed. Patients with a positive CAT underwent a laparoscopy with tubal testing immediately after the fertility work-up. Only patients who had undergone a laparoscopy and tubal testing with methylene blue dye were included in the present study. Patients who had undergone previous pelvic surgery (except for an uneventful appendectomy or Caesarean section) were excluded.

Two independent investigators, who were unaware of the CAT results, scored 313 successive laparoscopy reports to assess the grade of tubal pathology. In cases of disagreement, consensus was reached by consultation. For the sake of the study, tubal pathology was defined as extensive peri-adnexal adhesions and/or distal occlusion of at least one tube (Land et al., 1998). Subfertile women without distal tubal pathology served as controls. The controls had unexplained subfertility, partners with mild male factor subfertility, or proximal occlusion of at least one tube.

\section{Serological methods}

IgG antibodies to $C$. trachomatis were detected using the species-specific Chlamydia pneumoniae IgG micro-immunofluorescence (MIF) test (AniLabsystems, Finland), as described previously (Den Hartog et al., 2004). This species-specific test, which is the currently used screening test for $C$. trachomatis IgG antibodies in our clinic, has been 
found to be a good predictor of tubal pathology (Land et al., 2003). The threshold titre used for a positive test was 32 .

IgA antibodies to $C$. trachomatis were detected using the Chlamydia trachomatis IgA enzyme immunoassay (AniLabsystems, Finland). The test was used according to the manufacturer's instructions. The threshold index for a positive test was 1.4.

IgG antibodies to cHSP60 were detected using the cHSP60 IgG enzyme-linked immunosorbent assay (ELISA; Medac, Germany), which is available for research use only. The test was used according to the manufacturer's instructions. The threshold index for a positive test was 1.11.

CRP was determined using the CRP ELISA (DiaMed Eurogen, Belgium). The test was used according to the manufacturer's instructions. In order to reliably detect low CRP concentrations, this high-sensitivity (hs) CRP test was used. CRP levels between 1.0 and $10.0 \mathrm{mg} / \mathrm{L}$ (slightly raised levels, but still within the normal range) are assumed to reflect a persistent infection, and were considered as positive. CRP levels < $1.0 \mathrm{mg} / \mathrm{L}$ (low risk of persistent infection) or $>10.0 \mathrm{mg} / \mathrm{L}$ (probably acute infection) were considered as negative (Pearson et al., 2003).

\section{Statistical methods}

Characteristics of women with and without distal tubal pathology were compared using the Mann-Whitney U-test. For comparison of the prevalence of IgG and IgA antibodies to $C$. trachomatis, IgG antibodies to cHSP60 and hs-CRP in women with and without distal tubal pathology, the $\chi^{2}$-test was used. The prognostic value of single tests as well as test combinations for distal tubal pathology was determined by calculating sensitivity, specificity, positive predictive value (PPV), negative predictive value (NPV), odds ratio (OR) and 95\% confidence interval (CI). A forward stepwise logistic regression analysis was used to select the best combination of tests. The bootstrap technique was used to test the difference between ORs (Efron and Tibshiram, 1993). $P<0.05$ was considered statistically significant.

\section{RESULTS}

In 313 subfertile women, serological test results and laparoscopy reports were available for analysis. Of those 313 women, 59 (18.8\%) met the definition of distal tubal pathology (extensive peri-adnexal adhesions and/or distal occlusion of at least one tube), whereas 254 women (81.2\%) did not have distal tubal pathology and served as controls. Of those 254 women without distal tubal pathology, $94.9 \%$ had patent tubes and $5.1 \%$ had proximal occlusion of at least one tube. Since proximal tubal occlusion is considered not to be related to chlamydia disease, all 254 women without distal tubal pathology served as controls. In women with and without distal 
tubal pathology, mean age (30.6 and 31.2 years, respectively) and duration of subfertility ( 2.4 and 2.3 years, respectively) were comparable.

CRP levels between 1.0 and $10.0 \mathrm{mg} / \mathrm{L}$ (slightly raised levels, but still within the normal range) were assumed to reflect a persistent infection, and were considered as positive. CRP values $>10.0 \mathrm{mg} / \mathrm{L}$ were considered as negative, since these values were assumed to reflect acute infections. Twelve women (3.8\%) had CRP levels > $10.0 \mathrm{mg} / \mathrm{L}$ (median 16.1, range 11.2 > 130.3). Of these twelve patients, two had severe endometriosis, which is a known cause of elevated CRP levels (Abrão et al., 1997). In the remaining ten patients, no clinical evidence of acute infections or other underlying inflammatory diseases could be found. Since seven out of these ten serum samples were obtained in autumn or winter, minor or subclinical infections (e.g. influenza-like infections) might have caused the elevated CRP levels.

First, we evaluated the prevalence of $\operatorname{IgG}$ and $\operatorname{IgA}$ antibodies to $C$. trachomatis, IgG antibodies to CHSP60 and a positive hs-CRP in subfertile women with and without distal tubal pathology. As shown in Table I, IgG and IgA antibodies to C. trachomatis, IgG antibodies to CHSP60 and a positive hs-CRP test were found significantly more often in women with distal tubal pathology as compared to women without distal tubal pathology.

Table I. The prevalence of positive tests in subfertile women with and without distal tubal pathology.

\begin{tabular}{|c|c|c|c|}
\hline & DTP $(n=59)$ & No DTP $(n=254)$ & $P$ \\
\hline $\mathrm{Ctr}-\lg G+{ }^{\mathrm{a}}$ & $32(54.2)$ & 20 (7.9) & $<0.05$ \\
\hline$C t r-\lg A+{ }^{b}$ & $21(35.6)$ & $21(8.3)$ & $<0.05$ \\
\hline cHSP60- $\operatorname{lgG}+{ }^{c}$ & $30(50.8)$ & $38(15.0)$ & $<0.05$ \\
\hline hs-CRP $+{ }^{d}$ & $32(54.2)$ & $95(37.4)$ & $<0.05$ \\
\hline
\end{tabular}

Values in parentheses are percentages; ${ }^{a}$ Threshold titre for a positive test: $32 .{ }^{b}{ }^{b}$ Threshold index for a positive test: $1.4 ;{ }^{\mathrm{c}}$ Threshold index for a positive test: $1.11 ;{ }^{\mathrm{d}}$ Threshold concentration for a positive test: 1.0-10.0 mg/L. Abbreviations: cHSP60=chlamydia heat shock protein 60; Ctr= C. trachomatis; DTP = distal tubal pathology; hs-CRP= high-sensitivity $\mathrm{C}$-reactive protein; Ig = immunoglobulin.

Table II shows that, of all four single tests, the $C$. trachomatis IgG test was the best predictor of tubal pathology (OR 13.9). A forward stepwise logistic regression analysis and bootstrap analysis revealed that only adding the hs-CRP test significantly improved the diagnostic performance of the $C$. trachomatis IgG test (OR of test combination 39.7). Adding the $C$. trachomatis IgA test to the above-mentioned test combination led to an OR of 51.6, but the increase in OR was not statistically significant as compared to the combination C. trachomatis IgG/hs-CRP (OR 39.7). Combining three or four tests led to $100 \%$ specificity, but sensitivity decreased to $15 \%$. In order to limit the number of data in Table II, we have only shown data on test combinations which included a positive $C$. trachomatis IgG test (i.e. the best single test). 
Table II. The predictive value of single tests as well as combinations of tests including a positive $C$. trachomatis-IgG for distal tubal pathology.

\begin{tabular}{|c|c|c|c|c|c|c|c|c|c|c|c|c|}
\hline $\begin{array}{l}\text { No. of tests } \\
\text { performed }\end{array}$ & $\begin{array}{l}\text { Ctr- } \\
\operatorname{lgG}^{a}\end{array}$ & $\begin{array}{l}\text { Ctr- } \\
\lg A^{b}\end{array}$ & $\begin{array}{l}\text { cHSP } \\
60-\operatorname{lgG}^{\mathrm{c}}\end{array}$ & $\begin{array}{l}\text { hs } \\
- \text { CRP }^{d}\end{array}$ & $\begin{array}{l}\text { No. of patients } \\
\text { with positive } \\
\text { test result }\end{array}$ & $\begin{array}{l}\text { No. of patients } \\
\text { with positive } \\
\text { test result and } \\
\text { DTP }\end{array}$ & $\begin{array}{l}\text { Sens } \\
\text { (\%) }\end{array}$ & $\begin{array}{l}\text { Spec } \\
(\%)\end{array}$ & $\begin{array}{l}\text { PPV } \\
\text { (\%) }\end{array}$ & $\begin{array}{l}\text { NPV } \\
(\%)\end{array}$ & OR & $95 \% \mathrm{Cl}$ \\
\hline \multirow[t]{4}{*}{ One test } & + & & & & 52 & 32 & 54 & 92 & 62 & 90 & $13.9^{\mathrm{e}}$ & $7.0-27.5$ \\
\hline & & + & & & 42 & 21 & 36 & 92 & 50 & 86 & $6.1^{f}$ & $3.1-12.3$ \\
\hline & & & + & & 68 & 30 & 51 & 85 & 44 & 88 & $5.9^{f}$ & $3.2-10.9$ \\
\hline & & & & + & 127 & 32 & 54 & 63 & 25 & 85 & $2.0^{f}$ & $1.1-3.5$ \\
\hline \multirow[t]{3}{*}{ Two tests } & + & + & & & 27 & 17 & 29 & 96 & 63 & 85 & 9.9 & $4.2-23.0$ \\
\hline & + & & + & & 41 & 28 & 47 & 95 & 68 & 89 & 16.7 & $7.9-35.7$ \\
\hline & + & & & + & 22 & 19 & 32 & 99 & 86 & 86 & $39.7^{f}$ & $11.2-140.5$ \\
\hline \multirow{3}{*}{ Three tests } & + & + & + & & 22 & 15 & 25 & 97 & 68 & 85 & 12.0 & $4.6-31.2$ \\
\hline & + & + & & + & 11 & 10 & 17 & 100 & 91 & 84 & $51.6^{f}$ & $6.5-412.6$ \\
\hline & + & & + & + & 16 & 16 & 27 & 100 & 100 & 86 & $\infty$ & - \\
\hline Four tests & + & + & + & + & 9 & 9 & 15 & 100 & 100 & 84 & $\infty$ & - \\
\hline
\end{tabular}

${ }^{\mathrm{a}}$ Threshold titre for a positive test: $32 ;{ }^{\mathrm{b}}$ Threshold index for a positive test: $1.4{ }^{\mathrm{c}}$ Threshold index for a positive test: $1.11 ;{ }^{\mathrm{d}}$ Threshold concentration for a positive test: $1.0-10.0 \mathrm{mg} / \mathrm{L}$; ${ }^{\mathrm{e}}$ versus ${ }^{\mathrm{f}} P<0.05$ (only $P$ values of Ctr-IgG versus the other single tests and test combinations were calculated). Abbreviations: cHSP60=chlamydia heat shock protein $60 ; \mathrm{Cl}=$ confidence interval; $\mathrm{Ctr}=\mathrm{C}$. trachomatis; $\mathrm{DTP}=$ distal tubal pathology; hs-CRP= high-sensitivity $\mathrm{C}$-reactive protein; NPV= negative predictive value; $\mathrm{OR}=$ odds ratio; $\mathrm{PPV}=$ positive predictive value; sens = sensitivity; $\mathrm{spec}=$ specificity.

\section{DISCUSSION}

In this study, we hypothesized that the course of $C$. trachomatis infections is related to the risk of tubal damage. The natural course of $C$. trachomatis infections, duration of exposure to the micro-organism and re-infection rates are difficult to study, since $C$. trachomatis infections often remain asymptomatic, and consequently the onset of the infection is generally unknown. It is important, however, to identify subfertile women with persistent $C$. trachomatis infections, since they are supposed to have the highest risk of tubal pathology. In the present study, we have tested three serological markers of persistent infections in a cohort of 313 subfertile women. Our results indicate that persistent $C$. trachomatis infections play an important role in the development of tubal pathology.

IgA antibodies have been associated with chronic inflammation and infection. With respect to chlamydia, previous studies have demonstrated an association between C. pneumoniae IgA antibodies and its chronic sequelae, e.g. respiratory and cardiovascular morbidity. Falck et al. (2002) have found that the prevalence of symptoms of chronic respiratory tract disease increases parallel to the increase in C. pneumoniae IgA titre. In patients with coronary symptoms, a positive $C$. pneumoniae IgA titre significantly increases the risk of myocardial injury (OR 1.95) (Wong et al., 2002). It has been suggested that serum IgA antibodies, as compared to IgG antibod- 
ies, may be more reliable markers of persistent $C$. pneumoniae infections (Saikku, 1999).

cHSP60 is a chlamydia genus-specific protein, serving as a strong antigenic target for the immune system (Morrison et al., 1989, Kaufmann, 1990). It has been suggested that antibodies to cHSP60 are markers of chronic inflammation (Kaufmann, 1990). Studies have shown a strong association between anti-cHSP60 antibodies and tubal factor subfertility. Anti-cHSP60 antibodies are significantly more prevalent in subfertile women with tubal disease (44-76\%) as compared to those without tubal disease (8-19\%) (Freidank et al., 1995, Claman et al., 1997). Among subfertile women with antibodies to $C$. trachomatis, anti-cHSP60 antibodies are significantly more prevalent in women with tubal pathology $(76-81 \%)$ as compared to those without tubal pathology (0-43\%) (Toye et al., 1993, Arno et al., 1995).

CRP is an acute phase protein. Slightly raised CRP concentrations, but still within the normal range, are known indicators of chronic inflammation. Research on the pathophysiology of coronary heart disease has shown that the association between C. pneumoniae infections and the risk of cardiovascular events is stronger if CRP is slightly raised, but within the normal range (Gattone et al., 2001). As compared to patients without $C$. pneumoniae antibodies and a low CRP, the risk of coronary events increased when $C$. pneumoniae antibodies were present (OR 1.22; $95 \% \mathrm{Cl}$ 0.74-2.01), but increased even more when both $C$. pneumoniae antibodies and a slightly elevated CRP were present (OR 5.40; 95\% Cl 2.35-12.43) (Roivainen et al., 2000). Serum CRP levels were significantly higher in patients with $C$. pneumoniaeinfected atherosclerotic plaques $(8 \mathrm{mg} / \mathrm{L})$ as compared to patients with non-infected atherosclerotic plaques (undetectable CRP) (Johnston et al., 2001). The role of CRP in tubal factor subfertility has not yet been studied.

In the present study, all evaluated serological markers of persistent infections were significantly more prevalent in women with tubal pathology as compared to women without tubal pathology. However, as single tests, the markers of persistent infections performed poorly as compared to the current screening test for tubal pathology (IgG to $C$. trachomatis). Odds ratios of IgA antibodies to C. trachomatis (6.1), IgG antibodies to CHSP60 (5.9) and hs-CRP (2.0) were significantly lower as compared to IgG antibodies to $C$. trachomatis (13.9).

The low OR of the $C$. trachomatis IgA and cHSP60 IgG tests might be explained by these antibodies being poorer markers of chronic inflammation than is currently presumed. The significantly lower OR of the CHSP60 IgG test, as compared to the $C$. trachomatis IgG test, might be explained by cross-reaction with the highly similar $C$. pneumoniae. Anti-C. pneumoniae antibodies are highly prevalent in subfertile women (detectable in $83.1 \%$ of women with distal tubal pathology and in $72.8 \%$ of women without distal tubal pathology), and are not associated with tubal disease (Den Hartog et al., 2004). The manufacturer of the cHSP60 IgG test mentions that cross-reaction with other chlamydia species may occur, due to the homology of $>$ 
95\% between cHSP60 of the different species. The low OR of the hs-CRP test as a single test might be explained by CRP being a general, and not a chlamydia-specific, marker of chronic inflammation.

A forward stepwise logistic regression analysis was performed in order to determine if the prognostic value of the best single test (i.e. C. trachomatis IgG) could be significantly improved by adding one or more tests. Only combining the $C$. trachomatis IgG test and the hs-CRP test resulted in a significantly higher OR (39.7) as compared to the $C$. trachomatis IgG test only (13.9). Measuring $C$. trachomatis IgG antibodies (markers of a previous infection), in combination with hs-CRP (a marker of the course of the infection), seems to identify a subset of subfertile women with the highest risk of persistent infections and distal tubal pathology. These results are comparable to previous studies, in which risk factors for cardiovascular disease were studied. In these studies, the association between $C$. pneumoniae and cardiovascular disease, which is commonly known, is stronger when elevated CRP levels, but within the normal range, are also detectable (Roivainen et al., 2000, Gattone et al., 2001, Johnston et al., 2001). Using the forward stepwise logistic regression model, no significant increase in test performance was noted when adding a third and fourth test to the combination $C$. trachomatis IgG/hs-CRP.

A limitation of this study is selection and referral bias. Only women who had undergone a laparoscopy with tubal testing, which is the reference standard in diagnosing tubal pathology, were included in the present study. This inclusion criterion will cause selection bias, as has been discussed previously (Den Hartog et al., 2004). This bias will be worsened by referral bias, since the $C$. trachomatis IgG test was used in the decision regarding who received a laparoscopy. However, it is hard to prevent selection and referral bias in a study like ours, since a laparoscopy, which has costs and risks, is not a routine procedure in all subfertility patients.

The clinical purpose of serial testing is to find a combination of tests which can estimate the risk of tubal disease more accurately. The ultimate goal would be a test combination with a PPV and NPV of $100 \%$. In these cases, invasive tubal testing may no longer be indicated. This goal has not yet been achieved in the present study. However, if our results could be confirmed in a larger study, the test combination $C$. trachomatis IgG/hs-CRP might be a better screening method for tubal pathology as compared to the current method ( $C$. trachomatis IgG only). In daily practice, all $C$. trachomatis-positive samples could be retested with the hs-CRP test, in order to identify those women who are at highest risk of a persistent $C$. trachomatis infection and tubal disease.

In summary, we hypothesized that the risk of tubal pathology is increased in subfertile women with persistent $C$. trachomatis infections. We have studied serological markers of persistent infections in subfertile women. All evaluated serological markers of persistent $C$. trachomatis infections are significantly more common in subfertile women with tubal pathology as compared to women without tubal pa- 
thology. C. trachomatis IgG-positive subfertile women with raised CRP concentrations, but still within the normal range, are supposed to have persistent $C$. trachomatis infections and are at highest risk of tubal pathology.

\section{Acknowledgements}

The authors acknowledge Gert Grauls, from the Department of Medical Microbiology, for laboratory assistance and Medac (Germany) and Oxoid (the Netherlands) for providing part of the cHSP60 IgG ELISA kits. 


\section{REFERENCES}

Abrão MS, Podgaec S, Filho BM, Ramos LO, Pinotti JA, De Oliveira RM (1997) The use of biochemical markers in the diagnosis of pelvic endometriosis. Hum Reprod 12, 2523-2527.

Arno JN, Yuan Y, Cleary RE, Morrison RP (1995) Serologic responses of infertile women to the 60-kd chlamydial heat shock protein (hsp60). Fertil Steril 64, 730-735.

Campbell LA, Patton DL, Moore DE, Cappuccio AL, Mueller BA, Wang SP (1993) Detection of Chlamydia trachomatis deoxyribonucleic acid in women with tubal infertility. Fertil Steril 59, 45-50.

Claman P, Honey L, Peeling RW, Jessamine P, Toye B (1997) The presence of serum antibody to the chlamydial heat shock protein (CHSP60) as a diagnostic test for tubal factor infertility. Fertil Steril 67, 501-504.

Den Hartog JE, Land JA, Stassen FRM, Slobbe-Van Drunen MEP, Kessels AGH, Bruggeman CA (2004) The role of chlamydia genus-specific and species-specific IgG-antibody testing in predicting tubal disease in subfertile women. Hum Reprod 19, 1380-1384.

Efron B, Tibshiram RJ (1993) An Introduction to the Bootstrap. Chapman \& Hall, New York, pp. 224-227.

Falck G, Gnarpe J, Hansson LO, Svärdsudd K, Gnarpe H (2002) Comparison of individuals with and without specific IgA antibodies to Chlamydia pneumoniae. Respiratory morbidity and the metabolic syndrome. Chest 122, 1587-1593.

Freidank HM, Clad A, Herr AS, Wiedmann-Al-Ahmad M, Jung B (1995) Immune response to Chlamydia trachomatis heat-shock protein in infertile female patients and influence of Chlamydia pneumoniae antibodies. Eur J Clin Microbiol Infect Dis 14, 1063-1069.

Gattone M, lacoviello L, Colombo M, Di Castelnuovo A, Soffiantino F, Gramoni A, Picco D, Benedetta M, Giannuzzi P (2001) Chlamydia pneumoniae and cytomegalovirus seropositivity, inflammatory markers, and the risk of myocardial infarction at a young age. Am Heart J 142, 633-640.

Gérard HC, Branigan PJ, Balsara GR, Heath C, Minassian SS, Hudson AP (1998) Viability of Chlamydia trachomatis in fallopian tubes of patients with ectopic pregnancies. Fertil Steril 70, 945-948.

Grayston JT, Wang SP, Yeh LJ, Kuo CC (1985) Importance of reinfection in the pathogenesis of trachoma. Rev Infect Dis 7, 717-725.

Johnston SC, Messina LM, Browner WS, Lawton MT, Morris C, Dean D (2001) C-reactive protein levels and viable Chlamydia pneumoniae in carotid artery atherosclerosis. Stroke 32, 2748-2752.

Kaufmann SHE (1990) Heat shock proteins and the immune response. Immunol Today 11, 129-136.

Land JA, Evers JLH, Goossens VJ (1998) How to use Chlamydia antibody testing in subfertility patients. Hum Reprod 13, 1094-1098.

Land JA, Gijsen AP, Kessels AGH, Slobbe MEP, Bruggeman CA (2003) Performance of five serological chlamydia antibody tests in subfertile women. Hum Reprod 18, 2621-2627.

Morré SA, Van den Brule AJC, Rozendaal L, Boeke AJP, Voorhorst FJ, De Blok S, Meijer CJLM (2002) The natural course of asymptomatic Chlamydia trachomatis infections: $45 \%$ clearance and no development of clinical PID after one-year follow-up. Int J STD AIDS 13 (Suppl 2), 12-18.

Morrison RP, Lyng K, Caldwell HD (1989) Chlamydial disease pathogenesis. Ocular hypersensitivity elicited by a genus-specific 57-kD protein. J Exp Med 169, 663-675.

Patton DL, Cosgrove Sweeney YT, Kuo CC (1994a) Demonstration of delayed hypersensitivity in Chlamydia trachomatis salpingitis in monkeys: a pathogenic mechanism of tubal damage. J Infect Dis 169 , 680-683.

Patton DL, Askienazy-Elbhar M, Henry-Suchet J, Campbell LA, Cappuccio A, Tannous W, Wang SP, Kuo CC (1994b) Detection of Chlamydia trachomatis in fallopian tube tissue in women with postinfectious tubal infertility. Am J Obstet Gynecol 171, 95-101.

Pearson TA, Mensah GA, Alexander RW, Anderson JL, Cannon RO, Criqui M, Fadl YY, Fortmann SP, Hong $Y$, Myers GL et al. (2003) Markers of inflammation and cardiovascular disease. Application to clinical and public health practice. A statement for healthcare professionals from the Centers for Disease Control and Prevention and the American Heart Association. Circulation 107, 499-511. 
Punnonen R, Terho P, Nikkanen V, Meurman O (1979) Chlamydial serology in infertile women by immunofluorescence. Fertil Steril 31, 656-659.

Roivainen M, Viik-Kajander M, Palosuo T, Toivanen P, Leinonen M, Saikku P, Tenkanen L, Manninen V, Hovi T, Mänttäri M (2000) Infections, inflammation, and the risk of coronary heart disease. Circulation 101, 252-257.

Saikku P (1999) Epidemiology of Chlamydia pneumoniae in atherosclerosis. Am Heart J 138, S500-S503.

Toye B, Laferrière C, Claman P, Jessamine P, Peeling R (1993) Association between antibody to the chlamydial heat-shock protein and tubal infertility. J Infect Dis 168, 1236-1240.

Wong BYL, Gnarpe J, Teo KK, Ohman EM, Prosser C, Gibler WB, Langer A, Chang WC, Armstrong PW (2002) Does chronic Chlamydia pneumoniae infection increase the risk of myocardial injury? Insights from patients with non-ST-elevation acute coronary syndromes. Am Heart J 144, 987-994. 


\section{Chapter 3}

The role of chlamydia genus-specific and species-specific IgG antibody testing in predicting tubal disease in subfertile women

JE den Hartog, JA Land, FRM Stassen, MEP Slobbe-van Drunen, AGH Kessels, CA Bruggeman

Human Reproduction 2004, 19 (6): 1380-1384 


\section{ABSTRACT}

\section{Background}

We evaluated whether measuring chlamydia genus- and species-specific immunoglobulin (Ig) $\mathrm{G}$ antibodies might improve the predictive value of Chlamydia (C.) trachomatis antibody testing (CAT) in screening for distal tubal pathology (DTP).

\section{Methods}

Serum of 313 subfertile women was tested for the presence of species-specific antibodies to $C$. trachomatis, $C$. pneumoniae and $C$. psittaci and genus-specific antibodies to chlamydia lipopolysaccharide (LPS). Only patients who had undergone a laparoscopy with tubal testing, to assess the grade of DTP, were included in this study.

\section{Results}

The presence of $C$. trachomatis antibodies was the only independent predictor for DTP. The predictive value of CAT for DTP could not be improved by adding test results of $C$. pneumoniae or LPS antibody testing. The role of $C$. psittaci could not be evaluated, due to the absence of $C$. psittaci IgG-positive patients in our cohort.

\section{Conclusions}

In spite of the high interspecies homology, $C$. pneumoniae does not contribute to the development of DTP. Anti-LPS antibodies, which are considered to be markers for ongoing infections, do not identify $C$. trachomatis-positive subfertile women who are at highest risk of DTP. The high prevalence of anti-LPS antibodies in C. trachomatis-positive subfertile women may suggest that $C$. trachomatis remains more active in the upper genital tract than currently is presumed. 


\section{INTRODUCTION}

Chlamydia species which can cause infections in humans are Chlamydia (C.) pneumoniae, $C$. psittaci and $C$. trachomatis. C. pneumoniae is a widespread pathogen that causes respiratory tract infections, and is associated with asthma (Hahn et al., 1991) and cardiovascular disease (Saikku et al., 1988). The prevalence of immunoglobulin (Ig) G antibodies to C. pneumoniae in subfertile women ranges from 56 to $76 \%$, regardless of the cause of subfertility (Freidank et al., 1995, Gijsen et al., 2001), and is comparable to the prevalence in healthy males and females (63-74\%) (Karvonen et al., 1994, Wong et al., 1999).

C. psittaci is most prevalent in birds (psittacosis), but can also infect humans and result in pneumonia. The prevalence of $C$. psittaci IgG antibodies in serum depends on population characteristics. A prevalence of $39 \%$ is reported in pigeon fanciers, a risk group for acquiring psittacosis (Bourke et al., 1992). In healthy males and females, as well as in patients attending a genitourinary clinic, the prevalence of IgG antibodies to C. psittaci is $0.1 \%$ (Moss et al., 1993, Wong et al., 1999).

The role of $C$. trachomatis in tubal factor subfertility is well established. The prevalence of $C$. trachomatis IgG antibodies is significantly higher in subfertile women with bilaterally occluded tubes (52-73\%) as compared to subfertile women without tubal pathology (17-24\%) (Freidank et al., 1995, Gijsen et al., 2001). Healthy (supposedly fertile) female controls have the lowest prevalence (9-10\%) (Freidank et al., 1995).

A widely used screening method for tubal factor subfertility is chlamydia antibody testing (CAT) by measuring serum IgG antibodies to $C$. trachomatis. However, its predictive value is limited, due to false-positive and false-negative test results (Mol et al., 1997). The predictive value of CAT might be improved by using other serological markers for chlamydia-associated tubal damage.

First, it has been questioned whether $C$. pneumoniae and $C$. psittaci, following a primary $C$. trachomatis infection, may play a role in the development of tubal pathology. In a previous study, tubal factor subfertility seemed to be more common in subfertile women with IgG antibodies to both $C$. trachomatis and $C$. pneumoniae (49\%) as compared to those with antibodies to $C$. trachomatis only (30\%), but the difference was not statistically significant (Gijsen et al., 2001). Based on the findings of our previous study, we hypothesize that other chlamydia species, besides $C$. trachomatis, may play a role in the development of tubal factor subfertility.

Furthermore, it has been assumed that repeated exposure to $C$. trachomatis (by reactivation or reinfection) is an important risk factor for the development of tubal damage (Grayston et al., 1985, Patton et al., 1994). A previous study suggested that anti-lipopolysaccharide (LPS) antibodies are indicators of ongoing chlamydia infections (Tuuminen et al., 2000). Therefore, our second hypothesis is that serum IgG 
antibodies to chlamydia LPS may be useful (as potential markers of ongoing $C$. trachomatis infections) in predicting the risk of distal tubal pathology.

In the present study, we used a commercially available micro-immunofluorescence (MIF) test to detect species-specific antibodies to $C$. trachomatis, C. pneumoniae and C. psittaci. A commercially available enzyme-linked immunosorbent assay (ELISA) was used for the detection of genus-specific antibodies to chlamydia LPS. We evaluated the prevalence of species-specific IgG antibodies to $C$. trachomatis, $C$. pneumoniae and C. psittaci respectively, as well as genus-specific IgG antibodies to chlamydia LPS in subfertile women who had undergone a laparoscopy with tubal testing. The serological data were correlated with the presence of distal tubal pathology at laparoscopy.

\section{MATERIALS AND METHODS}

The study was performed in subfertile women who entered our clinic between December 1990 and November 2000. As part of the fertility work-up, blood was drawn from all patients at their initial visit for CAT, using a MIF test (Biomérieux, the Netherlands). All spare sera were cryopreserved. Patients with a negative CAT and an otherwise normal fertility work-up underwent a hysterosalpingography (HSG) to evaluate the tubal status. If the HSG showed abnormalities, or if they did not conceive within 6 months after the HSG, a laparoscopy with tubal testing was performed. Patients with a positive CAT underwent a laparoscopy with tubal testing immediately after the fertility work-up. Only patients who had undergone a laparoscopy and tubal testing with methylene blue dye were included in the present study. Patients who had undergone previous pelvic surgery (except for an uneventful appendectomy or Caesarean section) were excluded.

For this study, the spare sera of the participating patients were thawed to perform a species-specific MIF test (AniLabsystems, Finland) and a Chlamydia LPS ELISA (Medac, Germany), as described below. In the present study, the MIF test by AniLabsystems was used to detect IgG antibodies to $C$. trachomatis, instead of the MIF test by Biomérieux which was used in the fertility work-up, since the test by AniLabsystems was found to predict tubal pathology more accurately than the test by Biomérieux (Land et al., 2003).

Two independent investigators, who were unaware of the CAT results, scored 313 successive laparoscopy reports to assess the grade of distal tubal pathology. In this study, distal tubal pathology was defined as extensive peri-adnexal adhesions and/or distal occlusion of at least one tube (Land et al., 1998). Subfertile women without distal tubal pathology served as controls. The controls had an unexplained subfertility, partners with mild male factor subfertility, or proximal occlusion of at least one tube. 


\section{Serological methods}

IgG antibodies to $C$. trachomatis, $C$. pneumoniae and $C$. psittaci were detected using the Chlamydia pneumoniae IgG MIF test (AniLabsystems, Finland). For this purpose, $10 \mu \mathrm{l}$ of the serum was diluted eight times in phosphate-buffered saline (PBS) and incubated on the microscope slides dotted with three chlamydia antigens for $30 \mathrm{~min}$ at $37^{\circ} \mathrm{C}$ in a moist chamber. The slides were washed four times with PBS and twice with distilled water and incubated with goat anti-human IgG-fluorescein isothiocyanate conjugate for $30 \mathrm{~min}$ at $37^{\circ} \mathrm{C}$. Again the slides were washed four times with PBS and twice with distilled water. Mounting fluid was added on the slides, and a cover slip was placed on the slides. Under the microscope the slides were read. All slides were evaluated independently by two readers. In case of disagreement, which was the case in $\sim 10 \%$ of all slides, the judgement of a third reader was decisive. For a quantitative determination, serial dilutions in PBS were performed. In the present study, we considered the test results of each chlamydia species as a single test. For C. trachomatis and C. pneumoniae, the cut-off titre for a positive test was 32, according to the manufacturer's instructions. According to the manufacturer's instructions, LPS was still present on the $C$. psittaci elementary bodies of the MIF test, while the LPS activity on the $C$. trachomatis and $C$. pneumoniae elementary bodies had been reduced. Therefore, the fluorescence on the $C$. psittaci spot could be due to species-specific anti-C. psittaci antibodies or genus-specific anti-LPS antibodies. We considered the $C$. psittaci IgG antibodies positive when the IgG titre was $\geq 2$-fold than the titre of IgG antibodies to $C$. trachomatis or $C$. pneumoniae, a commonly used definition in literature (Moss et al., 1993, Wong et al., 1999).

IgG antibodies to chlamydia LPS were detected using the Chlamydia IgG rELISA (Medac, Germany). For this purpose, sera were diluted 1:100 in PBS and tested in microplates coated with chlamydia-specific recombinant LPS fragments. The plates were incubated for $60 \mathrm{~min}$ at $37^{\circ} \mathrm{C}$ in a humid chamber. The plates were washed three times with $200 \mu \mathrm{l}$ PBS and tapped dry. To each well, $50 \mu$ of conjugate (goat anti-human IgG, horseradish peroxidase-conjugated) was added and the plates were incubated for $60 \mathrm{~min}$ at $37^{\circ} \mathrm{C}$. Again the plates were washed three times with $200 \mu \mathrm{l}$ PBS and tapped dry. To each well, $50 \mu$ of tetramethylbenzidine substrate was added and the plates were incubated for $30 \mathrm{~min}$ at $37^{\circ} \mathrm{C}$. Finally, $100 \mu \mathrm{l}$ of $0.5 \mathrm{~mol} / \mathrm{L}$ sulphuric acid was added to stop the colouring reaction. The optical density of the plates was measured in a spectrophotometer at $450 \mathrm{~nm}$. Threshold indexes were calculated according to the manufacturer's instructions. The threshold index for a positive test was 1.1 . 


\section{Statistical methods}

Characteristics of women with and without distal tubal pathology were compared using the Mann-Whitney $U$-test. For comparison of the prevalence of IgG antibodies to $C$. trachomatis, C. pneumoniae, $C$. psittaci and LPS in women with and without distal tubal pathology, the $\chi^{2}$-test was used. The association between chlamydia genus- and species-specific antibodies and the presence of distal tubal pathology at laparoscopy was calculated by a logistic regression analysis. The prognostic value of single testing as well as combined testing for distal tubal pathology was determined by calculating sensitivity, specificity, odds ratio (OR) and $95 \%$ confidence interval (CI). The bootstrap technique was used to test the difference between ORs (Efron and Tibshiram, 1993). $P<0.05$ was considered statistically significant.

\section{RESULTS}

In 313 subfertile women, chlamydia IgG antibody titres in serum and laparoscopy results were available for analysis. At the start of the fertility work-up, the mean age of the women (30.6 and 31.2 years) and the mean duration of subfertility (2.4 and 2.3 years) did not differ significantly between women with and without distal tubal pathology. In total, there were 59 women (18.8\%) who met the definition of distal tubal pathology, whereas 254 women (81.2\%) did not have distal tubal pathology at laparoscopy. Of those 254 women without distal tubal pathology, $94.9 \%$ had patent tubes and $5.1 \%$ had proximal occlusion of at least one tube. Since proximal tubal occlusion is considered not to be associated with chlamydia disease, all 254 women without distal tubal pathology served as controls.

First, we evaluated all four tests (C. trachomatis, C. pneumoniae, C. psittaci and LPS) separately. Table I shows the prevalences of IgG antibodies to $C$. trachomatis, $C$. pneumoniae, C. psittaci and LPS in women with and without distal tubal pathology. The prevalence of species-specific IgG antibodies to $C$. trachomatis was significantly higher in women with distal tubal pathology (54.2\%), as compared to women without distal tubal pathology (7.9\%). Species-specific antibodies to $C$. pneumoniae were detected in $83.1 \%$ of women who had distal tubal disease, and in $72.8 \%$ of women without distal tubal disease. This difference was not statistically significant. No patients met the definition of a positive test for species-specific $C$. psittaci IgG antibodies. Genus-specific anti-LPS antibodies were detectable in $62.7 \%$ of women with tubal pathology, and in $33.9 \%$ of women without tubal pathology $(P<0.0001)$.

Using a logistic regression model, the association between $C$. trachomatis IgG antibodies and the presence of distal tubal pathology was statistically significant $(P<$ 0.0001). The presence of IgG antibodies to $C$. pneumoniae $(P=0.6)$ or LPS $(P=0.8)$ was not an independent predictor for distal tubal disease. 
Table I. Prevalence of IgG antibodies to C. trachomatis (Ctr), C. pneumoniae (Cpn), C. psittaci (Cps) and lipopolysaccharide (LPS) in women with and without distal tubal pathology (DTP).

\begin{tabular}{llllll}
\hline & $\mathrm{n}$ & $\mathrm{Ctr}^{\mathrm{a}}$ & $\mathrm{Cpn}^{\mathrm{a}}$ & $\mathrm{Cps}^{\mathrm{b}}$ & ${ }^{\mathrm{LPS}+{ }^{\mathrm{c}}}$ \\
\hline DTP & 59 & $32(54.2)^{\mathrm{d}}$ & $49(83.1)$ & 0 & $37(62.7)^{\mathrm{d}}$ \\
No DTP & 254 & $20(7.9)^{\mathrm{e}}$ & $185(72.8)$ & 0 & $86(33.9)^{\mathrm{e}}$ \\
\hline
\end{tabular}

Values in parentheses are percentages. ${ }^{\mathrm{a}}$ Threshold titre for a positive test: $32 ;{ }^{\mathrm{b}}$ Threshold titre for a positive test: a $\geq 2$-fold titre than $\mathrm{Ctr}$ or $\mathrm{Cpn}$; ${ }^{\mathrm{c}}$ Threshold index for a positive test: $1.1 ;{ }^{\mathrm{d}}$ versus ${ }^{\mathrm{e}}: P<$ 0.0001 .

Secondly, the outcome of combined testing was evaluated. In combined testing, antibodies to $C$. trachomatis were measured in combination with antibodies to $C$. pneumoniae and/or LPS. The results are shown in Table II. The OR of $C$. trachomatis antibody testing was 13.9. The OR increased to 15.4 when both $C$. trachomatis and C. pneumoniae antibodies were detectable. When both $C$. trachomatis and LPS antibodies were present, the OR was 13.6. The highest OR (16.6) was reached in patients in whom all three antibodies were present. The increase in OR, when one or two more test results were added, as compared to testing for $C$. trachomatis antibodies only, was not statistically significant.

Table II. Predictive value of single testing as well as combined testing for distal tubal pathology.

\begin{tabular}{|c|c|c|c|c|c|c|c|c|}
\hline $\begin{array}{l}\text { No. of tests } \\
\text { performed }\end{array}$ & $\mathrm{Ctr}^{\mathrm{a}}$ & $\mathrm{Cpn}^{\mathrm{a}}$ & $\mathrm{LPS}^{\mathrm{b}}$ & $\begin{array}{c}\text { No. of patients } \\
\text { with positive } \\
\text { test result }\end{array}$ & Sensitivity (\%) & Specificity (\%) & OR & $95 \% \mathrm{Cl}$ \\
\hline \multirow[t]{3}{*}{ One test } & + & NA & NA & 52 & 54.2 & 92.1 & $13.9^{c}$ & $6.6-29.2$ \\
\hline & NA & + & NA & 234 & 83.1 & 27.2 & $1.8^{d}$ & $0.9-4.3$ \\
\hline & NA & NA & + & 123 & 62.7 & 66.1 & $3.3^{d}$ & $1.8-6.2$ \\
\hline \multirow[t]{2}{*}{ Two tests } & + & NA & + & 48 & 50.8 & 92.9 & 13.6 & $6.4-29.0$ \\
\hline & + & + & NA & 46 & 50.8 & 93.7 & 15.4 & $7.1-33.8$ \\
\hline Three tests & + & + & + & 43 & 49.2 & 94.5 & 16.6 & $7.4-37.5$ \\
\hline
\end{tabular}

${ }^{a}$ Threshold titre for a positive test: $32 ;{ }^{b}$ Threshold index for a positive test: $1.1 ;{ }^{c}$ versus ${ }^{d}: P<0.0001$. Abbreviations: $\mathrm{Cl}=$ confidence interval; $\mathrm{Cpn}=\mathrm{C}$. pneumoniae, $\mathrm{Ctr}=\mathrm{C}$. trachomatis; $\mathrm{LPS}=$ lipopolysaccharide; $\mathrm{NA}=$ not analyzed; $\mathrm{OR}=$ odds ratio.

\section{DISCUSSION}

We evaluated whether potential alternative serological markers for distal tubal pathology might improve the predictive value of $C$. trachomatis IgG antibody testing. In the present study, serological test results were compared with the findings at laparoscopy. Therefore, only women who had undergone a laparoscopy, the reference standard in diagnosing tubal pathology, were included. This inclusion criterion will cause selection bias, which will influence the prevalence of tubal pathology, but which is hard to prevent in clinical studies. In our cohort, the prevalence of tubal 
Genus- and species-specific antibody testing

pathology will be higher as compared to an unselected population. The prevalence of tubal pathology in our tertiary care population (18.8\%), however, is comparable to findings reported from other tertiary care centres (Collins et al., 1995).

The first aim of this study was to evaluate the role of different chlamydia species in the development of distal tubal pathology, since there is a high interspecies homology in various chlamydia antigens, such as chlamydia heat shock protein 60 (cHSP60) (Kikuta et al., 1991) and LPS (Caldwell and Hitchcock, 1984). The potential role of $C$. pneumoniae or $C$. psittaci infections in the development of tubal disease, following a primary $C$. trachomatis infection, could be explained by a chlamydia genus-specific auto-immune inflammatory response, leading to tissue damage. Such a mechanism has previously been suggested by Wick et al. (2001), who studied the role of $C$. pneumoniae in the development of atherosclerosis. The immune response to $C$. pneumoniae, a highly prevalent micro-organism, does not normally result in vascular damage. It is hypothesized that in the presence of a stressor (e.g. hypertension), the vascular endothelial cells express human heat shock protein 60 (hHSP60) on their surface, which may become a target for antibodies initially directed against the highly similar cHSP60. This may lead to destruction of the endothelial cells and the development of atherosclerotic lesions (Wick et al., 2001). Extrapolating this hypothesis to the development of tubal damage, we hypothesize that the basic condition for the development of tubal pathology is a primary (silent) $C$. trachomatis infection (stressor), leading to the expression of hHSP60 on the tubal epithelium. During an infection, genus-specific antibodies to cHSP60 are produced, which can cross-react with hHSP60 on the epithelial cells in the tubes, leading to epithelial damage and subsequently to tubal pathology. Since cHSP60 is genus-specific, the auto-immune response may be induced by all chlamydia species.

To evaluate the role of different chlamydia species in the development of distal tubal pathology, we first studied the prevalence of antibodies to the three chlamydia species in our cohort. In subfertile women with and without distal tubal pathology, the prevalences of antibodies to $C$. trachomatis, $C$. pneumoniae and $C$. psittaci (Table I) were comparable to the prevalences as reported earlier (Moss et al., 1993, Freidank et al., 1995, Wong et al., 1999, Gijsen et al., 2001).

The association between serum IgG antibodies to $C$. trachomatis and tubal pathology is commonly known (Punnonen et al., 1979, meta-analysis by Mol et al., 1997), and was confirmed in the present study. A significant additive role of $C$. pneumoniae in the development of distal tubal pathology could not be found, and, in spite of enlargment of the cohort, the findings of our previous study (Gijsen et al., 2001) could not be confirmed. The role of $C$. psittaci infections could not be evaluated in the present study.

The second aim of this study was to evaluate genus-specific IgG antibodies to chlamydia LPS, as potential serological markers of repeated exposure to $C$. trachomatis. LPS is an outer membrane component shared by all three chlamydia species (Cald- 
well and Hitchcock, 1984), which has antigenic capacities comparable to the major outer membrane protein (MOMP). It has been reported previously that genusspecific anti-LPS antibodies increase rapidly in the early phases of infections, whereas more specific anti-MOMP antibodies are produced at a later stage (Ekman et al., 1993). It is assumed that repeated exposure to $C$. trachomatis is an important risk factor for the development of tubal damage (Grayston et al., 1985, Patton et al., 1994). Repeated exposure to pathogens causes repeated stimulation of the immune system, and subsequently may cause a continuously high level of anti-LPS antibodies. A study of Tuuminen et al. (2000) supports this hypothesis. Repeated stimulation might be caused by an endogenous reactivation of persistent $C$. trachomatis micro-organisms or by an exogenous reinfection with $C$. trachomatis.

As shown in Table I, the prevalence of anti-LPS antibodies was significantly higher in women with distal tubal pathology (62.7\%) as compared to women without distal tubal pathology (33.9\%). Further analysis revealed a remarkable overlap between women with IgG antibodies to $C$. trachomatis and to LPS: in $92.3 \%$ of the women with $C$. trachomatis antibodies, anti-LPS antibodies were detectable (data not shown). However, the presence of anti-LPS antibodies was no independent predictor for tubal disease. The low OR of the LPS-only test (3.3) might be explained by the high prevalence of $C$. pneumoniae antibodies in our cohort, causing a positive LPS test in women who do not necessarily have $C$. trachomatis IgG antibodies and tubal pathology. We did not find a significant additive role of anti-LPS antibodies in predicting the risk of tubal disease.

The high prevalence of anti-LPS antibodies in subfertile women with distal tubal pathology $(62.7 \%)$ is in agreement with findings in previous studies, in which other markers of ongoing infections were demonstrated in the upper genital tract of subfertile women with late sequelae of $C$. trachomatis (Gérard et al., 1998, Kinnunen et al., 2002). The high prevalence of anti-LPS antibodies in C. trachomatis-positive subfertile women without distal tubal pathology (33.9\%), however, suggests that $C$. trachomatis may remain more active in the genital tract than is currently presumed. These women may also have viable micro-organisms in the upper genital tract, which may cause minimal tubal epithelial damage or silent endometritis, and may compromise their fertility, despite normal findings at laparoscopy.

In summary, we evaluated whether additional determination of IgG antibodies to $C$. pneumoniae, $C$. psittaci and chlamydia LPS might improve the predictive value of $C$. trachomatis IgG antibody testing in screening for tubal factor subfertility. Nonetheless, in spite of the high interspecies homology, C. pneumoniae does not seem to contribute to the development of distal tubal pathology. The role of $C$. psittaci cannot be evaluated, due to the absence of $C$. psittaci IgG-positive patients in our cohort. Although anti-LPS antibodies are considered as markers for chronic inflammation, their presence is not useful in selecting a subset of $C$. trachomatis-positive subfertile women which is most likely to have tubal damage. The high prevalence of 
anti-LPS antibodies in our cohort suggests that $C$. trachomatis may remain more active in the upper genital tract than is currently presumed. $C$. trachomatis-positive subfertile women with anti-LPS antibodies, but without tubal disease, may have a mild chronic infection, which may also compromise their fertility.

\section{Acknowledgements}

The authors acknowledge Gert Grauls, from the Department of Medical Microbiology, for laboratory assistance. 


\section{REFERENCES}

Bourke SJ, Carrington D, Frew CE, McSharry CP, Boyd G (1992) A comparison of the seroepidemiology of chlamydial infection in pigeon fanciers and farmers in the U.K. J Infect 25 (Suppl 1), 91-98.

Caldwell HD, Hitchcock PJ (1984) Monoclonal antibody against a genus-specific antigen of Chlamydia species: location of the epitope on chlamydial lipopolysaccharide. Infect Immun 44, 306-314.

Collins JA, Burrows EA, Willan AR (1995) The prognosis for live birth among untreated infertile couples. Fertil Steril 64, 22-28.

Efron B, Tibshiram RJ (1993) An Introduction to the Bootstrap. Chapman \& Hall, New York, pp. 224-227.

Ekman MR, Leinonen M, Syrjälä H, Linnanmäki E, Kujala P, Saikku P (1993) Evaluation of serological methods in the diagnosis of Chlamydia pneumoniae pneumonia during an epidemic in Finland. Eur J Clin Microbiol Infect Dis 12, 756-760.

Freidank HM, Clad A, Herr AS, Wiedmann-Al-Ahmad M, Jung B (1995) Immune response to Chlamydia trachomatis heat-shock protein in infertile female patients and influence of Chlamydia pneumoniae antibodies. Eur J Clin Microbiol Infect Dis 14, 1063-1069.

Gérard HC, Branigan PJ, Balsara GR, Heath C, Minassian SS, Hudson AP (1998) Viability of Chlamydia trachomatis in fallopian tubes of patients with ectopic pregnancy. Fertil Steril 70, 945-948.

Gijsen AP, Land JA, Goossens VJ, Leffers P, Bruggeman CA, Evers JLH (2001) Chlamydia pneumoniae and screening for tubal factor subfertility. Hum Reprod 16, 487-491.

Grayston JT, Wang SP, Yeh LJ, Kuo CC (1985) Importance of reinfection in the pathogenesis of trachoma. Rev Infect Dis 7, 717-725.

Hahn DL, Dodge RW, Golubjatnikov R (1991) Association of Chlamydia pneumoniae (strain TWAR) infection with wheezing, asthmatic bronchitis, and adult-onset asthma. J Am Med Assoc 266, 225-230.

Karvonen M, Tuomilehto J, Pitkäniemi J, Naukkarinen A, Saikku P (1994) Chlamydia pneumoniae IgG antibody prevalence in south-western and eastern Finland in 1982 and 1987. Int J Epidemiol 23, 176184.

Kikuta LC, Puolakkainen M, Kuo CC, Campbell LA (1991) Isolation and sequence analysis of the Chlamydia pneumoniae GroE operon. Infect Immun 59,4665-4669.

Kinnunen A, Molander P, Morrison R, Lehtinen M, Karttunen R, Tiitinen A, Paavonen J, Surcel HM (2002) Chlamydial heat shock protein 60 -specific $T$ cells in inflamed salpingeal tissue. Fertil Steril $77,162-$ 166.

Land JA, Evers JLH, Goossens VJ (1998) How to use Chlamydia antibody testing in subfertility patients. Hum Reprod 13, 1094-1098.

Land JA, Gijsen AP, Kessels AGH, Slobbe MEP, Bruggeman CA (2003) Performance of five serological chlamydia antibody tests in subfertile women. Hum Reprod 18, 2621-2627.

Mol BWJ, Dijkman B, Wertheim P, Lijmer J, Van der Veen F, Bossuyt PMM (1997) The accuracy of serum chlamydial antibodies in the diagnosis of tubal pathology: a meta-analysis. Fertil Steril 67, 10311037.

Moss TR, Darougar S, Woodland RM, Nathan M, Dines RJ, Cathrine V (1993) Antibodies to Chlamydia species in patients attending a genitourinary clinic and the impact of antibodies to $C$. pneumoniae and $C$. psittaci on the sensitivity and the specificity of $C$. trachomatis serology tests. Sex Transm Dis 20, 61-65.

Patton DL, Sweeney YT, Kuo CC (1994) Demonstration of delayed hypersensitivity in Chlamydia trachomatis salpingitis in monkeys: a pathogenic mechanism of tubal damage. J Infect Dis 169, 680-683.

Punnonen R, Terho P, Nikkanen V, Meurman O (1979) Chlamydial serology in infertile women by immunofluorescence. Fertil Steril 31, 656-659.

Saikku P, Mattila K, Nieminen MS, Huttunen JK, Leinonen M, Ekman MR, Mäkelä PH, Valtonen V (1988) Serological evidence of an association of a novel Chlamydia, TWAR, with chronic coronary heart disease and acute myocardial infarction. Lancet 2, 983-986. 


\section{Chapter 3}

Genus- and species-specific antibody testing

Tuuminen T, Palomäki P, Paavonen J (2000) The use of serologic tests for the diagnosis of chlamydial infections. J Microbiol Meth 42, 265-279.

Wick G, Perschinka H, Millonig G (2001) Atherosclerosis as an autoimmune disease: an update. Trends Immunol 22, 665-669.

Wong YK, Sueur JM, Fall CHD, Orfila J, Ward ME (1999) The species specificity of the microimmunofluorescence antibody test and comparisons with a time resolved fluoroscopic immunoassay for measuring IgG antibodies against Chlamydia pneumoniae. J Clin Pathol 52, 99-102. 


\section{Chapter 4}

\section{Screening strategies for tubal factor subfertility}

JE den Hartog, CMJG Lardenoije, JL Severens, JA Land, JLH Evers, AGH Kessels

Human Reproduction 2008, 23 (8): 1840-1848 


\section{ABSTRACT}

\section{Background}

Different screening strategies exist to estimate the risk of tubal factor subfertility preceding laparoscopy. Three screening strategies, comprising Chlamydia trachomatis IgG antibody testing (CAT), high-sensitivity C-reactive protein (hs-CRP) and hysterosalpingography (HSG), were explored using laparoscopy as reference standard and the occurrence of a spontaneous pregnancy as surrogate marker for the absence of tubal pathology.

\section{Methods}

In this observational study, 642 subfertile women, who underwent tubal testing, participated. Data on serological testing, HSG, laparoscopy and interval conception were collected. Multiple imputations were used to compensate for missing data.

\section{Results}

Strategy A (HSG) has limited value in estimating the risk of tubal pathology. Strategy B (CAT $\rightarrow$ HSG) shows that CAT significantly discerns patients with a high versus low risk of tubal pathology, whereas HSG following CAT has no additional value. Strategy C (CAT $\rightarrow$ hs-CRP $\rightarrow$ HSG) demonstrates that hs-CRP may be valuable in CATpositive patients only and HSG has no additional value.

\section{Conclusions}

CAT is proposed as first screening test for tubal factor subfertility. In CAT-negative women, HSG may be performed because of its high specificity and fertilityenhancing effect. In CAT-positive women, hs-CRP seems promising, whereas HSG has no additional value. The position and timing of laparoscopy deserves critical reappraisal. 


\section{INTRODUCTION}

The reference standard for diagnosing tubal factor subfertility is laparoscopy with tubal dye testing, by which tubal patency and the presence of peri-adnexal adhesions and endometriosis can be assessed. It also provides additional information on uterine malformations. Laparoscopy has several disadvantages, e.g. it is an invasive and expensive procedure requiring general anaesthesia, and it holds a $1.5 \%$ risk of surgical complications (Chapron et al., 1998). Furthermore, operating facilities may not be easily available in every clinic. Owing to these disadvantages, laparoscopy is unsuitable for routine application in subfertile women on a large scale. Obtaining a reliable estimate of the risk of tubal pathology preceding laparoscopy would allow for selecting only high-risk patients for this procedure. The chance of finding tubal pathology at laparoscopy can be estimated preoperatively by applying screening tests. Among different countries the preferred screening method to determine the risk of tubal pathology varies (Portuondo et al., 1984, Helmerhorst et al., 1995, Balasch, 2000, Mol et al., 2001). Commonly used and well-evaluated modalities to screen for tubal pathology in the fertility evaluation are serum Chlamydia (C.) trachomatis IgG antibody testing (CAT) and hysterosalpingography (HSG) (Swart et al., 1995, Mol et al., 1997, Mol et al., 2001).

CAT is a serological marker of a previous $C$. trachomatis infection, but does not reflect the course of the infection. Because mainly persistent $C$. trachomatis infections, rather than cleared infections, are associated with an increased risk of tubal pathology (Grayston et al., 1985, Patton et al., 1994), the combination of CAT and high-sensitivity C-reactive protein (hs-CRP), reflecting a previous $C$. trachomatis infection and persistence of the micro-organism respectively, has been proposed as a valuable set of markers for identifying subfertile women at highest risk of persistent $C$. trachomatis infection and the ensuing tubal pathology (Den Hartog et al., 2005). In the present study, HSG is considered as a screening test (as opposed to a diagnostic test) because of its lower performance in diagnosing tubal pathology and predicting future fertility as compared to laparoscopy (Swart et al., 1995, Mol et al., 1999) and because at present, in many clinics, HSG is used to differentiate between patients who qualify for further tubal testing and those who do not. The role of HSG in the investigation of the subfertile couple covers more than testing tubal patency only, because it also provides additional information on uterine malformations and intracavitary pathology.

No consensus exists on which screening test (or series of screening tests) is to be preferred for assessing the risk of tubal pathology in subfertile women. In the present observational study, we evaluated different screening strategies in predicting tubal pathology, in order to develop a useful screening strategy in the diagnostic work-up of subfertile couples. For this purpose, three different screening strategies comprising the test modalities CAT, hs-CRP and HSG were explored in a population 
of subfertile women by constructing decision tables (Glasziou and Hilden, 1986), and using laparoscopy as reference standard and the occurrence of a spontaneous pregnancy as a surrogate marker for the absence of tubal pathology.

\section{MATERIALS AND METHODS}

\section{Study population}

The study population consisted of 642 women who visited the Maastricht University Medical Centre Fertility Clinic because of subfertility between December 1990 and May 2004, and who consecutively underwent tubal testing (HSG and/or laparoscopy) as part of their fertility evaluation. In all women, blood was drawn at their initial visit to measure $C$. trachomatis IgG antibodies using CAT. Spare serum samples were cryopreserved and stored. In patients with a negative CAT and an otherwise normal basic fertility evaluation, tubal status was evaluated initially by HSG. If HSG showed abnormalities, or if patients did not conceive in the 6 months following HSG, the fertility evaluation was concluded by laparoscopy with tubal testing using methylene blue dye. In patients with a positive CAT, no HSG was performed, but tubal status was evaluated primarily by laparoscopy. Patients with a history of pelvic surgery (except for an uneventful appendectomy or Caesarean section) or pelvic inflammatory disease, and patients with suspected severe endometriosis, based on history and findings at pelvic examination, directly underwent laparoscopy and were excluded from the present study.

In the Netherlands, for retrospective analysis of anonymized patient data and stored sera, no ethical committee approval is required. In the Fertility Clinic of the Maastricht University Medical Centre, all couples are informed at intake about possible use of their anonymized data and stored sera for research purposes, and a "no objection procedure" is followed. Only patients having not objected participated in the present study.

\section{CAT}

For the present study, stored serum samples of 475 patients were available and retested for CAT by using an enzyme-linked immunosorbent assay (ELISA) (C. trachomatis IgG pELISA, Medac, Germany). The test was performed according to the manufacturer's instructions. The cut-off level used for a positive test was $>1.1$. 


\section{hs-CRP}

In each of the 475 available stored samples, hs-CRP was determined using CRP ELISA (DiaMed Eurogen, Belgium). A high-sensitivity test was used in order to reliably detect low CRP concentrations. The test was used according to the manufacturers' instructions. Hs-CRP levels between 1.0 and $10.0 \mathrm{mg} / \mathrm{L}$ were considered positive, whereas hs-CRP levels $<1.0$ and $>10.0 \mathrm{mg} / \mathrm{L}$ were considered negative (Den Hartog et al., 2005).

\section{HSG}

In 424 patients, HSG was performed using oil-soluble contrast medium. The procedure was recorded on videotape, and radiographs were made during the procedure and $24 \mathrm{~h}$ afterwards to visualize the residual intra-abdominal spread of the contrast medium. The video recordings and radiographs of all HSGs were discussed in a consensus meeting. Besides tubal patency and intra-abdominal spread of contrast medium, uterine malformations and intracavitary pathology were assessed. HSG was considered normal when both tubes were patent and contrast medium had spread normally after $24 \mathrm{~h}$, or when only a uterine malformation or minor intracavitary pathology (both unlikely to be related to the patient's fertility) was found. HSG was considered abnormal when both tubes were occluded and no spill of contrast medium was seen in the abdominal cavity after $24 \mathrm{~h}$. HSG was considered inconclusive in all other cases (i.e. unilateral tubal occlusion, uncertain unilateral or bilateral tubal patency, high pressure needed to fill the tubes, pockets of contrast medium other than in the pouch of Douglas, or when the procedure had been abandoned).

\section{Laparoscopy with tubal testing}

In 355 patients, laparoscopy with tubal testing using methylene blue dye was performed. Tubal patency and the presence of peri-adnexal adhesions and endometriosis were assessed. For endometriosis, the 1996 revised American Society for Reproductive Medicine (rASRM) classification was used (The American Society for Reproductive Medicine, 1997). Laparoscopies were performed by gynaecologists who were not blinded for CAT and/or HSG results. For the present study, all laparoscopy reports were scored independently by two investigators (J.A.L. and J.L.H.E.) who were unaware of CAT and/or HSG results. In cases of disagreement, consensus was reached by consultation. On the basis of tubal patency and the presence of peri-adnexal adhesions and endometriosis, findings at laparoscopy were categorized into three levels according to the patient's estimated spontaneous pregnancy chance: normal spontaneous pregnancy chance (subcategories: no abnormalities and no fertility-impairing factors), reduced spontaneous pregnancy chance and 
(nearly) absent spontaneous pregnancy chance respectively. Subfertile women with reduced and (nearly) absent spontaneous pregnancy chances were considered together as a group having tubal pathology, whereas those with normal spontaneous pregnancy chances were considered not to have tubal pathology. This categorization was based on the Hull and Rutherford classification (Rutherford and Jenkins, 2002) and on our experts' group opinion (J.A.L. and J.L.H.E.). Table I reflects the classification of the findings at laparoscopy.

Table I. Overview of the classification of tubal pathology and estimated spontaneous pregnancy chance, respectively, based on findings at laparoscopy (if available) or on interval conception.

\begin{tabular}{|c|c|c|c|}
\hline & $\mathrm{n}$ & $\begin{array}{l}\text { Estimated spontaneous } \\
\text { pregnancy chance }\end{array}$ & $\begin{array}{l}\text { Findings at laparoscopy, based on tubal patency and the } \\
\text { presence of peri-adnexal adhesions and endometriosis }\end{array}$ \\
\hline \multirow{3}{*}{$\begin{array}{l}\text { No tubal } \\
\text { pathology } \\
(n=455)\end{array}$} & 89 & Normal (no abnormalities) & Patent tubes, no adhesions, no endometriosis \\
\hline & 161 & $\begin{array}{l}\text { Normal (no fertility- } \\
\text { impairing factors ) }\end{array}$ & $\begin{array}{l}\text { Patent tubes, no/any adhesions, no/Stage I endometriosis } \\
\text { Unilateral tubal occlusion, no adhesions, no/Stage I en- } \\
\text { dometriosis }\end{array}$ \\
\hline & 205 & Normal & $\begin{array}{l}\text { No laparoscopy because of interval conception before } \\
\text { laparoscopy (spontaneous or treatment-dependent con- } \\
\text { ception, IVF-pregnancies not included) }\end{array}$ \\
\hline \multirow[t]{2}{*}{$\begin{array}{l}\text { Tubal } \\
\text { pathology } \\
(\mathrm{n}=105)\end{array}$} & 58 & Reduced & $\begin{array}{l}\text { Patent tubes, any/extensive unilateral adhesions, } \\
\text { no/Stage I/II/III endometriosis } \\
\text { Patent tubes (high pressure needed), no/any/extensive } \\
\text { adhesions, no/Stage I endometriosis } \\
\text { Unilateral tubal occlusion with normal contralateral side, } \\
\text { no/any/extensive unilateral adhesions, no/Stage I endo- } \\
\text { metriosis }\end{array}$ \\
\hline & 47 & (Nearly) absent & $\begin{array}{l}\text { Patent tubes, extensive bilateral adhesions, no/Stage } \\
\text { I/II/III endometriosis } \\
\text { Patent tubes (very high pressure needed), } \\
\text { no/any/extensive adhesions, no/Stage I/II/III endometrio- } \\
\text { sis } \\
\text { Unilateral tubal occlusion with suboptimal contralateral } \\
\text { side, no/any/extensive adhesions, no/Stage I/II/III endo- } \\
\text { metriosis } \\
\text { Bilateral tubal occlusion, no/any/extensive adhesions, } \\
\text { no/Stage I/II/III endometriosis }\end{array}$ \\
\hline $\begin{array}{l}\text { Unknown } \\
(n=82)\end{array}$ & 82 & Unknown & $\begin{array}{l}\text { No laparoscopy, no interval conception (active or passive } \\
\text { discontinuation of fertility evaluation or referral for IVF) }\end{array}$ \\
\hline TOTAL & 642 & & \\
\hline
\end{tabular}

\section{No laparoscopy because of interval conception}

No laparoscopy was performed in 205 patients, because they conceived either spontaneously or following treatment (other than IVF) before laparoscopy. Interval conception was used as a surrogate marker for the absence of tubal pathology, and therefore these 205 patients were categorized as having no tubal pathology (Table 
I), although it cannot be ruled out that minor degrees of tubal pathology may have been present. Patients who conceived by IVF were not included in this subgroup, because IVF-pregnancies are independent of tubal function.

\section{No laparoscopy and no interval conception}

In 82 patients, no laparoscopy was performed and no pregnancy occurred either spontaneously or after treatment (other than IVF) following HSG, because these patients decided to stop treatment, were advised to stop treatment or were referred for IVF. In this subgroup of patients, no reference standard was available and neither was a surrogate outcome.

\section{Statistical methods}

In the study population of 642 women, serum samples were missing from 167 patients, HSG was not performed in 218 patients and no laparoscopy or interval conception occurred in 82 women (Figure I). Exclusion of all patients with an incomplete data set would result in an inefficient reduction of the population size and might introduce bias if the excluded group were a non-randomly selected subsample from the entire population. Therefore, we used an alternative approach based on multiple imputations (Van Buuren et al., 1999, Altman and Bland, 2007, Horton and Kleinman, 2007). Five imputations were performed (A.G.H.K.), in which the missing data on CAT, hs-CRP and HSG were imputed as described extensively by Van Buuren et al. (1999). Imputed data were calculated by using all available data of the entire population. Each of the five completed data sets was analyzed, and the results were integrated into a final result (C.M.J.G.L.) (Van Buuren et al., 1999, Horton and Kleinman, 2007).

In 82 patients, no reference standard was available (Figure I). Excluding this subgroup might also introduce selection bias. With a logistic regression model, we determined which subgroups were underrepresented and in all analyses, weights were used to compensate for this underrepresentation (Horton and Kleinman, 2007). 


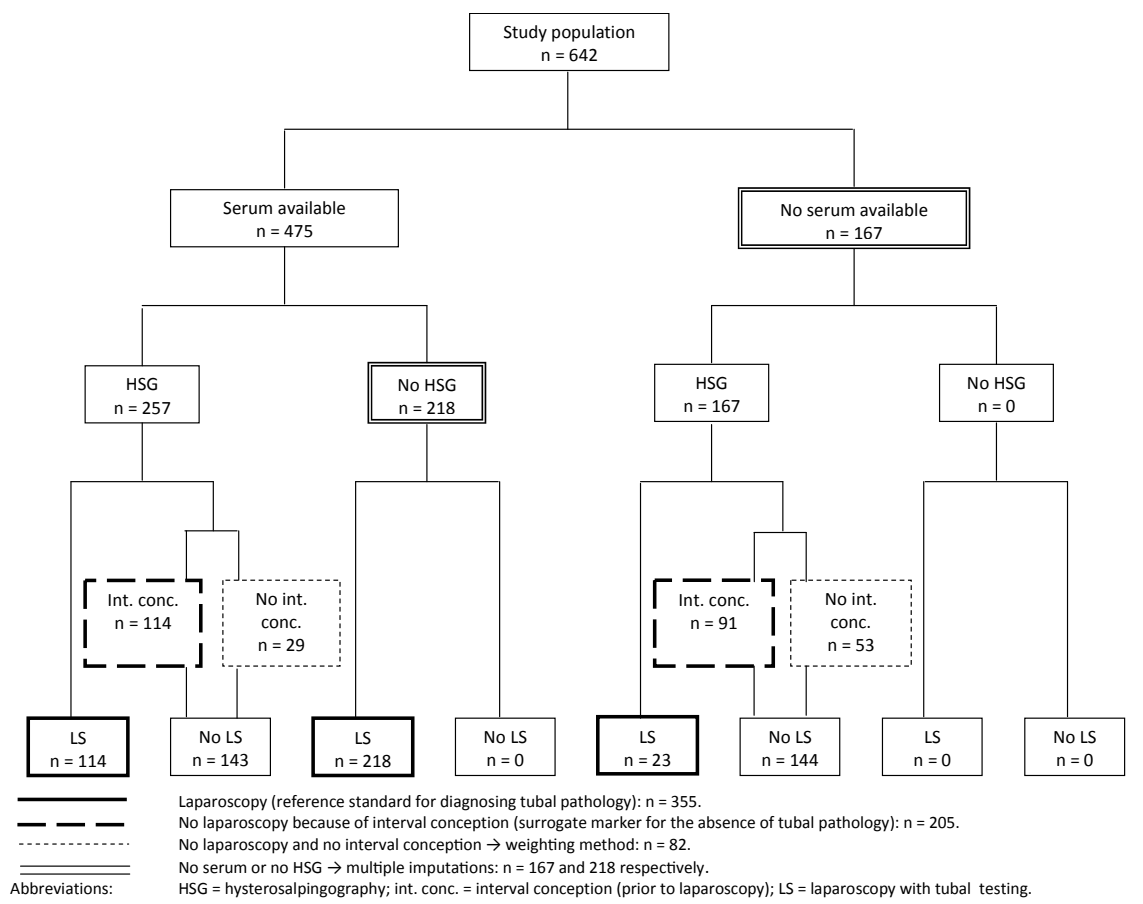

Figure I. Overview of the obtained data.

\section{Screening strategies}

Three screening strategies for tubal factor subfertility were evaluated comprising the test modalities CAT, hs-CRP and HSG. In strategy A, HSG was performed. In strategy $B$, CAT and HSG were performed consecutively. In strategy C, CAT, hs-CRP and HSG were performed consecutively. All strategies were designed in a manner that tests were performed in order of increasing invasiveness. Laparoscopy was used as reference standard for the presence or absence of tubal pathology, and the occurrence of a spontaneous pregnancy was used as surrogate marker for the absence of tubal pathology. For all strategies, decision tables were constructed, in which all possible combinations of test results were listed (Glasziou and Hilden, 1986). Subsequently, the posterior probabilities of tubal pathology and $95 \%$ confidence intervals were calculated for all combinations using a logistic regression model. Furthermore, with this model, the significance of diagnostic coefficients was tested. 


\section{RESULTS}

\section{Population characteristics}

The study population consisted of 642 subfertile women who attended our Fertility Clinic and who consecutively underwent tubal testing by HSG and/or laparoscopy. In $71 \%$, subfertility was primary and in $28 \%$, it was secondary. In $1 \%$, this information was not available. At intake, the median age was 31 years (range 19-41) and the median duration of subfertility was 17 months (range 0-162). Serum samples were obtained at the initial visit, and spare samples of 475 women were available for CAT and hs-CRP testing. Of these 475 women, CAT was negative in $88 \%$ and positive in $12 \%$ of patients. Hs-CRP was negative in $76 \%$ and positive in $24 \%$ of patients. HSG was performed in 424 women, of whom $66 \%$ had a normal HSG, $2 \%$ had an abnormal HSG and $32 \%$ had an inconclusive HSG. Laparoscopy was performed in 355 women, of whom 70\% had no tubal pathology and 30\% had tubal pathology. In 205 women, no laparoscopy was performed because of interval conception, and these patients were considered not to have tubal pathology. The median duration between initial visit and HSG was 4 months (range 0-59). The median duration between HSG and laparoscopy was 8 months (range 1-46). The median duration between initial visit and laparoscopy was 10 months (range 0-71). Figure I shows an overview of the obtained data (number of serum samples, HSG, laparoscopy and spontaneous pregnancies), the imputed data and the subgroup for which a weighted analysis was performed.

\section{Screening strategies}

Figure II shows the results of screening strategy A (HSG). Figure III shows the results of screening strategy $B$ (CAT $\rightarrow$ HSG). Figure IV shows the results of screening strategy C (CAT $\rightarrow$ hs-CRP $\rightarrow$ HSG). The diagnostic performance of HSG, as expressed by the coefficients in the logistic regression model, was not statistically significant in all three strategies ( $P$-values between 0.4 and 0.8$)$. Moreover, the diagnostic performance of CAT in strategy $B$ and $C(P<0.0001)$ and hs-CRP in strategy $C(P<0.003)$ were highly significant. 


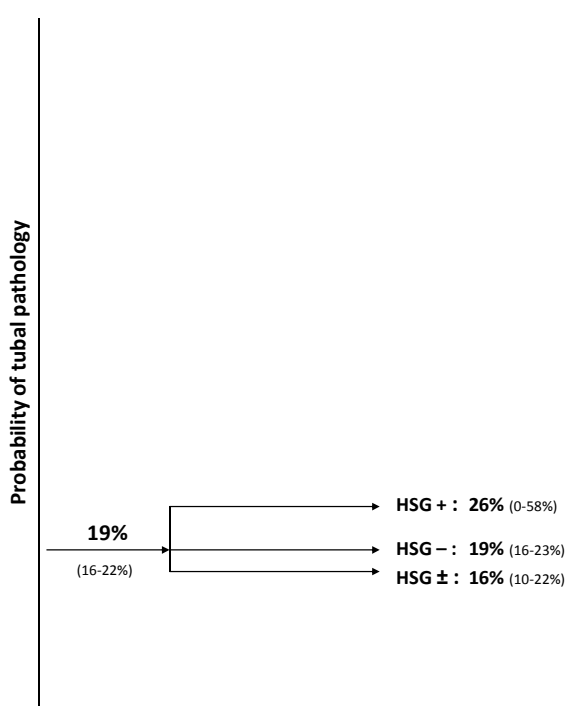

Figure II. Strategy A: HSG.

Abbreviation: HSG = hysterosalpingography. HSG $=$ = normal, $\mathrm{HSG} \pm=$ inconclusive; $\mathrm{HSG}+=$ abnormal. Values in parentheses are $95 \%$ confidence intervals.

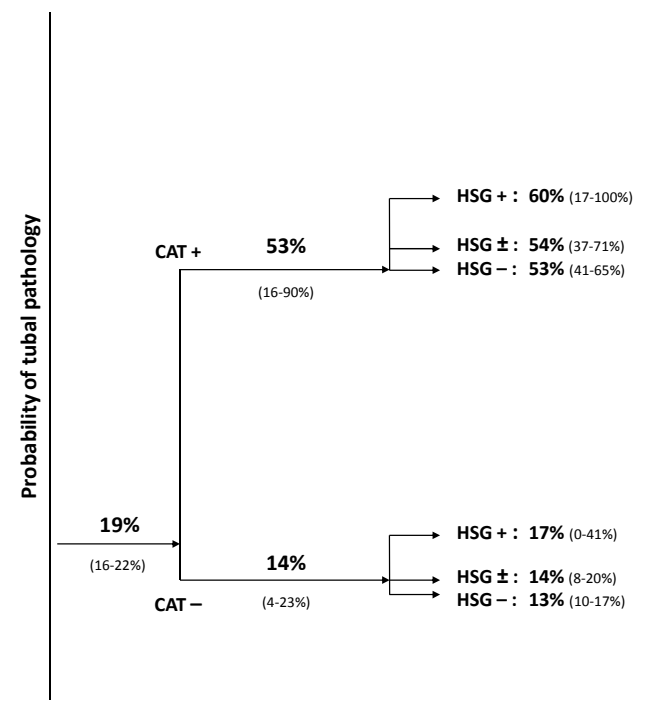

Figure III. Strategy B: CAT $\rightarrow$ HSG.

Abbreviations: $\mathrm{CAT}=\mathrm{C}$. trachomatis IgG antibody testing; HSG = hysterosalpingography. $\mathrm{CAT}-=$ negative; CAT + = positive; $\mathrm{HSG}=$ = normal, $\mathrm{HSG} \pm=$ inconclusive; $\mathrm{HSG}+=$ abnormal. Values in parentheses are $95 \%$ confidence intervals. 


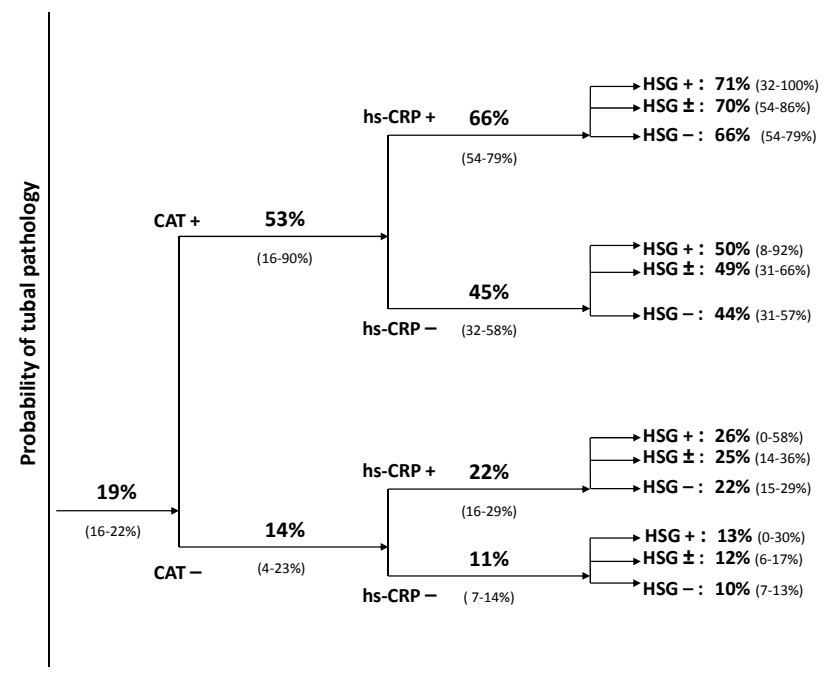

Figure IV. Strategy C: CAT $\rightarrow$ hs-CRP $\rightarrow$ HSG.

Abbreviations: $\mathrm{CAT}=\mathrm{C}$. trachomatis IgG antibody testing; hs-CRP = high-sensitivity C-reactive protein; HSG = hysterosalpingography. $\mathrm{CAT}-=$ negative; $\mathrm{CAT}+=$ positive; hs-CRP-= negative; hs-CRP + = positive; $\mathrm{HSG}-=$ normal, HSG $\pm=$ inconclusive; HSG + = abnormal. Values in parentheses are $95 \%$ confidence intervals.

\section{Additional findings at HSG and laparoscopy}

Uterine malformations and intracavitary pathology at HSG.

Uterine malformations were found in $2.4 \%$ of the HSGs (10/424): arcuate uterus (3), bicornuate uterus (3), unicornuate uterus (2), septate uterus (1) and T-shaped uterus (1). Intracavitary pathology was found or suspected in $2.1 \%$ of the HSGs (9/424): polyps (6), fibroids (2) and suspected intracavitary adhesions (1). In two patients with suspected polyps, and in the patient with suspected intracavitary adhesions, hysteroscopy was performed, in which no abnormalities were found. In the other six cases with intracavitary pathology, no hysteroscopy was performed and an expectant management was observed.

\section{Endometriosis at laparoscopy.}

Lesions suspect for endometriosis were found in $50 \%$ of all patients undergoing laparoscopy (176/355). Of these 176 patients, 88\% had minimal peritoneal endometriosis without adhesions (compatible with rASRM stage I), 5\% had peritoneal endometriosis with adhesions (stages II and III), $2 \%$ had ovarian endometriosis without adhesions (stages I and II) and 6\% had ovarian endometriosis with adhesions (stages II and III). No stage IV endometriosis was found at laparoscopy in our study population, which was according to our expectation, because suspected severe endometriosis (based on history and findings at pelvic examination) was an exclusion criterion. 


\section{DISCUSSION}

In the present study, we assessed the clinical value of three different screening strategies for assessing the risk of tubal pathology in a population of subfertile women, using serological testing (CAT and hs-CRP) and HSG as screening methods, laparoscopy as a reference standard and the occurrence of a spontaneous pregnancy as a surrogate marker for the absence of tubal pathology. The aim was to develop a useful minimally invasive screening strategy which can be used in the diagnostic work-up of subfertile couples to estimate the risk of tubal pathology preceding laparoscopy. Estimating the cost-effectiveness of the different screening strategies or analyzing cost-minimization of the screening strategies was beyond the scope of this study. Tubal pathology was defined as reduced or (nearly) absent spontaneous pregnancy chances based on tubal patency and the presence of periadnexal adhesions and endometriosis at laparoscopy. Patients with normal spontaneous pregnancy chances based on the laparoscopy reports and patients who conceived prior to laparoscopy were considered not to have tubal pathology (Table I). We have also re-analyzed our data using a more strict definition of tubal pathology, in which the subgroup with reduced spontaneous pregnancy chances was categorized as having no tubal pathology. Obviously, the pre-test probability of tubal pathology was lower $(8 \%)$, but the trends in post-test probabilities as noted in the present analysis remained unchanged (data not shown). In our opinion, the definition of tubal pathology which has been used in the present study [i.e. reduced or (nearly) absent spontaneous pregnancy chances] is applicable to the average subfertile population. The more strict definition may be used in a clinical setting in which only a very high suspicion of tubal pathology, based on the results of a screening strategy, may alter clinical decision-making (e.g. in the case of limited access to operating facilities).

\section{Strategy A: HSG}

According to the fertility-guideline of the National Institute for Clinical Excellence (NICE, 2004), HSG should be offered to women who are not known to have comorbidities (such as a history of pelvic inflammatory disease, previous ectopic pregnancy or endometriosis) to screen for tubal pathology. In women who are assumed to have co-morbidities, laparoscopy should be offered instead of HSG. Strategy A corresponds with the screening method proposed by NICE, in which only women at low risk for tubal pathology (based on the medical history) undergo HSG.

In our study population, consisting of women without known co-morbidities, the pre-test probability of tubal pathology was $19 \%$, and the post-HSG probabilities ranged from 16 to $26 \%$ ( $95 \% \mathrm{Cl} 0-58$ ), depending on the HSG result. It should be noted that the risk of tubal pathology did not differ between women with a normal 
HSG versus an inconclusive HSG (e.g. unilateral tubal occlusion, uncertain unilateral or bilateral tubal patency, high pressure needed to fill the tubes and pockets of contrast medium other than in the pouch of Douglas), indicating that inconclusive HSGs can be categorized as normal. These results are in accordance with a study of Mol et al. (1999), who conclude that fertility prospects in women with unilateral tubal occlusion at HSG are only slightly lower when compared with women with bilateral tubal patency at HSG. The risk of tubal pathology in the case of a normal or inconclusive HSG is slightly lower when compared with findings of previous studies, which state that $~ 20-25 \%$ of women with normal HSG findings have tubal pathology caused by adhesions or endometriosis (Henig et al., 1991, Tanahatoe et al., 2003), which often remain undetected at HSG (Swart et al., 1995). From our data, it can be concluded that in low pre-test risk women, a normal or inconclusive HSG is of little additional value in discerning women with a high versus low post-HSG risk of tubal pathology. No conclusion can be drawn in case of an abnormal HSG, owing to the wide $95 \%$ confidence interval of post-HSG risk of tubal pathology (0-58), although the prevalence of abnormal HSGs in our low-risk population is only $2 \%$ (9/424).

\section{Strategy B: CAT $\rightarrow$ HSG}

CAT has been introduced in the fertility evaluation as a screening test to estimate the risk of tubal pathology, because an association exists between the presence of C. trachomatis IgG antibodies in serum and tubal pathology (Punnonen et al., 1979). The value of CAT in assessing the risk of tubal pathology is at least comparable with HSG (Dabekausen et al., 1994, Perquin et al., 2007). The advantage of CAT is that it is a simple, inexpensive and minimally inconvenient test method, which makes CAT recommended in subfertile women as the first screening test for tubal pathology after medical history taking (Dabekausen et al., 1994, Mol et al., 1997, Mol et al., 2001, Veenemans and Van der Linden, 2002, Coppus et al., 2007). Strategy B reflects the use of CAT prior to HSG (in the order of increasing invasiveness). Our data show that CAT accurately discerns patients with a high versus low risk of tubal pathology [post-test probability $14 \%(95 \% \mathrm{Cl} 4-23)$ in CAT-negative patients and $53 \%$ (95\% Cl 16-90) in CAT-positive patients]. Our present findings on the predictive value of CAT for tubal pathology are comparable with those reported by others (as summarized by Den Hartog et al., 2006). Performing HSG after CAT does not change the probability of tubal pathology significantly. In CAT-negative women (post-CAT probability of tubal pathology 14\%) the post-HSG probabilities ranged between 13 and $17 \%$ (95\% Cl $0-41$ ), whereas in CAT-positive women (post-CAT probability of tubal pathology 53\%) the post-HSG probabilities ranged between 53 and $60 \%$ (95\% $\mathrm{Cl}$ 17-100). From these results, it can be concluded that CAT, as a first screening test to estimate the risk of tubal pathology in the fertility work-up, is more accurate 
in comparison with HSG (strategy A). In both CAT-negative and CAT-positive women, HSG following CAT has no significant additional value in estimating the risk of tubal pathology. Furthermore, it should be taken into account that HSG in CAT-positive women holds a $10 \%$ risk of post-HSG complications (e.g. fever and infection) in women with tubal pathology (Forsey et al., 1990). Therefore, the value of HSG following CAT in screening for tubal factor subfertility should be critically reappraised: the post-HSG risk of tubal pathology in CAT-negative and CAT-positive women remains invariably low and high respectively, HSG is relatively contra-indicated in CATpositive women because of increased post-infectious morbidity and CAT-positive women may benefit from early laparoscopy in order to provide a definitive diagnosis without delay.

\section{Strategy C: CAT $\rightarrow$ hs-CRP $\rightarrow$ HSG}

Because persistence of $C$. trachomatis infections is an important risk factor for tubal pathology, the additional value of serological markers of persistence has been evaluated previously (Den Hartog et al., 2005). Combining CAT (as a marker of a previous $C$. trachomatis infection) and hs-CRP (as a marker of persistence) has been found a valuable test set to identify women at highest risk of tubal pathology (Den Hartog et al., 2005). Strategy C reflects the use of hs-CRP following CAT and preceding HSG. Because hs-CRP is a general marker of inflammation, it is considered of importance in CAT-positive women only, in whom it may discern women with a high risk of persistence and tubal pathology (both CAT and hs-CRP positive) from those with a lower risk of persistence and tubal pathology (CAT positive and hs-CRP negative). Our results confirmed that the value of hs-CRP in assessing the risk of tubal pathology in CAT-negative women is limited. In CAT-positive women [post-CAT probability of tubal pathology $53 \%$ (95\% Cl 16-90)], the post-hs-CRP probabilities were $45 \%(95 \% \mathrm{Cl} 32-58)$ in hs-CRP-negative women and $66 \%$ (95\% Cl 54-79) in hs-CRP-positive women, respectively. After adding HSG as a third test, the probability of tubal pathology does not change significantly [44-71\% (95\% Cl 8-100)]. It can be concluded that hs-CRP, which is simple, inexpensive and minimally inconvenient to patients and has previously been shown to improve the predictive value of CAT significantly (Den Hartog et al., 2005), seems of additional value in estimating the risk of tubal pathology in CAT-positive subfertile women only. As discussed in strategy $B, H S G$ has little additional value in assessing the risk of tubal pathology in CATnegative women, and is relatively contra-indicated in CAT-positive women.

\section{Limitations of the study}

Our study has several limitations. First, serum samples from 167 patients (mainly those who visited our clinic in the early 1990s) were missing. Although CAT had 
been performed as a part of their fertility evaluation, no spare samples were available for the present study. The original CAT results were obtained by a different CAT test, which has later been shown to be inferior to the CAT test used in the present study (Land et al., 2003), and therefore it was decided not to use the results of the original CAT. Missing data on CAT and hs-CRP were replaced by plausible values by using multiple imputations (Van Buuren et al., 1999, Altman and Bland, 2007, Horton and Kleinman, 2007). An important limitation of our study is verification bias, because the CAT result in the fertility evaluation determined whether HSG or laparoscopy was performed. In our clinic, HSG is not performed in CAT-positive women owing to the $10 \%$ risk of febrile and infectious morbidity reported in women with tubal pathology (Forsey et al., 1990). Therefore, abnormal HSGs were rare $(9 / 424=2 \%)$, causing wide ranges in the $95 \%$ confidence intervals. We have used multiple imputations to fill in the missing data of HSG, in order to minimize the influence of verification bias (Van Buuren et al., 1999, Altman and Bland, 2007, Horton and Kleinman, 2007). This verification bias is difficult to avoid, unless one is willing to perform HSG in all subfertile women, thereby accepting its potential harmful effects, and unless one is prepared to perform both HSG and laparoscopy in all women, preferably even on the same day. Another contributor to verification bias is that only patients who underwent tubal testing (HSG and/or laparoscopy) were included. Previously, we have calculated that $70-80 \%$ of all subfertile women who start a fertility work-up will not undergo tubal testing, because of spontaneous pregnancies, immediate referral for IVF or drop out (Fiddelers et al., 2005). The risk of tubal pathology will therefore be over-estimated in our study. Finally, we are aware that nowadays other methods for evaluating tubal function [such as hysterosalpingo (contrast) sonography and transvaginal hydrolaparoscopy] are used, but we have limited our study to HSG and laparoscopy because these wellevaluated tests are performed on a routine-basis in most clinics.

\section{Omitting HSG?}

It may be questioned whether HSG should still be performed in the fertility investigation, as our results indicate that HSG has limited value in the risk assessment of tubal pathology and is relatively contra-indicated in CAT-positive women. Although HSG may provide additional information on uterine malformations and intracavitary pathology, their prevalence is low (in our study $2.4 \%$ and $2.1 \%$, respectively, which is comparable to prevalences found in the literature) (Varasteh et al., 1999, Grimbizis et al., 2001). The majority of these abnormalities can also be diagnosed by ultrasonography (which in most clinics is performed routinely in all subfertile patients), their presumed effect on fertility is debatable, and the effectiveness of treatment of uterine abnormalities on improving pregnancy rates has not been established (NICE, 2004). However, HSG also has advantages; therefore, omitting 
HSG in CAT-negative women deserves careful consideration. The first advantage of HSG is that it has a high specificity (Swart et al., 1995), i.e. HSG is accurate in confirming the absence of tubal pathology. Furthermore, tubal flushing using oil-soluble contrast medium has a positive effect on pregnancy rates (Luttjeboer et al., 2007). As a consequence, omitting HSG using oil-soluble contrast medium may result in lower pregnancy rates. So far, this positive effect on pregnancy rates has not been found when water-soluble contrast medium was used (Perquin et al., 2006). On the basis of these considerations, the role of HSG in the fertility evaluation of low-risk patients (i.e. CAT-negative women) deserves critical reappraisal. In CAT-positive high-risk patients, HSG should be omitted because of the $10 \%$ risk of post-HSG complications in the absence of additional value in risk assessment of tubal pathology.

\section{Omitting laparoscopy?}

Although laparoscopy is the reference standard in diagnosing tubal pathology, it may be questioned whether it should be performed routinely in all patients. Laparoscopy is still considered a useful test in women with known co-morbidities which may have compromised tubal function, such as a history of pelvic inflammatory disease (NICE, 2004). In patients with an uneventful medical history, it has been suggested that laparoscopy can be omitted after a normal HSG (Fatum et al., 2002, Lavy et al., 2004), although prevalence figures for tubal pathology of 20-25\% have been reported in women with normal HSGs (Henig et al., 1991, Tanahatoe et al., 2003). In our study, the prevalence of tubal pathology in CAT-negative women ranged from 10 to $22 \%$ in patients with a normal HSG and from 12 to $25 \%$ in patients with an inconclusive HSG. Omitting laparoscopy in patients with a very low (or very high) risk of tubal pathology, based on the results of screening tests, implicates that potential other causes of subfertility, such as endometriosis, remain undiagnosed and hence untreated. In our study, half of all patients undergoing laparoscopy had endometriosis, but this was limited to Stages I and II disease in over $90 \%$ of them. It is subject of discussion whether Stages I and II endometriosis reduce fertility and should therefore be treated. A meta-analysis of two randomized controlled trials showed that subfertile women with Stages I and II endometriosis benefit at least temporarily from laparoscopic surgery (Jacobson et al., 2002, Kennedy et al., 2005), although the number needed to treat is 24 (i.e. 24 subfertile women need to undergo laparoscopy in order to identify and treat 12 women with Stages I and II endometriosis and to achieve one additional pregnancy) (ESHRE Capri Workshop Group, 2004). The decision whether to perform a laparoscopy in patients with an uneventful medical history and normal pelvic examination therefore depends on how certain one wishes to be in finding fertility-impairing factors, and on the value attributed to treating Stages I and II endometriosis. Furthermore, it remains difficult 
to establish the precise position and timing of laparoscopy in subfertile women due to a lack of randomized controlled studies (Bosteels et al., 2007).

Practically, in couples with an otherwise unexplained subfertility, a negative CAT and a normal or inconclusive HSG, laparoscopy may be substituted by several cycles of combined gonadotrophins and intrauterine insemination, and subsequently IVF in those who failed to achieve a pregnancy (Fatum et al., 2002). This strategy limits the number of unnecessary laparoscopies and does not introduce a large delay in treatment in the small proportion of women who would have been diagnosed with tubal pathology at laparoscopy, especially now that IVF is rapidly replacing reconstructive microsurgery as the treatment of choice in these patients. On the basis of our data, the clinical consequences of omitting laparoscopy in these low-risk patients seem limited, because after appropriate screening, little residual unexpected (and treatable) pathology is found. In CAT-positive women, laparoscopy remains justified in order to prevent unnecessary delay before going for IVF in those with abnormal findings and in order to prevent going for IVF prematurely in those in whom less demanding treatment options might still offer acceptable pregnancy chances. Furthermore, the subgroup of women with bilateral tubal occlusion at HSG also clearly benefits from laparoscopy with tubal testing, because laparoscopy shows not more than unilateral tubal pathology in the majority of these women (Mol et al., 1999, Bosteels et al., 2007), as was confirmed in our study. In this subgroup, immediate IVF can thus be avoided in the majority of women by excluding bilateral tubal occlusion at laparoscopy.

\section{SUMMARY AND CONCLUSION}

We evaluated three screening strategies, comprising serological testing (CAT and hsCRP) and HSG, for assessing the risk of tubal pathology [i.e. reduced or (nearly) absent spontaneous pregnancy chances] in a population of subfertile women. Laparoscopy was used as a reference standard for detecting tubal pathology, and the occurrence of a spontaneous pregnancy was used as a surrogate marker for the absence of tubal pathology. Despite several limitations of the study, the results of the present study may be used to optimize the risk assessment for tubal factor subfertility. CAT is the most valuable test to screen for tubal pathology, because it accurately discerns low-risk patients (negative CAT) from high-risk patients (positive CAT). Based on biological grounds, hs-CRP may be applied in CAT-positive patients only. To assess the additional role of hs-CRP more accurately, further studies are needed. HSG has little additional value in estimating the risk of tubal pathology in low-risk and high-risk patients. In low-risk patients, HSG may be performed to confirm the absence of tubal pathology and to allow the patient to benefit from the positive perturbation effect of tubal flushing with oil-soluble contrast medium on pregnancy 
rates. In high-risk patients, HSG is relatively contra-indicated owing to the $10 \%$ risk of post-HSG febrile and infectious morbidity in patients in whom tubal pathology is confirmed. In these high-risk patients and in women with bilateral tubal occlusion at HSG, laparoscopy is justified to provide a definite diagnosis. The role of laparoscopy in low-risk patients deserves critical reconsideration. The disadvantage of omitting laparoscopy would be that non-C. trachomatis-associated tubal pathology such as endometriosis (which was present in half of the women in our study population undergoing laparoscopy) remains undiagnosed and untreated. However, at least $90 \%$ of women with endometriosis at laparoscopy were classified as having Stages I or stage II disease, of which the lasting benefit of treatment is still a matter of debate. The consequences of omitting laparoscopy in these women may be of limited clinical significance, especially since eventually all those failing to conceive will be referred for IVF.

On the basis of the findings of the present observational study, we propose CAT as the first screening test for tubal pathology in subfertile women. In CAT-negative women, HSG may be performed because of its high specificity and, when using oilsoluble contrast medium, its fertility-enhancing effect. In CAT-positive women, hsCRP is promising, although more studies are needed to further corroborate the value of hs-CRP in this respect. HSG has no additional diagnostic value and is relatively contra-indicated in CAT-positive women. The precise position and timing of laparoscopy deserves critical reappraisal and depends on the risk of tubal pathology, as assessed by screening tests. In CAT-negative patients and in patients with normal or inconclusive HSGs, laparoscopy may be omitted. In CAT-positive women and in women with abnormal HSGs, laparoscopy remains justified. 


\section{REFERENCES}

Altman DG, Bland JM (2007) Missing data. BMJ 334, 424.

Balasch J (2000) Investigation of the infertile couple: Investigation of the infertile couple in the era of assisted reproductive technology: a time for reappraisal. Hum Reprod 15, 2251-2257.

Bosteels J, Van Herendael B, Weyers S, D'Hooghe T (2007) The position of diagnostic laparoscopy in current fertility practice. Hum Reprod Update 13, 477-485.

Chapron C, Querleu D, Bruhat MA, Madelenat P, Fernandez H, Pierre F, Dubuisson JB (1998) Surgical complications of diagnostic and operative gynaecological laparoscopy: a series of 29966 cases. Hum Reprod 13, 867-872.

Coppus SFPJ, Opmeer BC, Logan S, Van der Veen F, Bhattacharya S, Mol BWJ (2007) The predictive value of medical history taking and Chlamydia IgG ELISA antibody testing (CAT) in the selection of subfertile women for diagnostic laparoscopy: a clinical prediction model approach. Hum Reprod 22, 13531358.

Dabekausen YA, Evers JLH, Land JA, Stals FS (1994) Chlamydia trachomatis antibody testing is more accurate than hysterosalpingography in predicting tubal factor infertility. Fertil Steril 61, 833-837.

Den Hartog JE, Land JA, Stassen FRM, Kessels AGH, Bruggeman CA (2005) Serological markers of persistent $C$. trachomatis infections in women with tubal factor subfertility. Hum Reprod 20, 986-990.

Den Hartog JE, Morré SA, Land JA (2006) Chlamydia trachomatis-associated tubal factor subfertility: Immunogenetic aspects and serological screening. Hum Reprod Update 12, 719-730.

ESHRE Capri Workshop Group (2004) Diagnosis and management of the infertile couple: Missing information. Hum Reprod Update 10, 295-307.

Fatum M, Laufer N, Simon A (2002) Investigation of the infertile couple: Should laparoscopy be performed after normal hysterosalpingography in treating infertility suspected to be of unknown origin? Hum Reprod 17, 1-3.

Fiddelers AAA, Land JA, Voss G, Kessels AGH, Severens JL (2005) Cost-effectiveness of Chlamydia antibody tests in subfertile women. Hum Reprod 20, 425-432.

Forsey JP, Caul EO, Paul ID, Hull MGR (1990) Chlamydia trachomatis, tubal disease and the incidence of symptomatic and asymptomatic infection following hysterosalpingography. Hum Reprod 5, 444-447.

Glasziou P, Hilden J (1986) Decision tables and logic in decision analysis. Med Decis Making 6, 154-160.

Grayston JT, Wang SP, Yeh LJ, Kuo CC (1985) Importance of reinfection in the pathogenesis of trachoma. Rev Infect Dis 7, 717-725.

Grimbizis GF, Camus M, Tarlatzis BC, Bontis JN, Devroey P (2001) Clinical implications of uterine malformations and hysteroscopic treatment results. Hum Reprod Update 7, 161-174.

Helmerhorst FM, Oei SG, Bloemenkamp KWM, Keirse MJNC (1995) Consistency and variation in fertility investigations in Europe. Hum Reprod 10, 2027-2030.

Henig I, Prough SG, Cheatwood M, DeLong E (1991) Hysterosalpingography, laparoscopy and hysteroscopy in infertility. A comparative study. J Reprod Med 36, 573-575.

Horton NJ, Kleinman KP (2007) Much ado about nothing: A comparison of missing data methods and software to fit incomplete data regression models. Am Stat 61, 79-90.

Jacobson TZ, Barlow DH, Koninckx PR, Olive D, Farquhar C (2002) Laparoscopic surgery for subfertility associated with endometriosis. Cochrane Database Syst Rev Issue 4: CD001398.

Kennedy S, Bergqvist A, Chapron C, D’Hooghe T, Dunselman G, Greb R, Hummelshoj L, Prentice A, Saridogan $E$ on behalf of the ESHRE Special Interest Group for Endometriosis and Endometrium Guideline Development Group (2005) ESHRE guideline for the diagnosis and treatment of endometriosis. Hum Reprod 20, 2698-2704.

Land JA, Gijsen AP, Kessels AGH, Slobbe MEP, Bruggeman CA (2003) Performance of five serological chlamydia antibody tests in subfertile women. Hum Reprod 18, 2621-2627. 
Lavy Y, Lev-Sagie A, Holtzer H, Revel A, Hurwitz A (2004) Should laparoscopy be a mandatory component of the infertility evaluation in infertile women with normal hysterosalpingogram or suspected unilateral distal tubal pathology? Eur J Obstet Gynecol Reprod Biol 114, 64-68.

Luttjeboer F, Harada T, Hughes E, Johnson N, Lilford R, Mol BWJ (2007) Tubal flushing for subfertility. Cochrane Database Syst Rev Issue 3: CD003718.

Mol BWJ, Dijkman B, Wertheim P, Lijmer J, Van der Veen F, Bossuyt PMM (1997) The accuracy of serum chlamydial antibodies in the diagnosis of tubal pathology: a meta-analysis. Fertil Steril 67, 10311037.

Mol BWJ, Collins JA, Burrows EA, Van der Veen F, Bossuyt PMM (1999) Comparison of hysterosalpingography and laparoscopy in predicting fertility outcome. Hum Reprod 14, 1237-1242.

Mol BWJ, Collins JA, Van der Veen F, Bossuyt PMM (2001) Cost-effectiveness of hysterosalpingography, laparoscopy, and Chlamydia antibody testing in subfertile couples. Fertil Steril 75, 571-580.

National Institute for Clinical Excellence (2004) Fertility: assessment and treatment for people with fertility problems. http://www.nice.org.uk.

Patton DL, Cosgrove Sweeney YT, Kuo CC (1994) Demonstration of delayed hypersensitivity in Chlamydia trachomatis salpingitis in monkeys: a pathogenic mechanism of tubal damage. J Infect Dis 169, 680683.

Perquin DAM, Dörr PJ, De Craen AJM, Helmerhorst FM (2006) Routine use of hysterosalpingography prior to laparoscopy in the fertility workup: a multicentre randomized controlled trial. Hum Reprod 21, 1227-1231.

Perquin DAM, Beersma MFC, De Craen AJM, Helmerhorst FM (2007) The value of Chlamydia trachomatisspecific IgG antibody testing and hysterosalpingography for predicting tubal pathology and occurrence of pregnancy. Fertil Steril 88, 224-226.

Portuondo JA, Pena Irala J, Ibanez E, Echanojauregui AD (1984) Clinical selection of infertile patients for laparoscopy. Int J Fertil 29, 234-238.

Punnonen R, Terho P, Nikkanen V, Meurman O (1979) Chlamydial serology in infertile women by immunofluorescence. Fertil Steril 31, 656-659.

Rutherford AJ, Jenkins JM (2002) Hull and Rutherford classification of infertility. Hum Fertil 5 (Suppl), S41S45.

Swart P, Mol BWJ, Van der Veen F, Van Beurden M, Redekop WK, Bossuyt PMM (1995) The accuracy of hysterosalpingography in the diagnosis of tubal pathology: a meta-analysis. Fertil Steril 64, 486-491.

Tanahatoe S, Hompes PGA, Lambalk CB (2003) Accuracy of diagnostic laparoscopy in the infertility workup before intrauterine insemination. Fertil Steril 79, 361-366.

The American Society for Reproductive Medicine (1997) Revised American Society for Reproductive Medicine classification of endometriosis: 1996. Fertil Steril 67, 817-821.

Van Buuren S, Boshuizen HC, Knook DL (1999) Multiple imputation of missing blood pressure covariates in survival analysis. Stat Med 18, 681-694.

Varasteh NN, Neuwirth RS, Levin B, Keltz MD (1999) Pregnancy rates after hysteroscopic polypectomy and myomectomy in infertile women. Obstet Gynecol 94, 168-171.

Veenemans LMW, Van der Linden PJQ (2002) The value of Chlamydia trachomatis antibody testing in predicting tubal factor infertility. Hum Reprod 17, 695-698. 


\section{Chapter 5}

\section{Toll-like receptor 4 in Chlamydia trachomatis} infections: knockout mice, STD patients and women with tubal factor subfertility

JE den Hartog, JM Lyons, S Ouburg, JSA Fennema, HJC de Vries, CA Bruggeman, JI Ito, AS Peña, JA Land, SA Morré

Drugs of Today 2009, 45 (Suppl B): 75-82 


\begin{abstract}
Chlamydia $(C$.$) trachomatis is the most prevalent sexually transmitted bacterium in$ the world with almost 100 million new cases each year, some of which will develop tubal pathology. Clear differences in the clinical course of infections have been observed, and recently it has been shown that $40 \%$ is based on host genetic factors. We used an integrated approach based on infection of toll-like receptor (TLR) 4 knockout mice and immunogenetic analysis of female sexually transmitted disease (STD) patients (susceptibility) and women with $C$. trachomatis-associated tubal factor subfertility (severity). The results in TLR4 knockout mice suggest that the protection against reinfection is more solid in normal as compared to the TLR4deficient mice. In humans, the functional TLR4 single nucleotide polymorphism (SNP) studied was not involved in the susceptibility to infection. However, C. trachomatis immunoglobulin (Ig) G-positive subfertile women with tubal pathology were more than twice as likely to be carriers of the mutant TLR4 $+896 \mathrm{G}$ allele as compared to those without tubal pathology; however, this observation did not reach statistical significance. In conclusion, both the murine model and the human immunogenetics studies show a slight effect upon TLR4 deficiency in the severity of infection but not in the susceptibility to infection.
\end{abstract}




\section{INTRODUCTION}

Although Chlamydia (C.) trachomatis infection is a predominant cause of tubal pathology in subfertile women (Anestad et al., 1997), not all women develop this complication following infection. The susceptibility, course and outcome of infectious diseases are determined by environmental factors (e.g. co-infection), bacterial factors (e.g. virulence) and host factors (e.g. immunogenetic differences between individuals).

C. trachomatis bacterial factors have been studied in relation to the clinical course of infection, such as symptomatic versus asymptomatic infection, lower versus upper genital tract infection, and clearance versus persistence. In previous studies, no strong associations were found between the different serovars of $C$. trachomatis and the clinical course (Ito et al., 1990, Persson et al., 1993, Dean et al., 1995, Lampe et al., 1995, Stothard et al., 1998, Dean et al., 2000, Morré et al., 2000, Geisler et al., 2003, Molano et al., 2005). Host immune factors are considered more important determinants of the interpatient variability in the susceptibility, course and outcome of infectious diseases in general (Jeremias et al., 1999, Smirnova et al., 2003, Franchimont et al., 2004, Peeters et al., 2004, Frodsham, 2005, Puthothu et al., 2006), and C. trachomatis infections in particular (Kinnunen et al., 2002). Recently, pattern recognition receptors (PRRs) of the toll-like receptor (TLR) family have been shown to be essential components of the host innate immune system, by playing a role in the recognition of pathogens and initiation of the immune response. TLR4 recognizes chlamydial lipopolysaccharide (LPS) via its co-receptor cluster of differentiation (CD) 14 (Poltorak et al., 1998, Ohashi et al., 2000). CD14 exists in a membrane-bound type (mCD14) and a soluble type (sCD14). Both mCD14 and $\mathrm{SCD} 14$ are able to form a complex with LPS and the LPS-binding protein (LBP). Combined with TLR4, this complex induces the nuclear factor kappa B (NF-KB) signal transduction cascade. Its end product NF-KB initiates the innate immune response by binding to specific DNA sequences in the nucleus, thereby enhancing the production of proinflammatory cytokines and acute phase proteins.

To investigate the role of specific genes and the proteins they encode, such as PRRs, in the susceptibility, course and outcome of diseases, different strategies can be employed. Two well-defined methods are the knockout (KO) mouse model and the human candidate gene approach.

The KO mouse model offers the opportunity to remove entire genes of interest from the genome, in order to compare the course and outcome (e.g. duration, amount of shedding and upper genital tract progression) of $C$. trachomatis infection and reinfection between KO mice and control mice, which possess the gene of interest. Previously, we developed a murine model using a human genital isolate of $C$. trachomatis in interferon (IFN)- $\gamma$ and IFN- $\gamma$ receptor KO mice, in which we were able 
to demonstrate a major role of IFN- $\gamma$ in controlling $C$. trachomatis infection (Ito and Lyons, 1999).

The human candidate gene approach, which is based on determining the frequencies of functional single nucleotide polymorphisms (SNPs) within phenotypically defined groups, can be used to investigate the relevance of genes in the susceptibility, course and outcome of diseases. SNPs in genes encoding for PRRs may influence receptor function, thereby leading to an aberrant immune response and an increased risk of adverse outcome of the disease. The TLR4 +896 A>G SNP has been associated with hyporesponsiveness to LPS (Arbour et al. 2000). In a previous study, we did not observe an association between the TLR4 +897 A>G SNP and tubal factor subfertility, but the cohort was relatively small (Morré et al., 2003).

For the present study, the first objective was to assess the role of TLR4 in C3H/HeJ (TLR4 deficient) and $\mathrm{C} 3 \mathrm{H} / \mathrm{HeN}$ (TLR4 functional) mice. Secondly, we enlarged the cohort of subfertile women that was previously described (Morré et al., 2003) and added a cohort of patients visiting a sexually transmitted diseases (STD) clinic with and without $C$. trachomatis infections to investigate the role of the TLR4 +896 A>G SNP in the susceptibility to $C$. trachomatis infections and in the development of $C$. trachomatis-associated tubal factor subfertility.

\section{MATERIALS AND METHODS}

\section{Murine model}

Mice

Seven-week-old female $\mathrm{C} 3 \mathrm{H} / \mathrm{HeJ}$ (TLR4 deficient) and $\mathrm{C} 3 \mathrm{H} / \mathrm{HeN}$ (TLR4 functional) mice were purchased from Jackson Laboratories (USA) and allowed to acclimate for 2 weeks prior to use. Mice were maintained in accordance with American Association of Accreditation of Laboratory Animal Care guidelines, and were provided food and water ad libitum in an environmentally controlled BL-2 containment room with a 12-hour light/dark cycle.

\section{C. trachomatis}

A type pure and Mycoplasma free strain of $C$. trachomatis serovar D was propagated, titrated and isolated in cycloheximide-treated McCoy cell monolayers using standard techniques. Density gradient concentrated stock cultures were suspended in transport media and frozen at $-70^{\circ} \mathrm{C}$ until used.

\section{Genital tract infection}

In order to induce prolonged diestrous state and thus enhance the infection rate, progesterone in the form of medroxyprogesterone acetate (Depo-Provera ${ }^{\circledR}$, Phar- 
macia \& Upjohn Co., USA) was administered subcutaneously in $2.5 \mathrm{mg}$ doses, 10 and 3 days prior to infection. The mice were inoculated intravaginally with $10 \mu \mathrm{L}$ of a $C$. trachomatis elementary body suspension containing $1 \times 10^{5}$ inclusion forming units. Control mice for the re-infection arm of the experiment received $10 \mu \mathrm{L}$ of sterile transport media and were treated in every way similar to infected mice. All mice were progesterone-treated and infected with $C$. trachomatis in a similar manner 8 weeks later. All procedures were performed under protocols approved by the City of Hope National Medical Center and Beckman Research Institute Research Animal Care Committee.

\section{Assessment of infection}

The presence of $C$. trachomatis in the lower genital tract was determined by culturing material obtained by swabbing the vaginal vault and ectocervix every $2-7$ days with a Dacron tipped urethral swab that was stored in transport media at $-70^{\circ} \mathrm{C}$ until tested. Specimens were plated onto McCoy cell monolayers in duplicate 96well plates, centrifuged and incubated at $37^{\circ} \mathrm{C}$ for $72 \mathrm{~h}$. One plate was fixed, stained with iodine and enumerated for iodine straining inclusions, while the other plate was stored at $-70^{\circ} \mathrm{C}$ and used to verify the status of primary culture negative specimens. An animal was considered productively infected if culture was positive on at least 1 day post-infection, and a specimen was considered positive if inclusions were observed in either the primary or secondary cultures. At the end of the experiment, all mice were visually examined for hydrosalpinx or other gross upper genital tract pathology.

\section{Human study population}

\section{STD cohort}

Women of Dutch Caucasian origin ( $n=614$ ), under the age of 33 (range 14-33 years), visiting the STD outpatient clinic in Amsterdam, the Netherlands, in the period of July 2001 to December 2004 participated in this cohort. Participants were asked to sign an informed consent form and fill out a questionnaire regarding their complaints at that moment, varying from increased discharge, having bloody discharge during and/or after intercourse, recent abdominal pain (not gastrointestinal or menses related) and/or dysuria. A cervical swab was taken for the detection of $C$. trachomatis DNA by polymerase chain reaction (PCR) (Van Doornum et al., 2001). Peripheral venous blood was collected for the analysis of IgG antibodies against $C$. trachomatis. A titer of $\geq 1: 50$ was considered positive. Samples with grey-zone values, e.g. cut-off $\pm 10 \%$, were repeated and considered positive when the result was positive, or again within the grey zone. 


\section{Subfertile women}

The human study was performed in women who visited the Maastricht University Medical Centre between December 1990 and November 2000 because of subfertility. In all patients, blood was drawn at their initial visit for a $C$. trachomatis immunoglobulin (Ig) G antibody test (CAT). All spare sera were cryopreserved. Only patients who had undergone a laparoscopy and tubal testing as part of their fertility work-up were included in the present study. Since the prevalence of SNPs may depend on ethnic background, only Dutch Caucasian women were included. Patients who had undergone previous pelvic surgery (except for an uneventful appendectomy or Caesarean section) were excluded.

Two independent investigators, who were unaware of the CAT results, scored 259 successive laparoscopy reports to assess the presence of tubal pathology. Tubal pathology was defined as extensive peri-adnexal adhesions and/or distal occlusion of at least one tube (Land et al., 1998). In case of disagreement, consensus was reached by consultation. Of the 259 women who underwent a laparoscopy, only women who had tubal pathology (according to the above mentioned definition) or had no tubal pathology (no peri-adnexal adhesions and patent tubes) were included in the present study. Women who had minor or non- $C$. trachomatis-related abnormalities (any peri-adnexal adhesions and/or proximal occlusion of at least one tube) were excluded.

In the Netherlands, for retrospective analysis of anonymized patient data and stored sera, no ethical committee approval is required. In the fertility clinic of the Maastricht University Medical Centre, all couples are informed at intake about possible use of their anonymized data and stored sera for research purposes, and a "no objection procedure" is followed. Only patients who did not object participated in the present study.

\section{C. trachomatis IgG antibody testing}

IgG antibodies to $C$. trachomatis were detected using the species-specific Chlamydia pneumoniae IgG micro-immunofluorescence (MIF) test (AniLabsystems, Finland), as described previously (Den Hartog et al., 2004). This species-specific test is able to detect IgG antibodies to both $C$. pneumoniae and $C$. trachomatis (using an antigen derived from a $C$. trachomatis lymphogranuloma venereum [LGV] strain, serovar L2). We previously studied the test performances of five commercially available $C$. trachomatis IgG tests, including the $C$. trachomatis IgG spot in the $C$. pneumoniae MIF (AniLabsystems, Finland) (Land et al., 2003). In our hands, the C. trachomatis IgG titer obtained by the $C$. pneumoniae MIF (AniLabsystems, Finland) had the best predictive value for tubal factor subfertility (Land et al., 2003). Therefore, we used this test in the present study. The cut-off titer used for a positive test was 32 . 


\section{Immunogenetic analysis}

For the immunogenetic analyses, genomic DNA was extracted from the cryopreserved serum samples using either the MagNaPure LC isolator according to the manufacturer's instructions (Roche Molecular Biochemicals, Germany) or the High Pure PCR Template Preparation Kit according to the manufacturer's instructions (Roche Molecular Biochemicals, Germany). Both techniques provide enough DNA for reproducible genetic analyses.

\section{TLR4 +896 A>G gene polymorphism}

Genotyping of the TLR4 +896 A $>$ G SNP (rs4986790) was performed with forward primer 5'-TTT ACC CTT TCA ATA GTC ACA CTC A-3' and reverse primer 5'-AGC ATA CTT AGA CTA CCT CCA TG-3'. PCR for restriction fragment length polymorphism (RFLP) analyses was performed on a thermal cycler GeneAmp 9700 (Perkin-Elmer Cetus, USA). PCR conditions were as follows: initial denaturation at $94^{\circ} \mathrm{C}$ for $5 \mathrm{~min}$, followed by 35 cycles of denaturation at $94^{\circ} \mathrm{C}$ for $30 \mathrm{~s}$, annealing at $55^{\circ} \mathrm{C}$ for $30 \mathrm{~s}$ and extension at $72^{\circ} \mathrm{C}$ for $30 \mathrm{~s}$. The cycling was followed by a final extension step at $72^{\circ} \mathrm{C}$ for $5 \mathrm{~min}$, followed by cooling to $4^{\circ} \mathrm{C}$. The 102 base pairs (bp) amplicons were digested overnight at $37^{\circ} \mathrm{C}$ with $\mathrm{Ncol}$ (New England Biolabs, UK) resulting in amplicons that either were cut in two fragments of $80 \mathrm{bp}$ and $22 \mathrm{bp}$ ( $\mathrm{G}$ allele) or were not restricted ( $A$ allele). These fragments were analyzed by electrophoresis on $4 \%$ low melting agarose gels (Tebu-Bio, the Netherlands) stained with ethidium bromide.

\section{Control group for background genotyping}

For ethnic-matched background genotyping, genomic DNA was extracted from whole blood of 166 healthy Dutch Caucasian employees of the VU University Medical Center. They gave written informed consent for use of their anonymized sera to serve as control sera for genetic research purposes.

\section{Statistical analyses}

The genotype distribution was tested for Hardy-Weinberg equilibrium to assess Mendelian inheritance. Fisher's exact or chi-square tests were used to compare the genotypes between $C$. trachomatis IgG-positive and IgG-negative subfertile women with and without tubal pathology and the healthy control group. $P<0.05$ was considered statistically significant. 


\section{RESULTS}

\section{Murine model}

The median duration of infection between the previously non-infected control groups of each strain were similar (Table I). This was similar to what was observed during the initial infection arm of the experiment. In the first week, the amount of $C$. trachomatis shedding in the control groups was slightly higher in the wild-type mice as compared to the TLR4-deficient mice. Upon re-infection, a significant level of protection was observed in both mouse strains when compared to the initial infection in the appropriate age- and conditions-matched control group: $\mathrm{C} 3 \mathrm{H} / \mathrm{HeJ}$ (TLR4 deficient), 31.5 vs. 7 days; and $\mathrm{C} 3 \mathrm{H} / \mathrm{HeN}$ (wild-type), 26 days vs. 4 days. Remarkably, none of the wild-type mice was infected 4 days after re-infection, while $75 \%$ of the TLR4-deficient mice were still $C$. trachomatis positive after 1 week, and one mouse even during the complete follow-up period of 2 weeks.

Table I: Duration of genital tract infection and culture results in C3H/HeJ (TLR4 deficient) and C3H/HeN (TLR4 functional) mice following $C$. trachomatis infection or mock-infection (at $\mathrm{t}=0$ ) and $\mathrm{C}$. trachomatis infection (at $\mathrm{t}=56$ ).

\begin{tabular}{|c|c|c|c|c|c|c|c|c|c|c|c|c|}
\hline & Time & $t=0$ & & & $t=56$ & & & $t=58$ & $t=60$ & $t=63$ & $t=66$ & $t=70$ \\
\hline & Mouse & Infection & $\begin{array}{l}\text { Infection } \\
\text { duration }\end{array}$ & $\begin{array}{l}\text { Median } \\
\text { duration }\end{array}$ & Infection & $\begin{array}{l}\text { Infection } \\
\text { duration }\end{array}$ & $\begin{array}{l}\text { Median } \\
\text { duration }\end{array}$ & Cult & ture result & ts on indic & cated day & (IFU) \\
\hline \multirow{8}{*}{$\begin{array}{l}\mathrm{C} 3 \mathrm{H} / \mathrm{HeJ} \\
\text { ( } T L R 4 \\
\text { deficient) }\end{array}$} & $\mathrm{C} 1$ & CT & 28 & \multirow{4}{*}{26} & CT & 7 & \multirow{4}{*}{7} & 6,300 & 1,850 & 360 & 0 & 0 \\
\hline & $\mathrm{C} 2$ & CT & 24 & & CT & 7 & & 26,870 & 1,190 & 400 & 0 & 0 \\
\hline & $\mathrm{C} 3$ & CT & 35 & & CT & 4 & & 17,580 & 10 & 0 & 0 & 0 \\
\hline & $\mathrm{C} 4$ & CT & 24 & & CT & 21 & & 3,180 & 150 & 680 & 660 & 250 \\
\hline & $\mathrm{J} 1$ & Mock & - & & CT & 28 & \multirow{4}{*}{31.5} & 33,900 & 5,370 & 12,900 & 1,680 & 1,390 \\
\hline & $\mathrm{J} 2$ & Mock & - & & CT & 14 & & 13,000 & 8,900 & 4,220 & 70 & 280 \\
\hline & $\mathrm{J} 5$ & Mock & - & & CT & 35 & & 28,810 & 14,040 & 21,150 & 8,200 & 2,950 \\
\hline & J6 & Mock & - & & CT & 42 & & 24,230 & 5,600 & 23,400 & 4,160 & 1,670 \\
\hline \multirow{8}{*}{$\begin{array}{l}\mathrm{C} 3 \mathrm{H} / \mathrm{HeN} \\
\text { (TLR4 } \\
\text { func- } \\
\text { tional) }\end{array}$} & B1 & CT & 17 & \multirow{4}{*}{28} & CT & 4 & \multirow{4}{*}{4} & 68,120 & 2,770 & 0 & 0 & 0 \\
\hline & B2 & CT & 35 & & CT & 4 & & 35,010 & 20 & 0 & 0 & 0 \\
\hline & B3 & CT & 21 & & CT & 4 & & 6,240 & + & 0 & 0 & 0 \\
\hline & B25 & CT & 35 & & CT & 4 & & 33,450 & 100 & 0 & 0 & 0 \\
\hline & 11 & Mock & - & & CT & 24 & \multirow{4}{*}{26} & 72,800 & 4,970 & 8,720 & 830 & 1,120 \\
\hline & 12 & Mock & - & & CT & 24 & & 23,400 & 13,520 & 10,460 & 120 & 110 \\
\hline & 14 & Mock & - & & CT & 28 & & 18,510 & 30,160 & 48,360 & 2,310 & 290 \\
\hline & 15 & Mock & - & & CT & 35 & & 22,360 & 67,600 & 10,920 & 3,350 & 530 \\
\hline
\end{tabular}

Abbreviations: $\mathrm{CT}=\mathrm{C}$. trachomatis serovar $\mathrm{D} ; \mathrm{IFU}=$ inclusion-forming units; mock = infection with sterile transport media; $T L R 4=$ toll-like receptor 4 . 
However, and although small, there is a suggestion that the protection was more solid in $\mathrm{C} 3 \mathrm{H} / \mathrm{HeN}$ (TLR4 wildtype) compared to $\mathrm{C} 3 \mathrm{H} / \mathrm{HeJ}$ (TLR4 deficient) mice. Finally, at the conclusion of the experiment there was no hydrosalpinx or other gross upper tract pathology observed in any mice of either strain.

\section{Human candidate gene approach}

Of the 259 women who underwent laparoscopy, 227 participated in the present study. Of these, 43 (19\%) had tubal pathology and 184 (81\%) did not. Thirty-two women had minor or non-C. trachomatis-related abnormalities and were excluded. C. trachomatis IgG antibodies were present in 39 women, of whom 26 (67\%) had tubal pathology and 13 (33\%) did not have tubal pathology. C. trachomatis IgG antibodies were absent in 188 women, of whom 17 (9\%) had tubal pathology and 171 (91\%) did not have tubal pathology.

\section{Susceptibility of infection}

The genotype distribution for the STD cohort in shown in Table II and was in HardyWeinberg equilibrium showing Mendelian inheritance. The women who were positive versus those who were negative for $C$. trachomatis DNA had an equal genotype distribution, as did the more extreme subgroups of $C$. trachomatis DNA-positive and C. trachomatis serology-positive women versus the $C$. trachomatis DNA-negative and C. trachomatis serology-negative women (Table II).

Table II. TLR4 genotype distribution in female STD patients.

\begin{tabular}{|c|c|c|c|c|c|c|c|}
\hline \multirow[t]{2}{*}{$T L R 4+896 \mathrm{~A}>\mathrm{G}$} & \multirow[t]{2}{*}{$n$} & \multicolumn{2}{|c|}{1.1 (AA) } & \multicolumn{2}{|c|}{$1.2(\mathrm{AG})$} & \multicolumn{2}{|c|}{$2.2(\mathrm{GG})$} \\
\hline & & $\mathrm{n}$ & $\%$ & $\mathrm{n}$ & $\%$ & $\mathrm{n}$ & $\%$ \\
\hline Total STD patients & 614 & 530 & 86.3 & 83 & 13.5 & 1 & 0.2 \\
\hline DNA+ & 193 & 169 & 87.6 & 24 & 12.4 & 0 & 0.0 \\
\hline DNA+, IgG+ & 140 & 121 & 86.4 & 19 & 13.6 & 0 & 0.0 \\
\hline DNA- & 421 & 361 & 85.7 & 59 & 14.0 & 1 & 0.2 \\
\hline DNA-, IgG- & 331 & 283 & 85.5 & 47 & 14.2 & 1 & 0.3 \\
\hline
\end{tabular}

Abbreviations: IgG = immunoglobulin G; TLR4 = toll-like receptor 4; STD = sexually transmitted disease.

\section{Severity of infection}

The genotype distribution was in Hardy-Weinberg equilibrium in the subfertile women and the ethnic-matched control group. The overall genotype distribution in the cohort of subfertile women was $88 \%$ AA, 12\% AG and 0\% GG. The genotype distribution in subfertile women with tubal pathology ( $86 \%$ AA, $14 \% A G, 0 \% \mathrm{GG}$ ) did not differ from the distribution in subfertile women without tubal pathology $(89 \%$ 
AA, $11 \%$ AG, $0 \%$ GG). Introduction of $C$. trachomatis IgG serology, with special attention to $C$. trachomatis IgG-positive subfertile women with and without tubal pathology, did alter the observed genotype distribution, and a clear trend (OR 2.9) was noticed towards a higher frequency of $T L R 4+896$ A $>$ G SNP carriage in C. trachomatis IgG-positive subfertile women with tubal pathology $\left(19 \% *^{*}\right)$ as compared to those without tubal pathology $(8 \% * G)$. The results are summarized in Table III.

Table III. TLR4 genotype distribution in women with subfertility.

\begin{tabular}{|c|c|c|c|c|c|c|c|}
\hline \multirow[t]{2}{*}{ TLR4 +896 A>G } & \multirow[t]{2}{*}{$\mathrm{n}$} & \multicolumn{2}{|c|}{1.1 (AA) } & \multicolumn{2}{|c|}{$1.2(\mathrm{AG})$} & \multicolumn{2}{|c|}{$2.2(\mathrm{GG})$} \\
\hline & & $\mathrm{n}$ & $\%$ & $\mathrm{n}$ & $\%$ & $\mathrm{n}$ & $\%$ \\
\hline All subfertile women & 227 & 200 & 88.1 & 27 & 11.9 & 0 & 0.0 \\
\hline $\mathrm{TP}+$ & 43 & 37 & 86.0 & 6 & 14.0 & 0 & 0.0 \\
\hline TP - & 184 & 163 & 88.6 & 21 & 11.4 & 0 & 0.0 \\
\hline $\mathrm{CT}+\mathrm{TP}+$ & 26 & 21 & 80.8 & 5 & 19.2 & 0 & 0.0 \\
\hline$C T+T P-$ & 13 & 12 & 92.3 & 1 & 7.7 & 0 & 0.0 \\
\hline Control group & 166 & 148 & 89.2 & 17 & 10.2 & 1 & 0.6 \\
\hline
\end{tabular}

Abbreviations: $\mathrm{CT}=\mathrm{C}$. trachomatis IgG; TLR4 = toll-like receptor 4; TP = tubal pathology. Control group = ethnic-matched healthy employees of the VU University Medical Center.

\section{DISCUSSION}

The current study used an integrated approach to study the role of TLR4 in the susceptibility to and severity of $C$. trachomatis infection based on both the murine model and human candidate gene approaches in women. The results of the KO mouse model indicate an important level of protection against $C$. trachomatis reinfection, as reflected by a faster clearance, as compared to mice that were infected only once. Our data suggest that the protection is more solid in TLR4 functional mice as compared to the TLR4-deficient mice. C. trachomatis IgG-positive subfertile women with tubal pathology were more than twice as likely to be carriers of the mutant TLR4 $+896 \mathrm{G}$ allele compared to those without tubal pathology. This difference, however, was not statistically significant due to sample size limitations.

Although the TLR4-deficient mice had clear differences in the level of shedding and duration of infection following re-infection, the role was minimal and as anticipated. It has previously been shown that TLR2, but not TLR4, is more essential for recognition of a different chlamydia species (C. pneumoniae) (Prebeck et al., 2001), LPSsignaling (Erridge et al., 2004), and the development of murine tubal pathology (Darville et al., 2003), respectively. Our results are consistent with these findings, indicating that TLR4 does play only a modest role in the recognition of $C$. trachomatis and that signaling through TLR2 may be a more prominent element in the immune response. Indeed Karimi et al. (2009) have recently shown that specific TLR2 
haplotypes were associated with the development of tubal pathology and the severity of infection.

The current lack of a strong association between the TLR4 SNP studied and C. trachomatis-associated tubal factor subfertility may be explained by several other factors besides the suggested prominent role of TLR2, rather than TLR4, in the immune response to $C$. trachomatis. First, Erridge and co-workers (2003) have shown that only the rare homozygous carriers of the TLR4 +897 A $>$ G SNP are less responsive to LPS, whereas heterozygous carriage does not affect LPS responsiveness. Our study cohort consisted of women with a normal TLR4 genotype or heterozygous TLR4 +897 A>G SNP carriers, whereas no patients were homozygous SNP carriers. However, LPS is not the only ligand for TLR4 and both human heat shock protein 60 (hHSP60) and chlamydia HSP60 (cHSP80) are also ligands for TLR4. Secondly, the recognition of $C$. trachomatis involves a complex system of multiple PRRs. Partial or complete loss of receptor function may be compensated by other receptors, preserving an adequate immune response via other pathways. Deregulation of the immune response, leading to a more severe course of $C$. trachomatis infection, may only occur when different pathways are affected concomitantly, i.e. when multiple SNPs in multiple PRR genes (in a so-called carrier trait) are present. This hypothesis has already been tested for several diseases (Smirnova et al., 2003, Hugot et al., 2001, El-Omar et al., 2003, Machado et al., 2003, Heresbach et al., 2004), and a preliminary study has shown promising results for $C$. trachomatis-associated tubal pathology (Den Hartog et al., 2006).

In the current study, the most prominent effect was seen between $C$. trachomatispositive women with and without serologically confirmed $C$. trachomatis infection. We added cHSP60 serology to the assessment (data not shown), since TLR4 also responds to CHSP60, and increased expression of $\mathrm{CHSP60}$ has been reported in infertile women (Jha et al., 2009). Interestingly, all women positive for $C$. trachomatis IgG and cHSP60 IgG, and with the mutant G allele in TLR4, had tubal pathology. This potentially interesting phenomenon will be further explored in larger cohorts, and by adding SNPs in other TLRs and genes involved in the recognition and inflammatory processes upon infection. This is of importance, since not all women with tubal pathology are positive for $C$. trachomatis IgG and CHSP60 IgG and yet have the G allele in TLR4.

\section{CONCLUSIONS}

$T L R 4$ functional mice seem to be more protected against $C$. trachomatis re-infection as compared to the TLR4 deficient mice. In humans, the single TLR4 $+896 \mathrm{~A}>\mathrm{G}$ SNP does not play a major role in susceptibility, as shown in women with uncomplicated C. trachomatis infection. In women with serological responses to $C$. trachomatis and 
carrying the TLR4 SNP, the risk of developing tubal pathology was higher but did not reach statistical significance. Since other receptors may compensate for the loss of function in patients carrying the TLR4 SNP, further studies are necessary to determine if carrying multiple SNPs in multiple PRR genes and having serological responses to cHSP60 has a more profound impact on the development of tubal pathology following $C$. trachomatis infection as compared to the risk associated with carrying a single SNP in a single gene.

\section{Acknowledgements}

The aim of this work is in line with the European EpiGenChlamydia Consortium which is supported by the European Commission within the Sixth Framework Program through contract no. LSHG-CT-2007-037637. See www.EpiGenChlamydia.eu for more details about this Consortium. 


\section{REFERENCES}

Anestad G, Lunde O, Moen M, Dalaker K (1997) Infertility and chlamydial infection. Fertil Steril 48, 787790.

Arbour NC, Lorenz E, Schutte BC, Zabner J, Kline JN, Jones M, Frees K, Watt JL, Schwartz DA (2000) TLR4 mutations are associated with endotoxin hyporesponsiveness in humans. Nat Genet 25, 187-191.

Darville T, O'Neill JM, Andrews CW, Nagarajan UM, StahI L, Ojcius DM (2003) Toll-like receptor-2, but not toll-like receptor-4, is essential for development of oviduct pathology in chlamydial genital tract infection. J Immunol 171, 6187-6197.

Dean D, Oudens E, Bolan G, Padian N, Schachter J (1995) Major outer membrane protein variants of Chlamydia trachomatis are associated with severe upper genital tract infections and histopathology in San Francisco. J Infect Dis 172, 1013-1022.

Dean D, Suchland RJ, Stamm WE (2000) Evidence for long-term cervical persistence of Chlamydia trachomatis by omp1 genotyping. J Infect Dis 182, 909-916.

Den Hartog JE, Land JA, Stassen FRM, Slobbe-Van Drunen MEP, Kessels AGH, Bruggeman CA (2004) The role of chlamydia genus-specific and species-specific IgG antibody testing in predicting tubal disease in subfertile women. Hum Reprod 19, 1380-1384.

Den Hartog JE, Ouburg S, Land JA, Lyons JM, Ito JI, Peña AS, Morré SA (2006) Do host genetic traits in the bacterial sensing system play a role in the development of Chlamydia trachomatis-associated tubal pathology in subfertile women? BMC Infect Dis 6, 122.

El-Omar EM, Rabkin CS, Gammon MD, Vaughan TL, Risch HA, Schoenberg JB, Stanford JL, Mayne ST, Goedert J, Blot WJ et al. (2003) Increased risk of noncardia gastric cancer associated with proinflammatory cytokine gene polymorphisms. Gastroenterology 124, 1193-1201.

Erridge C, Stewart J, Poxton IR (2003) Monocytes heterozygous for the Asp299Gly and Thr399lle mutations in the toll-like receptor 4 gene show no deficit in lipopolysaccharide signalling. J Exp Med 197, 1787-1791.

Erridge C, Pridmore A, Eley A, Stewart J, Poxton IR (2004) Lipopolysaccharides of Bacteroides fragilis, Chlamydia trachomatis and Pseudomonas aeruginosa signal via toll-like receptor 2. J Med Microbiol $53,735-740$.

Franchimont D, Vermeire S, El Housni H, Pierik M, Van Steen K, Gustot T, Quertinmont E, Abramowicz M, Van Gossum A, Devière J et al. (2004) Deficient host-bacteria interactions in inflammatory bowel disease? The toll-like receptor (TLR)-4 Asp299gly polymorphism is associated with Crohn's disease and ulcerative colitis. Gut 53, 987-992.

Frodsham AJ (2005) Host genetics and the outcome of hepatitis B viral infection. Transpl Immunol 14, 183-186.

Geisler WM, Suchland RJ, Whittington WLH, Stamm WE (2003) The relationship of serovar to clinical manifestations of urogenital Chlamydia trachomatis infection. Sex Transm Dis 30, 160-165.

Heresbach D, Gicquel-Douabin V, Birebent B, D'Halluin PN, Heresbach-Le Berre N, Dreano S, Siproudhis L, Dabadie A, Gosselin M, Mosser J et al. (2004) NOD2/CARD15 gene polymorphisms in Crohn's disease: a genotype-phenotype analysis. Eur J Gastroenterol Hepatol 16, 55-62.

Hugot JP, Chamaillard M, Zouali H, Lesage S, Cézard JP, Belaiche J, Almer S, Tysk C, O'Morain CA, Gassull $\mathrm{M}$ et al. (2001) Association of NOD2 leucine-rich repeat variants with susceptibility to Crohn's disease. Nature 411, 599-603.

Ito JI, Lyons JM, Airo-Brown LP (1990) Variation in virulence among oculogenital serovars of Chlamydia trachomatis in experimental genital tract infection. Infect Immun 58, 2021-2023.

Ito JI, Lyons JM (1999) Role of gamma interferon in controlling murine chlamydial genital tract infection. Infect Immun 67, 5518-5521.

Jeremias J, Giraldo P, Durrant S, Ribeiro-Filho A, Witkin SS (1999) Relationship between Ureoplasma urealyticum vaginal colonization and polymorphism in the interleukin-1 receptor antagonist gene. J Infect Dis 180, 912-914. 
Jha R, Vardhan H, Bas S, Salhan S, Mittal A (2009) Cervical epithelial cells from Chlamydia trachomatisinfected sites coexpress higher levels of Chlamydial heat shock proteins 60 and 10 in infertile women than in fertile women. Gynecol Obstet Invest 68, 160-166.

Karimi O, Ouburg S, De Vries HJC, Peňa AS, Pleijster J, Land JA, Morré SA (2009). TLR2 haplotypes in the susceptibility to and severity of Chlamydia trachomatis infections in Dutch women. Drugs Today 45 (Suppl B), 67-74.

Kinnunen AH, Surcel HM, Lehtinen M, Karhukorpi J, Tiitinen A, Jalttunen M, Bloigu A, Morrison RP, Karttunen R, Paavonen J (2002) HLA DQ alleles and interleukin-10 polymorphism associated with Chlamydia trachomatis-related tubal factor infertility: a case-control study. Hum Reprod 17, 2073-2078.

Lampe MF, Wong KG, Stamm WE (1995) Sequence conservation in the major outer membrane protein gene among Chlamydia trachomatis strains isolated from the upper and lower urogenital tract. J Infect Dis 2, 589-592.

Land JA, Evers JLH, Goossens VJ (1998) How to use Chlamydia antibody testing in subfertility patients. Hum Reprod 13, 1094-1098.

Land JA, Gijsen AP, Kessels AGH, Slobbe MEP, Bruggeman CA (2003) Performance of five serological chlamydia antibody tests in subfertile women. Hum Reprod 18, 2621-2627.

Machado JC, Figueiredo C, Canedo P, Pharoah P, Carvalho R, Nabais S, Castro Alves C, Campos ML, Van Doorn LJ, Caldos C et al. (2003) A proinflammatory genetic profile increases the risk for chronic atrophic gastritis and gastric carcinoma. Gastroenterology 125, 364-371.

Molano M, Meijer CJLM, Weiderpass E, Arslan A, Posso H, Franceschi S, Ronderos M, Muňoz N, Van den Brule AJC (2005) The natural course of Chlamydia trachomatis infection in asymptomatic Colombian women: a 5-year follow-up study. J Infect Dis 191, 907-916.

Morré SA, Rozendaal L, Van Valkengoed IGM, Boeke AJP, Van Voorst Vader PC, Schirm J, De Blok S, Van den Hoek JAR, Van Doornum GJ, Meijer CJLM et al. (2000) Urogenital Chlamydia trachomatis serovars in men and women with a symptomatic or asymptomatic infection: an association with clinical manifestations? J Clin Microbiol 38, 2292-2296.

Morré SA, Murillo LS, Bruggeman CA, Peña AS (2003) The role that the functional Asp299Gly polymorphism in the toll-like receptor-4 gene plays in the susceptibility to Chlamydia trachomatis-associated tubal infertility. J Infect Dis 187, 341-342.

Ohashi K, Burkart V, Flohé S, Kolb H (2000) Cutting edge: Heat shock protein 60 is a putative endogenous ligand of the toll-like receptor-4 complex. J Immunol 164, 558-561.

Peeters H, Vander Cruyssen B, Laukens D, Coucke P, Marichal D, Van Den Berghe M, Cuvelier C, Remaut E, Mielants H, De Keyser F et al. (2004) Radiological sacroiliitis, a hallmark of spondylitis, is linked with CARD15 gene polymorphisms in patients with Crohn's disease. Ann Rheum Dis 63, 1131-1134.

Persson K, Osser S (1993) Lack of evidence of a relationship between genital symptoms, cervicitis and salpingitis and different serovars of Chlamydia trachomatis. Eur J Clin Microbiol Infect Dis 12, 195199.

Poltorak A, He X, Smirnova I, Liu MY, Van Huffel C, Du X, Birdwell D, Alejos E, Silva M, Galanos C et al. (1998) Defective LPS signaling in C3H/HeJ and C57BL/10ScCr mice: mutations in T/r4 gene. Science 282, 2085-2088.

Prebeck S, Kirschning C, Dürr S, Da Costa C, Donath B, Brand K, Redecke V, Wagner H, Miethke T (2001) Predominant role of toll-like receptor 2 versus 4 in Chlamydia pneumoniae-induced activation of dendritic cells. J Immunol 167, 3316-23.

Puthothu B, Forster J, Heinzmann A, Krueger M (2006) TLR-4 and CD14 polymorphisms in respiratory syncytial virus associated disease. Dis Markers 22, 303-308.

Smirnova I, Mann N, Dols A, Derkx HH, Hibberd ML, Levin M, Beutler B (2003) Assay of locus-specific genetic load implicates rare Toll-like receptor 4 mutations in meningococcal susceptibility. Proc Natl Acad Sci U S A 100, 6075-6080.

Stothard DR, Boguslawski G, Jones RB (1998) Phylogenetic analysis of the Chlamydia trachomatis major outer membrane protein and examination of potential pathogenic determinants. Infect Immun 66 , 3618-3625. 
Van Doornum GJ, Schouls LM, Pijl A, Cairo I, Buimer M, Bruisten S (2001) Comparison between the LCX Probe system and the COBAS AMPLICOR system for detection of Chlamydia trachomatis and Neisseria gonorrhoeae infections in patients attending a clinic for treatment of sexually transmitted diseases in Amsterdam, The Netherlands. J Clin Microbiol 39, 829-835. 



\section{Chapter 6}

The CD14 functional gene polymorphism -260 $\mathrm{C}>\mathrm{T}$ is not involved in either the susceptibility to Chlamydia trachomatis infection or the development of tubal pathology

S Ouburg, J Spaargaren, JE den Hartog, JA Land, JSA Fennema, J Pleijster, AS Peña, SA Morré

BMC Infectious Diseases 2005, 5: 114 


\section{ABSTRACT}

\section{Background}

The functional polymorphism -260 C>T in the LPS-sensing TLR4 co-receptor CD14 gene enhances the transcriptional activity and results in a higher CD14 receptor density. Individuals carrying the T/T genotype also have significantly higher serum levels of soluble CD14. The T allele of this polymorphism has recently been linked to Chlamydia (C.) pneumoniae infection. We investigated the role of the CD14-260 C>T polymorphism in the susceptibility to and severity (defined as subfertility and/or tubal pathology) of $C$. trachomatis infection in Dutch Caucasian women.

\section{Methods}

The different CD14 -260 C>T genotypes were assessed by PCR-based RFLP analysis in three cohorts: 1 ) A cohort $(n=576)$ of women attending a STD clinic, 2 ) a cohort ( $n$ $=253$ ) of women with subfertility, and 3 ) an ethnically matched control cohort ( $n=$ 170). The following variables were used in the analysis: In cohort 1 , the $C$. trachomatis DNA status, $C$. trachomatis IgG serology status and self-reported symptoms, and in cohort 2 , the $C$. trachomatis IgG serology status and the tubal status at laparoscopy.

\section{Results}

In the control cohort, the CC, CT and TT genotype distribution was $28.2 \%, 48.2 \%$, and $23.5 \%$, respectively. No differences were found in the overall prevalence of CD14 -260 genotypes (28.1\%, 50.7\%, and $21.2 \%$ ) in cohort 1 when compared to the control cohort. Also no differences were observed in women with or without $C$. trachomatis DNA, with or without serological C. trachomatis responses, with or without symptoms, or in combinations of these three variables. In subfertile women with tubal pathology (cohort $2, n=50$ ), the genotype distribution was $28.0 \%, 48.0 \%$, and $24.0 \%$, and in subfertile women without tubal pathology ( $n=203$ ), $27.6 \%$, $49.3 \%$ and $23.2 \%$. The genotype distribution was unchanged when $C$. trachomatis IgG status was introduced in the analyses.

\section{Conclusion}

The CD14 -260 C>T genotype distributions were identical in all three cohorts, showing that this polymorphism is not involved in the susceptibility to or severity of sequelae of $C$. trachomatis infection. 


\section{INTRODUCTION}

Chlamydia species are related to a broad clinical spectrum of human disease, including Chlamydia (C.) pneumoniae in lung and cardiovascular disease, C. psittaci in pulmonary emphysema and psittacosis, and $C$. trachomatis in ocular and urogenital infections (Smieja et al., 2002a, Smieja et al., 2002b, Numazaki et al., 2003).

C. trachomatis is the most prevalent sexually transmitted disease in Europe and the USA. Due to the mostly asymptomatic course of infection, these women will most likely not be treated, resulting in an enhanced risk for the development of late complications, which include pelvic inflammatory disease, ectopic pregnancy and tubal infertility.

The female reproductive tract is a very complex system where many factors, including hormones, vaginal flora and immune mediators, combine to provide protection on the one hand, while on the other hand maintaining an environment suitable for conception (Wira et al., 2005). Clear differences in the clinical course of infection have been described and are due to an interaction between environmental (e.g. coinfection), bacterial (e.g. virulence factors) and host factors (genetic differences between individuals). In previous studies, no clear associations have been demonstrated between $C$. trachomatis serotype, $C$. trachomatis genotype, and the course of C. trachomatis infection (Workowski et al., 1994, Lyons et al., 2004), although differences in cytotoxicity for different serovars have been described (Lyons et al., 2005) and an association between $C$. trachomatis serovar $\mathrm{G}$ and cervical squamous cell carcinoma has been suggested (Anttila et al., 2001). In addition, virulence gene expression studies and genomic comparisons of strains, isolated from clearly symptomatic or asymptomatic infected persons, revealed no strong role for the $C$. trachomatis bacterium in relation to the course of infection (Morré et al., 2000, Pannekoek et al., 2005).

A limited number of studies has recently demonstrated the influence of host genetic factors on the susceptibility to and the severity of $C$. trachomatis infection. Host factors including HLA-DQ and interleukin 10 (IL-10) have been associated with chlamydia infection (Kinnunen et al., 2002).

The toll-like receptor (TLR) family is a group of pattern recognition receptors, which recognize several microbial products, including bacterial cell wall components and DNA (Takeda et al., 2003). Poltorak et al. (1998) associated TLR4 with lipopolysaccharide (LPS) recognition in mice. Further studies in mice corroborated these data (Beutler, 2000, Netea et al., 2002a), while studies in humans demonstrated associations between TLR4 mutations and LPS hyporesponsiveness (Arbour et al., 2000). We did not observe an association between the TLR4 Asp299Gly polymorphism in patients with tubal pathology, although the study population was relatively small (Morré et al., 2003). The lack of association can be explained by recent publications showing that heterozygous carriage of the TLR4 Asp299Gly mutation does not affect 
LPS responsiveness, and that only the rare homozygous carriers are less responsive to LPS (Erridge et al., 2003).

Cluster of differentiation (CD) 14 acts as a co-receptor for TLR4 and confers responsiveness to LPS, a component of the cell wall of most Gram-negative bacteria. CD14 forms a complex with LPS and the LPS-binding protein (LBP) (Figure I) (Wright et al., 1990). Combined with TLR4, this complex induces nuclear factor (NF)-KB associated immune responses including the release of a broad spectrum of cytokines that include tumor necrosis factor alpha (TNF- $\alpha$ ), IL-1, IL-6, and IL-8 to initiate immune response (Baldini et al., 1999).

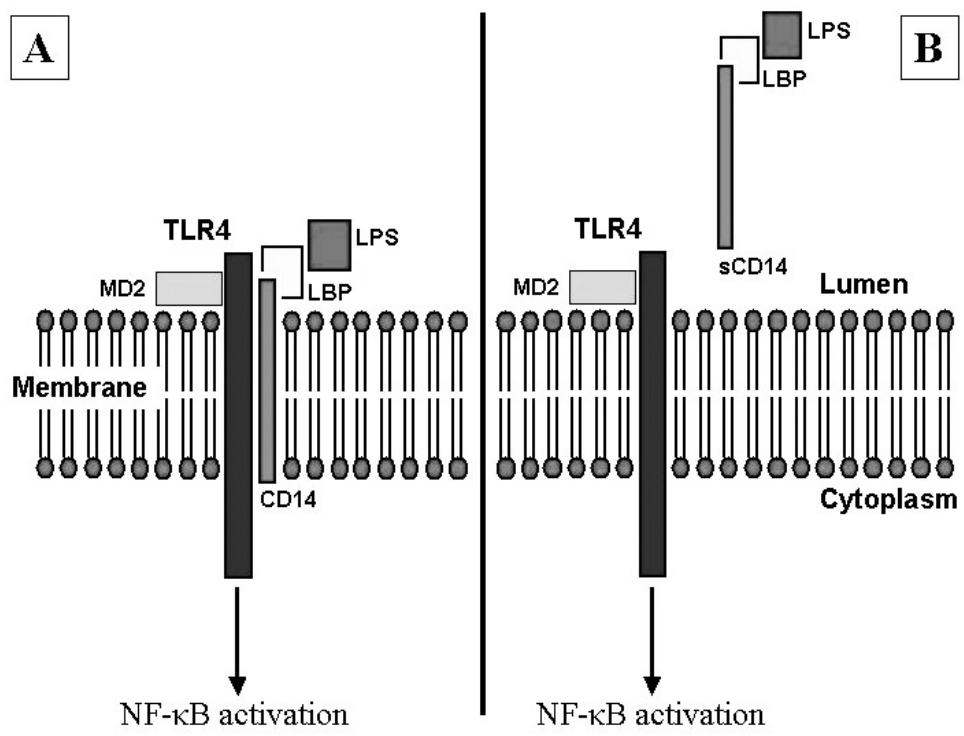

Figure I. CD14 localization. A: Membrane-bound CD14 (mCD14) complexed with TLR4 and the LBP-LPS complex. Panel B: Soluble CD14 (sCD14).

Abbreviations: $C D$ = cluster of differentiation; $L P B=L P S-$ binding protein; $L P S=$ lipopolysaccharide; MD2 = myeloid differentiation protein-2; NF-KB = nuclear factor- $\mathrm{KB} ; \mathrm{TLR}=$ toll-like receptor.

The promotor region of the $C D 14$ gene contains a single nucleotide polymorphism (SNP) at position -260. The $-260 \mathrm{C}>\mathrm{T}$ genetic variation affects the binding of transcription factors (Zhang et al., 1994), and has been associated with levels of soluble CD 14 (sCD14) and inversely associated with serum IgE levels (Baldini et al., 1999). This SNP has been associated with myocardial infarction (Hubacek et al., 1999), Crohn's disease (Klein et al., 2003) and an increased susceptibility to develop chronic spondyloarthropathy in women (Repo et al., 2002).

Eng et al. (2004) demonstrated that carriers of the T allele of this promotor polymorphism have a higher expression of both membrane-bound CD14 (mCD14) and sCD14, and that TNF- $\alpha$ production is increased in the homozygous CD14 -260 T car- 
riers when stimulated with either $C$. pneumoniae or $C$. trachomatis. In a recent article, Rupp et al. (2004) described an association between the mutant allele and an increased susceptibility to chronic $C$. pneumoniae infection in coronary artery disease patients. Since the CD14 -260 C>T is functional (Eng et al., 2004) and is associated with C. pneumoniae infection (Rupp et al., 2004), one could hypothesize that in C. trachomatis infection this polymorphism could influence the susceptibility to and severity of this most prevalent sexually transmitted bacterium which is associated with female infertility.

Therefore, we investigated the role of the CD14 -260 C>T polymorphism in the susceptibility to and severity (defined as subfertility and/or tubal pathology) of $C$. trachomatis infection in Dutch Caucasian women. A cohort of women attending a Sexually Transmitted Diseases (STD) outpatient clinic was used to assess the susceptibility to $C$. trachomatis infection, taking into account both $C$. trachomatis DNA and C. trachomatis IgG detection, symptoms and co-infections. A cohort of subfertile women with or without clinically well-defined tubal pathology was used to assess the role of CD14 in the severity of sequelae of $C$. trachomatis infection.

\section{METHODS}

\section{Patient populations}

STD cohort

Women of Dutch Caucasian origin ( $n=576$ ), under the age of 33 (range 14 to 33 years; median 22 years) and visiting the STD outpatient clinic in Amsterdam, the Netherlands, were included in this study (collection period: July 2001-December 2004) (Table I). All 576 women were consecutively included as the first part of a large prospective study. For every $C$. trachomatis DNA positive woman, two consecutive $C$. trachomatis DNA negative controls were included in the study. The women were asked to sign an informed consent form and to fill out a questionnaire, regarding their complaints at that moment, varying from increased discharge, having bloody discharge during and/or after intercourse, recent abdominal pain (not gastrointestinal or menses related) and/or dysuria. A cervical swab was taken for the detection of $C$. trachomatis DNA by polymerase chain reaction (PCR; COBAS AMPLICOR, Hoffman-La Roche, Basel, Switzerland) (Van Doornum et al., 2002). 


\section{Chapter 6}

Cluster of differentiation 14

Table I. Patient characteristics in the STD and subfertility cohorts.

\begin{tabular}{|c|c|c|c|}
\hline & & $\begin{array}{l}\text { STD cohort } \\
(n=576)\end{array}$ & $\begin{array}{l}\text { Subfertility cohort } \\
(\mathrm{n}=253)\end{array}$ \\
\hline \multirow[t]{2}{*}{ CT DNA } & + & 184 & NA \\
\hline & - & 392 & NA \\
\hline \multirow[t]{2}{*}{ CT IgG (ELISA) $)^{a}$} & + & 217 & NA \\
\hline & - & 359 & NA \\
\hline \multirow[t]{2}{*}{$\mathrm{CT} \operatorname{IgG}(\mathrm{MIF})^{\mathrm{b}}$} & + & NA & 41 \\
\hline & - & NA & 212 \\
\hline Co-infections & + & 175 & NA \\
\hline Candida albicans & & 160 & NA \\
\hline Neisseria gonorrhoea & & 7 & NA \\
\hline Trichomonas vaginalis & & 6 & NA \\
\hline Herpes simplex virus 1 & & 2 & NA \\
\hline \multirow[t]{2}{*}{ Herpes simplex virus 2} & & 5 & NA \\
\hline & - & 401 & NA \\
\hline Symptoms & + & 221 & NA \\
\hline Vulvovaginal discharge & & 157 & NA \\
\hline Abdominal pain & & 81 & NA \\
\hline Dysuria & & 58 & NA \\
\hline \multirow[t]{2}{*}{ Bleeding during/after coitus } & & 25 & NA \\
\hline & - & 335 & NA \\
\hline \multirow[t]{3}{*}{ Age } & Average & $23.6 \mathrm{y}$ & $30 y$ \\
\hline & Range & $15-41 y$ & $19-39 y$ \\
\hline & Median & 23 y & 31 y \\
\hline \multirow[t]{2}{*}{ Tubal pathology } & + & NA & 50 \\
\hline & - & NA & 203 \\
\hline
\end{tabular}

${ }^{a}$ C. trachomatis IgG ELISA (Medac, Germany); $\geq 1: 50=$ positive; ${ }^{b}$ C. trachomatis IgG MIF (AniLabSystems, Finland); $\geq 32$ = positive. Abbreviations: $\mathrm{CT}=$ Chlamydia trachomatis; IgG = immunoglobulin G; NA = not available; STD cohort $=$ female visitors of a Sexually Transmitted Diseases outpatient clinic; subfertility cohort $=$ subfertile women undergoing a fertility work-up.

Peripheral venous blood was collected for the analysis of IgG antibodies against $C$. trachomatis (ELISA; Medac Diagnostika $\mathrm{mbH}$, Hamburg, Germany). A titre of $\geq 1: 50$ was considered positive. Samples with grey zone values, e.g. cut off $\pm 10 \%$, were repeated and considered positive when the result was positive or again within the grey zone. Infections with the micro-organisms Candida albicans, Neisseria gonorrhoea, Trichomonas vaginalis and Herpes simplex virus 1/2 may result in symptoms similar to $C$. trachomatis infection. Infection status for these micro-organisms was recorded. Herpes simplex virus 1/2 was detected according to the methods described by Bruisten et al. (2001). Neisseria gonorrhoea was detected according to methods described by Spaargaren et al. (2001). Trichomonas vaginalis was cultured on Trichosel medium according to standard procedures (Murray et al., 1995), and 
detection of Trichomonas vaginalis was according the methods described by Van der Schee et al. (2001). Candida albicans was cultured on Chrom agar, and detection of Candida albicans was performed according to standard procedures (Murray et al., 1995).

\section{Subfertility cohort}

The study was performed in 253 consecutive Dutch Caucasian women who visited the department of Obstetrics and Gynaecology of the Academisch Ziekenhuis Maastricht, the Netherlands, between December 1990 and November 2000 because of subfertility (Land et al., 2003). In these women, a laparoscopy with tubal testing had been performed as part of their fertility work-up. Preoperatively, blood was drawn from all patients for $C$. trachomatis IgG antibody testing (CAT), and spare sera were cryopreserved.

Two independent investigators, who were unaware of the CAT results, scored the laparoscopy reports to assess the grade of tubal pathology. Tubal pathology was defined as extensive peri-adnexal adhesions and/or distal occlusion of at least one tube at laparoscopy (Land et al., 1998). Subfertile women who had no peri-adnexal adhesions and had patent tubes at laparoscopy served as negative controls. Based on these criteria, 50 women had tubal pathology and 203 women served as controls.

IgG antibodies to $C$. trachomatis were detected with a species-specific MIF test (AniLabSystems, Finland), as described previously (Land et al., 2003), with comparable sensitivity and specificity as compared to the IgG ELISA from Medac used for the STD cohort (Morré et al., 2002). A positive $C$. trachomatis IgG MIF test was defined as a titre $\geq 1: 32$. Findings at laparoscopy were correlated with the MIF test results. Based on the MIF test, 41 women were found to be $C$. trachomatis IgG-positive, while 212 were $C$. trachomatis IgG-negative. Of the $C$. trachomatis IgG-positive women, $28(68.8 \%)$ had tubal pathology, while 22 women $(10.4 \%)$ of the C. trachomatis IgG-negative women had tubal pathology.

\section{Healthy controls}

A healthy Dutch Caucasian control group $(n=170)$ was included to assess the general frequency of the CD14 -260 genotypes in the Dutch Caucasian population.

\section{DNA extraction}

STD cohort

Eukaryotic DNA from peripheral blood mononuclear cells (PBMCs) was isolated using the isopropanol isolation method. In short: $100 \mu \mathrm{L}$ PBMC in phosphatebuffered saline were added to $600 \mu \mathrm{L}$ L6 (Nuclisens Lysisbuffer, Organon Teknika, Boxtel, the Netherlands) and $1 \mu \mathrm{L}$ glycogen (Roche Molecular Diagnostics, Almere, 
the Netherlands). The samples were incubated for $30 \mathrm{~min}$ at $65^{\circ} \mathrm{C}$ and left to cool at room temperature. An equal volume of cold $\left(-20^{\circ} \mathrm{C}\right)$ isopropanol was added to the samples. The samples were then centrifuged ( $20 \mathrm{~min}$ at $20.000 \mathrm{G}$ ). The supernatant was discarded and the pellets were washed twice in $75 \% \mathrm{EtOH}$. The pellets were dissolved in $\mathrm{T} 10$ overnight $(\mathrm{O} / \mathrm{N})$ at $4^{\circ} \mathrm{C}$ and then stored at $-20^{\circ} \mathrm{C}$ until further analysis.

\section{Subfertility cohort}

Genomic DNA was extracted out of the cryopreserved sera using High Pure PCR Template Preparation Kit according to the manufacturer's instructions (Roche Molecular Biochemicals, Mannheim, Germany).

\section{Healthy controls}

Blood was collected in EDTA-tubes and stored at room temperature until the genomic DNA was extracted from PBMCs according to an in-house DNAzol (Invitrogen, the Netherlands) isolation procedure.

\section{Immunogenetic analysis}

\section{CD14-260 C>T gene polymorphism}

The C>T substitution in the proximal CD14 promoter GC box at position - 260 from the translation start site (NCBI SNP CLUSTER ID:rs2569190) results in a Haelll restriction site. We developed a PCR assay using the primers 5' TCA CCT CCC CAC CTC TCT T 3' (sense) and 5' CCT GCA GAA TCC TTC CTG TT 3' (antisense) (Invitrogen Life Technologies, Breda, the Netherlands), flanking this restriction site. Amplification was performed using a thermal cycler Perkin-Elmer 9700 (Applied Biosystems, Forter City, CA, USA). The parameters were an initial denaturation at $95^{\circ} \mathrm{C}$ for $5 \mathrm{~min}$, followed by 35 cycles of denaturation at $95^{\circ} \mathrm{C}$ for $30 \mathrm{~s}$, annealing at $59^{\circ} \mathrm{C}$ for $30 \mathrm{~s}$, and elongation at $72^{\circ} \mathrm{C}$ for $1 \mathrm{~min}$. The final elongation was at $72^{\circ} \mathrm{C}$ for $7 \mathrm{~min}$, followed by a cooling to $4^{\circ} \mathrm{C}$. The 107 base pairs (bp) fragments were digested overnight at $37^{\circ} \mathrm{C}$ with Haelll (Invitrogen, the Netherlands) resulting in fragments that either were cut in two fragments of $83 \mathrm{bp}$ and $24 \mathrm{bp}$ (allele $\mathrm{C}$ ) or were not restricted ( $T$ allele). These fragments were analyzed by electrophoresis on $4 \%$ low melting agarose gels (Tebu-Bio, the Netherlands) stained with ethidium bromide.

\section{Statistical analyses}

All groups were tested for Hardy-Weinberg equilibrium to check for Mendelian inheritance. Statistical analyses were performed using Instat Graphpad and SPSS version 11 (SPSS Inc., Chicago, IL, USA). Fisher exact and $\chi^{2}$ tests were used to test 
for differences in CD14 allele/genotype/carrier frequencies between the (sub)groups. $P$-values $<0.05$ were considered statistically significant.

\section{RESULTS}

All genotype distributions assessed were in Hardy-Weinberg equilibrium. The CD14 260 C>T SNP was assessed in the STD, subfertility and control cohorts.

\section{CD14 -260 in the susceptibility to $C$. trachomatis infection}

To determine the effects of $C D 14-260 \mathrm{C}>\mathrm{T}$ on the susceptibility to $C$. trachomatis infection, the prevalence of CD14 -260 C>T genotypes were assessed in the STD cohort (Table II). The overall genotype distribution was $28.1 \%$ CC, $50.7 \%$ CT and 21.2\% TT. This distribution was comparable to the healthy controls (Figure II). The distribution was $28.8 \%$ CC, $50.0 \%$ CT and $21.2 \%$ TT in C. trachomatis DNA-positive women, while in C. trachomatis DNA-negative women the distribution was $27.8 \%$ CC, $51.0 \%$ CT and $21.2 \%$ TT. In women with or without serological C. trachomatis responses, the distribution was $30.4 \%$ CC, $49.3 \%$ CT and $20.3 \%$ TT, and $26.7 \%$ CC, $51.5 \% \mathrm{CT}$ and $21.7 \% \mathrm{TT}$, respectively. No differences could be observed in women with or without symptoms. Co-infection with other micro-organisms or combinations of these four variables (C. trachomatis DNA, C. trachomatis serology, symptoms and micro-organisms) did not introduce statistically significant differences or trends in CD14 genotype distributions.

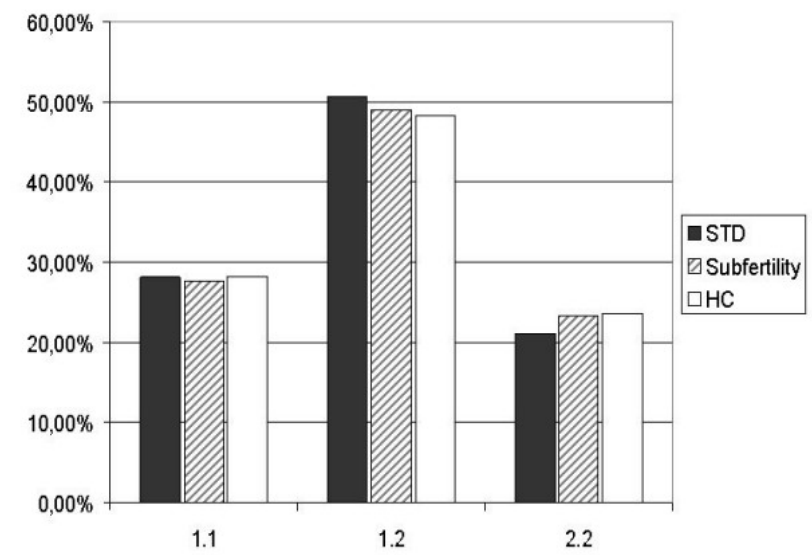

Figure II. CD14 genotype distribution in the STD, subfertility and control cohorts.

Abbreviations: $\mathrm{HC}=$ healthy controls; STD cohort = female visitors of a Sexually Transmitted Diseases outpatient clinic; subfertility cohort = subfertile women undergoing a fertility work-up. 
Table II. CD14 genotype distribution in the STD cohort.

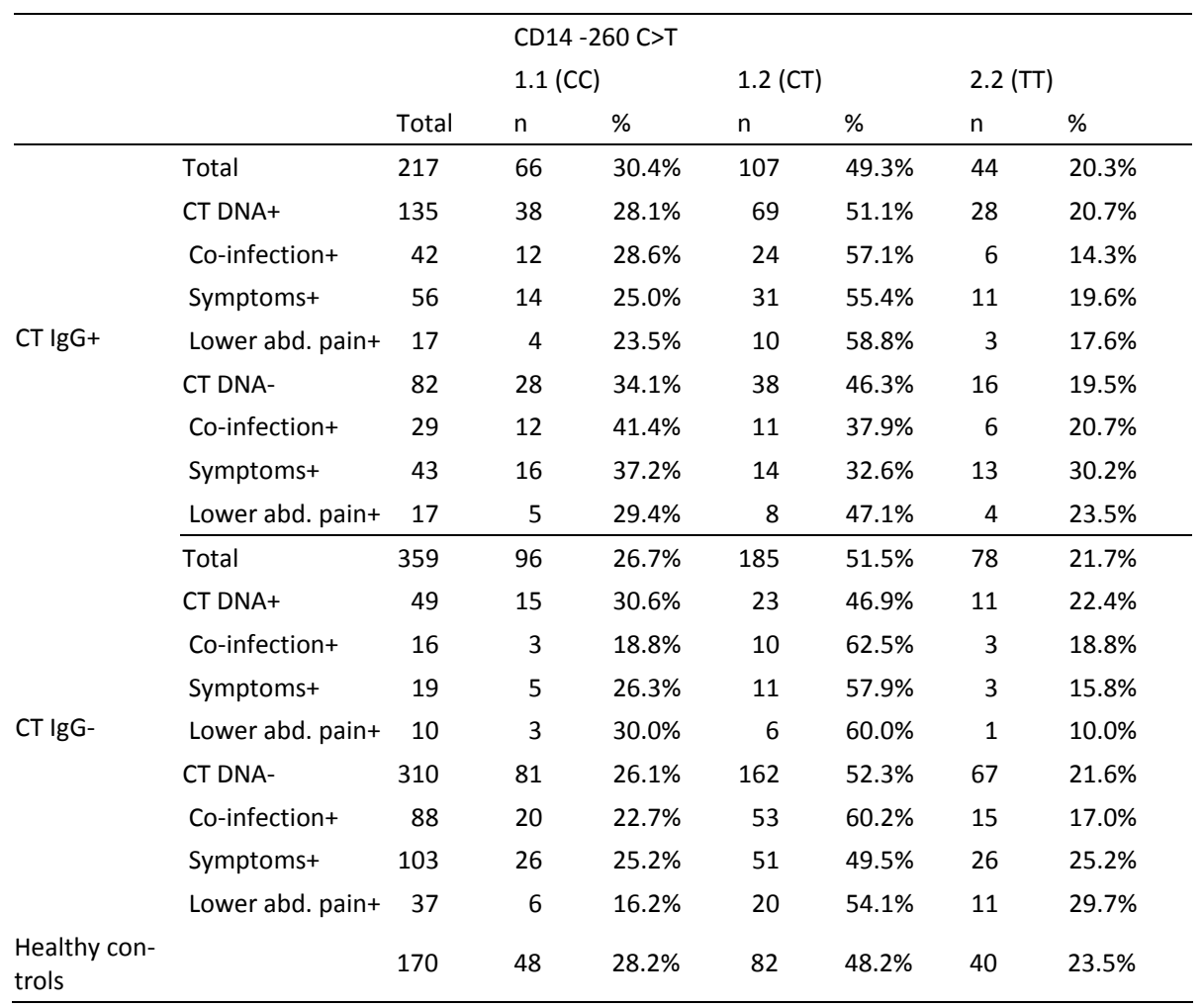

Distribution of the CD14 genotype in C. trachomatis IgG-positive and IgG-negative female visitors of a Sexually Transmitted Diseases outpatient clinic, divided in CT DNA-positive and CT DNA-negative patients, and subdivided in patients with co-infection with other micro-organisms (Neisseria gonorrhoea, Trichomonas vaginalis, Candida albicans, Herpes simplex virus 1 \& 2), symptoms (vulvovaginal discharge, abdominal pain, dysuria, bleeding during/after coitus) and lower abdominal pain. Abbreviation: $\mathrm{CT}=\mathrm{C}$. trachomatis.

\section{CD14 -260 in the severity of sequelae of $C$. trachomatis infection}

The effect of CD14 -260 C>T on the severity of sequelae of $C$. trachomatis infection was assessed in a cohort of subfertile women with clinically well-defined tubal pathology. The overall genotype distribution in the cohort was $27.7 \%$ CC, $49.0 \%$ CT and $23.3 \%$ TT (Figure II). The genotype distribution in women with tubal pathology was similar to the distribution in women without tubal pathology $(28.0 \%$ CC, $48.0 \%$ CT and $24.0 \%$ TT, and $27.6 \%$ CC, $49.3 \%$ CT and $23.2 \%$ TT respectively) and to the distribution in the healthy controls (Table III). Introduction of C. trachomatis IgG serology, with special attention to $C$. trachomatis IgG-positive women who did develop tubal pathology as compared to those who did not develop tubal pathology, did not alter the observed genotype distribution. 
Table III. CD14 genotype in the subfertility cohort.

\begin{tabular}{|c|c|c|c|c|c|c|c|}
\hline \multirow[b]{3}{*}{ Total } & \multirow[b]{3}{*}{253} & \multicolumn{6}{|c|}{ CD14 -260 C>T } \\
\hline & & \multicolumn{2}{|c|}{$1.1(\mathrm{CC})$} & \multicolumn{2}{|c|}{$1.2(\mathrm{CT})$} & \multicolumn{2}{|c|}{$2.2(\mathrm{TT})$} \\
\hline & & 70 & $27.7 \%$ & 124 & $49.0 \%$ & 59 & $23.3 \%$ \\
\hline $\mathrm{TP}+$ & 50 & 14 & $28.0 \%$ & 24 & $48.0 \%$ & 12 & $24.0 \%$ \\
\hline TP- & 203 & 56 & $27.6 \%$ & 100 & $49.3 \%$ & 47 & $23.2 \%$ \\
\hline CT IgG+ and TP+ & 28 & 9 & $32.1 \%$ & 15 & $53.6 \%$ & 4 & $14.3 \%$ \\
\hline CT IgG+ and TP- & 13 & 4 & $30.8 \%$ & 6 & $46.2 \%$ & 3 & $23.1 \%$ \\
\hline Healthy controls & 170 & 48 & $28.2 \%$ & 82 & $48.2 \%$ & 40 & $23.5 \%$ \\
\hline
\end{tabular}

Distribution of the CD14 genotype in C. trachomatis IgG-positive and IgG-negative subfertile women undergoing a fertility work-up, divided in women with and without tubal pathology, and in $C$. trachomatis IgG positive women with and without tubal pathology. Abbreviations: $\mathrm{CT}=\mathrm{C}$. trachomatis; IgG $=\mathrm{immu}$ noglobulin G; TP = tubal pathology.

\section{DISCUSSION}

We did not find an association between the functional up-regulating CD14-260 C>T polymorphism and the susceptibility to or subsequent severity of sequelae of $C$. trachomatis infection, as assessed in the STD and subfertility populations (Figure II). However, these results do not exclude that a still unknown CD14 expression decreasing SNP may influence the course of $C$. trachomatis infection.

Recent studies have shown that chlamydia LPS is capable of inducing an inflammatory response through CD14 (Ingalls et al., 1995, Heine et al., 2003), although the potency to induce an inflammatory response was 100-1 000 times less when compared to the responses induced by S. minnesota, N. gonorrhoea (Ingals et al., 1995) and the enterobacteria S. enterica and E. coli (Heine et al., 2003). Heine et al. (2003) demonstrated that the CD14-associated inflammatory response was TLR4 but not TLR2 mediated. These results are corroborated by studies showing the role of the CD14-TLR4-MD2 complex in intracellular signalling by LPS (Poltorak et al., 1998, Akashi et al., 2003) and studies showing the dependency on CD14 of phagocytosis of Gram-negative bacteria (Grunwald et al., 1996).

The absence of an association between CD14 and susceptibility to $C$. trachomatis infection might be explained by the compartmentalization of TLR4. The differential expression of TLR4 has been described in immortalized cell-lines derived from the female urogenital tract (Fichorova et al., 2002), and has recently been demonstrated in cells isolated from patients by Pioli et al. (2004) and Fazeli et al. (2005). TLRs 1-6 were found to be expressed in the epithelia of the female urogenital tract. TLR2 and TLR4 were the only toll-like receptors with a clear differential expression, low expression in the lower urogenital tract and high expression in the upper genital tract (Pioli et al., 2004, Fazeli et al., 2005). The expression remained similar in all subjects irrespective of age or status of the reproductive cycle (Fazeli et 
al., 2005). It is hypothesized that through this expression pattern, TLR4 modulates immunological tolerance in the lower genital tract and induces host defence against ascending infection in the upper genital tract (Fazeli et al., 2005). In the upper genital tract, Fazeli et al. (2005) found TLR4 positive vacuole-like structures that seemed to be secreted from endocervical glands. A secretory form of TLR4 has been described in mice, where the soluble TLR4 appears to inhibit LPS-mediated signals, while at the same time sTLR4 mRNA is upregulated by LPS (Iwami et al., 2000). This may represent a feedback mechanism to prevent excessive responses to LPS in the endocervix, which can be seen as a boundary between the lower and upper genital tract. Further evidence for the regulation of immune responses to LPS by TLR4 is provided by the study of Harju et al. (2005), who demonstrated the intrauterine expression of TLR4 and endotoxin responsiveness in mice in the perinatal period. mCD14 is expressed on human endometrial stromal cells, but not on endometrial epithelial gland cells. The epithelial cells are dependent on SCD14 for LPS recognition (Bäckhed et al., 2002). sCD14 is present in the cervical mucosa and may be present in the endometrium (Lawn et al., 2000).

Combining the afore-mentioned studies with the knowledge that CD14 can signal through TLR4, it might be hypothesized that the absence of an association between the CD14 -260 SNP and the susceptibility to $C$. trachomatis infection might be due to the low expression or absence of TLR4 in the lower urogenital tract. In the upper genital tract, strict regulation of immune responses to LPS by TLR4 may inhibit CD14 signalling through TLR4 (Iwami et al., 2000, Harju et al., 2005), thus limiting the influence of CD14 on the development of tubal pathology.

However, this hypothesis does not take into account the ability of CD14 to signal through TLR2 (Netea et al., 2002b). Furthermore, it has been demonstrated that non-LPS components of $C$. pneumoniae can stimulate cytokine production through TLR2-dependent but CD14-independent pathways (Yoshioka et al., 2001). If a similar mechanism would exist for $C$. trachomatis-induced cytokine production in urogenital tract infections, the role of CD14 may be questioned.

Since TLR2 is involved in chlamydia-induced transforming growth factor $\beta$, an antiinflammatory cytokine with an important role in fibrosis, and thus very likely in post-infection tubal pathology, it might explain why CD14 polymorphisms may not severely impact the development of tubal pathology (Yoshioka et al., 2001).

Darville et al. (2003) have demonstrated that TLR2 is an important mediator of innate immune responses in $C$. trachomatis infection in mice and plays an important role in early production of immune mediators and development of tubal pathology (Darville et al., 2003, Erridge et al., 2004). In a recent publication by Opitz et al. (2005), it was shown that C. pneumoniae is capable of activating endothelial cells by TLR2 as initial extracellular $C$. pneumoniae receptor, whereas NOD1 was shown to be a potent intracellular immune receptor for $C$. pneumoniae in endothelial cells. Further research may extend these results to $C$. trachomatis infections. Overall, the 
recognition of bacterial LPS involves a complex system of multiple receptors and a complex orchestration of protein-protein interactions (Triantafilou and Triantafilou, 2002).

\section{CONCLUSION}

Our study showed that the functional up-regulating CD14 -260 C>T SNP did neither influence the susceptibility to nor the severity of late sequelae of $C$. trachomatis infection. However, this does not exclude a prominent role for CD14 in the course of an active $C$. trachomatis infection and not yet described CD14 expression decreasing SNPs may affect the course of $C$. trachomatis infection profoundly. Further studies on the immunogenetics of $C$. trachomatis infection will provide more insight in the clear differences in the clinical course that this microorganism induces in individuals and lead to potential vaccine candidates.

\section{Acknowledgements}

Sander Ouburg is an AstraZeneca Nederland BV fellow.

Servaas A. Morré is supported by the Department of Internal Medicine of the VU University Medical Centre, the Netherlands.

The authors are indebted to prof. dr. Cathrien Bruggeman, head of the department of Medical Microbiology, Academisch Ziekenhuis Maastricht, Maastricht, the Netherlands, for the serological testing of the subfertility cohort.

The ICTI consortium (Integrated approach to Chlamydia trachomatis Infections (Morré et al., 2006) provides a broad specialized network for the multidisciplinary studies described. 


\section{REFERENCES}

Akashi S, Saitoh S, Wakabayashi Y, Kikuchi T, Takamura N, Nagai Y, Kusumoto Y, Fukase K, Kusumoto S, Adachi $Y$ et al. (2003) Lipopolysaccharide interaction with cell surface Toll-like receptor 4-MD-2: higher affinity than that with MD-2 or CD14. J Exp Med 198, 1035-1042.

Anttila T, Saikku P, Koskela P, Bloigu A, Dillner J, Ikaheimo I, Jellum E, Lehtinen M, Lenner P, Hakulinen T et al. (2001) Serotypes of Chlamydia trachomatis and risk for development of cervical squamous cell carcinoma. JAMA 285, 47-51.

Arbour NC, Lorenz E, Schutte BC, Zabner J, Kline JN, Jones M, Frees K, Watt JL, Schwartz DA (2000) TLR4 mutations are associated with endotoxin hyporesponsiveness in humans. Nat Genet 25, 187-191.

Bäckhed F, Meijer L, Normark S, Richter-Dahlfors A (2002) TLR4-dependent recognition of lipopolysaccharide by epithelial cells requires SCD14. Cell Microbiol 4, 493-501.

Baldini M, Lohman IC, Halonen M, Erickson RP, Holt PG, Martinez FD (1999) A polymorphism* in the 5' flanking region of the CD14 gene is associated with circulating soluble CD14 levels and with total serum immunoglobulin E. Am J Respir Cell Mol Biol 20, 976-983.

Beutler B (2000) TIr4: central component of the sole mammalian LPS sensor. Curr Opin Immunol 12, 20 26.

Bruisten SM, Cairo I, Fennema H, Pijl A, Buimer M, Peerbooms PGH, Van Dyck E, Meijer A, Ossewaarde JM, Van Doornum GJJ (2001) Diagnosing genital ulcer disease in a clinic for sexually transmitted diseases in Amsterdam, The Netherlands. J Clin Microbiol 39, 601-605.

Darville T, O’Neill JM, Andrews CW, Nagarajan UM, Stahl L, Ojcius DM (2003) Toll-like receptor-2, but not toll-like receptor-4, is essential for development of oviduct pathology in chlamydial genital tract infection. J Immunol 171, 6187-6197.

Eng $\mathrm{HL}$, Wang $\mathrm{CH}$, Chen $\mathrm{CH}$, Chou MH, Cheng CT, Lin TM (2004) A CD14 promoter polymorphism is associated with CD14 expression and Chlamydia-stimulated TNF alpha production. Genes Immun 5, 426430.

Erridge C, Stewart J, Poxton IR (2003) Monocytes heterozygous for the Asp299Gly and Thr399Ile mutations in the toll-like receptor 4 gene show no deficit in lipopolysaccharide signalling. J Exp Med 197, 1787-1791.

Erridge C, Pridmore A, Eley A, Stewart J, Poxton IR (2004) Lipopolysaccharides of Bacteroides fragilis, Chlamydia trachomatis and Pseudomonas aeruginosa signal via Toll-like receptor 2. J Med Microbiol 53, 735-740.

Fazeli A, Bruce C, Anumba DO (2005) Characterization of Toll-like receptors in the female reproductive tract in humans. Hum Reprod 20, 1372-1378.

Fichorova RN, Cronin AO, Lien E, Anderson DJ, Ingalls RR (2002) Response to Neisseria gonorrhoeae by cervicovaginal epithelial cells occurs in the absence of toll-like receptor 4-mediated signaling. J Immunol 168, 2424-2432.

Grunwald U, Fan X, Jack RS, Workalemahu G, Kallies A, Stelter F, Schütt C (1996) Monocytes can phagocytose Gram-negative bacteria by a CD14-dependent mechanism. J Immunol 157, 4119-4125.

Harju K, Ojaniemi M, Rounioja S, Glumoff V, Paananen R, Vuolteenaho R, Hallman M (2005) Expression of toll-like receptor 4 and endotoxin responsiveness in mice during perinatal period. Pediatr Res 57 , 644-648.

Heine H, Müller-Loennies S, Brade L, Lindner B, Brade H (2003) Endotoxic activity and chemical structure of lipopolysaccharides from Chlamydia trachomatis serotypes E and L2 and Chlamydophila psittaci 6BC. Eur J Biochem 270, 440-450.

Hubacek JA, Rothe G, Pit'ha J, Škodová Z, Staněk V, Poledne R, Schmitz G (1999) C(-260) $\rightarrow$ T polymorphism in the promoter of the CD14 monocyte receptor gene as a risk factor for myocardial infarction. Circulation. 99, 3218-3220.

Ingalls RR, Rice PA, Qureshi N, Takayama K, Lin JS, Golenbock DT (1995) The inflammatory cytokine response to Chlamydia trachomatis infection is endotoxin mediated. Infect Immun 63, 3125-3130. 
Iwami KI, Matsuguchi T, Masuda A, Kikuchi T, Musikacharoen T, Yoshikai Y (2000) Cutting edge: naturally occurring soluble form of mouse Toll-like receptor 4 inhibits lipopolysaccharide signaling. J Immunol 15, 6682-6686.

Kinnunen AH, Surcel HM, Lehtinen M, Karhukorpi J, Tiitinen A, Halttunen M, Bloigu A, Morrison RP, Karttunen R, Paavonen J (2002) HLA DQ alleles and interleukin-10 polymorphism associated with Chlamydia trachomatis-related tubal factor infertility: a case-control study. Hum Reprod 17, $2073-$ 2078.

Klein W, Tromm A, Griga T, Folwaczny C, Hocke M, Eitner K, Marx M, Duerig N, Epplen JT (2003) Interaction of polymorphisms in the CARD15 and CD14 genes in patients with Crohn disease. Scand J Gastroenterol 38, 834-836.

Land JA, Evers JLH, Goossens VJ (1998) How to use Chlamydia antibody testing in subfertility patients. Hum Reprod 13, 1094-1098.

Land JA, Gijsen AP, Kessels AGH, Slobbe MEP, Bruggeman CA (2003) Performance of five serological chlamydia antibody tests in subfertile women. Hum Reprod 18, 2621-2627.

Lawn SD, Subbarao S, Wright Jr TC, Evans-Strickfaden T, Ellerbrock TV, Lennox JL, Butera ST, Hart CE (2000) Correlation between human immunodeficiency virus type 1 RNA levels in the female genital tract and immune activation associated with ulceration of the cervix. J Infect Dis 181, 1950-1956.

Lyons JM, Ito JI Jr, Morré SA (2004) Chlamydia trachomatis serovar E isolates from patients with different clinical manifestations have similar courses of infection in a murine model: host factors as major determinants of $C$. trachomatis mediated pathogenesis. J Clin Pathol 57, 657-659.

Lyons JM, Ito JI Jr, Peña AS, Morré SA (2005) Differences in growth characteristics and elementary body associated cytotoxicity between Chlamydia trachomatis oculogenital serovars D and $\mathrm{H}$ and Chlamydia muridarum. J Clin Pathol 58, 397-401.

Manukyan M, Triantafilou K, Triantafilou M, Mackie A, Nilsen N, Espevik T, Wiesmüller KH, Ulmer AJ, Heine $H$ (2005) Binding of lipopeptide to CD14 induces physical proximity of CD14, TLR2 and TLR1. Eur J Immunol 35, 911-921.

Morré SA, Ossewaarde JM, Savelkoul PHM, Stoof J, Meijer CJLM, Van den Brule AJC (2000) Analysis of genetic heterogeneity in Chlamydia trachomatis clinical isolates of serovars D, E and $\mathrm{F}$ by amplified fragment length polymorphism. J Clin Microbiol 38, 3463-3466.

Morré SA, Munk C, Persson K, Krüger-Kjaer S, Van Dijk R, Meijer CJLM, Van den Brule AJC (2002) Comparison of three commercially available peptide-based immunoglobulin $\mathrm{G}(\operatorname{IgG})$ and IgA assays to microimmunofluorescence assay for detection of Chlamydia trachomatis antibodies. J Clin Microbiol 40, 584-587.

Morré SA, Murillo LS, Bruggeman CA, Peña AS (2003) The role that the functional Asp299Gly polymorphism in the toll-like receptor-4 gene plays in the susceptibility to Chlamydia trachomatis-associated tubal infertility. J Infect Dis 187, 341-342.

Morré SA, Spaargaren J, Ossewaarde JM, Land JA, Bax CJ, Dörr PJ, Oostvogel PM, Vanrompay D, Savelkoul PHM, Pannekoek Y et al. (2006) Description of the ICTI consortium: an integrated approach to the study of Chlamydia trachomatis infection. Drugs Today 42 (Suppl A), 107-114.

Murray PR, Baron EJ, Pfaller MA, Tenover FC, Yolken RH (editors) (1995) Manual of Clinical Microbiology, $6^{\text {th }}$ ed. American Society for Microbiology Press, Washington D.C., USA.

Netea MG, Van der Graaf CAA, Vonk AG, Verschueren I, Van der Meer JWM, Kullberg BJ (2002a) The role of toll-like receptor (TLR) 2 and TLR4 in the host defense against disseminated candidiasis. J Infect Dis $185,1483-1489$.

Netea MG, Kullberg BJ, Galama JMD, Stalenhoef AFH, Dinarello CA, Van der Meer JWM (2002b) Non-LPS components of Chlamydia pneumoniae stimulate cytokine production through Toll-like receptor 2dependent pathways. Eur J Immunol 32, 1188-1195.

Numazaki K, Asanuma H, Niida Y (2003) Chlamydia trachomatis infection in early neonatal period. BMC Infect Dis 3, 2.

Opitz B, Förster S, Hocke AC, Maass M, Schmeck B, Hippenstiel S, Suttorp N, Krüll M (2005) Nod1mediated endothelial cell activation by Chlamydophila pneumoniae. Circ Res 96, 319-326. 
Pannekoek Y, Spaargaren J, Langerak AAJ, Merks J, Morré SA, Van der Ende A (2005) Interrelationship between polymorphisms of incA, fusogenic properties of Chlamydia trachomatis strains, and clinical manifestations in patients in The Netherlands. J Clin Microbiol 43, 2441-2443.

Pioli PA, Amiel E, Schaefer TM, Connolly JE, Wira CR, Guyre PM (2004) Differential expression of Toll-like receptors 2 and 4 in tissues of the human female reproductive tract. Infect Immun 72, 5799-5806.

Poltorak A, He X, Smirnova I, Liu MY, Van Huffel C, Du X, Birdwell D, Alejos E, Silva M, Galanos C et al. (1998) Defective LPS signaling in $\mathrm{C} 3 \mathrm{H} / \mathrm{HeJ}$ and $\mathrm{C} 57 \mathrm{BL} / 10 \mathrm{ScCr}$ mice: mutations in T/r4 gene. Science 282, 2085-2088.

Repo H, Anttonen K, Kilpinen SK, Palotie A, Salven P, Orpana A, Leirisalo-Repo M (2002) CD14 and TNFa promoter polymorphisms in patients with acute arthritis. Special reference to development of chronic spondyloarthropathy. Scand J Rheumatol 31, 355-361.

Rupp J, Goepel W, Kramme E, Jahn J, Solbach W, Maass M (2004) CD14 promoter polymorphism -159C>T is associated with susceptibility to chronic Chlamydia pneumoniae infection in peripheral blood monocytes. Genes Immun 5, 435-438.

Smieja M, Leigh R, Petrich A, Chong S, Kamada D, Hargreave FE, Goldsmith CH, Chernesky M, Mahony JB (2002a) Smoking, season, and detection of Chlamydia pneumoniae DNA in clinically stable COPD patients. BMC Infect Dis 2, 12.

Smieja M, Mahony J, Petrich A, Boman J, Chernesky M (2002b) Association of circulating Chlamydia pneumoniae DNA with cardiovascular disease: a systematic review. BMC Infect Dis 2, 21.

Spaargaren J, Stoof J, Fennema H, Coutinho RA, Savelkoul PH (2001) Amplified fragment length polymorphism fingerprinting for identification of a core group of Neisseria gonorrhoeae transmitters in the population attending a clinic for treatment of sexually transmitted diseases in Amsterdam, The Netherlands. J Clin Microbiol 39, 2335-2337.

Takeda K, Kaisho T, Akira S (2003) Toll-like receptors. Annu Rev Immunol 21, 335-376.

Triantafilou M, Triantafilou K (2002) Lipopolysaccharide recognition: CD14, TLRs and the LPS-activation cluster. Trends Immunol 23, 301-304.

Van der Schee C, Sluiters HJF, Van der Meijden WI, Van Beek P, Peerbooms PGH, Verbrugh H, Van Belkum A (2001) Host and pathogen interaction during vaginal infection by Trichomonas vaginalis and $M y$ coplasma hominis or Ureaplasma urealyticum. J Microbiol Methods 45, 61-67.

Van Doornum GJJ, Schouls LM, Pijl AS, Cairo I, Buimer M, Bruisten SM (2001) Comparison between the LCX probe system and the COBAS AMPLICOR system for detection of Chlamydia trachomatis and Neisseria gonorrhoeae infections in patients attending a clinic for treatment of sexually transmitted diseases in Amsterdam, The Netherlands. J Clin Microbiol 39, 829-835.

Wira CR, Fahey JV, Sentman CL, Pioli PA, Shen L (2005) Innate and adaptive immunity in female genital tract: cellular responses and interactions. Immunol Rev 206, 306-335.

Workowski KA, Stevens CE, Suchland RJ, Holmes KK, Eschenbach DA, Pettinger MB, Stamm WE (1994) Clinical manifestations of genital infection due to Chlamydia trachomatis in women: differences related to serovar. Clin Infect Dis 19, 756-760.

Wright SD, Ramos RA, Tobias PS, Ulevitch RJ, Mathison JC (1990) CD14, a receptor for complexes of lipopolysaccharide (LPS) and LPS binding protein. Science 249, 1431-1433.

Yoshioka T, Morimoto Y, Iwagaki H, Itoh H, Saito S, Kobayashi N, Yagi T, Tanaka N. Bacterial lipopolysaccharide induces transforming growth factor beta and hepatocyte growth factor through toll-like receptor 2 in cultured human colon cancer cells. J Int Med Res 29, 409-420.

Zhang DE, Hetherington CJ, Tan S, Dziennis SE, Gonzalez DA, Chen HM, Tenen DG (1994) Sp1 is a critical factor for the monocytic specific expression of human CD14. J Biol Chem 269, 11425-11434. 


\section{Chapter 7}

Do host genetic traits in the bacterial sensing system play a role in the development of Chlamydia trachomatis-associated tubal pathology in subfertile women? 


\section{ABSTRACT}

\section{Background}

In women, Chlamydia (C.) trachomatis upper genital tract infection can cause distal tubal damage and occlusion, increasing the risk of tubal factor subfertility and ectopic pregnancy. Variations, like single nucleotide polymorphisms (SNPs), in immunologically important host genes are assumed to play a role in the course and outcome of a $C$. trachomatis infection. We studied whether genetic carrier traits (carrying multiple SNPs in different genes) in the bacterial sensing system are associated with an aberrant immune response and subsequently with tubal pathology following a $C$. trachomatis infection. The genes studied all encode for pattern recognition receptors (PRRs) involved in sensing bacterial components.

\section{Methods}

Of 227 subfertile women, serum was available for $C$. trachomatis IgG antibody testing and genotyping (common versus rare allele) of the PRR genes TLR9, TLR4, CD14 and CARD15/NOD2. In all women, a laparoscopy was performed to assess the grade of tubal pathology. Tubal pathology was defined as extensive peri-adnexal adhesions and/or distal occlusion of at least one tube.

\section{Results}

Following a C. trachomatis infection (i.e. C. trachomatis IgG positive), subfertile women carrying two or more SNPs in $C$. trachomatis PRR genes were at increased risk of tubal pathology compared to women carrying less than two SNPs ( $73 \%$ vs $33 \%$ risk). The differences were not statistically significant $(P=0.15)$, but a trend was observed.

\section{Conclusion}

Carrying multiple SNPs in C. trachomatis PRR genes tends to result in an aberrant immune response and a higher risk of tubal pathology following $C$. trachomatis infection. Larger studies are needed to confirm our preliminary findings. 


\section{INTRODUCTION}

A large variation exists in the individual response to a Chlamydia (C.) trachomatis infection. Some women clear a $C$. trachomatis infection adequately without developing tissue damage, whereas others get a persistent infection which may ascend to the upper genital tract, increasing the risk of tubal damage and subfertility. The susceptibility, course and outcome of infectious diseases are determined by environmental factors, virulence factors of the pathogen and host factors.

Immunogenetic studies evaluate the role of genetic variations in immunologically important host genes as determinants of the susceptibility, course and outcome of infectious diseases. Among these variations are single nucleotide polymorphisms (SNPs), in which one nucleotide has been substituted, inserted or deleted. This may lead to synthesis of a potentially aberrant protein, or to up- or downregulation of the normal protein, and subsequently to an aberrant immune response, increasing the risk of late sequelae of infectious diseases (e.g. tubal pathology following a $C$. trachomatis infection).

In the present study, we have evaluated SNPs in genes encoding for pattern recognition receptors (PRRs). PRRs are present on or in circulating cells of the innate immune system (e.g. macrophages) and local cells (e.g. epithelial cells of the upper genital tract). PRRs are involved in the bacterial sensing pathways of the innate immune system by recognizing the so-called pathogen-associated molecular patterns (PAMPs), which are pathogen-specific cell wall components or intracellular components. Since different PRRs recognize different PAMPs, pathogen recognition and initiation of the immune response is a complex and flexible system.

Carrying a SNP in a single PRR may not result in a large effect on disease severity, since other PRRs may compensate for the partial loss of function in a specific pathogen recognition route. Subsequently, SNPs in only one PRR may not play a significant role as risk factors for the development of $C$. trachomatis-associated tubal pathology, as shown for the PRR toll-like receptor (TLR) 4 (Morré et al., 2003) and its co-receptor cluster of differentiation (CD) 14 (Ouburg et al., 2005). However, carrying multiple SNPs in one gene or in multiple genes (in so-called carrier traits) may be associated with an increased risk of tubal pathology. Smirnova et al. (2003) have found that combinations of TLR4 variants are markedly more common in patients with meningococcal infections, whereas single variants are not over-represented in those patients. In studies on gastrointestinal malignancies, it has been concluded that carrying multiple pro-inflammatory polymorphisms is associated with an increased risk of gastric cancer (El-Omar et al., 2003, Machado et al., 2003). Furthermore, studies on the relationship between caspase recruitment domain (CARD) 15/nucleotide oligomerisation domain (NOD) 2 genetic variants, of which SNP8, SNP12 and SNP13 are most studied, and Crohn's disease have shown that compound heterozygous subjects (carriers of two different genetic variants, e.g. SNP12 
genotype 1.2 and SNP13 genotype 1.2) have a higher risk of Crohn's disease as compared to homozygous subjects (carriers of the same genetic variant on both chromosomes, e.g. SNP12 genotype 2.2) (Hugot et al., 2001, Heresbach et al., 2004). Analogous to these findings, we hypothesized that carrying multiple genetic variations in multiple PRRs (in a so-called carrier trait) may increase the risk of $C$. trachomatis-associated tubal pathology in subfertile women. According to their biological function (recognition of $C$. trachomatis PAMPs: see Table I), four PRRs were selected: TLR9, TLR4, CD14 and CARD15/NOD2. Five relatively common SNPs, which are assumed to influence the receptor function, in these four PRR genes were studied in this carrier trait analysis (see Table I).

Table I. The pattern recognition receptors (PRRs), which recognize $C$. trachomatis pathogen-associated molecular patterns (PAMPs), and the single nucleotide polymorphisms (SNPs) studied.

\begin{tabular}{lll}
\hline PRR & PAMP & SNP \\
TLR9 & CpG-rich motifs & $-1237 \mathrm{~T}>\mathrm{C}$ and $+2848 \mathrm{G}>\mathrm{A}$ \\
TLR4 & LPS and HSP & $+896 \mathrm{~A}>\mathrm{G}$ \\
CD14 & LPS and HSP (co-receptor of TLR4) & $-260 \mathrm{C}>\mathrm{T}$ \\
CARD15/NOD2 & Peptidoglycans & Leu1007fsinsC (SNP13) \\
\hline
\end{tabular}

Abbreviations: $A$ = adenine; $C=$ cytosine; $C A R D=$ caspase recruitment domain; $C D=$ cluster of differentiation; $\mathrm{CpG}=$ cytosine-phosphate-guanine; fsins = frameshift insertion; $\mathrm{G}=$ guanine; $\mathrm{HSP}=$ heat shock protein; Leu = leucine-rich repeat domain; LPS = lipopolysaccharide; NOD = nucleotide oligomerisation domain; $T$ = thymine; TLR = toll-like receptor.

\section{METHODS}

\section{Study population}

The study was performed in women who visited the Academic Hospital Maastricht between December 1990 and November 2000 because of subfertility. In all patients, blood was drawn at their initial visit for a Chlamydia IgG antibody test (CAT). All spare sera were cryopreserved. Only patients who had undergone a laparoscopy and tubal testing as part of their fertility work-up were included in the present study. Since the prevalence of SNPs may depend on ethnical background, only Dutch Caucasian women were included. Patients who had undergone previous pelvic surgery (except for an uneventful appendectomy or Caesarean section) were excluded. In the Netherlands, for retrospective analysis of anonymized patient data and stored sera no ethical committee approval is required. In the fertility clinic of the Academic Hospital Maastricht, all couples are informed at intake about possible use of their anonymized data and stored sera for research purposes, and a "no objection procedure" is followed. Only patients having not objected participated in the present study. 
Two independent investigators, who were unaware of the CAT results, scored 259 successive laparoscopy reports to assess the grade of tubal pathology. Tubal pathology was defined as extensive peri-adnexal adhesions and/or distal occlusion of at least one tube (Land et al., 1998). In case of disagreement, consensus was reached by consultation.

Of the 259 women who underwent a laparoscopy, 43 (17\%) had tubal pathology (according to the above-mentioned definition) and 184 (71\%) had no tubal pathology (no peri-adnexal adhesions and patent tubes), and these 227 women participated in the present study. Thirty-two women (12\%) had minor or non-C. trachomatis-related abnormalities (any peri-adnexal adhesions and/or proximal occlusion of at least one tube) and were excluded.

\section{C. trachomatis IgG antibody testing}

IgG antibodies to $C$. trachomatis were detected using the species-specific Chlamydia pneumoniae IgG micro-immunofluorescence (MIF) test (AniLabsystems, Finland), as described previously (Den Hartog et al., 2004). This species-specific test is able to detect IgG antibodies to both $C$. pneumoniae and $C$. trachomatis (using an antigen derived from a $C$. trachomatis LGV strain, serovar L2). We have previously studied the test performances of five commercially available $C$. trachomatis IgG tests, including the $C$. trachomatis IgG spot in the C. pneumoniae MIF (AniLabsystems, Finland) (Land et al., 2003). In our hands, the C. trachomatis IgG titre obtained by the $C$. pneumoniae MIF (AniLabsystems, Finland) had the best predictive value for tubal factor subfertility (Land et al., 2003). Therefore, we have used this test in the present study. The cut-off titre used for a positive test was 32.

\section{Immunogenetic analysis}

For the immunogenetic analyses, genomic DNA was extracted from the cryopreserved serum samples using either the MagNaPure LC isolator according to the manufacturer's instructions (Roche Molecular Biochemicals, Germany) or the High Pure PCR Template Preparation Kit according to the manufacturer's instructions (Roche Molecular Biochemicals, Germany). Both techniques provide enough DNA for reproducible genetic analyses. Genotyping was performed using a polymerase chain reaction (PCR)-based restriction fragment length polymorphism (RFLP)-assay or TaqMan-assay as described previously (Morré et al., 2002, Murillo et al., 2002, Lammers et al., 2005, Ouburg et al., 2005). The SNPs studied are summarized in Table I. Chromosomal locations and further information on the genes studied are: TLR9 chromosomal location 3p21.3, TLR9 -1237 T>C rs5743836 and TLR9 +2848 G>A rs352140; TLR4 chromosomal location 9q32-q33, TLR4 +896 A>G rs4986790; CD14 chromosomal location 5q31.1, CD14 -260 C>T rs25691909; CARD15/NOD2 chromo- 
somal location 16q21, CARD15/NOD2 Leu1007fsinsC (SNP13) rs2066847. For ethnically matched background genotyping, genomic DNA was extracted from whole blood of 97 healthy Dutch Caucasian employees of the VU University Medical Center. They gave written informed consent for use of their anonymized sera to serve as control sera for genetic research purposes.

\section{Statistical methods}

The genotype distribution was tested for Hardy-Weinberg equilibrium to assess Mendelian inheritance. Fisher's exact or $\chi^{2}$ tests were used to compare the single genotypes between $C$. trachomatis IgG-positive and IgG-negative subfertile women with and without tubal pathology and the healthy control group. Subsequently, the single genotypes were used to define carrier traits. The carrier traits were tested in $\chi^{2}$ and trend analyses. $P<0.05$ was considered statistically significant.

\section{RESULTS}

Of all 227 subfertile women participating in the present study, 43 (19\%) had tubal pathology, whereas 184 (81\%) did not have tubal pathology. C. trachomatis IgG antibodies were present in 39 women, of whom 26 (67\%) had tubal pathology and $13(33 \%)$ did not have tubal pathology. C. trachomatis IgG antibodies were absent in 188 women, of whom 17 (9\%) had tubal pathology and 171 (91\%) did not have tubal pathology.

For all genes studied, the genotype distribution was in Hardy-Weinberg equilibrium in the subfertile women and the ethnically matched control group.

The genotype distribution did not differ between subfertile women, the C. trachomatis IgG-positive subgroup of subfertile women and the healthy control group (Table II), indicating that the subfertile women participating in the study reflect an average Dutch Caucasian population regarding the genotype distribution. 
Table II. The risk of tubal pathology (TP) in relation to the genotype of the single genes studied.

\begin{tabular}{|c|c|c|c|c|c|}
\hline & & \multicolumn{2}{|l|}{1.1} & \multicolumn{2}{|l|}{1.2 and 2.2} \\
\hline & & $\mathrm{n}$ & Risk of TP & $\mathrm{n}$ & Risk of TP \\
\hline \multirow[t]{3}{*}{ TLR9 -1237 T>C } & All subfertile women & $155(68 \%)$ & $20 \%$ & $72(32 \%)$ & $17 \%$ \\
\hline & $\mathrm{CT}+$ subfertile women & $26(67 \%)$ & $62 \%$ & $13(33 \%)$ & $77 \%$ \\
\hline & Control group & $66(68 \%)$ & - & $31(32 \%)$ & - \\
\hline \multirow[t]{3}{*}{$T L R 9+2848 \mathrm{G}>\mathrm{A}$} & All subfertile women & $45(20 \%)$ & $18 \%$ & $182(80 \%)$ & $19 \%$ \\
\hline & $\mathrm{CT}+$ subfertile women & $6(15 \%)$ & $50 \%$ & $33(85 \%)$ & $70 \%$ \\
\hline & Control group & $15(15 \%)$ & - & $82(85 \%)$ & - \\
\hline \multirow[t]{3}{*}{$T L R 4+896 \mathrm{~A}>\mathrm{G}^{\mathrm{a}}$} & All subfertile women & $200(88 \%)$ & $19 \%$ & $27(12 \%)$ & $22 \%$ \\
\hline & $\mathrm{CT}+$ subfertile women & $33(85 \%)$ & $64 \%$ & $6(15 \%)$ & $83 \%$ \\
\hline & Control group & 87 (90\%) & - & $10(10 \%)$ & - \\
\hline \multirow[t]{3}{*}{$C D 14-260 \mathrm{C}>\mathrm{T}^{\mathrm{b}}$} & All subfertile women & $60(26 \%)$ & $17 \%$ & $167(74 \%)$ & $20 \%$ \\
\hline & $\mathrm{CT}+$ subfertile women & $12(31 \%)$ & $67 \%$ & 27 (69\%) & $67 \%$ \\
\hline & Control group & $26(27 \%)$ & - & $71(73 \%)$ & - \\
\hline \multirow{3}{*}{$\begin{array}{l}\text { CARD15/NOD2 } \\
\text { Leu1007fsinsC } \\
\text { (SNP13) }\end{array}$} & All subfertile women & $211(93 \%)$ & $18 \%$ & $16(7 \%)$ & $25 \%$ \\
\hline & $\mathrm{CT}+$ subfertile women & $37(95 \%)$ & $65 \%$ & $2(5 \%)$ & $100 \%$ \\
\hline & Control group & 95 (98\%) & - & $2(2 \%)$ & - \\
\hline
\end{tabular}

All subfertile women: $n=227$, of whom $19 \%$ has TP. CT + (C. trachomatis IgG-positive) subfertile women: $\mathrm{n}=39$, of whom $67 \%$ has TP. Control group: $n=97$ ethnically matched healthy employees of the VU University Medical Center. 1.1 = normal genotype (homozygous for the common allele). 1.2 = heterozygous SNP carrier (one common allele and one rare allele). 2.2 = homozygous SNP carrier (homozygous for the rare allele). Abbreviations: see Table I. ${ }^{a}$ Adapted from Morré et al. (2003). ${ }^{\text {b }}$ Adapted from Ouburg et al. (2005).

\section{Single gene analysis}

The risk of tubal pathology was assessed in all subfertile women and in the $C$. trachomatis IgG-positive subgroup in relation to the genotype of TLR9, TLR4, CD14 and CARD15/NOD2 (Table II; Figure I). An increasing risk of tubal pathology was observed across the genotypes in all genes except CD14. Carrying SNPs in these genes increased the risk of tubal pathology (on average almost 20\%). These differences did not reach statistical significance. These single genotypes were used to define carrier traits.

\section{Carrier trait analysis}

The SNPs in the single genes were combined in carrier traits. The risk of tubal pathology was assessed in C. trachomatis IgG-positive and IgG-negative subfertile women in relation to the number of SNPs. Carrying two or more SNPs did not influence the risk of tubal pathology in C. trachomatis IgG-negative women as compared to $C$. trachomatis IgG-negative women carrying less than two SNPs ( $9 \%$ vs. $8 \%$ risk respectively; Figure II). However, carrying multiple SNPs doubled the risk of tubal 
Host genetic traits

pathology in C. trachomatis IgG-positive women as compared to C. trachomatis IgGpositive women with less than two SNPs (73\% vs. 33\% risk respectively; Figure II). These differences did not reach statistical significance $(P=0.15)$ but a clear trend was observed.

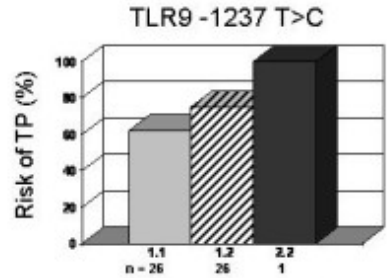

CD14 -260 C> $>T^{\mathrm{b}}$

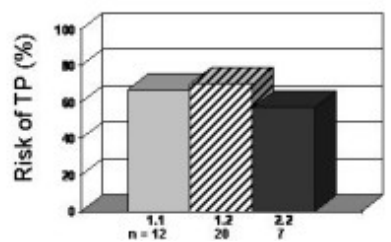

TLR9 +2848 G>A

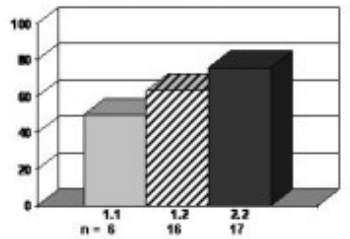

\section{CARD15 / NOD2 SNP13}

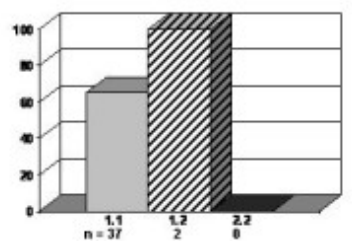

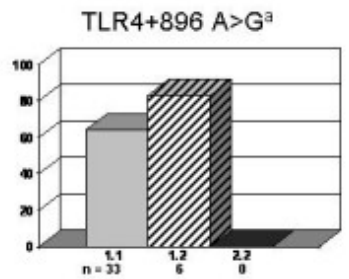

1.1 (Wildtype)

WIII 1.2 (Heterozygote)

2.2 (Mutant)

Figure I. The risk of tubal pathology (TP) in C. trachomatis IgG-positive subfertile women in relation to the genotype of the single pattern recognition receptor genes.

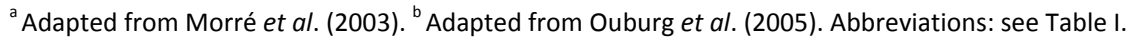
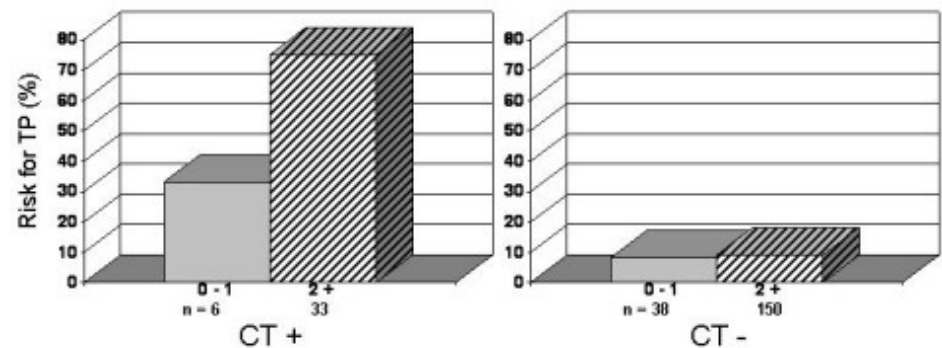

$0-1$ mutations

WIIA 2+ mutations

Figure II. The risk of tubal pathology (TP) in C. trachomatis IgG-positive (CT+) and IgG-negative (CT-) subfertile women in relation to carrying five single nucleotide polymorphisms in four pattern recognition receptor genes. 


\section{DISCUSSION}

Over the last decade, immunogenetic studies have provided insight in the pathogenesis of and susceptibility to infectious diseases. So far, the role of SNPs in immunologically relevant genes has been established in numerous diseases, e.g. sexually transmitted infections (Jeremias et al., 1999, Kinnunen et al., 2002, Wang et al., 2005) and inflammatory bowel diseases (Crohn's disease and ulcerative colitis) (Franchimont et al., 2004, Peeters et al., 2004). In this study, we analyzed the role of single SNPs and multiple SNPs in multiple genes (in a so-called carrier trait) as risk factors of $C$. trachomatis-related tubal pathology and we confirmed our hypothesis that a carrier trait based on genes in bacterial sensing pathways had a stronger association with the risk of tubal pathology than a single gene analysis.

Recent studies have shown the value of genetic traits in complex diseases. Carrying multiple SNPs in the same gene, or multiple SNPs in multiple genes, has been associated with an increased risk of infectious diseases and malignancies (Hugot et al., 2001, El-Omar et al., 2003, Smirnova et al., 2003, Heresbach et al., 2004). Analogous to these findings, we hypothesized that the disregulation of the immune response by the presence of multiple SNPs may lead to an even higher risk of tubal pathology following a $C$. trachomatis infection as compared to carrying a single SNP.

In this study, we investigated the role of five SNPs in four genes which are assumed to play a role in the recognition of $C$. trachomatis (see Table I). An adequate recognition of $C$. trachomatis by PRRs is the first step in the immune response. Recent studies have shown that TLR1-9 are expressed in the human female genital tract. TLR4 and its co-receptor CD14 are predominantly expressed in the fallopian tubes, where they may play an important role in the innate host defence mechanism against ascending C. trachomatis infections (Pioli et al., 2004, Schaefer et al., 2004, Fazeli et al., 2005). Regarding CARD15/NOD2, it is not clear whether it plays a role in the $C$. trachomatis recognition in the genital tract, although NOD proteins have been shown to be involved in the intracellular sensing of $C$. pneumoniae in endothelial cells (Opitz et al., 2005).

Our data show a doubling of the risk of tubal pathology in C. trachomatis IgGpositive women carrying two or more SNPs as compared to C. trachomatis IgGpositive women carrying less than two SNPs (73\% vs. 33\% risk). The differences did not reach statistical significance $(P=0.15)$ due to the small sample size (227 subfertile women in total, including 39 C. trachomatis IgG-positive subfertile women, of whom $67 \%$ has tubal pathology). If the association found in this pilot study would be confirmed in a larger cohort, a $50 \%$ increase in sample size (to 341 subfertile women) would result in a significant difference $(P=0.047)$ between $C$. trachomatis IgG-positive subfertile women carrying two or more SNPs versus $C$. trachomatis IgGpositive subfertile women carrying less than two SNPs regarding the risk of tubal pathology. A $100 \%$ increase in sample size (to 454 subfertile women) would result in 
a strong association ( $P=0.016$; OR 5.3 ) between carrying two or more SNPs and an increased risk of tubal pathology. Increasing the sample size twofold would not be possible, however, in our setting in a reasonable time frame. Although the present study was performed in a large fertility clinic and patients were included during a ten-year period, the number of affected women remained small, due to the low prevalence of $C$. trachomatis IgG-positivity in combination with both carrying multiple SNPs and tubal pathology.

From our results it can be concluded that an adequate recognition of the pathogen at the site of infection seems to be a relevant step in the immune response, and that carrying multiple SNPs in multiple $C$. trachomatis PRR genes tends to increase the risk of an aberrant immune response and tubal pathology. To draw significant conclusions, our hypothesis should be retested in further studies using a larger cohort.

As expected, a difference in risk of tubal pathology between $C$. trachomatis IgGpositive women and $C$. trachomatis IgG-negative women was observed. In previous studies, the presence of $C$. trachomatis IgG antibodies, an indicator of a previous $C$. trachomatis infection, has been associated with tubal pathology (Punnonen et al., 1979). Our data show that carrying multiple SNPs in bacterial sensing pathways and a previous $C$. trachomatis infection synergistically enhance the risk of tubal pathology, while carrying these SNPs does not influence the risk of tubal pathology in the absence of a previous $C$. trachomatis infection (Figure II).

\section{CONCLUSION}

We hypothesized that carrier traits (i.e. carrying multiple SNPs in multiple genes) that likely result in an aberrant immune response are associated with tubal pathology following a $C$. trachomatis infection. In 227 subfertile women, we studied five variations in four genes encoding for PRRs, which recognize several pathogenassociated molecular patterns of $C$. trachomatis. The presence of two or more SNPs tends to correlate with an increased risk of tubal pathology following a $C$. trachomatis infection as compared to a lower number of SNPs. Further studies in a larger cohort are needed to confirm our preliminary findings. An adequate recognition of C. trachomatis by receptors in the genital tract seems to be a relevant step in the immune response, and may play a role in protecting the host against the development of late sequelae following a $C$. trachomatis infection. 


\section{Acknowledgements}

Sander Ouburg is an AstraZeneca Nederland BV fellow.

Servaas A. Morré is supported by the Foundation of Immunogenetics, the Netherlands.

The authors acknowledge Jolein Pleijster, from the Laboratory of Immunogenetics of the VU University Medical Center, for excellent technical assistance, and Gert Grauls, from the Department of Medical Microbiology of the Academic Hospital Maastricht, for laboratory assistance.

The ICTI consortium (Integrated approach to the study of Chlamydia trachomatis Infections) provides a broad specialized network for the multidisciplinary studies described (Morré et al., 2006). The EpiGenChlamydia consortium (http://www.EpiGenChlamydia.eu) is a European Framework Programme 6 (FP6) financially supported Co-ordination Action (CA) in functional genomics research, entitled: Contribution of molecular epidemiology and host-pathogen genomics to understand Chlamydia trachomatis disease. 


\section{REFERENCES}

Den Hartog JE, Land JA, Stassen FRM, Slobbe-Van Drunen MEP, Kessels AGH, Bruggeman CA (2004) The role of chlamydia genus-specific and species-specific IgG-antibody testing in predicting tubal disease in subfertile women. Hum Reprod 19, 1380-1384.

El-Omar EM, Rabkin CS, Gammon MD, Vaughan TL, Risch HA, Schoenberg JB, Stanford JL, Mayne ST, Goedert J, Blot WJ et al. (2003) Increased risk of noncardia gastric cancer associated with proinflammatory cytokine gene polymorphism. Gastroenterology 124, 1193-1201.

Fazeli A, Bruce C, Anumba DO (2005) Characterization of Toll-like receptors in the female reproductive tract in humans. Hum Reprod 20, 1372-1378.

Franchimont D, Vermeire S, El Housni H, Pierik M, Van Steen K, Gustot T, Quertinmont E, Abramowicz M, Van Gossum A, Devière J et al. (2004) Deficient host-bacteria interactions in inflammatory bowel disease? The toll-like receptor (TLR)-4 Asp299gly polymorphism is associated with Crohn's disease and ulcerative colitis. Gut 53, 987-992.

Heresbach D, Gicquel-Douabin V, Birebent B, D'Halluin PN, Heresbach-Le Berre N, Dreano S, Siproudhis L, Dabadie A, Gosselin M, Mosser J et al. (2004) NOD2/CARD15 gene polymorphisms in Crohn's disease: a genotype-phenotype analysis. Eur J Gastroenterol Hepatol 16, 55-62.

Hugot JP, Chamaillard M, Zouali H, Lesage S, Cézard JP, Belaiche J, Almer S, Tysk C, O'Morrain CA, Gassull $\mathrm{M}$ et al. (2001) Association of NOD2 leucine-rich repeat variants with susceptibility to Crohn's disease. Nature 411, 599-603.

Jeremias J, Giraldo P, Durrant S, Ribeiro-Filho A, Witkin SS (1999) Relationship between Ureoplasma urealyticum vaginal colonization and polymorphism in the interleukin-1 receptor antagonist gene. J Infect Dis 180, 912-914.

Kinnunen $A H$, Surcel HM, Lehtinen M, Karhukorpi J, Tiitinen A, Halttunen M, Bloigu A, Morrison RP, Karttunen R, Paavonen J (2002) HLA DQ alleles and interleukin-10 polymorphism associated with Chlamydia trachomatis-related tubal factor infertility: a case-control study. Hum Reprod 17, $2073-$ 2078.

Lammers KM, Ouburg S, Morré SA, Crusius JBA, Gionchetti P, Rizzello F, Morselli C, Caramelli E, Conte R, Poggioli G et al. (2005) Combined carriership of TLR9 -1237C and CD14 -260T alleles enhances the risk of developing chronic relapsing pouchitis. World J Gastroenterol 11, 7323-7329.

Land JA, Evers JLH, Goossens VJ (1998) How to use Chlamydia antibody testing in subfertility patients. Hum Reprod 13, 1094-1098.

Land JA, Gijsen AP, Kessels AGH, Slobbe MEP, Bruggeman CA (2003) Performance of five serological chlamydia antibody tests in subfertile women. Hum Reprod 18, 2621-2627.

Machado JC, Figueiredo C, Canedo P, Pharoah P, Carvalho R, Nabais S, Castro Alves C, Campos ML, Van Doorn LJ, Caldos C et al. (2003) A proinflammatory genetic profile increases the risk for chronic atrophic gastritis and gastric carcinoma. Gastroenterology 125:364-371.

Morré SA, Murillo LS, Spaargaren J, Fennema JSA, Peña AS (2002) Role of the toll-like receptor 4 Asp299Gly polymorphism in susceptibility to Candida albicans infection. J Infect Dis 186, 1377-1379.

Morré SA, Murillo LS, Bruggeman CA, Peña AS (2003) The role that the functional Asp299Gly polymorphism in the toll-like receptor-4 gene plays in the susceptibility to Chlamydia trachomatis-associated tubal infertility. J Infect Dis 187, 341-342.

Morré SA, Spaargaren J, Ossewaarde JM, Land JA, Bax CJ, Dörr PJ, Oostvogel PM, Vanrompay D, Savelkoul PHM, Pannekoek Y et al. (2006) Description of the ICTI consortium: an integrated approach to the study of Chlamydia trachomatis infection. Drugs Today 42 (Suppl A), 107-114.

Murillo L, Crusius JBA, Van Bodegraven AA, Alizadeh BZ, Peña AS (2002) CARD15 gene and the classification of Crohn's disease. Immunogenetics 54, 59-61.

Opitz B, Förster S, Hocke AC, Maass M, Schmeck B, Hippenstiel S, Suttorp N, Krüll M (2005) Nod1mediated endothelial cell activation by Chlamydophila pneumoniae. Circ Res 96, 319-326. 
Ouburg S, Spaargaren J, Den Hartog JE, Land JA, Fennema JSA, Pleijster J, Peña AS, Morré SA (2005) The $C D 14$ functional gene polymorphism $-260 \mathrm{C}>\mathrm{T}$ is not involved in either the susceptibility to Chlamydia trachomatis infection or the development of tubal pathology. BMC Infect Dis 5, 114.

Peeters H, Vander Cruyssen B, Laukens D, Coucke P, Marichal D, Van Den Berghe M, Cuvelier C, Remaut E, Mielants H, De Keyser F et al. (2004) Radiological sacroiliitis, a hallmark of spondylitis, is linked with CARD15 gene polymorphisms in patients with Crohn's disease. Ann Rheum Dis 63, 1131-1134.

Pioli PA, Amiel E, Schaefer TM, Connolly JE, Wira CR, Guyre PM (2004) Differential expression of Toll-like receptors 2 and 4 in tissues of the human female reproductive tract. Infect Immun 72, 5799-5806.

Punnonen R, Terho P, Nikkanen V, Meurman O (1979) Chlamydial serology in infertile women by immunofluorescence. Fertil Steril 31, 656-659.

Schaefer TM, Desouza K, Fahey JV, Beagley KW, Wira CR (2004) Toll-like receptor (TLR) expression and TLR-mediated cytokine/chemokine production by human uterine epithelial cells. Immunology 112 , 428-436.

Smirnova I, Mann N, Dols A, Derkx HH, Hibberd ML, Levin M, Beutler B (2003) Assay of locus-specific genetic load implicates rare Toll-like receptor 4 mutations in meningococcal susceptibility. Proc Natl Acad Sci U S A 100, 6075-6080.

Wang C, Tang J, Geisler WM, Crowley-Nowick PA, Wilson CM, Kaslow RA (2005) Human leukocyte antigen and cytokine gene variants as predictors of recurrent Chlamydia trachomatis infection in high-risk adolescents. J Infect Dis 191, 1084-1092. 



\section{Chapter 8}

Detection of Chlamydia trachomatis in endometrium of subfertile women: a pilot study using immunohistochemical staining and PCR

JE den Hartog, PG Groothuis, R Kamps, FRM Stassen, CA Bruggeman, JA Land, JLH Evers, SA Morré

In preparation 


\section{ABSTRACT}

\section{Background}

Chlamydia $(C$.) trachomatis infections are a known cause of tubal factor subfertility. Persistent $C$. trachomatis endometrial infection may also negatively influence fertility by decreasing the implantation capacity of the endometrium. The present study evaluates the detection rate of C. trachomatis in endometrial samples of subfertile women with and without tubal pathology using immunohistochemical staining and polymerase chain reaction (PCR).

\section{Methods}

Forty subfertile women were included in the present study. C. trachomatis antibody testing (CAT) and laparoscopy with tubal testing were performed as part of the fertility work-up. Endometrial samples were collected for immunohistochemical staining (with four different antibodies directed against $C$. trachomatis major outer membrane protein and heat shock protein) and PCR. C. trachomatis-infected human epithelial (HEp2) cells and mock-infected HEp2 cells served as positive and negative controls respectively.

\section{Results}

Of all forty women participating in the present study, 17 women $(42.5 \%)$ had a positive CAT, and 9 women (22.5\%) had tubal pathology at laparoscopy. For none of the four antibodies, significant differences were found in immunohistochemical staining results between endometrial samples of subfertile women with a positive or negative CAT, and with or without tubal pathology. All thirteen endometrial samples tested by PCR were negative.

\section{Conclusions}

No correlation was found between immunohistochemical staining results in endometrial samples and clinical parameters in our cohort of 40 patients. PCR results were negative in all thirteen samples tested, but this subgroup was very small. Larger cohorts are needed to re-evaluate the relation between CAT, C. trachomatis PCR on endometrial samples, tubal status and clinical outcome (implantation rates). 


\section{INTRODUCTION}

Chlamydia $(C$.$) trachomatis lower genital tract infections usually remain asympto-$ matic and untreated, and therefore may ascend from the cervix to the upper genital tract. It is generally accepted that long term persistence of $C$. trachomatis in the upper genital tract increases the risk for late sequelae, such as tubal pathology, causing ectopic pregnancy and subfertility.

Several test methods have been described to detect $C$. trachomatis in genital tract samples. Nucleic acid amplification tests (NAATs) on both DNA and RNA levels, such as polymerase chain reaction (PCR), have been shown to be the most accurate detection methods (sensitivity $\geq 90 \%$ and specificity 98-100\%) (Van Dyck et al, 2001, Watson et al., 2002). NAATs are capable of detecting DNA and RNA sequences with a length of less than 50 base pairs or nucleotides respectively (Noguchi et al., 2002). Immunohistochemical staining methods have other targets (proteins or lipopolysaccharides) and are less accurate in detecting $C$. trachomatis as compared to NAATs because no amplification occurs and larger epitopes are needed to identify the micro-organism (Noguchi et al., 2002).

Despite the known association between $C$. trachomatis genital tract infections and subfertility, active endocervical $C$. trachomatis infections are infrequently found in subfertile women because the interval between initial infection and subfertility is generally several years. A mean prevalence of $\sim 3 \%$ has been demonstrated in studies using NAATs on cervical samples obtained from subfertile women (Witkin et al., 1994, Witkin et al., 1995, Eggert-Kruse et al., 1997, Macmillan and Templeton, 1999, Land et al., 2002, Debattista et al., 2004, De Barbeyrac et al., 2006, Guven et al., 2007, Machado et al., 2007, Imudia et al., 2008, Svenstrup et al., 2008, WilkowskaTrojniel et al., 2009, Dietrich et al., 2010) (Table I).

When using NAATs on tubal samples of women with ectopic pregnancy or tubal factor subfertility, a mean prevalence of $C$. trachomatis of $12 \%$ has been found (Osser and Persson, 1992, Lan et al., 1995, Haeusler et al., 1997, Gérard et al., 1998, Hinton et al., 2000, Barlow et al., 2001, Noguchi et al., 2002, Debattista et al., 2004, Bjartling et al., 2007) (Table II). C. trachomatis detection rates in tubal tissue as high as $70 \%$ show that women who have previously undergone a $C$. trachomatis infection (usually during adolescence) and who suffer from late sequelae, may still harbour the micro-organism in the upper genital tract. Others, however, were unable to confirm the presence of $C$. trachomatis in tubal tissue of women with ectopic pregnancy (Osser and Persson, 1992, Bjartling et al., 2007) (Table II). The large differences in prevalence figures between the studies mentioned may be explained by differences in study cohort, sample size, preservation method of the tissue (freshfrozen or paraffin-embedded) or test method. 
Table I. The prevalence of $C$. trachomatis in cervical samples of subfertile women using nucleic acid amplification tests.

\begin{tabular}{|c|c|c|c|}
\hline Author and year & Patients & Controls & Results (\% CT-positive) \\
\hline Witkin et al., 1994 & $\begin{array}{l}198 \text { subfertile women under- } \\
\text { going IVF }\end{array}$ & None & $\begin{array}{l}\text { Overall: } 9.1 \%(18 / 198) \\
\text { Pregnant: } 4.4 \%(3 / 68) \\
\text { Not pregnant: } 11.5 \%(15 / 130)\end{array}$ \\
\hline Witkin et al., 1995 & $\begin{array}{l}307 \text { subfertile women under- } \\
\text { going IVF }\end{array}$ & None & $\begin{array}{l}\text { Overall: } 6.5 \%(20 / 307) \\
\text { Ongoing pregnancy: } 1.8 \%(2 / 112) \\
\text { Abortion: } 9.8 \%(4 / 41) \\
\text { Not pregnant: } 9.6 \%(13 / 135) \\
\text { No fertilization: } 5.3 \%(1 / 19)\end{array}$ \\
\hline $\begin{array}{l}\text { Eggert-Kruse et al., } \\
1997\end{array}$ & $\begin{array}{l}150 \text { subfertile women under- } \\
\text { going a fertility work-up }\end{array}$ & None & $1.3 \%(2 / 150)$ \\
\hline $\begin{array}{l}\text { Macmillan and } \\
\text { Templeton, } 1999\end{array}$ & $\begin{array}{l}210 \text { subfertile women under- } \\
\text { going a fertility work-up }\end{array}$ & None & $1.9 \%(4 / 210)$ \\
\hline Land et al., 2002 & $\begin{array}{l}255 \text { subfertile women under- } \\
\text { going a fertility work-up }\end{array}$ & None & $2.0 \%(5 / 255)$ \\
\hline $\begin{array}{l}\text { Debattista et al., } \\
2004\end{array}$ & $\begin{array}{l}39 \text { subfertile women undergo- } \\
\text { ing a laparoscopy }\end{array}$ & None & $0 \%(0 / 39)$ \\
\hline $\begin{array}{l}\text { De Barbeyrac } \\
\text { et al., } 2006\end{array}$ & $\begin{array}{l}261 \text { subfertile women under- } \\
\text { going IVF }\end{array}$ & None & $2.7 \%(7 / 261)$ \\
\hline Guven et al., 2007 & $\begin{array}{l}31 \text { unexplained subfertile } \\
\text { women }\end{array}$ & $\begin{array}{l}31 \text { women } \\
\text { undergoing } \\
\text { sterilization }\end{array}$ & $\begin{array}{l}\text { Patients: } 3.2 \%(1 / 31) \\
\text { Controls: } 0 \%(0 / 31)\end{array}$ \\
\hline $\begin{array}{l}\text { Machado et al., } \\
2007\end{array}$ & $\begin{array}{l}33 \text { women with tubal factor } \\
\text { subfertility } \\
22 \text { women with } \geq 1 \text { prior } \\
\text { ectopic pregnancy }\end{array}$ & $\begin{array}{l}55 \text { parous } \\
\text { women }\end{array}$ & $\begin{array}{l}\text { Tubal factor subfertility: } 6.1 \%(2 / 33) \\
\text { Prior ectopic pregnancy: } 0 \%(0 / 22) \\
\text { Controls: } 0 \%(0 / 55)\end{array}$ \\
\hline Imudia et al., 2008 & $\begin{array}{l}236 \text { subfertile women under- } \\
\text { going a fertility work-up }\end{array}$ & None & $2.2 \%(5 / 231)$ \\
\hline $\begin{array}{l}\text { Svenstrup et al., } \\
2008\end{array}$ & $\begin{array}{l}212 \text { subfertile women under- } \\
\text { going a fertility work-up }\end{array}$ & None & $0.5 \%(1 / 212)$ \\
\hline $\begin{array}{l}\text { Wilkowska-Trojniel } \\
\text { et al., } 2009\end{array}$ & $\begin{array}{l}71 \text { subfertile women } \\
23 \text { women with tubal factor } \\
\text { subfertility } \\
48 \text { women with non-tubal } \\
\text { factor subfertility }\end{array}$ & None & $\begin{array}{l}\text { Overall: } 8.5 \%(6 / 71) \\
\text { Tubal factor subfertility: } 8.7 \%(2 / 23) \\
\text { Non-tubal factor subfertility: } 8.3 \% \\
(4 / 48)\end{array}$ \\
\hline $\begin{array}{l}\text { Dietrich et al., } \\
2010\end{array}$ & $\begin{array}{l}202 \text { subfertile women under- } \\
\text { going a laparoscopy }\end{array}$ & None & $1.0 \%(2 / 202)$ \\
\hline
\end{tabular}

Several studies have evaluated the involvement of the endometrium (i.e. plasma cell endometritis and, more specific, endometrial $C$. trachomatis infection) in women with $C$. trachomatis lower or upper genital tract infection. Histopathological manifestations of endometritis (plasma cells and infiltrations of leucocytes) have been found in $30-40 \%$ of women with C. trachomatis cervicitis (Paavonen et al., 1985a; Wiesenfeld et al., 2002) and in 70\% of women with suspected pelvic inflammatory disease (Paavonen et al., 1985b). The micro-organism itself has been detected in the endometrium of $17 \%$ (range $3-50 \%$ ) of women with signs of endometritis or tubal pathology in studies using NAATs (Winkler et al., 1984, Lan et al., 
1995, Stern et al., 1996, Barlow et al., 2001) (Table III). In studies using immunohistochemical staining methods, $C$. trachomatis prevalence figures of $4-57 \%$ have been reported in women with ectopic pregnancy or chronic endometritis (Winkler et al., 1984, Toth et al., 2000).

Table II. The prevalence of $C$. trachomatis in tubal samples of women with subfertility and/or tubal pathology using nucleic acid amplification tests.

\begin{tabular}{|c|c|c|c|}
\hline Author and year & Patients & Controls & Results (\% CT-positive) \\
\hline Osser and Persson, 1992 & $\begin{array}{l}86 \text { women with ectopic } \\
\text { pregnancy }\end{array}$ & None & $0 \%(0 / 86)$ \\
\hline Lan et al., 1995 & $\begin{array}{l}37 \text { women with ectopic } \\
\text { pregnancy }\end{array}$ & None & $2.7 \%(1 / 37)$ \\
\hline Haeusler et al., 1997 & $\begin{array}{l}20 \text { subfertile women } \\
\text { undergoing a hys- } \\
\text { teroscopy + laparoscopy }\end{array}$ & None & $5.0 \%(1 / 20)$ \\
\hline Gérard et al., 1998 & $\begin{array}{l}10 \text { women with ectopic } \\
\text { pregnancy }\end{array}$ & None & $70.0 \%(7 / 10)$ \\
\hline Hinton et al., 2000 & $\begin{array}{l}77 \text { women with chronic } \\
\text { salpingitis }\end{array}$ & $\begin{array}{l}77 \text { women with histologi- } \\
\text { cally normal tubes }\end{array}$ & $\begin{array}{l}\text { Patients: } 11.7 \%(9 / 77) \\
\text { Controls: } 0 \%(0 / 77)\end{array}$ \\
\hline Barlow et al., 2001 & $\begin{array}{l}30 \text { women with ectopic } \\
\text { pregnancy } \\
14 \text { women with tubal } \\
\text { factor subfertility }\end{array}$ & $\begin{array}{l}50 \text { women undergoing } \\
\text { hysterectomy or steriliza- } \\
\text { tion }\end{array}$ & $\begin{array}{l}\text { Ectopic pregnancy: } 46.7 \% \\
(14 / 30) \\
\text { Tubal factor subfertility: } \\
35.7 \%(5 / 14) \\
\text { Controls: } 6.0 \%(3 / 50)\end{array}$ \\
\hline Noguchi et al., 2002 & $\begin{array}{l}11 \text { women with ectopic } \\
\text { pregnancy, pyosalpinx or } \\
\text { hydrosalpinx }\end{array}$ & None & $36.4 \%(4 / 11)$ \\
\hline Debattista et al., 2004 & $\begin{array}{l}41 \text { subfertile women } \\
\text { undergoing a laparoscopy }\end{array}$ & None & $2.4 \%(1 / 41)$ \\
\hline Bjartling et al., 2007 & $\begin{array}{l}55 \text { women with ectopic } \\
\text { pregnancy }\end{array}$ & None & $0 \%(0 / 55)$ \\
\hline
\end{tabular}

Table III. The prevalence of $C$. trachomatis in endometrial samples of women with endometritis or tubal pathology using nucleic acid amplification tests.

\begin{tabular}{|c|c|c|c|}
\hline Author & Patients & Controls & Results (\% CT-positive) \\
\hline Lan et al., 1995 & $\begin{array}{l}18 \text { women with ectopic } \\
\text { pregnancy }\end{array}$ & None & $16.7 \%(3 / 18)$ \\
\hline Stern et al., 1996 & $\begin{array}{l}38 \text { women with abnormal } \\
\text { bleeding and chronic } \\
\text { endometritis }\end{array}$ & None & $2.6 \%(1 / 38)$ \\
\hline Barlow et al., 2001 & $\begin{array}{l}30 \text { women with ectopic } \\
\text { pregnancy } \\
14 \text { women with tubal } \\
\text { factor subfertility }\end{array}$ & $\begin{array}{l}50 \text { women undergoing } \\
\text { hysterectomy or steriliza- } \\
\text { tion }\end{array}$ & $\begin{array}{l}\text { Ectopic pregnancy: } 20.0 \% \\
(6 / 30) \\
\text { Tubal factor subfertility: } \\
50.0 \%(7 / 14) \\
\text { Controls: } 2.0 \%(1 / 50)\end{array}$ \\
\hline
\end{tabular}


It has been hypothesized that persistent endometrial infections (as reflected by the presence of microbial products or inflammatory mediators) affect either the conceptus or the implantation capacity of the endometrium, leading to implantation failure (Kamiyama et al., 2004, Romero et al., 2004). More specifically, ongoing $C$. trachomatis infections have been associated with lower implantation rates and lower pregnancy rates in women undergoing IVF (Witkin et al., 1994, Witkin et al., 1995, Pacchiarotti et al., 2009).

However, as mentioned before, detection rates of $C$. trachomatis in endometrial samples as described in literature vary between 3 and 57\%, due to - amongst others - different test methods and different study populations. Therefore, the precise clinical significance and consequences of harbouring $C$. trachomatis in the endometrium remain unclear. The aim of the present pilot study was to evaluate the detection rate of $\mathrm{C}$. trachomatis in endometrial samples of subfertile women with and without tubal factor subfertility using two different test methods: immunohistochemical staining (detecting $C$. trachomatis major outer membrane protein [MOMP] and heat shock protein [HSP]) and PCR (detecting C. trachomatis DNA).

\section{MATERIALS AND METHODS}

\section{Study population}

The study population consisted of 40 women who visited the Maastricht University Medical Center Fertility Clinic and who underwent a laparoscopy with tubal testing as part of the fertility work-up between April 2001 and February 2005. In all patients blood was drawn at their initial visit for the purpose of $C$. trachomatis IgG antibody testing (CAT). In patients with a negative CAT and an otherwise normal basic fertility evaluation, tubal status was evaluated initially by hysterosalpingography (HSG). If HSG showed abnormalities, or if patients did not conceive in the six months following HSG, the fertility evaluation was concluded by laparoscopy with tubal testing using methylene blue dye. In patients with a positive CAT no HSG was performed, but tubal status was evaluated primarily by laparoscopy. Patients with a history of pelvic surgery (except for an uneventful appendectomy or Caesarean section) or pelvic inflammatory disease, and patients with suspected severe endometriosis, based on history and findings at pelvic examination, also underwent laparoscopy directly.

All women received a single oral dose of azithromycin $1000 \mathrm{mg}$ on the evening preceding laparoscopy. Just prior to starting laparoscopy, endometrial samples were collected by transvaginal biopsy using a sampling device (Gynotec, Malden, the Netherlands). The obtained tissue was embedded in paraffin. All patients gave their 
written informed consent for collection and use of the endometrial samples for the purpose of fertility research.

Tubal pathology was defined as extensive peri-adnexal adhesions and/or at least unilateral tubal occlusion at laparoscopy.

\section{Serological methods}

During the years, different CAT tests have been used in our Fertility Clinic. In serum samples obtained before 2003, the micro-immunofluorescence (MIF) test by Biomérieux (Boxtel, the Netherlands) was performed, whereas in 2003 it was replaced by the MIF test of AniLabsystems (Vantaa, Finland), which by then had been shown to be superior (Land et al., 2003). Both MIF tests were performed according to the manufacturer's instructions (Land et al., 2003). The cut-off level for a positive test was 32 for both MIF tests.

\section{Patient characteristics}

Of all 40 subfertile women participating in the present study, $80 \%$ had a primary subfertility and $20 \%$ had a secondary subfertility. The mean age at intake was 30.9 years (range 25-38). The mean duration of subfertility was 23 months (range 0-82). Seventeen women (57.5\%) had a negative CAT, whereas 23 women $(42.5 \%)$ had a positive CAT.

All women took care of appropriate contraception (condoms or no intercourse) in the month that laparoscopy was performed. None of the patients used oral contraceptives. Laparoscopy reports were scored independently by two investigators who were unaware of the CAT results, and were categorized according to the presence of adhesions and tubal patency. Of all 40 women, 31 women (77.5\%) had no tubal pathology and 9 women (22.5\%) had tubal pathology. Of the 31 women without tubal pathology, 6 had a history of abdominal surgery (four uneventful appendectomies, one Caesarean section and one uneventful appendectomy and ileocoecal resection because of Crohn's disease) and 2 had a history of proven and treated $C$. trachomatis cervicitis. Of the 9 women with tubal pathology, 6 had previous abdominal surgery (one ectopic pregnancy following an episode of suspected and treated PID, one extensive surgery for endometriosis, one unilateral cystectomy, one uneventful appendectomy and repeated coagulation of endometriosis and two uneventful appendectomies).

\section{Immunohistochemical staining}

For the purpose of immunohistochemical staining, sections of $5 \mu \mathrm{m}$ thickness were cut from the paraffin-embedded blocks. 


\section{Monoclonal anti-MOMP and anti-HSP antibodies}

Paraffin sections were deparaffinized in xylene for $2 * 5$ minutes and rehydrated in alcohol series. Endogenous peroxidase was blocked by incubation with $0.25 \%$ hydrogen peroxide in methanol for 25 minutes. Sections were washes three times in phosphate-buffered saline (PBS). Antigen retrieval was performed by microwave irradiation in sodium citrate $\mathrm{pH} 6.0$ for 20 minutes, followed by cooling for $20 \mathrm{~min}$ utes. Sections were washed three times in PBS and preincubated with $2 \%$ bovine serum albumin (BSA) in PBS for 10 minutes. Sections were incubated overnight at $4^{\circ} \mathrm{C}$ with the primary monoclonal anti-MOMP antibody (1:1500; Fitzgerald Industries International, Inc., Concord, USA) or were incubated for two hours at $4^{\circ} \mathrm{C}$ with the primary monoclonal anti-HSP antibody (1:750; Affinity BioReagents, Golden, USA) respectively. After washing once in $0.1 \%$ Tween 20 in PBS and twice in PBS (in case of the anti-HSP antibody: three times in PBS), sections were exposed to ChemMate DAKO EnVision (DakoCytomation, Glostrup, Denmark) for 30 minutes. After washing once in $0.1 \%$ Tween 20 in PBS and twice in PBS (in case of the anti-HSP antibody: three times in PBS), antibody binding was visualized by incubation with 3,3'diaminobenzidine (DAB) for 7 minutes. Sections were washed in Milli-Q, counterstained in haematoxylin, washed in tap water, dehydrated and mounted in Entellan for light microscopic evaluation.

\section{Polyclonal anti-MOMP antibodies}

Paraffin sections were deparaffinized in xylene for $2 * 5$ minutes and rehydrated in alcohol series. Endogenous peroxidase was blocked by incubation with $0.25 \%$ hydrogen peroxide in methanol for 25 minutes. Sections were washes three times in PBS. Antigen retrieval was performed by microwave irradiation in sodium citrate $\mathrm{pH}$ 6.0 for 20 minutes, followed by cooling for 20 minutes. Sections were washed three times in PBS and preincubated with $2 \%$ BSA in PBS for 10 minutes. Sections were incubated overnight at $4^{\circ} \mathrm{C}$ with the primary polyclonal antibodies (both 1:3000; Fitzgerald Industries International, Inc., Concord, USA and US Biological, Swampscott, USA). After washing once in $0.1 \%$ Tween 20 in PBS and twice in PBS, sections were incubated with the secondary polyclonal biotinylated rabbit anti-goat antibody (1:100; DakoCytomation, Glostrup, Denmark) for 30 minutes. After washing once in $0.1 \%$ Tween20 in PBS and twice in PBS, sections were exposed to ChemMate DAKO EnVision (DakoCytomation, Glostrup, Denmark) for 30 minutes. After washing once in $0.1 \%$ Tween 20 in PBS and twice in PBS, antibody binding was visualized by incubation with $D A B$ for 7 minutes. Sections were washed in Milli-Q, counterstained in haematoxylin, washed in tap water, dehydrated and mounted in Entellan for light microscopic evaluation. 
PCR

Genomic DNA was extracted from the paraffin-embedded endometrial tissue using the High Pure PCR Template Preparation Kit according to the manufacturers' instructions (Roche Molecular Biochemicals, Grenzach-Wyhlen, Germany). C. trachomatis detection was performed using an in-house real time PCR-based TaqManassay, as described elsewhere (Catsburg et al., 2006).

\section{Positive and negative controls for immunohistochemical staining and PCR}

Human epithelial cells (HEp2, ATCC CCL-23) were cultured in culture medium [Eagle's Minimal Essential Medium (Cambrex BioScience, Verviers, Belgium) supplemented with $10 \%$ fetal calf serum, non-essential aminoacids and $200 \mathrm{mM}$ LGlutamin] at $37^{\circ} \mathrm{C}$ with $5 \% \mathrm{CO}_{2}$ and saturated humidity. The HEp2 positive controls were inoculated with $C$. trachomatis (human serovar L2) at a multiplicity of infection of 1 and diluted in infection medium [Eagle's Minimal Essential Medium (Cambrex BioScience, Verviers, Belgium) supplemented with $2 \%$ fetal calf serum, non-essential aminoacids, $200 \mathrm{mM}$ L-Glutamin and $0.5 \mathrm{ug} / \mathrm{mL}$ cycloheximide]. Cells were incubated for one hour at room temperature and 1900 rounds per minute, and subsequently cultivated at $37^{\circ} \mathrm{C}$. The HEp2 negative controls were inoculated with sucrose-phosphate-glucose solution in infection medium and processed in the same manner as the HEp2 positive controls. Finally, the cells were harvested and embedded in paraffin.

\section{Scoring methods}

Two investigators (F.R.M.S. and S.A.M.), who were unaware of the CAT results and laparoscopy reports, independently scored all 160 patient sections (40 patients * 4 antibodies) and the positive and negative HEp2 controls. A semi-quantitative scoring method was developed and applied in multiple high power fields (* 400). The following consensus-based definitions were used: no cells stained $=$ negative (score 0 ); less than five cells stained = equivocal (score 1); five or more cells to a maximum of $50 \%$ of all cells stained $=$ positive (score 2 ); more than $50 \%$ of all cells stained $=$ highly positive (score 3 ). Sections in which it was impossible to quantify the staining score (e.g. extensive background staining, too little tissue or folded sections) were excluded from the analyses.

\section{Statistical analysis}

Kappa was calculated to measure the agreement in staining score between both observers for each of the four antibodies in sections in which both investigators were able to quantify the staining score. For this purpose, the semi-quantitative scoring method had to be dichotomized. For all four antibodies, we have calculated 
kappa-values twice: once with equivocal sections categorized as positive and once with equivocal sections categorized as negative. Kappa-values between 0 and 0.19 indicate poor agreement, values between 0.20 and 0.39 indicate fair agreement, values between 0.40 and 0.59 indicate moderate agreement, values between 0.60 and 0.79 indicate substantial agreement and values between 0.80 and 1.00 indicate (almost) perfect agreement between both observers.

For a comparison between immunohistochemical staining results and clinical parameters (CAT and tubal status), a mean staining score was calculated for each section for the four antibodies separately. Furthermore, a total mean staining score was calculated for each section, i.e.the sum of the staining scores for all four antibodies separately and for both observers divided by the number of sections in which the staining could be quantified. The Mann-Whitney $U$-test was used to compare the mean staining score in CAT-positive and CAT-negative women. The KruskalWallis test was used to compare the mean staining score in CAT-positive and CATnegative women with and without tubal pathology. $P$-values $<0.05$ were considered to be statistically significant.

\section{RESULTS}

\section{Immunohistochemical staining}

The positive controls (C. trachomatis infected HEp2 cells) were all highly positive with all four antibodies used in this study (Figure I), whereas the negative controls (mock-infected HEp2 cells) were all negative (Figure II).

The percentage of endometrial sections in which the staining could be quantified was $79 \%, 80 \%, 78 \%$ and $34 \%$ for the monoclonal anti-MOMP antibody (Fitzgerald Industries International), both polyclonal anti-MOMP antibodies (Fitzgerald Industries International and US Biological) and the monoclonal anti-HSP antibody (Affinity BioReagents) respectively.

Kappa was calculated to document inter-observer variability. First, equivocal sections were categorized as positive. Kappa was $0.93,1.00$ and 0.92 for the monoclonal anti-MOMP antibody and both polyclonal anti-MOMP antibodies respectively, indicating (almost) perfect agreement between both observers. For the monoclonal anti-HSP antibody, kappa was 0.35, indicating moderate agreement between both observers. If equivocal sections were categorized as negative, kappa was $0.90,0.89,0.70$ and 0.74 for all four antibodies respectively. In the present study, the intra-observer variability was not determined. 


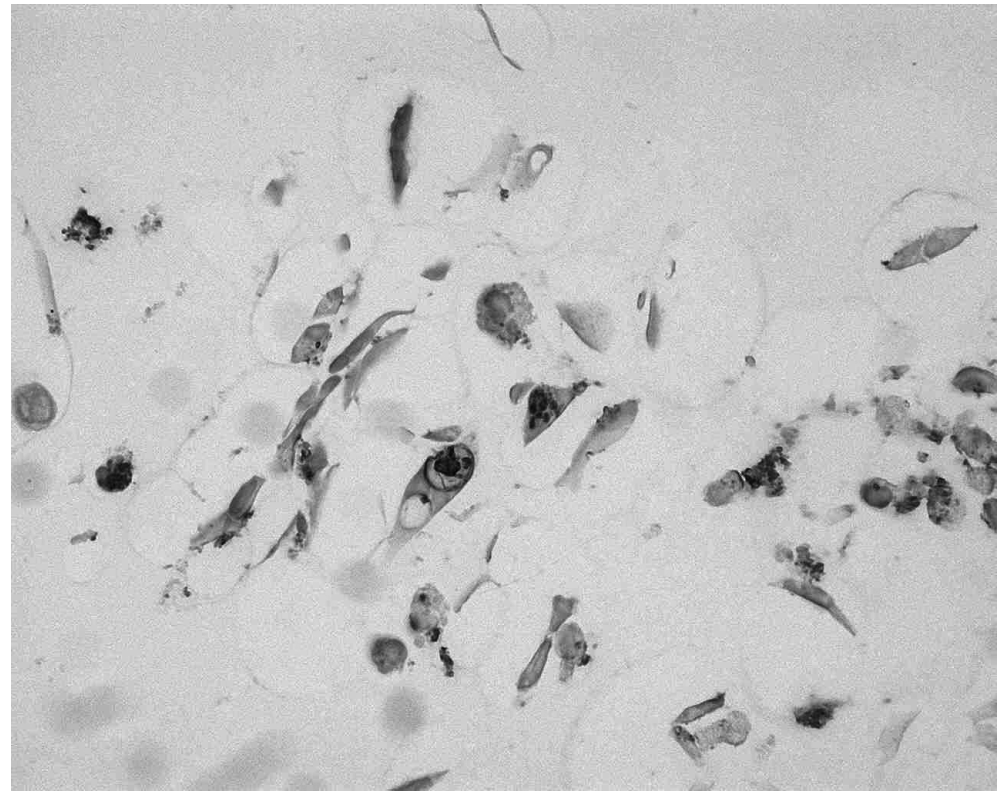

Figure I. C. trachomatis-infected HEp2 cells stained with anti-MOMP antibody (1:1500; Fitzgerald Ind. Int.) (* 400).

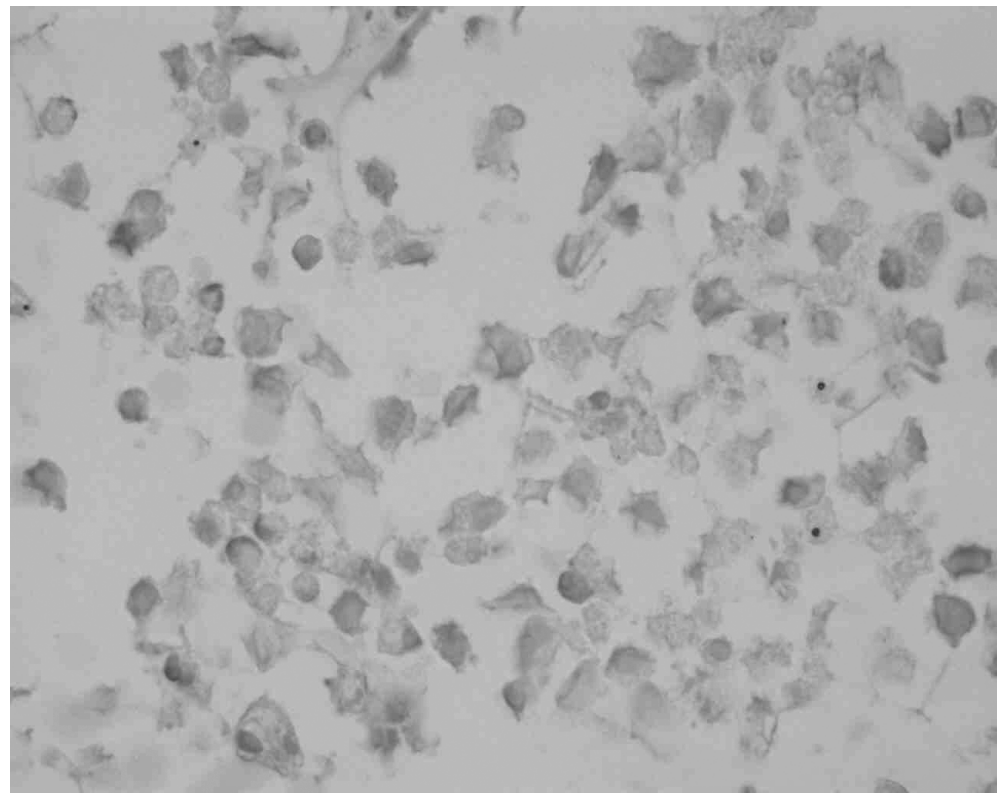

Figure II. Mock-infected HEp2 cells stained with anti-MOMP antibody (1:1500; Fitzgerald Ind. Int.) (* 400). 
Table IV and V reflect the relation between clinical parameters (CAT and the presence of tubal pathology) and the mean staining score. When comparing the mean staining scores in CAT-negative and CAT-positive women, respectively, no significant differences were found (Table IV). Also, when taking the tubal status into account, no significant differences were found in staining scores between the subgroups mentioned (Table V).

Table IV. Relation between CAT and mean staining score.

\begin{tabular}{|c|c|c|c|c|c|}
\hline \multirow[t]{2}{*}{$\mathrm{CAT}^{\mathrm{a}}$} & \multicolumn{5}{|c|}{ Mean staining score ${ }^{b}$} \\
\hline & $\begin{array}{l}\text { Monoclonal anti- } \\
\text { MOMP antibody } \\
\text { (Fitzgerald Ind. } \\
\text { Int.) }\end{array}$ & $\begin{array}{l}\text { Monoclonal anti- } \\
\text { HSP antibody } \\
\text { (Affinity Bio- } \\
\text { Reagents) }\end{array}$ & $\begin{array}{l}\text { Polyclonal anti- } \\
\text { MOMP antibody } \\
\text { (Fitzgerald Ind. } \\
\text { Int.) }\end{array}$ & $\begin{array}{l}\text { Polyclonal anti- } \\
\text { MOMP antibody } \\
\text { (US Biological) }\end{array}$ & $\begin{array}{l}\text { All four antibodies } \\
\text { combined }\end{array}$ \\
\hline \multicolumn{2}{|c|}{ Negative0.9 } & 1.0 & 0.8 & 0.8 & 0.8 \\
\hline \multicolumn{2}{|c|}{ Positive 0.7} & 1.2 & 0.3 & 0.7 & 0.6 \\
\hline
\end{tabular}

${ }^{\mathrm{a}}$ C. trachomatis IgG antibody test; ${ }^{\mathrm{b}}$ Mean staining score: no cells stained = negative (score 0); less than five cells stained $=$ equivocal (score 1 ); five or more cells to a maximum of $50 \%$ of all cells stained $=$ positive (score 2 ); more than $50 \%$ of all cells stained = highly positive (score 3 ).

Table V. Relation between CAT, tubal status and mean staining score.

\begin{tabular}{llll}
\hline CAT $^{\mathrm{a}}$ & $\mathrm{TP}^{\mathrm{b}}$ & $\mathrm{n}$ & $\begin{array}{l}\text { Mean staining score for all } \\
\text { four antibodies combined }\end{array}$ \\
\hline Negative & No & $17^{\mathrm{d}}$ & 0.7 \\
Negative & Yes & 5 & 0.9 \\
Positive & No & $12^{\mathrm{e}}$ & 0.6 \\
Positive & Yes & 4 & 0.5 \\
\hline
\end{tabular}

${ }^{\mathrm{a}}$ C. trachomatis IgG antibody test; ${ }^{\mathrm{b}}$ Tubal pathology; ${ }^{\mathrm{c}}$ Mean staining score: no cells stained $=$ negative (score 0 ); less than five cells stained = equivocal (score 1); five or more cells to a maximum of $50 \%$ of all cells stained $=$ positive (score 2 ); more than $50 \%$ of all cells stained = highly positive (score 3 ); ${ }^{d}$ Exclusion of 1 CAT-negative patient: staining could not be quantified in all sections; ${ }^{\text {e }}$ Exclusion of 1 CAT-positive patient: staining could not be quantified in all sections.

\section{PCR}

The positive controls (C. trachomatis infected HEp2 cells) were positive in the PCR analysis, whereas the negative controls (mock-infected HEp2 cells) were negative. From 13 women (not including the three patients with a history of suspected PID or C. trachomatis cervicitis), sufficient endometrial tissue was available for PCR analysis. Of these 13 women, five women (38\%) had a negative CAT and no tubal pathology, two women (15\%) had a negative CAT and tubal pathology, four women (31\%) had a positive CAT and no tubal pathology and two women (15\%) had a positive CAT and tubal pathology. In these 13 endometrial samples, the mean staining score was 1.0, 0.8, 0.8 and 1.5 when using the monoclonal anti-MOMP antibody (Fitzgerald 
Industries International), both polyclonal anti-MOMP antibodies (Fitzgerald Industries International and US Biological) and the monoclonal anti-HSP antibody (Affinity BioReagents) respectively. Using PCR, all 13 endometrial samples tested were $C$. trachomatis negative, while the control beta globin PCR checking for the presence of human DNA was all positive in all samples.

\section{DISCUSSION}

It is known that $C$. trachomatis is able to persist in the fallopian tubes of women with tubal pathology (Patton et al., 1994, Lan et al., 1995, Haeusler et al., 1997, Gérard et al., 1998, Noguchi et al., 2002). It is hypothesized that the endometrium may also harbour persistent $C$. trachomatis micro-organisms, which may negatively affect implantation rates. In this pilot study, we have evaluated the detection rate of $C$. trachomatis in paraffin-embedded endometrial samples of subfertile women, using immunohistochemical staining and PCR.

Of all 40 women participating in the present study, $42.5 \%$ had serological evidence of a previous $C$. trachomatis infection (as reflected by the presence of $C$. trachomatis IgG antibodies in serum) and $22.5 \%$ had tubal pathology at laparoscopy.

Immunohistochemical staining resulted in moderately to well-consistent findings, as reflected by satisfactory kappa-values $(0.35-1.00)$. However, no significant relation was found between the staining results and clinical parameters (CAT and tubal status). Possible explanations for our findings may be that $C$. trachomatis was not present in the endometrium, it was missed in the sample or in the slices, or smaller pieces of the micro-organism were present, which immunohistochemical staining methods fail to detect. Furthermore, the staining that was observed in the endometrial samples may have been aspecific. In approximately 1 out of 5 sections (for the monoclonal anti-HSP antibody even in 2 out of 3 sections), we were not able to quantify the staining appropriately, indicating that this test method is of little use.

Because of the absence of a correlation between staining results and clinical parameters, we have decided to perform PCR, which is known to be a more accurate test method as compared to immunohistochemical staining, on part of the samples. The decision to perform immunohistochemical staining as a first test was made at the start of our pilot study, because we did not have sufficient tissue available for PCR on all samples. PCR (which is considered the most accurate test method) showed negative results in all 13 samples tested, while the control beta globin PCR checking for the presence of human DNA was positive in all samples. Different factors may explain our negative PCR results. It is possible that $C$. trachomatis was present in the endometrium, but it was missed when collecting the biopsy samples or cutting the slices. In literature, varying prevalence results (3-50\%; Table III) are described, and our population may be too small to include $C$. trachomatis-positive 
cases. Unfortunately, no sufficient endometrial tissue was available for PCR testing in the remaining 27 women.

Furthermore, all women received prophylactic antibiotics (a single oral dose of 1000 mg azithromycin on the evening preceding laparoscopy) to protect against iatrogenic spread or reactivation of unnoticed $C$. trachomatis genital tract infections during instrumentation (Land et al., 2002). Azithromycin is known for its ability to rapidly reach very high tissue concentrations (within a few hours) (Lode, 1991, Peters et al., 1992, Worm and Østerlind, 1995, McCarty, 1996) and to inhibit protein synthesis in C. trachomatis-infected cells (Engel, 1992). When administered orally preceding gynaecological surgery, highest tissue levels of azithromycin have been demonstrated after 24 hours, and even after up to 96 hours azithromycin has still been detectable in gynaecological tissues (Krohn, 1991). After administration of a single oral dose of $1000 \mathrm{mg}$ azithromycin to patients with a C. trachomatis genital tract infection, frequent PCR testing has revealed a clearance rate of $32 \%$ after one day and 60\% after one to three days (Bianchi et al., 1998, Gaydos et al., 1998), although $C$. trachomatis DNA may remain detectable for three to four weeks after antibiotic treatment (Morré et al., 1998). This indicates that the negative PCR results in our study may be explained by clearance following prophylactic treatment with azithromycin.

Implantation rates could not be studied, because only part of our patients eventually underwent IVF, which is the only treatment which allows for calculation of implantation rates. To our knowledge, of all 40 women studied, 29 (73\%) eventually conceived either spontaneously or following fertility treatment. The remaining 11 patients did not conceive despite fertility treatment ( $n=2$ ), underwent fertility treatment in another hospital $(n=2)$, discontinued fertility treatment $(n=2$ because of poor ovarian response, $n=1$ because of fertilization failure at IVF and $n=1$ for personal reasons) or were lost to follow-up $(n=3)$. Remarkably, for all four antibodies studied the mean staining score was lower in women who eventually conceived as compared to those who did not conceive, and this difference was statistically significant for the monoclonal anti-MOMP antibody (Fitzgerald Industries International) (data not shown). The pregnancy rate in the subgroup of $C$. trachomatis PCRnegative women was $77 \%$ (10/13). The hypothesis that endometrial involvement in C. trachomatis infections may influence implantation therefore still deserves further consideration. Future research may focus on PCR-testing of endometrial samples in a larger prospective cohort study, in which CAT, tubal status and implantation rates at IVF will be available.

In summary, the aim of the study was to evaluate the detection rate of C. trachomatis in endometrial samples of subfertile women with and without tubal factor subfertility using two different test methods (immunohistochemical staining and PCR). In our hands and with the antibodies used, no correlation was shown between immunohistochemical staining results and clinical parameters in our cohort of 40 pa- 
tients. PCR results were negative in all 13 samples tested, but our study population was very small. Our hypothesis may be retested in a larger cohort using PCR, clinical parameters (CAT and tubal status) and clinical outcome (implantation rates).

\section{Acknowledgements}

The authors would like to thank Ellen Boelen, Helen Dassen, Gert Grauls and Jolein Pleijster for excellent laboratory assistance, and Fons Kessels for statistical advise.

The ICTI consortium (Integrated approach to the study of Chlamydia trachomatis Infections) provides a broad specialized network for multidisciplinary studies (Morré et al., 2006). The EpiGenChlamydia consortium (www.EpiGenChlamydia.EU) is a European Framework Programme 6 (FP6) financially supported Co-ordination Action (CA) in functional genomics research, entitled: Contribution of molecular epidemiology and host-pathogen genomics to understand Chlamydia trachomatis disease. (contract no. LSHG-CT-2007-037637). 


\section{REFERENCES}

Barlow REL, Cooke ID, Odukoya O, Heatley MK, Jenkins J, Narayansingh G, Ramsewak SS, Eley A (2001) The prevalence of Chlamydia trachomatis in fresh tissue specimens from patients with ectopic pregnancy or tubal factor infertility as determined by PCR and in-situ hybridization. J Med Microbiol 50, 902-908.

Bianchi A, Bogard M, Cessot G, Bohbot JM, Malkin JE, Alonso JM (1998) Kinetics of Chlamydia trachomatis clearance in patients with azithromycin, as assessed by first void urine testing by PCR and transcription-mediated amplification. Sex Transm Dis 25, 366-367.

Bjartling C, Osser S, Persson K (2007) Deoxyribonucleic acid of Chlamydia trachomatis in fresh tissue from the Fallopian tubes of patients with ectopic pregnancy. Eur J Obstet Gynecol Reprod Biol 134, 95100.

Catsburg A, Savelkoul PHM, Vliet A, Algra J, Vandenbroucke-Grauls CMJE, Morré SA (2006). Development and evaluation of an internally controlled real-time quantitative PCR assay for the detection of Chlamydia trachomatis. Proceedings of the Eleventh International Symposium on Human Chlamydial Infections, Niagara-on-the-Lake, Ontario, Canada, June 18 - 23, 2006, pp 521-524.

De Barbeyrac B, Papaxanthos-Roche A, Mathieu C, Germain C, Brun JL, Gachet M, Mayer G, Bébéar C, Chene G, Hocké C (2006) Chlamydia trachomatis in subfertile couples undergoing an in vitro fertilization program: a prospective study. Eur J Obstet Gynecol Reprod Biol 129, 46-53.

Debattista J, Gazzard CM, Wood RN, Allan JA, Allan JM, Scarman A, Mortlock M, Timms P, Knox CL (2004) Interaction of microbiology and pathology in women undergoing investigations for infertility. Infect Dis Obstet Gynecol 12, 135-145.

Dietrich W, Rath M, Stanek G, Apfalter P, Huber JC, Tempfer C (2010) Multiple site sampling does not increase the sensitivity of Chlamydia trachomatis detection in infertility patients. Fertil Steril 93, 6871.

Eggert-Kruse W, Rohr G, Demirakca T, Rusu R, Näher H, Petzoldt D, Runnebaum B (1997) Chlamydial serology in 1303 asymptomatic subfertile couples. Hum Reprod 12, 1464-1475.

Engel JN (1992) Azithromycin-induced block of elementary body formation in Chlamydia trachomatis. Antimicrob Agents Chemother 36, 2304-2309.

Gaydos CA, Crotchfelt KA, Howell MR, Kralian S, Hauptman P, Quinn TC (1998) Molecular amplification assays to detect chlamydial infections in urine specimens from high school female students and to monitor the persistence of chlamydial DNA after therapy. J Infect Dis 177, 417-424.

Gérard HC, Branigan PJ, Balsara GR, Heath C, Minassian SS, Hudson AP (1998) Viability of Chlamydia trachomatis in fallopian tubes of patients with ectopic pregnancy. Fertil Steril 70, 945-948.

Guven MA, Dilek U, Pata O, Dilek S, Ciragil P (2007) Prevalence of Chlamydia trachomatis, Ureaplasma urealyticum and Mycoplasma hominis infections in the unexplained infertile women. Arch Gynecol Obstet 276, 219-223.

Haeusler G, Tempfer C, Lehner R, Sam C, Kainz C (1997) Fallopian tissue sampling with a cytobrush during hysteroscopy: a new approach for detecting tubal infection. Fertil Steril 67, 580-582.

Hinton EL, Bobo LD, Wu TC, Kurman RJ, Viscidi RP (2000) Detection of Chlamydia trachomatis DNA in archival paraffinized specimens from chronic salpingitis cases using the polymerase chain reaction. Fertil Steril 74, 152-157.

Imudia AN, Detti L, Puscheck EE, Yelian FD, Diamond MP (2008) The prevalence of ureaplasma urealyticum, mycoplasma hominis, chlamydia trachomatis and neisseria gonorrhoeae infections, and the rubella status of patients undergoing an initial infertility evaluation. J Assist Reprod Genet 25, 43-46.

Kamiyama S, Teruya Y, Nohara M, Kanazawa K (2004) Impact of detection of bacterial endotoxin in menstrual effluent on the pregnancy rate in in vitro fertilization and embryo transfer. Fertil Steril 82, 788792.

Krohn K (1991) Gynaecological tissue levels of azithromycin. Eur J Clin Microbiol Infect Dis 10, 864-868. 
Lan J, Van den Brule AJC, Hemrika DJ, Risse EKJ, Walboomers JMM, Schipper MEI, Meijer CJLM (1995) Chlamydia trachomatis and ectopic pregnancy: retrospective analysis of salpingectomy specimens, endometrial biopsies, and cervical smears. J Clin Pathol 48, 815-819.

Land JA, Gijsen AP, Evers JLH, Bruggeman CA (2002) Chlamydia trachomatis in subfertile women undergoing uterine instrumentation. Screen or treat? Hum Reprod 17, 525-527.

Land JA, Gijsen AP, Kessels AGH, Slobbe MEP, Bruggeman CA (2003) Performance of five serological chlamydia antibody tests in subfertile women. Hum Reprod 18, 2621-2627.

Lode $\mathrm{H}$ (1991) The pharmacokinetics of azithromycin and their clinical significance. Eur J Clin Microbiol Infect Dis 10, 807-812.

Macmillan S, Templeton A (1999) Screening for Chlamydia trachomatis in subfertile women. Hum Reprod 14, 3009-3012.

McCarty JM (1996) Azithromycin (Zithromax). Infect Dis Obstet Gynecol 4, 215-220.

Morré SA, Sillekens PTG, Jacobs MV, De Blok S, Ossewaarde JM, Van Aarle P, Van Gemen B, Walboomers JMM, Meijer CJLM, Van den brule AJC (1998) Monitoring of Chlamydia trachomatis infections after antibiotic treatment using RNA detection by nucleic acid sequence based amplification. J Clin Pathol Mol Pathol 51, 149-154.

Morré SA, Spaargaren J, Ossewaarde JM, Land JA, Bax CJ, Dörr PJ, Oostvogel PM, Vanrompay D, Savelkoul PHM, Pannekoek Y et al. (2006) Description of the ICTI consortium: an integrated approach to the study of Chlamydia trachomatis infection. Drugs Today 42 (Suppl A), 107-114.

Noguchi Y, Yabushita H, Noguchi M, Fujita M, Asai M, del Carpio CA (2002) Detection of Chlamydia trachomatis infection with DNA extracted from formalin-fixed paraffin-embedded tissues. Diagn Microbiol Infect Dis 43, 1-6.

Osser S, Persson K (1992) Chlamydial antibodies and deoxyribonucleic acid in patients with ectopic pregnancy. Fertil Steril 57, 578-582.

Paavonen J, Kiviat N, Brunham RC, Stevens CE, Kuo CC, Stamm WE, Miettinen A, Soules M, Eschenbach DA, Holmes KK (1985a) Prevalence and manifestations of endometritis among women with cervicitis. Am J Obstet Gynecol 152, 280-286.

Paavonen J, Aine R, Teisala K, Heinonen PK, Punnonen R, Lehtinen M, Miettinen A, Grönroos P (1985b) Chlamydial endometritis. J Clin Pathol 38, 726-732.

Pacchiarotti A, Sbracia M, Mohamed MA, Frega A, Pacchiarotti A, Espinola SM, Aragona C (2009) Autoimmune response to Chlamydia trachomatis infection and in vitro fertilization outcome. Fertil Steril 91, 946-948.

Patton DL, Askienazy-Elbhar M, Henry-Suchet J, Campbell LA, Capuccio A, Tannous W, Wang SP, Kuo CC (1994) Detection of Chlamydia trachomatis in fallopian tube tissue in women with postinfectious tubal infertility. Am J Obstet Gynecol 171, 95-101.

Peters DH, Friedel HA, McTavish D (1992) Azithromycin. A review of its antimicrobial activity, pharmacokinetic properties and clinical efficacy. Drugs 44, 750-799.

Romero R, Espinoza J, Mazor M (2004) Can endometrial infection/inflammation explain implantation failure, spontaneous abortion, and preterm birth after in vitro fertilization? Fertil Steril 82, 799-804.

Stern RA, Svodboda-Newman SM, Frank TS (1996) Analysis of chronic endometritis for Chlamydia trachomatis by polymerase chain reaction. Hum Pathol 27, 1085-1088.

Svenstrup HF, Fedder J, Kristoffersen SE, Trolle B, Birkelund S, Christiansen G (2008) Mycoplasma genitalium, Chlamydia trachomatis, and tubal factor infertility-a prospective study. Fertil Steril 90, 513520.

Toth M, Patton DL, Campbell LA, Carretta El, Mouradian J, Toth A, Shevchuk M, Baergen R, Ledger W (2000) Detection of Chlamydial antigenic material in ovarian, prostatic, ectopic pregnancy and semen samples of culture-negative subjects. AJRI 43, 218-222.

Van Dyck E, leven M, Pattyn S, Van Damme L, Laga M (2001) Detection of Chlamydia trachomatis and Neisseria gonorrhoeae by enzyme immunoassay, culture, and three nucleic acid amplification tests. J Clin Microbiol 39, 1751-1756. 
Watson EJ, Templeton A, Russell I, Paavonen J, Mardh PA, Stary A, Pederson BS (2002) The accuracy and efficacy of screening tests for Chlamydia trachomatis: a systematic review. J Med Microbiol 51, 1021-1031.

Wilkowska-Trojniel M, Zdrodowska-Stefanow B, Ostaszewska-Puchalska I, Zbucka M, Wolczynski S, Grygoruk C, Kuczynski W, Zdrodowski M (2009) Chlamydia trachomatis urogenital infection in women with infertility. Adv Med Sci 54, 82-85.

Winkler B, Reumann W, Mitao M, Gallo L, Richart RM, Crum CP (1984) Chlamydial endometritis. A histological and immunohistochemical analysis. Am J Surg Pathol 8, 771-778.

Witkin SS, Sultan KM, Neal GS, Jeremias J, Grifo JA, Rosenwaks Z (1994) Unsuspected Chlamydia trachomatis infection and in vitro fertilization outcome. Am J Obstet Gynecol 171, 1208-1214.

Witkin SS, Kligman I, Grifo JA, Rosenwaks Z (1995) Chlamydia trachomatis detected by polymerase chain reaction in cervices of culture-negative women correlates with adverse in vitro fertilization outcome. $\mathrm{J}$ Infect Dis 171, 1657-1659.

Worm AM, Østerlind A (1995) Azithromycin levels in cervical mucus and plasma after a single $1.0 \mathrm{~g}$ oral dose for chlamydial cervicitis. Genitourin Med 71, 244-246. 
Chapter 9

General discussion 
The topic of this thesis is persistent Chlamydia (C.) trachomatis infections and the ensuing tubal factor subfertility. How do we diagnose persistent $C$. trachomatis infections and tubal pathology, respectively, in subfertile women? And why does $C$. trachomatis persist? And do persistent $C$. trachomatis infections also influence endometrial receptivity?

In Chapters 2-4, different screening tests that can be used to estimate the risk of tubal factor subfertility have been evaluated. Chapters 5-7 have addressed the immunogenetic contribution to persistence of $C$. trachomatis infections. Chapter 8 has described different methods to detect persistent $C$. trachomatis infections in endometrial tissue of subfertile women, serving as a starting point for future studies on the association between $C$. trachomatis endometritis and subfertility.

The current chapter will highlight and discuss the present insights on persistent $C$. trachomatis infections and tubal factor subfertility, including the findings as described in this thesis and recommendations for further studies.

\section{PREVALENCE, CLINICAL MANIFESTATIONS AND COMPLICATIONS}

C. trachomatis is the most prevalent sexually transmitted disease in industrialized countries. Among the risk factors for acquiring $C$. trachomatis genital tract infections are a high level of urbanization, young age, low education, multiple lifetime sexual partners, a recent new sexual partner and recent unprotected sexual intercourse (Götz et al., 2005). Figure I represents the clinical course and outcome of $C$. trachomatis infections.

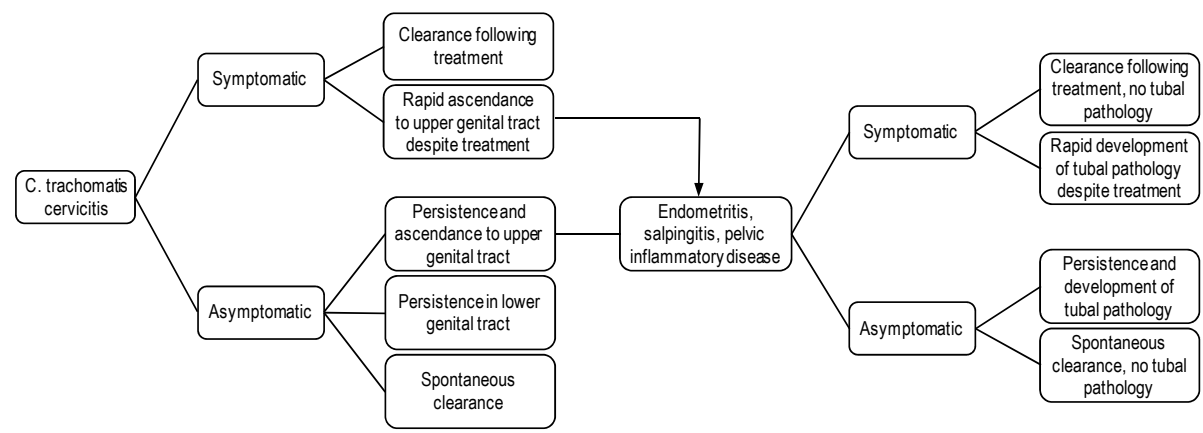

Figure I. Clinical course and outcome of $C$. trachomatis infections.

In the Netherlands, 35000 women are infected by $C$. trachomatis annually (Health Council of The Netherlands, 2005). The majority of these women have lower genital tract infections, which often remain asymptomatic. Spontaneous clearance rates of $\sim 50 \%$ in the first year and of up to $94 \%$ in five years have been reported (Morré et 
al., 2002, Molano et al., 2005). C. trachomatis lower genital tract infections seem to have no influence on the patient's fertility (Andersen et al., 2005). However, in the Netherlands each year an estimated 5000 to 10000 women develop upper genital tract infections, which are also asymptomatic in most women. The risk of subfertility following $C$. trachomatis upper genital tract infections varies between 0.6 and $40 \%$, depending on the number and severity of infections (Weström et al., 1992). C. trachomatis-associated tubal factor subfertility affects 1000 to 2000 women each year in the Netherlands (Health Council of The Netherlands, 2005), which is in concordance with the findings of Land and co-workers (2010), who have estimated that the risk of tubal factor subfertility following a $C$. trachomatis lower genital tract infection is up to $4.6 \%$.

The actual risk of subfertility due to $C$. trachomatis infections may even be higher, because women with persistent subclinical $C$. trachomatis endometritis - but patent tubes - may have impaired embryo implantation capacities and therefore lower pregnancy rates (Witkin et al., 1994, Witkin et al., 1995, Kamiyama et al., 2004, Romero et al., 2004, Pacchiarotti et al., 2009). Recent in vitro studies have shown that $C$. trachomatis infections are able to influence the metabolism of the trophoblast, which may not only affect implantation capacities, but may also be associated with adverse pregnancy outcomes such as preterm labor or preeclampsia (Azenabor et al., 2007, De la Torre et al., 2009).

Endometrial sampling is not performed routinely in the fertility work-up any longer, and therefore women with $C$. trachomatis endometritis may now be wrongly categorized as having an unexplained subfertility. The pilot study for the detection of $C$. trachomatis in endometrial tissue of subfertile women, as described in Chapter 8 , did not yield positive results, but can be considered as a first step towards a larger prospective study collecting data on patient characteristics, serological screening, endometrial sampling, tubal status and clinical outcome in order to retest the hypothesis that $C$. trachomatis endometritis may contribute to subfertility. Preferably, this is to be studied in a cohort of women undergoing IVF for both tubal and nontubal factor subfertility, respectively, in order to study pregnancy rates and implantation rates most accurately. If our hypothesis could be confirmed in further studies, it should also be tested whether antibiotic treatment would improve fertility in women with $C$. trachomatis endometritis. Women with subacute endometritis significantly benefit from antibiotic treatment with respect to clinical symptoms (e.g. abnormal bleeding, mucopurulent cervicitis and uterine tenderness) and histological findings (Eckert et al., 2004), but it is unclear whether fertility would improve by antibiotic treatment. 


\section{SCREENING FOR C. TRACHOMATIS-ASSOCIATED TUBAL FACTOR SUBFERTILITY}

As described in Chapters 2-4, C. trachomatis IgG antibody testing (CAT) remains the best method to accurately discern subfertile women with a high versus low risk of tubal pathology. In our population, with a prevalence of distal tubal pathology of $18.8 \%$, the positive predictive value of CAT was $62 \%$, whereas the negative predictive value was $90 \%$. Our results on the value of CAT are in agreement with findings in literature (as summarized by Den Hartog et al., 2006). Following a negative CAT, tubal testing by hysterosalpingography (HSG) may be performed because of its high specificity and fertility-enhancing effect (Chapter 4), although HSG does not help in discerning women with a high versus low risk of tubal pathology, respectively. In CAT-negative women, the probability of tubal pathology was $14 \%$, and the probability ranged between 13 and $17 \%$ after performing HSG .

We have been the first, in 2005 , to report that measuring high sensitivity C-reactive protein (hs-CRP) levels significantly increases the predictive value of CAT for tubal pathology (Chapter 2), with an increase in odds ratio from 13.9 to 39.7, although larger studies are needed to confirm that hs-CRP testing deserves a role in the fertility work-up. Two studies, published since then, have now also reported a higher risk of late sequelae in women with previous $C$. trachomatis infections and elevated hsCRP levels. Agrawal and co-workers (2007) have studied local and serological immune responses in 320 women with a previous $C$. trachomatis infection in relation to fertility disorders. Elevated hs-CRP levels, which are considered to reflect chronic inflammation, were significantly more prevalent in women with fertility disorders (46\%) as compared to those without fertility disorders (23\%). Combining hs-CRP (as a serological marker of chronic inflammation) and interferon gamma (IFN- $\gamma$; as a local marker of infection) resulted in a significantly higher predictive value for fertility disorders as compared to IFN- $\nu$ alone (OR 37.9 versus 15.4) (Agrawal et al., 2007). Karinen and co-workers (2005) have studied the association between persistent $C$. trachomatis infections, as tested in the first trimester of pregnancy, and the risk of preterm delivery in singleton pregnancies. A comparison was made between 402 term deliveries and 104 preterm deliveries (mean gestational age 34.4 weeks, range 26-36 weeks). The simultaneous presence of $C$. trachomatis IgG antibodies and elevated hs-CRP levels increased the risk of preterm delivery more than fourfold in comparison to women with no or only one marker present (Karinen et al., 2005).

Several other markers of persistence ( $C$. trachomatis IgA antibodies, heat shock protein 60 IgG antibodies and lipopolysaccharide IgG antibodies) have also been found to be significantly more prevalent in women with tubal pathology, although their performance was not as good as the performance of CAT (Chapters 2 and 3). Furthermore, no significant additive role of other Chlamydiaceae species in the 
development of tubal pathology could be established (Chapter 3), although it was hypothesized that other species could contribute in the pathogenesis of tubal damage by eliciting a genus-specific auto-immune inflammatory response. This hypothesis has recently been supported by Dean and co-workers (2008), who have demonstrated that one-third of the patients with trachoma has a mixed infection with multiple Chlamydiaceae species, and have suggested that these other species may also induce an inflammatory response leading to ocular scarring. Therefore, the discussion on the role of various Chlamydiaceae species on the course and outcome of $C$. trachomatis infections is still open.

\section{INTER-PATIENT VARIABILITY IN COURSE AND OUTCOME OF $\boldsymbol{C}$. TRACHOMATIS INFECTIONS}

Differences in course and outcome of $C$. trachomatis infections are determined by virulence factors of the pathogen, environmental factors and host immune factors. Carrying genetic variations in the innate immune system seems to be the most important determinant of the inter-patient variability in course and outcome of $C$. trachomatis infections (Chapter 1, Morré et al., 2009). In a recent study, Bailey and co-workers (2009) have also confirmed that host genetic factors contribute largely ( 40\%) to the course of $C$. trachomatis infections.

Cells of the innate immune system possess pattern recognition receptors (PRRs), which are able to recognize foreign micro-organisms, and subsequently destroy them (by ingestion of the micro-organism or by cytolysis). Carrying genetic variations in genes encoding PRRs [e.g. toll-like receptors (TLRs) and caspase recruitment domains (CARDs)/nucleotide oligomerization domains (NODs)] may negatively affect the immune response following $C$. trachomatis infections, resulting in a higher risk of developing tubal pathology (as summarized in Chapter 1). Chapter 7 shows a trend towards a higher risk of tubal factor subfertility in CAT-positive carriers of single nucleotide polymorphisms (SNPs) in genes encoding TLR9, TLR4 and CARD15/NOD2, especially in those patients carrying at least two SNPs (73\% risk of tubal pathology, in comparison to $33 \%$ in women carrying less than two SNPs). Cluster of differentiation (CD) 14, co-receptor of TLR4, does not play a role in susceptibility to or outcome of $C$. trachomatis infections (Chapters 6 and 7). In Chapter 5, a knockout mouse model was designed to study the role of TLR4 in C. trachomatis infection and re-infection. In TLR4 knockout mice, clearance of $C$. trachomatis occurred slower as compared to TLR4 wildtype mice. This difference was more solid in case of repeated $C$. trachomatis infections. Carrying a TLR4 SNP did not significantly influence the susceptibility to or outcome of $C$. trachomatis infections (Chapter 5). It has also been known that genetic variations in genes encoding cytokines, which are produced by cells of the innate immune system following recognition of a 
pathogen, can be associated with alterations in the course and outcome of infectious diseases. A recent study in 114 women with $C$. trachomatis-associated subfertility and 176 controls has shown that carrying a genetic variation in the gene encoding tumour necrosis factor alpha (TNF- $\alpha-308 \mathrm{G}>\mathrm{A}$ ) significantly increases the risk of severe tubal damage (odds ratio (OR) of 4.0 for TNF- $\alpha 308$ A allele) (Öhman et al., 2009). Other studies have also found a significant association between TNF- $\alpha-308$ G>A SNP and the risk of trachoma (as reviewed by Morré et al., 2009). Despite these positive findings, no significant difference in TNF- $\alpha 308$ genotype could be found between 35 CAT-positive women with tubal factor subfertility (4 carriers of the Aallele) and 35 CAT-negative women with tubal factor subfertility ( 6 carriers of the Aallele) in a previous study (Cohen et al., 2003). The latter study, however, might be too small to find significant differences, and did not include a control group of women without tubal pathology or without subfertility.

In contrast, SNPs in other genes seem to act in a protective way, i.e. they protect the host from tubal damage related to hyperinflammation. An example of this is a 32 basepair deletion in the gene encoding chemokine (C-C motif) receptor (CCR) 5 , which is a cytokine receptor on cells of the immune system. Among CAT-positive women, the $C C R 5 d 32$ deletion was present in $31 \%$ of women without tubal pathology and in only $7 \%$ of women with tubal pathology (OR 5.8, $P<0.05$ ) (Barr et al., 2005). Carrying the interleukin (IL) $10-1082$ A $>$ G SNP has also been shown to be protective against tubal pathology (OR for tubal pathology 7.3 for the wildtype IL10-1082AA genotype) (Öhman et al., 2009) and against trachoma (as summarized by Morré et al., 2009).

Further immunogenetic studies will help to elucidate the pathophysiology of $C$. trachomatis infections and to explain the inter-patient variability in course and outcome of $C$. trachomatis infections. The ultimate goal is to predict, without using invasive techniques, which subfertile women do or do not have tubal pathology following $C$. trachomatis infection. The European funded EpiGenChlamydia Consortium (see www.EpiGenChlamydia.EU), composed of 20 Universities and Institutes in Europe, Africa and the US, is developing Biobanks and data-warehouses to perform large scale host immunogenetic studies for obtaining genetic traits which - combined with serological markers - can be used for patient profiling. The various stakeholders in Public Health play a key role in translating the implications of genomics derived from molecular epidemiology and host-pathogen genomics. This knowledge will enable not only clinical interventions, but also health promotion messages and disease prevention programmes to be targeted at susceptible individuals as well as subgroups of the population based on their genomic profile (personalized healthcare) (Brand, 2009). The field involved in this translation is called Public Health Genomics, which has as major task "the responsible and effective translation of genome-based knowledge and technologies into public policy and 
health services for the benefit of population health" (Bellagio statement, 2005: see www.graphint.org for details).

\section{PRIMARY, SECONDARY AND TERTIARY PREVENTION OF C. TRACHOMATIS INFECTIONS}

Primary prevention of $C$. trachomatis infections mainly consists of public campaigns focussing on health education to prevent exposure to sexually transmitted infections and to increase awareness of the early symptoms of $C$. trachomatis infections. On an individual level, this education - as well as opportunistic screening - can also be supplied by general practitioners, e.g. when adolescents consult them for advise on contraceptive methods. Municipal Health Services are low-barrier health care suppliers, mainly occupied with the implementation of large population-based screening programmes and contact tracing, thereby supporting primary and secondary prevention measures. As long as an effective vaccine against $C$. trachomatis is not available, primary prevention is limited to the methods as described (Brunham and Rey-Ladino, 2005).

The goal of secondary prevention strategies is to diagnose $C$. trachomatis infections in an early stage, in order to immediately start treatment and prevent late complications. General practitioners play an important role in secondary prevention since they are easily accessible. The majority of women with symptoms suspected for a sexually transmitted disease turn to their general practitioner, and almost half of the total number of $C$. trachomatis tests which are processed by Dutch laboratories come from general practitioners (Health Council of The Netherlands, 2004). Nowadays, self-collected vaginal or urinary samples in combination with internet-based questionnaires have also shown to be accurate and acceptable methods to screen for C. trachomatis (Götz et al., 2005, Gaydos et al., 2006). Ninety percent of the participants of internet-based screening programmes (via websites such as www.iwantthekit.org) prefer self-collection of the samples and rate self-collection as easy or very easy (Gaydos et al., 2006). Low-barrier internet-based screening programmes thereby facilitate the detection and treatment of $C$. trachomatis infections, although the precise impact of screening programmes on the prevalence of tubal factor subfertility remains to be studied more precisely (Land et al., 2010).

Tertiary prevention strategies aim to minimize the risk of complications following $C$. trachomatis infections. The asymptomatic course of most $C$. trachomatis infections results in a disappointing role for tertiary prevention, because usually substantial tubal damage has already occurred by the time symptoms develop, or the patient has already presented with subfertility many years later (Paavonen and Lehtinen, 2006). 


\section{SUMMARY AND FUTURE PERSPECTIVES}

Subfertile couples seeking medical treatment are usually unaware of a previous $C$. trachomatis genital tract infection. Direct and non-invasive testing for the presence of $C$. trachomatis or signs of chronic inflammation is possible in only part of the genital tract. However, most subfertile women do not fulfill the risk profile of current infection, and indeed the prevalence of $C$. trachomatis lower genital tract infections in subfertile women has been shown to be low (Chapter 8). Also, since $C$. trachomatis cervicitis does not seem to influence fertility, cervical sampling - although easy to perform - does not contribute to the risk assessment of tubal pathology. The endometrium is also accessible for investigation, but the prevalence and precise role of $C$. trachomatis endometritis in subfertility (diminished implantation capacity?) is still unclear and needs further evaluation (Chapter 8). Furthermore, it is unknown whether antibiotic treatment improves fertility in women with C. trachomatis endometritis.

The reference standard for tubal testing is laparoscopy, but should preferably be reserved for women with a high risk of tubal pathology. Conjoint analysis studies have to determine how gynaecologists value different features of a patient (e.g. age, duration of subfertility, previous pregnancy, suspicion of intra-abdominal pathology including endometriosis and results of screening tests in the fertility workup) in the decision whether laparoscopy should be performed. Tubal patency can be tested by flushing the tubes with methylene blue dye during laparoscopy. However, this does not reflect the intraluminal status (damaged epithelial lining? impaired ciliary function?). Obtaining biopsies of the tubes should only be conducted for research purposes in women in whom tubectomy is necessary, whereas it does not deserve a place in the regular fertility investigations.

Screening strategies for $C$. trachomatis-associated tubal factor subfertility should at least comprise chlamydia antibody testing (CAT), and - in low-risk women only HSG may be performed (Chapters 2-4). Currently, individual patient data metaanalyses are being performed to re-evaluate the precise value of both CAT and HSG (Broeze et al. (a), in preparation, Broeze et al. (b), in preparation). In addition to CAT, serological markers of persistence, such as hs-CRP, may help to estimate the risk of tubal factor subfertility more accurately (Chapter 2). Laparoscopy can then be reserved for subfertile patients with the highest risk of tubal pathology, as assessed by serological screening tests.

Immunogenetic studies strongly support the hypothesis that the immune system plays a key role in the course and outcome of $C$. trachomatis infections (Chapters $5-7$ ) with a genetic predisposition of $40 \%$. Elucidating which genes are responsible for this $40 \%$ genetic predisposition in course and outcome of $C$. trachomatis infections is a major challenge, which will provide potential clinical relevant genetic SNP 
traits for patient management. Large scale initiatives are being employed by the European funded EpiGenChlamydia Consortium (www.EpiGenChlamydia.EU) which was recently linked to the field of Public Health Genomics (www.graphint.org, www.ecphg.eu and www.phgen.eu) to further explore the potential opportunities. 


\section{REFERENCES}

Agrawal T, Vats V, Salhan S, Mittal A (2007) Local markers for prediction of women at higher risk of developing sequelae to Chlamydia trachomatis infection. Am J Reprod Immunol 57, 153-159.

Andersen B, Østergaard L, Puho E, Skriver MV, Schønheuder HC (2005) Ectopic pregnancies and reproductive capacities after Chlamydia trachomatis positive and negative test results: a historical followup study. Sex Transm Dis 32, 377-381.

Azenabor AA, Kennedy P, Balistreri S (2007) Chlamydia trachomatis infection of human trophoblast alters estrogen and progesterone biosynthesis: an insight into the role of infection in pregnancy sequelae. Int J Med Sci 4, 223-231.

Bailey RL, Natividad-Sancho A, Fowler A, Peeling RWW, Mabey DCW, Whittle HC, Jepson AP (2009) Host genetic contribution to the cellular immune response to Chlamydia trachomatis: heritability estimate from a Gambian twin study. Drugs Today 45 (Suppl B), 45-50.

Barr EL, Ouburg S, Igietseme JU, Morré SA, Okwandu E, Eko FO, Ifere G, Belay T, He Q, Lyn D et al. (2005) Host inflammatory response and development of complications of Chlamydia trachomatis genital infection in CCR5-deficient mice and subfertile women with the CCR5delta32 gene deletion. J Microbiol Immunol Infect 38, 244-254.

Brand A (2009) Integrative genomics, personal-genome tests and personalized healthcare: the future is being built today. Eur J Hum Genet 17, 977-978.

Broeze KA, Opmeer BC, Coppus SF, Alves M, Ånestad G, Bhattacharya S, Allan J, Guerra-Infante MF, Den Hartog JE, Land JA et al. For the IPD TUBA study group (a). Chlamydia antibody titer testing for detection of tubal pathology in subfertile women: an individual patient data meta-analysis. In preparation.

Broeze KA, Opmeer BC, Coppus SF, Den Hartog JE, Van der Linden PJ, Marianowski P, Ng E, Van der Steeg JW, Steures P, Strandell A et al. For the IPD TUBA study group (b). Do patient characteristics influence the accuracy of hysterosalpingography in the diagnosis of tubal pathology? An individual patient data meta-analysis. In preparation.

Brunham RC, Rey-Ladino J (2005) Immunology of Chlamydia infection: implications for a Chlamydia trachomatis vaccine. Nat Rev Immunol 5, 149-161.

Bush RM, Everett KDE (2001) Molecular evolution of the Chlamydiaceae. Int J Syst Evol Microbiol 51 (Pt1), 203-220.

Cohen CR, Gichui J, Rukaria R, Sinei SS, Gaur LK, Brunham RC (2003) Immunogenetic correlates for Chlamydia trachomatis-associated tubal infertility. Obstet Gynecol 101, 438-444.

Dean D, Kandel RP, Adhikari HK, Hessel T (2008) Multiple Chlamydiaceae species in trachoma: implications for disease pathogenesis and control. PLoS 5, e14.

De la Torre E, Mulla MJ, Yu AG, Lee SJ, Kavathas PB, Abrahams VM (2009) Chlamydia trachomatis infection modulates trophoblast cytokine / chemokine production. J Immunol 182, 3735-3745.

Den Hartog JE, Morré SA, Land JA (2006). Chlamydia trachomatis-associated tubal factor subfertility: immunogenetic aspects and serological screening. Hum Reprod Update 12, 719-730.

Eckert LO, Thwin SS, Hillier SL, Kiviat NB, Essenbach DA (2004) The antimicrobial treatment of subacute endometritis: a proof of concept study. Am J Obstet Gynecol 190, 305-313.

Gaydos CA, Dwyer K, Barnes M, Rizzo-Price PA, Wood BJ, Flemming T, Hogan MT (2006) Internet-based screening for Chlamydia trachomatis to reach non-clinic populations with mailed self-administered vaginal swabs. Sex Transm Dis 33, 451-457.

Götz HM, Van Bergen JEAM, Veldhuijzen IK, Broer J, Hoebe CJPA, Richardus JH (2005) A prediction rule for selective screening of Chlamydia trachomatis infection. Sex Transm Infect 81, 24-30.

Götz HM, Veldhuijzen IK, Van Bergen JEAM, Hoebe CJPA, De Zwart O, Richardus JH, Broer J, Coenen AJJ, de Groot F, Van Schaik DT et al. For the PILOT CT Study Group (2005) Acceptability and consequences of screening for Chlamydia trachomatis by home-based urine testing. Sex Transm Dis 32, 557-562. 
Health Council of The Netherlands (2005) Screening for Chlamydia. The Hague: Health Council of The Netherlands, publication no. 2004/07.

Kamiyama S, Teruya Y, Nohara M, Kanazawa K (2004) Impact of detection of bacterial endotoxin in menstrual effluent on the pregnancy rate in in vitro fertilization and embryo transfer. Fertil Steril 82, 788792.

Karinen L, Pouta A, Bloigu A, Koskela P, Paldanius M, Leinonen M, Saikku P, Jêrvelin MR, Hartikainen AL (2005) Serum C-reactive protein and Chlamydia trachomatis antibodies in preterm delivery. Obstet Gynecol 106, 73-80.

Land JA, Van Bergen JEAM, Morré SA, Postma MJ (2010) Epidemiology of Chlamydia trachomatis infection in women and the cost-effectiveness of screening. Hum Reprod Update 16, 189-204.

Molano M, Meijer CJLM, Weiderpass E, Arslan A, Posso H, Franceschi S, Ronderos M, Muňoz N, Van den Brule AJC (2005) The natural course of Chlamydia trachomatis infection in asymptomatic Colombian women: a 5-year follow-up study. J Infect Dis 191, 907-916.

Morré SA, Van den Brule AJC, Rozendaal L, Boeke AJP, Voorhorst FJ, De Blok S, Meijer CJLM (2002) The natural course of asymptomatic Chlamydia trachomatis infections: $45 \%$ clearance and no development of clinical PID after one-year follow-up. Int J STD AIDS 13 (Suppl 2), 12-18.

Morré SA, Karimi O, Ouburg S (2009) Chlamydia trachomatis: identification of susceptibility markers for ocular and sexually transmitted infection by immunogenetics. FEMS Immunol Med Microbiol 55, 140-153.

Öhman H, Tiitinen A, Halttunen M, Lehtinen M, Paavonen J, Surcel H-M (2009) Cytokine polymorphisms and severity of tubal damage in women with Chlamydia-associated infertility. J Infect Dis 199, 13531359.

Paavonen J, Lehtinen M (1996) Chlamydial pelvic inflammatory disease. Hum Reprod Update 2, 519-529.

Pacchiarotti A, Sbracia M, Mohamed MA, Frega A, Pacchiarotti A, Espinola SM, Aragona C (2009) Autoimmune response to Chlamydia trachomatis infection and in vitro fertilization outcome. Fertil Steril 91, 946-948.

Romero R, Espinoza J, Mazor M (2004) Can endometrial infection/inflammation explain implantation failure, spontaneous abortion, and preterm birth after in vitro fertilization? Fertil Steril 82, 799-804.

Weström L, Joesoef R, Reynolds G, Hagdu A, Thompson SE (1992) Pelvic inflammatory disease and fertility. A cohort study of 1,844 women with laparoscopically verified disease and 657 control women with normal laparoscopic results. Sex Transm Dis 19, 185-192.

Witkin SS, Sultan KM, Neal GS, Jeremias J, Grifo JA, Rosenwaks Z (1994) Unsuspected Chlamydia trachomatis infection and in vitro fertilization outcome. Am J Obstet Gynecol 171, 1208-1214.

Witkin SS, Kligman I, Grifo JA, Rosenwaks Z (1995) Chlamydia trachomatis detected by polymerase chain reaction in cervices of culture-negative women correlates with adverse in vitro fertilization outcome. $\mathrm{J}$ Infect Dis 171, 1657-1659. 



\section{Summary}

Chlamydia (C.) trachomatis is the most prevalent sexually transmitted disease in industrialized countries, affecting 35000 women in the Netherlands each year. Because most women do not experience symptoms and, therefore, do not receive antibiotic treatment, $C$. trachomatis infections may ascend to the upper genital tract and may persist for many years, increasing the risk of late complications. Up to $4.6 \%$ of women with $C$. trachomatis lower genital tract infections will eventually develop tubal factor subfertility. The reference standard for diagnosing tubal pathology in subfertile women is laparoscopy with tubal testing. In order to prevent exposure to invasive tubal testing of all subfertile women, screening methods - comprising serological testing and hysterosalpingography (HSG) - are used to discern subfertile women with a high and low risk of tubal pathology, respectively.

An introduction to the subject, as well as the outline of this thesis, was provided in Chapter 1. The first aim of this thesis was to optimize the screening strategy for diagnosing persistent $C$. trachomatis infections and the ensuing tubal pathology in subfertile women. The second aim was to study the immunogenetic contribution to persistence of $C$. trachomatis infections. The third aim was to assess different test methods to detect persistent $C$. trachomatis infections in endometrial tissue of subfertile women.

Persistent $C$. trachomatis infections are assumed to be important risk factors for tubal pathology. In Chapters $\mathbf{2}$ and 3, several serological markers of persistence were studied in a cohort of 313 subfertile women, who all underwent laparoscopy with tubal testing to assess the tubal status. Besides the currently used screening test [C. trachomatis immunoglobulin (Ig) G antibody testing; CAT], IgG antibodies to chlamydia heat shock protein 60 (cHSP60) and to chlamydia lipopolysaccharide (LPS), IgA antibodies to C. trachomatis and high-sensitivity CRP (hs-CRP) were measured. The prevalence of tubal pathology - as defined as extensive peri-adnexal adhesions and/or distal occlusion of at least one tube at laparoscopy - was $18.8 \%$. All serological markers of persistence were significantly more prevalent in women with tubal pathology as compared to those without tubal pathology. CAT remained the best single test [odds ratio (OR) 13.9]. Only the combination of CAT (as a marker of a previous $C$. trachomatis infection) and hs-CRP (as a marker of persistence) resulted in a significantly higher OR (39.7), and therefore this test combination is a candidate screening method in the fertility work-up. 
In the same study cohort, the role of other Chlamydiaceae species in the development of tubal pathology was evaluated (Chapter 3 ). It was hypothesized that $C$. pneumoniae and $C$. psittaci contribute in the pathogenesis of tubal damage by eliciting a genus-specific auto-immune inflammatory response, but our findings could not support this hypothesis.

In Chapter 4, three different screening strategies (comprising CAT, hs-CRP and HSG) were explored in a population of 642 subfertile women who all underwent tubal testing (HSG and/or laparoscopy). The goal of this observational study was to develop a screening strategy which is able to accurately estimate the risk of tubal pathology in a non-invasive manner. Based on our findings, we proposed CAT as the first screening test for tubal pathology in subfertile women (risk of tubal pathology $14 \%$ in CAT-negative women and $53 \%$ in CAT-positive women, respectively). Hs-CRP seemed promising, and the value of HSG was shown to be limited. We suggested to omit laparoscopy in CAT-negative patients and in patients with normal or inconclusive HSGs, whereas in CAT-positive women and in women with abnormal HSGs, laparoscopy remains justified.

Variations in immunologically important host genes are assumed to result in an aberrant immune response against $C$. trachomatis infections, thereby increasing the risk of persistence and tubal pathology. Chapter $\mathbf{5}$ described a toll-like receptor $(T L R) 4$ knockout mouse model and human candidate gene approach. In TLR4 knockout mice, clearance of $C$. trachomatis infection and re-infection occurred slower as compared to TLR4 wildtype mice, indicating a role of TLR4 in the immune response to $C$. trachomatis infections. In 614 women visiting a Sexually Transmitted Diseases outpatient clinic and in 259 subfertile women, carrying the TLR4 +896 A>G single nucleotide polymorphism (SNP) did not play a significant role in susceptibility and outcome of $C$. trachomatis infections. However, $C$. trachomatis IgG-positive subfertile women with tubal pathology were more than twice as likely to be carriers of the mutant TLR4 $+896 \mathrm{G}$ allele as compared to those without tubal pathology. This observation did not reach statistical significance. In conclusion, both the murine model and the human immunogenetics studies show a slight effect upon TLR4 deficiency in the severity of infection but not in the susceptibility to infection.

In Chapter 6, negative results were found for the -260 C>T SNP in the gene encoding cluster of differentiation (CD) 14.

In Chapter 7, subsequently, a carrier trait analysis was performed, since we hypothesized that carrier traits (i.e. carrying multiple SNPs in multiple genes) that likely result in an aberrant immune response are associated with an increased risk of tubal pathology following a C. trachomatis infection. In 227 subfertile women, five variations in four genes encoding $C$. trachomatis receptors [TLR4, TLR9, CD14 and caspase recruitment domain (CARD) 15 / nucleotide-binding oligomerization domain (NOD) 2] were studied. The presence of two or more SNPs tended to corre- 
late with an increased risk of tubal pathology following a $C$. trachomatis infection (73\%) as compared to a lower number of SNPs (33\%). An adequate recognition of $C$. trachomatis by receptors in the genital tract seems to be a relevant step in the immune response, and may play a role in protecting the host against the development of late sequelae following a $C$. trachomatis infection.

Persistent $C$. trachomatis infections do not only result in tubal pathology, but have also been associated with impaired implantation capacities due to persistent lowgrade endometritis. Chapter 8 comprised a pilot study using immunohistochemical staining methods and polymerase chain reaction (PCR) to detect $C$. trachomatis in the endometrium of subfertile women. In 40 subfertile women, no correlation was found between immunohistochemical staining results, CAT and tubal status. PCR results were negative in a random subset of endometrial samples $(n=13)$. Based on findings in literature, further research on this topic should be encouraged.

In Chapter 9, the present insight regarding persistent $C$. trachomatis infections and tubal factor subfertility, including the findings as described in this thesis and recommendations for further studies, were discussed. 



\section{Samenvatting}

Chlamydia (C.) trachomatis is de meest voorkomende seksueel overdraagbare aandoening in ontwikkelde landen, en treft jaarlijks 35.000 vrouwen in Nederland. Aangezien de meeste vrouwen geen symptomen hebben en dus niet behandeld worden met antibiotica, kunnen $C$. trachomatis infecties opstijgen naar de hogere tractus genitalis en gedurende vele jaren persisteren, waardoor het risico op late complicaties toeneemt. Tot $4.6 \%$ van de vrouwen met $C$. trachomatis infecties van de lagere tractus genitalis zal uiteindelijk tubapathologie en subfertiliteit ontwikkelen. De gouden standaard voor het vaststellen van tubapathologie bij subfertiele vrouwen is de laparoscopie met tubatesten. Teneinde niet alle subfertiele vrouwen bloot te stellen aan invasieve tubadiagnostiek, worden screeningstesten - zoals serologische testen of hysterosalpingografie (HSG) - gebruikt om een onderscheid te maken tussen subfertiele vrouwen met een hoog respectievelijk laag risico op tubapathologie.

Hoofdstuk 1 geeft een introductie van het onderwerp en een overzicht van het proefschrift. Het eerste doel van dit proefschrift was om de screeningsstrategie voor het vaststellen van persisterende $C$. trachomatis infecties en tubapathologie bij subfertiele vrouwen te optimaliseren. Het tweede doel was om de immunogenetische bijdrage aan persistentie van $C$. trachomatis infecties te bestuderen. Het derde doel was om verschillende testmethoden voor detectie van persisterende $C$. trachomatis infecties in het endometrium van subfertiele vrouwen te beoordelen.

Persisterende $C$. trachomatis infecties worden beschouwd als een belangrijke risicofactor voor tubapathologie. In Hoofdstuk $\mathbf{2}$ en $\mathbf{3}$ werden diverse serologische markers van persistentie bestudeerd in een cohort van 313 subfertiele vrouwen, die allen een laparoscopie met tubatesten ondergingen om de tubastatus vast te stellen. Naast de momenteel gebruikte screeningstest [C. trachomatis immunoglobuline (Ig) antistof test; CAT], werden IgG antistoffen tegen chlamydia heat shock protein 60 (cHSP60) en tegen chlamydia lipopolysaccharide (LPS), IgA antistoffen tegen $C$. trachomatis en het hoog-sensitieve CRP (hs-CRP) gemeten. De prevalentie van tubapathologie - gedefinieerd als uitgebreide adhesies rondom de adnexa en/of distale occlusie van tenminste één tuba bij laparoscopie - was $18.8 \%$. Alle serologische markers van persistentie waren significant vaker aantoonbaar bij vrouwen met tubapathologie ten opzichte van vrouwen zonder tubapathologie. CAT bleef de beste enkele test [odds ratio (OR) 13.9]. Alleen de combinatie CAT (als marker van 
een eerdere $C$. trachomatis infectie) en hs-CRP (als marker van persistentie) resulteerde in een significant hogere OR (39.7), en daarom is deze testcombinatie een potentiële screeningsmethode voor in het fertiliteitsonderzoek.

Verder werd de rol van andere Chlamydiaceae species in de ontwikkeling van tubapathologie geëvalueerd in Hoofdstuk 3. De hypothese was dat $C$. pneumoniae en $C$. psittaci bijdragen aan de pathogenese van tubapathologie door een genusspecifieke auto-immuun ontstekingsrespons teweeg te brengen, maar onze bevindingen konden deze hypothese niet ondersteunen.

In Hoofdstuk 4 werden drie verschillende screeningsstrategieën (bestaande uit CAT, hs-CRP en HSG) onderzocht in een populatie van 642 subfertiele vrouwen die allen tubatesten (HSG en/of laparoscopie) hadden ondergaan. Het doel van deze observationele studie was om een screeningsstrategie te ontwikkelen die in staat is om op accurate en niet-invasieve wijze het risico op tubapathologie in te schatten. Gebaseerd op onze bevindingen, stelden wij CAT voor als eerste screeningstest voor tubapathologie bij subfertiele vrouwen (risico op tubapathologie respectievelijk $14 \%$ bij CAT-negatieve vrouwen en 53\% bij CAT-positieve vrouwen). Hs-CRP leek veelbelovend, en de waarde van het HSG bleek beperkt. Wij stelden voor om bij CATnegatieve vrouwen en vrouwen met normale of inconclusieve HSG's geen laparoscopie meer te verrichten, terwijl de laparoscopie wel verdedigbaar blijft bij CATpositieve vrouwen of vrouwen met een afwijkend HSG.

Variaties in immunologisch belangrijke gastheergenen worden verondersteld te resulteren in een afwijkende immuunrespons tegen $C$. trachomatis infecties, waardoor het risico op persistentie en tubapathologie toeneemt. Hoofdstuk $\mathbf{5}$ beschreef een toll-like receptor (TLR) 4 knockout muismodel en een humaan kandidaat-gen model. In TLR4 knockout muizen werden $C$. trachomatis infectie en re-infectie langzamer geklaard ten opzichte van TLR4 wildtype muizen, wat duidt op een rol van TLR4 in de immuunrespons tegen $C$. trachomatis infecties. Zowel bij 614 vrouwen die een Seksueel Overdraagbare Aandoeningen-polikliniek bezochten als bij 259 subfertiele vrouwen speelde dragerschap van de TLR4 +896 A>G single nucleotide polymorphism (SNP) geen significante rol in vatbaarheid en beloop van C. trachomatis infecties. $C$. trachomatis IgG-positieve subfertiele vrouwen met tubapathologie waren twee keer zo vaak drager van het mutante TLR4 $+896 \mathrm{G}$ allel ten opzichte van degenen zonder tubapathologie. Deze bevinding was niet statistisch significant. Concluderend tonen zowel het muismodel als de humane immunogenetische studies aan dat TLR4 deficiëntie enig effect heeft op de ernst van de infectie, maar niet op de vatbaarheid voor de infectie.

In Hoofdstuk 6 werden negatieve resultaten gevonden voor de -260 C>T SNP in het gen coderend voor cluster of differentiation (CD) 14.

In Hoofdstuk 7 werd vervolgens een carrier trait analyse verricht, aangezien we veronderstelden dat carrier traits (dat wil zeggen dragerschap van meerdere SNP's 
in meerdere genen), die waarschijnlijk leiden tot een afwijkende immuunrespons, geassocieerd zijn met een verhoogd risico op tubapathologie na een $C$. trachomatis infectie. Vijf variaties in vier genen coderend voor $C$. trachomatis receptoren [TLR4, TLR9, CD14 en caspase recruitment domain (CARD) 15 / nucleotide-binding oligomerization domain (NOD) 2] werden bestudeerd bij 227 subfertiele vrouwen. De aanwezigheid van twee of meer SNP's leek te correleren met een verhoogd risico op tubapathologie na een $C$. trachomatis infectie (73\%) ten opzichte van minder dan twee SNP's (33\%). Een adequate herkenning van C. trachomatis door receptoren in de tractus genitalis lijkt een belangrijke stap in de immuunrespons te zijn, en zou een rol kunnen spelen bij het beschermen van de gastheer tegen de ontwikkeling van late gevolgen na een $C$. trachomatis infectie.

Persisterende $C$. trachomatis infecties leiden niet alleen tot tubapathologie, maar zijn ook geassocieerd met een verstoord implantatievermogen ten gevolge van een persisterende low-grade endometritis. Hoofdstuk 8 bestaat uit een pilot studie, waarbij immunohistochemische kleuringen en polymerase chain reaction (PCR) zijn gebruikt om $C$. trachomatis aan te tonen in het endometrium van subfertiele vrouwen. Bij 40 subfertiele vrouwen werd geen correlatie gevonden tussen de resultaten van immunohistochemische kleuringen, CAT en tubastatus. PCR uitslagen waren negatief in een willekeurige subgroep van endometriumbiopten $(n=13)$. Gebaseerd op bevindingen in de literatuur zou verder onderzoek over dit onderwerp aan te moedigen zijn.

In Hoofdstuk 9 werden de huidige inzichten in persisterende $C$. trachomatis infecties en subfertiliteit ten gevolge van tubapathologie, inclusief de bevindingen zoals beschreven in dit proefschrift en aanbevelingen voor toekomstig onderzoek, besproken. 



\section{Dankwoord}

Promoveren is niet alleen een proeve van bekwaamheid, maar een minstens zo grote proeve van doorzettingsvermogen. $\mathrm{Nu}$ is het dan eindelijk zo ver. Velen hebben bijgedragen aan de tot stand koming van het boekje, enkelen wil ik in het bijzonder bedanken.

Professor Evers, al jaren bent $u$ de drijvende kracht achter de succesvolle onderzoekslijnen van de VPG. Ook uw klinische one-liners zijn altijd waar gebleken. De laatste maanden heeft $u$ me soepel door de laatste fase heen geloodst (en misschien nog wel soepeler dan we beiden gedacht hadden!). Veel dank voor alle mogelijkheden en kansen die u me geboden heeft.

Professor Land, beste Jolande, je hebt me tijdens mijn co-schap weten te enthousiasmeren voor de wetenschap en me in de loop van de jaren een steeds betere onderzoeker gemaakt. De respons van één van de referenten op ons HRU-manuscript was uniek en heb ik nog nèt niet ingelijst. Door een welverdiend hoogleraarschap zit je nu aan de andere kant van het land, maar desondanks hebben we dit boekje toch nog goed kunnen afronden.

Professor Bruggeman, uw inbreng tijdens mijn promotietraject was niet alleen uw expertise op het gebied van Chlamydia trachomatis, maar vooral ook uw geruststellende uitstraling en op z'n tijd een motiverend woord - die me in mindere tijden genoeg vertrouwen gaven om door te gaan. Veel dank hiervoor.

Servaas Morré, dat jij mijn zij-instromende co-promotor werd is voor mijn boekje in de meest ruime zin des woords - een hele zegen geweest. Dankzij jouw ongeëvenaarde werkritme en mijn dienstenrooster werd zelfs in de nachtelijke uurtjes menig overleg gevoerd. Ik ken niemand die zo snel op een e-mail reageert als jij. Je positiviteit en je gedrevenheid zijn een groot voorbeeld voor me.

Professor de Baets, dr. Dirksen, professor Helmerhorst en professor Savelkoul, hartelijk dank voor het plaatsnemen in de Beoordelingscommissie. Professor Brand, thank you for being a member of the Assessment Committee. Professor de Vries, hartelijk dank voor het plaatsnemen in de Promotiecommissie. 
Fons Kessels, wat was ik blij dat ik al voor je ledenstop op je lijstje stond. Onder het motto "herhaling doet beklijven" was je gelukkig zelfs bereid om dingen soms meer dan één keer uit te leggen. Veel dank dat je me al die jaren statistisch hebt bijgestaan.

Frank Stassen, fijn dat we je, na je bijdrage aan Tanja's proefschrift, nog even binnenboord hebben weten te houden om mee te denken voor Hoofdstuk 2, 3 en 8. Alleen mijn Ishikawa-spoor is wat doodgelopen, maar misschien moet ik dat wel niet zo erg vinden.

Gert Grauls, bedankt voor al je hulp en uitleg bij het verrichten van de vele ELISA's. Met jou op het lab kwam gelukkig altijd alles goed.

Sander Ouburg, AIO en inmiddels postdoc van Servaas, we hebben in de loop der jaren menig sub-overleg gevoerd. Gelukkig waren mijn vragen altijd een makkie voor je. Heel veel dank voor al je hulp. Enne, ik probeer te blijven denken aan de "Amsterdamse instelling"!

Jolein Pleijster, bedankt voor al het werk dat je op de VU voor me hebt verricht. Het SNP-pen was aan jou veilig toevertrouwd.

Patrick Groothuis, dat jouw deur altijd openstond en je volop met ons meedacht heb ik zeer gewaardeerd. Je bedacht altijd de meest fantastische experimenten. Jammer genoeg zijn we nooit toegekomen aan het proefje waarbij we endometrium onder het nierkapsel van de naakte muis zouden transplanteren en infecteren. Wie weet nog iets voor later?

Rick Kamps, zeer vele uurtjes hebben we aan de immuno's van de chronische pilot gespendeerd. Gelukkig reageerde je altijd erg beheersd als er eens een enkele keer iets anders liep dan gepland. Die liter verdunningsmedium is trouwens geheel tegen de verwachting toch maar mooi opgegaan.

Staf Obstetrie \& Gynaecologie van het MUMC+, Maatschap Gynaecologie \& Obstetrie van het Atrium MC Heerlen en collega-assistenten, dank voor de goede samenwerking sinds de start van mijn opleiding, en voor de niet aflatende interesse in de voortgang van het boekje. Vol trots kan ik inmiddels zeggen: ja, ik heb een datum! Dr. Bouckaert, ik zat nog geen maand in Heerlen of $u$ hengelde mij al uit de wetenschappelijke impasse. De Coffeelovers-sessie heeft me blijkbaar dan toch het zetje gegeven dat nodig was. Heel veel dank voor alles.

Lieve collega's van de verloskamer, poli, afdeling en secretariaat in Heerlen, jullie reputatie was jullie al vooruitgesneld en ik kan inderdaad zeggen: niets bleek minder waar. Jullie belangstelling, hartelijkheid en gevoel voor humor zijn onvolprezen en maken het werk zoveel leuker! 
Lieve collega's van de IVF-afdeling en het IVF-lab, Aafke, Carla, Cecile, Germaine, Laurence, Marie-José, Marijke, Marion D. en alle anderen, het waren mooie jaren op die paar vierkante meters van "de IVF". Het eerste jaar kreeg ik van jullie ter inburgering zelfs een cd met vastelaovend leedjes toegeschoven (ik draai ' $\mathrm{m}$ - serieus! - elk jaar wel een keertje). Nog steeds loop ik graag bij jullie binnen om gewoon eventjes wat bij te praten. Jullie zijn een fantastisch team.

Dr. Dunselman, u heeft mijn klinische en wetenschappelijke vorderingen deels vanaf de zijlijn kunnen bekijken. Dat $u$ daar wel stond was voor mij al een hele geruststelling.

Jacques Maas, ook afkomstig uit het fameuze IVF-nest en inmiddels alweer een tijdje gynaecoloog, ik bewonder je ambitieuze aard, en kan vooral ook erg genieten van je humor en je hartelijke lach.

Trudy Sagis, bedankt voor de secretariële ondersteuning in de afgelopen jaren. Je hebt altijd wel even tijd voor me kunnen vrijmaken, zelfs als ik de deadline onverhoopt wat dichtbij liet komen.

Lieve Aisha, Anja, Kim en Lilian, we zijn inmiddels een ijzersterk Ceramiquekwintetje geworden. De afgelopen jaren hebben jullie meegeleefd met alle hoogteen dieptepunten. Heel erg bedankt dat jullie er altijd voor me waren, van het griezelig steile sleepliftje de zwarte piste op tot het champagnemoment toen het boekje af was. Lieve Nienke, onder het genot van heel wat kopjes Coffeelovers latte hebben we regelmatig de gang van heel diverse zaken doorgenomen. Jammer dat je nu wat verder weg woont. Lieve Heidi en John, begonnen als kamergenoten in dat roerige AIO-hok, heeft zich inmiddels een waardevolle vriendschap ontwikkeld. Geweldig dat jullie er de $16^{\text {de }}$ toch nog bij kunnen zijn.

Lieve Tanja, ruim acht jaar geleden nam ik je plaats op de IVF over. Inmiddels hebben we al aardig wat lief en leed gedeeld. Ik wil je heel erg bedanken voor het vertrouwen dat je in me hebt. Onze vriendschap is me bijzonder dierbaar, en ik ben erg blij dat je me op deze belangrijke dag terzijde wilt staan.

Lieve Femke, ik ben onnoemlijk trots op hoe je het doet. Je doorzettingsvermogen, ook tijdens je opleiding, is echt geweldig. Je betekent veel voor me, en ik vind het heel erg fijn dat ik altijd bij je terecht kan (ook voor het uitzoeken van een mooi kaftje tijdens een zondagse brunch). Ik heb heel veel vertrouwen in je.

Lieve Marieke, het pad dat je de laatste jaren hebt afgelegd dwingt veel bewondering en respect af. Je wordt een hele goeie! Ik ben heel erg dankbaar voor alles wat je voor me doet. Nog steeds ben ik geroerd door de rol die jullie me voor jullie kroost hebben toevertrouwd. Ik vind het heel erg fijn dat je mijn paranimf wilt zijn. 
Lieve Koen en Martijn, ik bof maar met zulke leuke zwagers!

Lieve Jet en Daan, jullie zijn het leukste nichtje en neefje van de hele wereld. De afgelopen anderhalf jaar hebben jullie me veel afleiding gegeven. Zet het boekje trouwens eerst nog maar een paar jaar in de kast.

Lieve vader en mam, dat jullie niet altijd precies wisten wat ik hier op het lab nou allemaal uitspookte (en waarom dat dan in het verre Maastricht moest), maakte jullie niet minder trots. Door me zo'n stabiele thuisbasis te geven en me vrij te laten in mijn keuzes, ben ik geworden wie ik nu ben. Bedankt voor jullie onvoorwaardelijke steun en liefde. 


\section{Curriculum vitae}

Janneke den Hartog werd op 4 oktober 1976 geboren in Dordrecht. In 1994 behaalde zij het gymnasiumdiploma aan het Johan de Witt-gymnasium te Dordrecht. Van 1994 tot 1995 studeerde zij geneeskunde aan de Katholieke Universiteit Leuven. In 1995 werd gestart met de studie geneeskunde aan de Rijksuniversiteit Limburg te Maastricht. Na het behalen van het artsexamen in augustus 2001 werkte zij van september 2001 tot en met november 2001 als poortarts in het Atrium Medisch Centrum te Heerlen/Brunssum. Van december 2001 tot en met februari 2006 werkte zij als IVF-arts/onderzoeker in het Academisch Ziekenhuis Maastricht. Het onderzoek zoals beschreven in dit proefschrift werd uitgevoerd binnen het onderzoeksinstituut GROW - School for Oncology \& Developmental Biology, afdeling Obstetrie en Gynaecologie (promotores: prof. dr. J.L.H. Evers en prof. dr. J.A. Land) en Medische Microbiologie (promotor en co-promotor: prof. dr. C.A. Bruggeman en dr. S.A. Morré). Van maart 2006 tot en met augustus 2006 werkte zij als arts-assistent niet in opleiding op de afdeling Obstetrie en Gynaecologie in het Maaslandziekenhuis te Sittard. Vanaf 16 augustus 2006 is zij in opleiding tot gynaecoloog. De opleiding werd gestart in het Academisch Ziekenhuis Maastricht (opleider: prof. dr. G.G.M. Essed). Per 1 oktober 2008 heeft zij de opleiding voortgezet in het Atrium Medisch Centrum te Heerlen (opleider: dr. F.J.M.E. Roumen). 